Wilson, C.B. 1905

North American parasitic copepods belonging to the family Caligidae. Part 1. - The Caliginae.

Proceedings of the United States National Museum 28(1404): 479-672, plo. 5-29. (23-vi-1905).

Page proof 


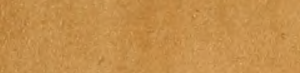
W. 720 .
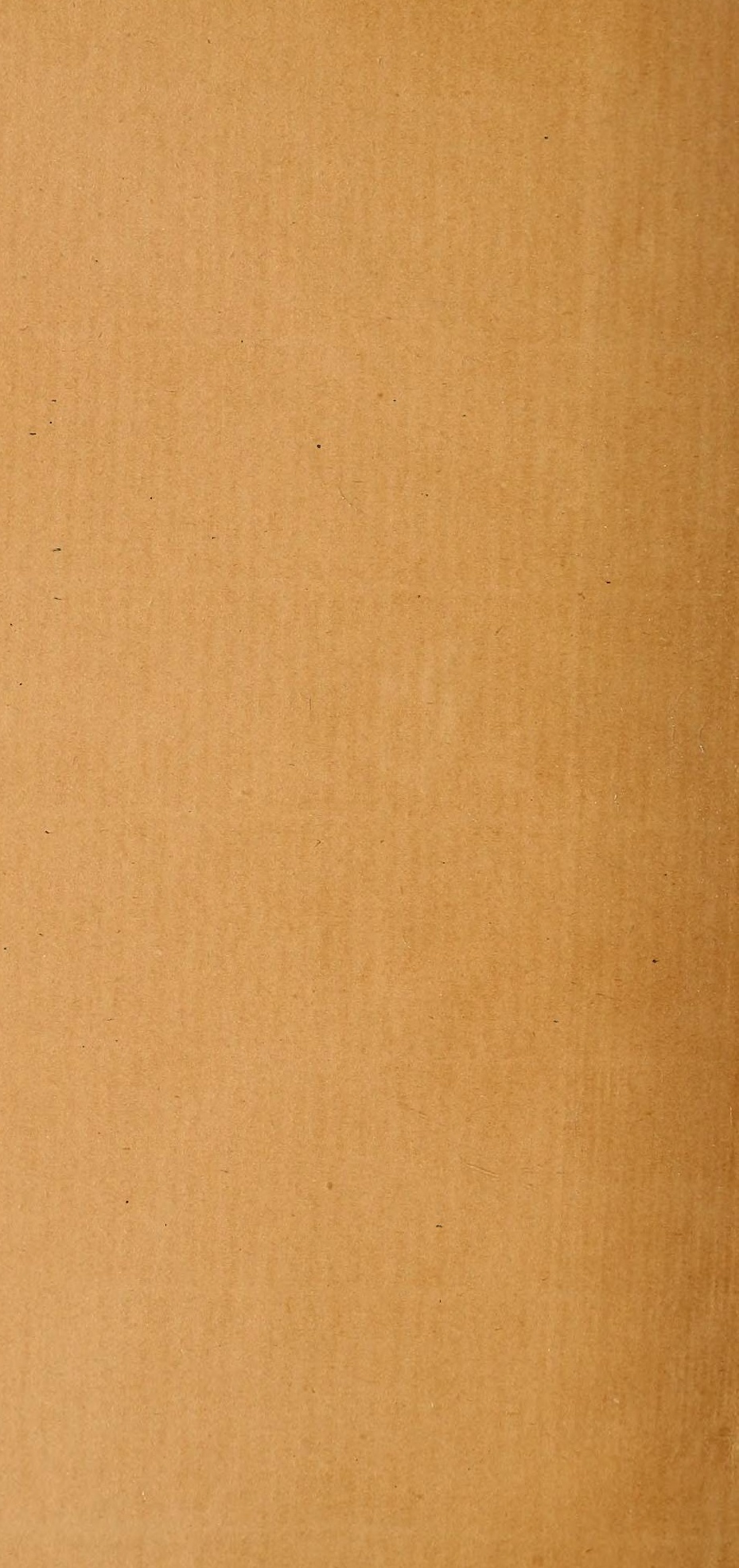


UNITED STATES NATIONAL MUSEUM.

\section{NORTH AMERICAN PARASITIC COPEPODS BELONGING TO THE FAMILY CALIGID $\mathbb{E}$.}

Part 1.-THE CALIGIN E.

BY

\section{CHARTES BRANCH WILSON,}

Department of Biology, Strite Normal School, Westfield, Mass.

From the Proceedings of the United States National Museum, Vol. XXVIII, pages 479-672 (with Plates V-XXIX).

[No. 1404.]

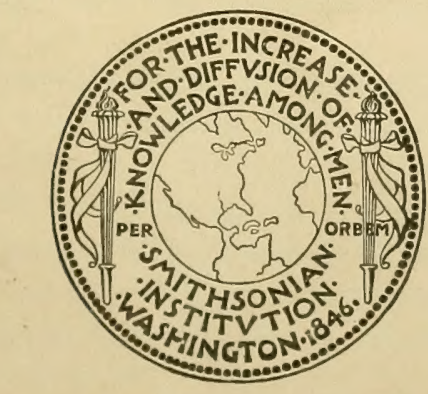

WASHINGTON:

GOVERNMENT PRINTING OFFICE.

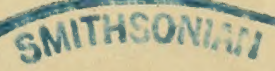

NOV 31083

LBRARIES 1905. 



\title{
NORTH AMERICAN PARASITIC COPEPODS BELONGING TO THE FAMILY CALIGIDA.
}

\author{
PART I.-THE CALIGINÆ.
}

\section{By Charles Branch Wilson,}

Department of Biology, State Normal School, Westfield, Massachusetts.

\section{INTRODUCTION.}

The present is the third paper in the series based upon the collection belonging to the United States National Museum.

The other two papers treated of the Argulidx and were published, the first in Volume XXV, and the second in Volume XXVI of these Proceedings. Acknowledgment was made in them of valuable assistance received from various sources, particularly from the United States Bureau of Fisheries. That assistance concerned the present family even more than the Argulidæ, and the author feels that any success which may have been attained in working out the habits and life histories is due almost entirely to the courtesy and assistance extended by the Bureau of Fisheries.

Additional sources of material will be found mentioned under the historical summary (p. 482).

This second family, the Caligidæ, includes about thirty genera, which separate naturally into groups differing as much in their habits as in their morphology, and thus constituting well-marked divisions. (See Key on p. 532).

The genera here treated include all of the first group, the Caliginæ, which have thus far been found in North American waters, and five species, including one which is the type of a new genus, from foreign localities. The North American species are twenty-three in number, of which thirteen are new, namely: Caligus rufimaculatus, C. schistonyx, C. mutabilis, C. aliuncus, C. chelifer, C. latifrons, C. bonito, Caligodes megacephahus, Lepeophtheirus longipes, L. edwardsi, L. dissimulatus, L. parviventris, L. bifurcatus.

Of the five non-American species included in the Museum collection four are new to science, namely, Caligus teres, from Lota, Chile; Lepeophtheirus innominatus, from Cornwall, England; Lepeophtheirus 
chilensis, from Lota, Chile, and Homoiotes palliata, the type of a new genus, locality unknown.

In addition to these seventeen new species the present paper gives for the first time the development stages of two species, Caligus rapax and $C$. curtus; almost the entire anatomy of a third, Echetus typicus Kröyer, while it corrects or largely supplements the anatomical details and rectifies the systematic position of seven other species, Caligus pelamydis Kröyer, C. productus Dana, C. thymni Dana, Lepeophtheirus thompsoni Baird, L. salmonis Kröyer, L. pacificus Gissler, and Caligus centrodonti Baird, the last a non-American species.

Here also are presented for the first time a. comparative anatomy of the different species of Caligus and Lepeophtheirus, and artificial keys for the determination of all known species under the several genera. In the development are given for the first time figures of a metanauplius and the details of its anatomy. And there is introduced the first continuous life history of any species belonging to the family, together with a comparison of the life histories of several species and at least two genera.

This subfamily, the Caliginæ, is particularly interesting because the genus Caligus, which is the type of the entire family, is one of the oldest among the parasitic copepods and formerly included many species which are now referred to other genera. Among these were some which resembled the true Caligus very closely, except that they lacked the lunules or sucking disks on the frontal plates. From these Van Nordmann created the genus Lepeophtheirus in 1832, but it was not generally accepted at first, and the species of both genera continued to be included under Caligus by many authors up to the appearance of Kröyer's excellent memoir in 1863.

The genus Anuretes also was first placed by Kollar under Caligus in the collection of the Vienna Museum. Like Lepeophtheirus it lacks the lunules on the frontal plates, and hence Kröyer, who was the first to publish a description of the species, classified it as a Lepeophtheirus, and it was not until 1865 that it was established as a distinct genus by Heller.

Of the other two genera, one, Caligodes, is simply a Caligus with the free segment elongated into a neck and the genital segment and abdomen modified slightly, while the appendages are identical in the two. The other genus is the new one Homoiotes, and differs only in having the genital segment covered with a dorsal plate. It has not thus far been found in North American waters, but there is every probability that it will be at some future time.

These genera are very closely related to one another therefore, and since both the males and females of all except Caligodes can swim about freely they furnish an excellent group to contrast with the Argulidæ on the one side and the Pandarinæ on the other. The Argulidæ are 


practically nondegenerate, while the Pandarina are very evidently degenerate; this group therefore forms a connecting link between the two and enables us to discover and emphasize the initiatory steps in degeneration.

They thus possess the greatest possible ecological interest, and a careful study of their habits and mode of life can not fail to yield valuable facts and suggestions.

\section{HISTORICAL.}

The first accounts that can be referred to these genera with any degree of certainty are those of Gumner (1765), Stroem (1762), and Baster (1765). They describe and figure some parasites which they call fish lice, but evidently they entirely mistook the nature of the animals, since they regarded the egg strings as antennx and printed their figures upside down.

But the figures were accurate enough to show that these were really parasitic copepods belonging to the family under discussion. Müller in 1776 showed that these "antenna" were egg strings, and he also found and described the true antenna. But he blundered in regard to the eyes as badly as his predecessors had done in regard to the antenne, mistaking for them the sucking disks on the frontal plates and failing entirely to find the true eyes. Hence he introduced his specimens under the genus name Binsculus, a name which survived for many years. Slabber (17\%s) described and pictured one of the Caliginx under the name (mixcus lutosus; he also delineated the antennx and many of the other appendages correctly and his figure is right side up. Müller in a second paper (1785) corrected his previous error by discovering that the sucking disks were not eyes. He then realized that these copepods could no longer be classed in the heterogeneous group known as Binoculus, and accordingly founded for them the genus Caligus.

But again he blundered, for the rery name ${ }^{a}$ tells us that he did not find the true eyer, but considered these parasites to be blind.

Stroem (1762) was the first to study the hahits of the genera from living specimens, and he has given us many interesting observations. A few additional data have been given hy Leach (1s13-14), Lamarck (1sis). Johnston (152t), Desmatrest (1525), Burmeister (1833), Rathe (1s+3), Batrol (1s.o(1), Kröyer (186:3), Heller (1865), Claus (1875), Hesse $(1877,1883)$, and T. Scott $(1894,1900)$.

But although this list of names looks quite formidable they have really given us almost nothing upon the habits and development of the group. Johmston established for the first time the external differences in the sexes of cirligns hy describing in detail a male and a female of Caligus curtus from the cod.

" Caligus, from caligo, a medical term for blindnews or weakness of the eyes. 
But the life history was so little known up to 1852 that one of the derelopmental stages, the chalimus stage, was regarded as an entirely distinct genus, and sereral species were described by various authors. F. Müller (1852) and Hesse (1877), however, explained the chalimus correctly, and recently A. Scott (1901) has given a brief life history of Lepeophtheims pectoralis, in which the chalimus was still further explained. But Scott states plainly that he has not worked out the changes which take place in the developing embryo, so that we are still left with only a general knowledge of the metamorphoses and without a single authentic life history.

The work of American authors upon these genera is somewhat superior both in quality and quantity to that upon the Argulida.

Thomas Say, in his account of the Crustacea of the United States, published in the Journal of the Academy of Natural Sciences at Philadelphia in 1818, mentions two parasitic copepods, Pondarus simuatus, found on the dogfish, and another which he calls Binoculus caudatus on Callianussa, the latter being evidently a species of Culigus. Following him came an admirable monograph by Dana and Pickering (1838) upon Caligus americanus $(=C$. curtus), which was the best account of a single species published up to that date and which remained without a rival until Scott's memoir just mentioned (1901). The subsequent American papers came at considerable intervals. Dana published several, which were entirely systematic, from $18+3$ to 1856. Smith in 1874 recorded all the species found in Vineyard Sound and adjacent waters, while Rathbun gave (1884) an annotated list of the species found in American waters, and in 1887 described a new species of Trebius from Vineyard Sound. And yet out of more than 100 species belonging to the genera here considered only 7 have been reported from North America and 6 from the West Indies. It is time, therefore, that the lists were thoroughly revised, for these parasites are as common upon the fishes of our own coast as they are in European waters.

The following account is drawn from all the sources here mentioned and many other published papers; from the records of the United States Bureau of Fisheries; from manuscript notes by R. R. Gurley on The Vermine and Crustacean Parasites of Fresh-Water Fishes; from very valuable manuscript notes and drawings by Richard Rathbun, J. H. Emerton, J. H. Blake, and S. I. Smith, all of which were kindly turned over to the author by Mr. Rathbun; and last of all from the author's own personal investigations extending over several years.

\section{ECOLOGY}

Advancing from a study of the Argulidas to that of Caligus and its associates the first thing to be noted, since it is the key to most of the changes we meet, is the fact that the female of these species carries 


$$
-
$$



her eggs about with her like most of the copepods. This habit necessitates several departures from the conditions found existing among the Argulidæ.

In the first place we must look for a greater difference between the sexes both in their morphology and in their habits.

The genital segment of the female is considerably larger than that of the male, and usually the first antenna are larger and stouter. On the other hand, the second maxillipeds are larger in the male, and the abdomen is often composed of two segments, while the female has only one. The increase in the genital segment of the female, together with the heary egg cases which she has to carry, restrict her freedom of motion.

And hence while both sexes can swim about freely it is only the males which can be expected to compare favorably with the Argulidæ in this regard. This sex difference is particularly emphasized during the breeding season or just at the time when there is the greatest incentive for free swimming. That this restriction of the female's motion is at least farorable to degeneration can not be doubted. But at the same time we have to remember that all the copepods save the Argulide are burdened in the same way, and yet all free-swimming forms are able to combat the condition successfully. The condition in itself, therefore, is scarcely enough to be regarded as the first step toward degeneration; we must seek something more.

In ordinary free-swimming forms the female, even when burdened with her egg strings, must move about in search of food. In fact, she needs food more then than at any other time.

Again, in the Argulidæ, the female deposits her eggs upon some conrenient surface away from the body of her host, and such deposition becomes not an incentive merely, but an imperative demand for free swimming. The males follow the females at these times and also search for them from fish to fish.

Culigus females, on the contrary (and the same applies to all parasitic genera), (arrying their eggs about until they hatch, find the surface of the fish's body one of the best possible positions to secure good aeration for the eggs and to discharge the nauplii when they are sufficiently matured.

Finally these parasites feed upon the blood of their host, or at least upon something which they obtain while upon the host's body; hence by remaining here they are nearest the source of their food supply. In short, all the incentives are for remaining, rather than leaving the host and swimming athout, and adult females almost always remain upon the fish, even during the periods when they are without egg strings.

The only inducement in these forms to free swimming on the part of the female would be that which is common to all parasites, plant 
and animal alike, namely, the original search for a suitable host. But this operates in derelopmental rather than in adult stages, and it is a significant fact in this connection that nearly every female of these genera which has been captured in the tow has been immature.

The mechanical hindrance afforded by the egg-strings, together with the strong incentives just enumerated for remaining upon the body of the host, may be fairly considered as constituting the first step toward degeneration. Let ns now look at the mode of locomotion in these genera in order to discover the second step.

\section{LOCOMOTION.}

There are two modes of locomotion as in the Argulidx, a freeswimming and a scuttling motion. The presence or absence of the latter has a greater significance than has hitherto been accorded to it. By watching specimens of Argulus and Caligus in an aquarium it can be seen that the latter are really the better swimmers. This is due to the increased surface of the first three pairs of legs, particularly to the large lamina or apron which connects the third pair across the ventral surface of the body. These legs furnish a swimming organ which propels the copepod through the water with strong and swift movements. Often the motion is so erratic and persistent that the animals seem to have fairly gone mad, dashing frantically about, turning summelsaults, rushing for a distance along the sides of the aquarium, or seuttling back downward across the under side of the surface film of the water. Equipped with such a swimming apparatus it would naturally be supposed that they would put it to frequent use, but we have already seen that they lack the incentive. As a matter of fact, mature females of but one or two species have erer been taken with the males at the surface.

Furthermore, as will appear in the descriptions which follow, these few specimens were all of the genus Culigus, the species rapax being most commonly secured. The other genera here treated do not show as much inclination to free swimming as Culigus and there are but one or two very doubtful records of their capture in the tow. Indeed, A. Scott goes no far as to conclude from a series of careful investigations that "Lperplitheirus throughout the remainder of its life and under normal conditions remains on the same fish that it attached itself to at the beginning of the chalimus stage." And the same might probably be said with regard to Anuretes and Trebius.

When we consider the amount of surface towing conducted every year under the anspices of the L'nited States Bureau of Fisheries, the scarcity of these parasitic forms can only mean that at least the mature females aro not acrustomed to swim freely at the surface, but only do so under extreme provocation. 




Such a change in habits, constituting as it does a long step toward that fixedness of position which precedes radical degeneration, must have some adequate cause. These three genera have practically the same swimming apparatus as Culiqus, and if it is never used there must be some preventive influence which operates in their case but not in that of Caligus.

In the author's opinion this influence may be found in the presence of sucking disks on the frontal plates of Caligus and their entire absence in the other genera. Their presence gives to Caligus the same scuttling motion as Argulus obtains from its first maxillipeds. In this way they move about over the surface of their hosts with great rapidity and upon the slightest provocation. But the other genera, lacking the sucking disks, are dependent upon the second antennæ and the maxillipeds for locomotion over the surface, and can not consequently move about with any rapidity. For this reason they do not change their position as often as Caligus but remain a long time fixed in one place. Indeed, when an attempt is made to remove them from their host, only the males and immature females move about in order to escape. The mature females usually settle down in situ and only cling the more tightly. When removed from their hosts and pliced in aquaria these genera settle upon the bottom or sides and remain stationary for long periods, in marked contrast to the restless activity of culigus. This fixity of position can not help reacting unfavorably upon any tendency toward free swimming which might still be retained by the copepod.

To recapitulate, then, we find that none of the Argulida exhibit degeneration or eren any tendency toward it. They have all retained completely both the ability and the inclination to swim freely and to move about over the body of their host.

Among the Caligine the genus Caligus possesses even more ability than 1 igulus, and the males and immature females retain practically the same incentives. But for the mature females every influence operates toward remaining upon their host, and they are very seldom captured swimming freely. All the species of Caligus, however, still move about orer their host's body upon the slightest provocation. Other genera, being destitute of lunules, lack the ability to move about on the body of their host with any freedom.

This acts as a still stronger damper upon their movements, and although they retain fully the ability to swim they almost never exercise it. They not only remain upon one host all their lives, but they also fasten themselves in a single spot and stay there continuously. They thus exhibit the initial stages of degeneration, whose next step is to be a partial loss of the ability left unused.

While speaking of locomotion mention must be made of a pernicious habit common to many of the Caligine. 'This consists in crawling up 
the sides of the dish or aquarium as far as possible abore the surface of the water and remaining there till thoroughly dried, and, of course, dead and worthless. For this reason it is very difficult to keep such species alive for any length of time. Even to carry them from the collecting ground to the laboratory, or to keep them alive while being examined, it is necessary to carefully stopper the bottle or to cover the dish, so that the air above the water shall be so saturated with moisture that the copepods can not dry in it.

Fortunately this disagreeable habit is practically confined to the genus Caligus, and the other genera make quite tractable subjects for aquaria. This is particularly the case with Lepeophtheirus, and A. Scott states that $L$. pectric may be keptalive "in sea water for upward of six weeks after removal from the fish."

\section{PREHENSION.}

The organs of prehension include both sucking disks and claws; the former are confined to a few genera; the latter are common to all the genera. The arched carapace, also, in all the genera, acts as a large sucking disk, its margin being pressed close to the surface, and the contact sealed with water and slime. This constitutes a secondary organ of prehension, vastly more effective than in the Argulidre, since its margin is made continuous posteriorly by the broad lamina connecting the third swimming legs. When flattened against a surface by muscular contraction and then released it works very powerfully.

The claws constitute the terminal joints of the second antennæ and the second maxillipeds, the entire joint functioning and being capable of strong flexure upon the basal joint.

It seems probable that these different organs of prehension are used in different localities upon the fish's borly. The lunules and the suction of the carapace afford the principal means of prehension on those portions of the outside surface of the host which are corered with scales. There is an integument over the scales, to be sure, and in many of the fish which serve as hosts the scales have small spines upon their free surfaces. But the integument is so thin and the spines are so small and weak that they afford but a feeble hold for claws. 'There is no chance to bury the claws sufficiently to withstand the ordinary friction of water, to say nothing of that of sand or mud, which must be orercome on the rentral surface of such fish as the flounder, skate, etc. The firs, on the other hand, have no scales and the covering integunent is firmer and thicker, and affords an admirable material in which the claws may fully bury themselves. So that although the tail and other fins must, from their movements, subject the parasites to considerable additional friction, this is more than counterbalanced by the superior hold which they afford. The blood vessels also are more 


easily accessible in the fins than under the scales. These two reasons are sufficient to explain the preference of copepod parasites for such localities.

It might be inferred that in those genera which are destitute of lunules there would be a somewhat stronger development of the claws. Possibly they are a.little larger and stouter, but the difference is very slight, and after careful examination it does not seem sufficient to warrant any statement.

This method of prehension by claws renders it more difficult to remove the parasite from its host. Caligus comes off easily, but it takes a decided pull to loosen one of the other genera, and often the posterior part of the body will be torn away from the anterior without weakening the hold, as noted by Scott.

Long experience has taught that the best way to remove these parasites intact is to slip one end of a pair of broad-tipped forceps well under the carapace and lift the copepod off quickly as one would a limpet.

Connected with prehension are the various devices to prevent slipping backward upon the fish's body. We miss in this group the spines upon the rentral surface of the carapace and the roughened plate with its posterior teeth on the basal joint of the second maxillipeds, which were so common amongst the Argulidæ.

But we find instead a small plate that often bears spines upon the basal joint of the first swimming legs, and a sternal fork. The broad lamina joining the third legs also, when applied closely to the surface, must act as a powerful preventative to slipping. And these creatures need something that is powerful for they are often found upon the rentral surface of such fish as the flounder, halibut, plaice, and skate which frequent the bottom and often bury themselves entirely in the sand or mud.

The friction at such times must be very great and tax to the utmost both the flattened form and the prehensile power's of the parasites.

HOSTS.

In general the Pleuronectidx and Gadidx are the most frequent hosts of the Caligids, but many widely divergent families and genera are represented in the host list. They may be found anywhere upon the external surface or in the gill carity of their host. while a few species are commonly found inside the mouth, the most notable instance heing the new species of c'uligfus from the Bonito. On the outer surface they often prefer the fins, especially the pectorals since these furnish good opportunities for attachment and food as already explained. And then as the parasite usually seeks the underside of the fin it must also be protected in great measure by the latter from the friction of the water or mud through which the tish is passing. 
Many species show a tendency to congregate in certain places to the almost entire exclusion of the rest of the fish's body, as in the case of Caligus bonito and Lepenphtheims pectoralis.

While many of the species stick to one particular host there are others which change hosts from time to time and which are able like the Argulide to live temporarily upon almost any fish that may be available. Caligus mpar easily takes the lead in this, having been found upon twenty-five or thirty different fish. A few of these like the flounder and cod are regular hosts, and an examination of a very few fish is almost certain to rereal the presence of this parasite. At the right seasons also the chalimus stages of development may be found attached to the fins and scales of the same fish. But for the other hosts there is often a record of only a single specimen which was evidently a straggler and took that particular fish until it could find something better.

\section{FOOD.}

These parasites feed upon the blood of their hosts which they obtain in the same manner as did the Argulids by burrowing under the scales or piercing the skin on the fins with their maxillipeds and proboscis. This blood, filling the central digestive system, may often be seen as a dark streak through the hody, and is sometimes very prominent in transparent specimens.

When taken from the fish those specimens usually live the longest which have the most blood in them; the latter seems to digest slowly and may often be seen for several days in the intestine.

Many authors write that these parasites, or some of them at least, feed upon the mucus of the fish's body and that no blood has ever been found in their stomachs.

This statement seems to rest entirely upon the fact that no red color can be seen in their digestive organs. A. Scott says of Leperphtheirus pectoralis, "when taken directly from the living fish and placed under" the microscope it rarely shows even the faintest trace of red coloring matter in the alimentary canal.'

But the same author concludes on the next page that this species feeds to some extent on blood, and a little later he adds "they do not hesitate to eat their comrades when these become feeble." For animals which will do this mucus must be a rather tame and inadequate food.

It is difficult to determine what the food really is, but there are sereral considerations which will help us to form a rational judgment in the matter. In the first place, it makes a difference what part of the fish's hody the parasite is taken from, whether it shows any red in the digestive organs or not.

If taken from the gill cavity the red is nearly always prominent, while it saldom apporas in those individuals taken form the ontside of the body. Some species are always found in the gill cavity and they 


$$
\text { - }
$$



always show blood in the alimentary canal. Other species are always found on the outside of the body and they are the so-called mucus eaters. But there are still other species, like Culigus ropur, which may be found in either place, and in them we find the same difference.

In explanation we must remember two facts: The gill cavity is the easiest place to get blood on the fish's body, and it is very possible that such a species as $(?$ repmern may slip into this eavity to get its food and then slip out again to the exterior of the body. Consequently when taken in the gill cavity it would have just finished eating, while on the outer surfuce of the body the blood may have had time to partially digest.

The second fact is that all these genera are supplied with powerful digestive glands unlike the Lerneans. We shall see later (p. 513) that one pair of these glands are situated in the anterior part of the earapace and pour their fluid upon the food as soon as it strikes the stomach. Only freshly aerated blood, in or near the fish's gills, has a deep red color; that in the capillaries of the skin and fins is not very red when swallowed. Hence it would not take very much of a digestive fluid to remove the color entirely.

It is rery suggestive to note in this connection that the adult Lerneans, in which the food is so red as to leave no doubt of its nature, have no digestive glands. During development, however, there is a digestive gland, and the contents of the alimentary canal are not red. It is scarcely possible that the young Lernean eats mueus while the adult eats blood.

Again, if these creatures are seeking mucus for food why do they not choose such fish as are most bountifully supplied with it? And how does it happen that they always hunt out those places upon the fish's body where the skin is unprotected and the thinnest? There is more musur on the scales than anywhere else; why should they choose the fins or the inside of the operculum? Finally, the mouth parts of species, which it is clamed eat mucus, are similar in every particular to those of species which are acknowledged blood-suckers. The eating of mucus, then, must be an acepuired taste, and it is difficult to undersiand how an animal with its mouth parts fitted for sucking blood should be content to merely sip mucus while it still retains enough of its old blood-sucking habits to choose the places on the tish's body best adapted for that purpose.

These parasites are very susceptible to any inerease in temperature, and a rise of a few degrees will speedily prove fatal.

This is the chief source of difliculty in keeping them alive in aquaria.

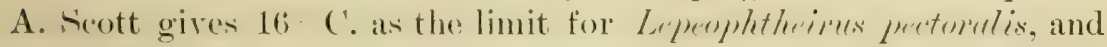
"xperiment has shown that other species do not differ much from this. A general arerage of all the species experimented with would raise this limit slightly, to $18^{\circ}$ or $20^{\circ} \mathrm{C}$. 
On the contrary, they can withstand a very great decrease in temperature. Scott states that the aquaria containing Lepeophtheims pectorulis wele frozen several times without injury to the parasites. Although this experiment has not been tried upon other species, there is no reason to doubt that they could withstand as severe cold. Repeated trials have shown that the best way to keep these creatures alive for any length of time, particularly during hot weather, is to pack the aquarium or bottle in ice. Those species which are otherwise prone to crawl up out of the water are much less likely to do so, but seem content to remain beneath the surface. Possibly this disagreeable habit may be connected ordinarily with a rise in temperature of the water in the aquarium.

\section{SUMMARY.}

1. The females of the genera here discussed carry their eggs about with them. This necessarily restricts their freedom of motion, but not to a greater extent than in free-swimming forms.

2. Added to the restriction, however, is a lack of incentive to free swimming, since the parasite obtains its food upon its host and finds there the best position for the aeration of its eggs.

These two conditions combined constitute the first step toward degeneration.

3. These genera are really better swimmers than the Argulidx, owing to the increased surface of their swimming legs, particularly the third pair. But they do not exercise this ability nearly as often as the Argulidx, for the reasons just stated.

t. In addition to their free swimming, the Caligus species also exhibit the same scuttling motion as the Argulidæ, and it is accomplished in a similar manner by means of the sucking disks on the frontal plates.

5. In other genera the sucking disks are absent, the scuttling motion is impossible, and we find still less of an inclination for free swimming. Careful observations indicate that these genera remain throughout life upon the same fish to which they attached themselves in the chalimus stage.

6. As another consequence of the loss of the scuttling motion they remain for long periods in the same position upon their host, moving only upon strong provocation. This fixity of position constitutes a second step toward degeneration.

7. For prehension we find the sucking disks in Caligus, and stout claws upon the second antenne and the second maxillipeds in all genera. 'The edge of the carapace also, supplemented by the broad lamina connocting the third swimming legs, is flattened against the supporting surface and functions as a large sucking disk.

6. To prevent slipping backward under friction there are weak spines upon the bases of the first swimming legs, and a stout sternal 
fork between the bases of the second maxillipeds. The lamina of the third swimming legs also renders effective service in this direction.

9. These genera show a decided preference for the Pleuronectidæ, and the Gadidie as hosts, but such of them as practice free swimming may be found upon almost any host temporarily. Many of the species, so far as observed, are confined to a single host.

10. These parasites feed upon the blood of their host in a similar manner to the Argulidx. They are rery susceptible to heat, and an increase of temperature of only a few degrees is quickly fatal. On the contrary, they can withstand very severe cold, even freezing, without apparent injury.

\section{MORPHOLOGY.}

A. Eriternal.--The ty pes upon which Müller founded his genus Catigus: in 1785 included several genera beside the true Caligus. Indeed, the only species amongst his types really belonging to the genus was Caligus curtus. Hence his genus diagnosis was very broad and would have included practically all our North American Caliginæ. In the present morphology the statements have been made equally inclusive and are to he understood as embracing all North American Caliginæ unless otherwise limited. The body of a Caligus is made up of four parts or sections, a cephalo-thorax, a free thorax, a genital segment, and an abdomen. The cephalon bears seven pairs of appendages, namely, antennules, antennæ, mandibles, first and second maxillæ, and first and second maxillipeds. The three anterior thoracic segments are fused with the cephalon so that the cephalo-thorax bears three pairs of swimming legs in addition to the appendages just enumerated. The free tholax consists of a small segment carrying the fourth pair of swimming legr and the genital or reproductive segment. The latter has in both sexes a pair of appendages which in the male are very evidently rudimentury swimming legs of the fifth pair. In the female they are often so reduced as to he recognized with difficulty, but their presence is sufficient to show that this segment must be regarded as a portion of the thorax if we are to be consistent in our nomenclature of the crustacea. Ilence, while retaining the designation "genital segment," already in general use, it will be understood that this is really the fifth thoracic segment, the second free one. It varies greatly in shape in different species, in different stages of derelopment in the same species, and in the two sexes. In the male and in immature females it is always smaller and often approximates the abdomen closely in size. But as the female approaches maturity it increases greatly and becomes usually much larger than the abdomen.

Furthermore, in undereioped forms of both sexes the rudimentary fifth legs are relatively much larger than in the mature indiridual, and may commonly be seen as a parr of large lobes or processes cleariy 
differentiated from the remainder of the genital segment (5, fig. 1). As development progresses these lobes become assimilated more and more with the body of the segment, until at the last they are oftentimes invisible except from the ventral surface, and then only after careful examination.

Owing to this extreme variation in size and shape the greatest care must be exercised in comparing different specimens for purposes of classification. The individuals compared must be alike in sex, in maturity, and even in the period of pregnancy if the size or shape of the genital segment is to have its full significance. Fortunately, one breeding season follows another so rapidly that the female is never

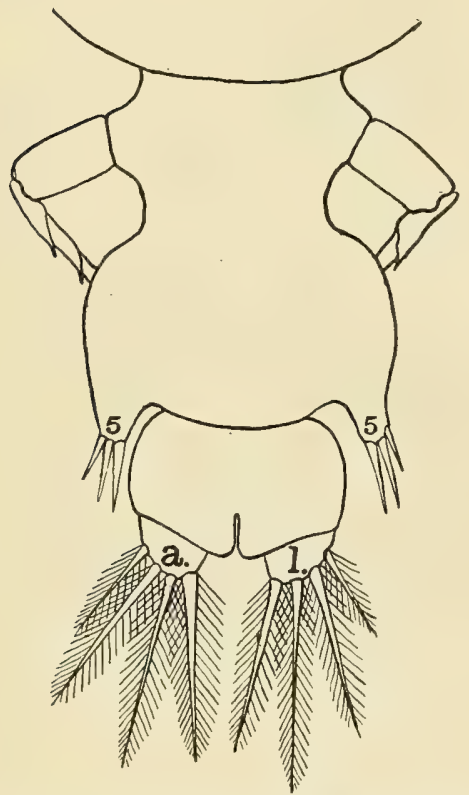

Fig. 1.-Young FEMALE OF LEPEOPHTHEIRUS EDWARDSI, SHOWING THE FIFTH PAIR OF SWIMMING LEGS AT THE POSTERIOR COR-

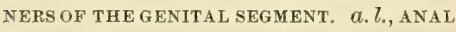
LAMINE; 5, RUDIMENTARY FIFTH LEGS. left for any long interval without her egg strings. Hence, in collecting these parasites, fully ripe females are very largely predominant. On being preserved the egg cases become very brittle and break off easily, but examination will quickly reveal the fact that they have been present, which of course is all that is required. In the Kay which is given later (see p. 555) the shape of the genital segment is made one of the final means of determination after the other more important ones have been exhausted, and even then it must not be given too much prominence.

The length of the egg strings and the size of the eggs vary greatly in different species and in different individuals of the same species, and the best that can be done is to give the general average. The size of the eggs is always a better guide than the number.

Like the genital segment, the abdo-

men is usually simple, but sometimes two-jointed, this condition occurring more frequently in the male. There are two species of Caligus also in which it is three-jointed, $C$. coryphxnx and $C$. angnstatus, and another in which it is four-jointed, $C$. aliuncus. (See Plates VII and IX.)

The abdomen is terminated by two processes, one on either side of the anus, and each furnished with three or four plumose seta (a. 1, fig. 1). These processes have been given different names by different authors. Milne Edwards calls them "lames caudales;" Kröyer designates them as "halevedhaengene" in Danish, while in his Latin diagnoses they are simply "appendices;" Heller speaks of them as 



"Schwanzanhange," in his Latin diagnoses as "appendices cuudales;" Claus calls them "Fulcalanhange," in Latin "foliola caudalia;" Gerstackel designates them as " Endgabel (Ful'a);" while BassettSnith speaks of them as "caudal plates."

There are several objections to these names. In the first place, most of them preserve in some form the old name of "tail," given to the abdomen, which was entirely a misnomer.

The use of "furca" or "fork" is eren worse, for we already have a furcal upon the rentral surface of the carapace, and the repetition of the name for a rery different appendage could not hut breed confusion. Why not apply to them the term "anal," since they are always situated beside the anus, and thus get a term to which there could be no objection as a misnomer and which would be free from any danger of confusion? Let us call them, then, anal plates or lamina, as we called the appendages in the Argulide, similar in position but different in shape, anal papillæ.

There is thus a cephalon bearing seven pair's of appendages, a thorax of tive segments, each bearing a single pair of appendages, the first three united with the cephalon, and an abdomen of from one to four segments, the last of which hears the paired anal lamine.

The cephalo-thorax is strongly flattened dorso-rentrally and is covcred with a hard shell or carapace, which serves to protect the softer parts underneath. In structure this shell is like that which covers the anterior portion of the body in the Argulida, but its shape is considerably different.

In the first place, the anterior antenne, instead of heing concealed beneath the carapace, form a wide articulated border across its anterior margin, their free ends standing out prominently on either side.

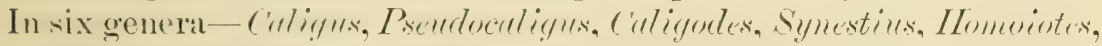
and l'urefulux-the frontal plates thus formed (al'y lipon their anterior margins sucking disks or lunules. In the other genera they are perfectly plain.

These lunules often stand out prominently and, with the plates themselves, gire a squared appearance to the anterior margin (Plates V. VI. XII). This is usually increased by an incision at the center where the two plates meet, or by an emargination extending for some distance on either side. In rare instances just the reverse takes place, and the frontal matrin is made pointed hy a protrusion of the plates hetween the lumules in the form of a heak or rostrum (Culligus hiemen-

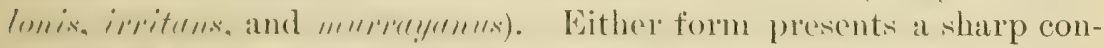

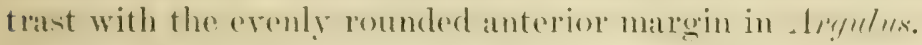

Suain, instead of a single median posterior sinus, there are two, one on aithor side, leaving a median lobe between them, which is usually half the entire width or more.

Proc. N. M. vol. xxviii-04-32 
But the regions of the cephalo-thorax are practically the same and are very similarly arranged in the two.

As boundaries of these regions we find grooves similar to those in

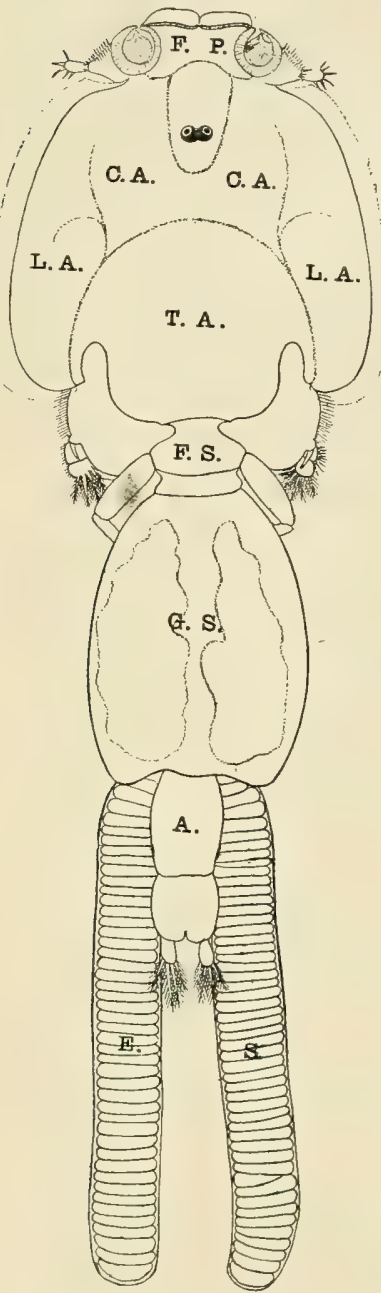

F'ig. 2,-Adult feMale of Caligus MUTABILIS, SHOWIXG THE BODY REGIONS AND THE AREAS OF THE CARAPACE. A., ABDOMEN; C. A., CEPHALIC AREA; E. S., EGG-STRINGS; F. P., FRONTAL PLATES; F. S., FREE THORACIC SEGMENT; G. S., GENITAI SEGMENT; L. A., LATERAL AREAS; T. A., THORACIC AREA. the Argulidæ but differently arranged, not merely in the different genera, but in different species as well.

In general they may be described as follows: A pair of longitudinal grooves, one on either side of the mid-line, more or less parallel with it and removed some distance from it, correspond with the sides of the horseshoe suture in the Argulidæ.

But they extend backward farther, reaching the posterior margin of the lateral lobes, while they do not reach forward to the frontal margin. They form the sides of a large letter $\mathrm{H}$ and are connected by the third groove transversely at or just posterior to the center of the carapace (fig. 2). The carapace is hinged along these sutures and capable of some motion upon them, as in the Argulidx. On the outside of the lateral grooves are the lateral areas, extending back in a lobe on either side of the carapace much narrower than in Argulus (L. A.).

The transverse suture marks the junc. ture of the head and thorax so that the central region in front of it is the cephalic area (C. A.), while behind it is the thoracic area (T. A.), the former being usually the larger. These three grooves are present in practically all the genera and species. In addition there are others which occur with more or less frequency. One of these is a horseshoe-shaped groove extending from the suture between the carapace and the frontal plates backward around the eyes.

It is similar in shape to that in the Argulidæ, but as the eyes in the two families are entirely different it does not correspond in morphological significance.

There are also grooves at the bases of the free portions of the first antennæ which extend inward on the carapace for a short distance, while others appear often in the anterior portion of the lateral areas. 


Rarely a second transverse groove is found in front of the crossbar of the $H$ as in culigus harmulomis and $C$. aliuncus and in Gloiopotes ornatus (See Plates IX, XVIII, XIX, XXIII).

The frontal plates (F. P.) are separated from the carapace in all the genera here considered by an irregular groove made up of several symmetrically arranged curves.

These frontal plates are really the hasal joints of the first antennæ, as can be readily seen in following the development, and they thus correspond in function to the hooked claws on the base of the first antennæ of the Argulidæ.

The two plates do not quite meet at the center, but are separated anteriorly by a deep and very narrow sinus which marks the former position of the filament for attachment in the chalimus stage, and by a slight projection of the carapace from which this filament emerged. On the ventral surface at the base of the suture there is an oval opening surrounded by a narrow fringe of chitin. This represents the median sucker which is considerably developed and forms an important organ of adbesion in the early chalimus stages (s. fig. 3). Its usefulness is almost entirely superseded in the adult Caligus by the sucking disks which develop during the later chalimus stages, but in the other genera it may serve as a "first aid in securing the animal to its host," as suggested by A. Scott (1901).

In favorable specimens a chitinous

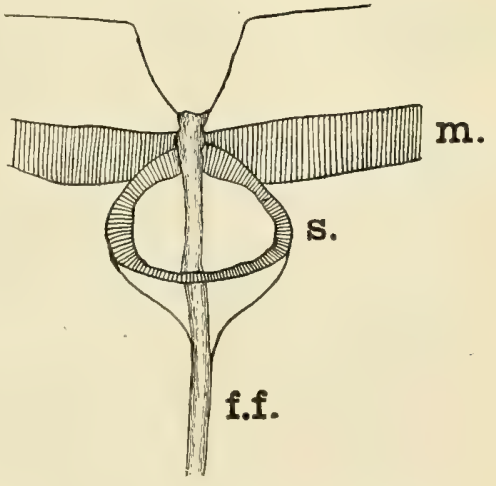

Fig. 3.-THE MEDIAN SUCKER OF CALIGUS RAPAX. f. f., FRONTAL FILAMENT; m., ANTERIOR MARGIN OF FRONTAL PLATES; S., SUCKER.

rod (f. f.) can be seen passing back from this sucker toward the eyes. This rod is the remains of the filament, and at its inner end may be seen the gland which secreted the substance of the filament.

The sucking disks, which in Culigus serve both for prehension and locomotion, are of peculiar construction, resembling not the body or basal portion of the sucking disks in Argulus, but rather the free membranous border. They consist of a short and rather flat cone of membrane, often split for a considerable distance down the ventral or anterior side.

This suture is often so wide that a cross section would take the form of a horseshoe rather than a circle. The membrane is supported by a very few transerse and by many longitudinal ribs of chitin, all of which, however, are simple hairs or threads and not the complicated affitirs found in the Argulidie. 
This cone is often partially or even almost completely concealed by the border of the frontal plate in a dorsal view, so that it is only by turning the animal over on its back that one could be sure whether it has lunules or not. This is the condition with the entire genera Caligodes, Synestius, and Parctpetalus, and rarely in some species of Caligus like $C$. diaphanus.

The carapace, like all the rest of the hody, is corered on both the dorsal and ventral surfaces by a thin cuticle. At the margin where these two cuticles come together they are fused and form a wide, perfectly transparent border along the frontal and lateral edges. Being smooth and fiexible this border can be applied very closely to the supporting surface and forms thereby a tight joint which greatly aids in prehension, as already noted (p. 486).

The eyes are situated on the median line, about one-third the distance from the front of the carapace. They are two in number, so closely approximated as to be partially flattened, and are embedded in a mass of pigment which lies wholly beneath the carapace. Each consists of a spherical mass of pigment flattened on the inner side, where it is separated from its fellow by a thin layer of chitin, lined with the same pigment.

The lens is spherical and projects about half its diameter from the outer or anterior margin. Behind the lens is a retina made up of a single row of relatively large cells, which are lined on the inner side with a layer of pigment. This pigment is usually black or very daik wine-red in color, while the lens is colorless and perfectly transparent.

In quite a number of species, scattered through all the different genera, the eyes are invisible (in preserved specimens) to even the most careful scrutiny. But it seems probable that they are merely concealed by overlying pigment and not really lacking. This point can be determined only by a study of sections which are not at present available.

From a study of the early development we find that these eyes are originally placed much farther back in the carapace and are separated by a greater distance from each other, and that they afterward migrate forward and inward toward the mid line, until they are so thoroughly fused as to appear as one eye with two lenses.

The free thoracic segment is small in nearly all the species; it represents the fourth thoracic segment of free-swimming copepods and carries the fourth pair of swimming legs attached to its outer margins (F. S. fig. 2). In all the species figured, with one or two doubtful exceptions ( $C$. dubius and $C$. fallax), it is so much narrower than the carapace and genital segment, especially where it joins the former, as to appear like a wasp waist connecting the two. This appearance is heightened in craligodes by a considerable lengthening of the segment. The rare instances in which it is figured as double instead of 



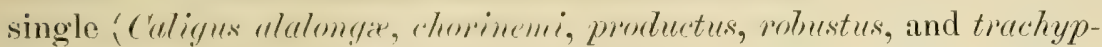
teri) are very doubtful and the probability is strongly against them.

For instance, while Kröyer's smaller figure of $C$. productus shows two segments, Dana's enlarged figure of the genital segment of the same species shows also the free segment as single. In several species (Culigne imitans, momaremthi, and rexutor) the sides of this segment are indented as if for another joint, but there is no actual division and the cases just mentioned are probably the same.

Indeed, if these or any other species really had two free segments, this would be sufficient ground for a generic rather than a specific distinction.

The genital segment (G. S. fig. 2) is not, as its name would imply, the seat of the reproductive organs proper, but merely of the ducts leading from them, in the female the internal oviduct, and in the male the vas deferens and the spermatophores (see figs. 32, 33, 3t).

But since in the female the convolutions of the oviduct contained within the genital segment are the place where most of the development of the egg occurs, it follows that this segment is usually plump and swollen. Its shape varies greatly and is indicated for each of the different species in the keys on pages 555 and 615 . In many of the species the walls are so transparent that the structure of the internal organs may be conveniently studied through them.

The abdomen (A. fig. 2) is always narrower than the genital segment (except in Caligus hirsutux), often markedly so, and is usually shorter and simple. In certain species, however, it is much longer (Caligus macrurus, pelamydis, scombri, and stromatei), and it is also sometimes segmented, this occurring oftener in males than in females. And then the abdomen in the male is relatively longer than in the female, so as to give this sex a narrowed, drawn-out appearance, contrasting strongly with the plump, stocky figure of the female. The external egg cares (E. A. fig. 2) are cylindrical tubes, the substance of which is secreted by a shell gland situated in the genital segment and opening into the internal oviduct very near its exit from the segment. The cylinder is divided into segments by ('ross partitions, one between erery two eggss, so that often when the nauplii have escaped from the rgges there is left behind a sort of moulted skin which retains the exact form of the origin: l, but is entirely empty. When full these egg cases are the most gotent influener to cheek the ahility of the female to move about freely. Oftentimes they are relatively rery large, and in one species, Cruligus dimplumm,s, the two strings taken together are nearly as large as the entire body.

There are twolye pair's of appendaces, namely, two pairs of antenna, one pair of mandibles, two pairs of maxillix, two pairs of maxillipeds, and five pairs of swimming legs, all on the rentral surface except the 
first antennæ (an', fig. 4). These latter are attached to the frontal margin of the carapace and project sidewise from the body. Each is made up of three joints; the basal joint is the largest and is in the form of a lamina or plate, which bears a lunule on its margin. The median joint is larger than the terminal and bears tactile plumose setæe on its anterior and outer margins. The terminal joint is usually more or

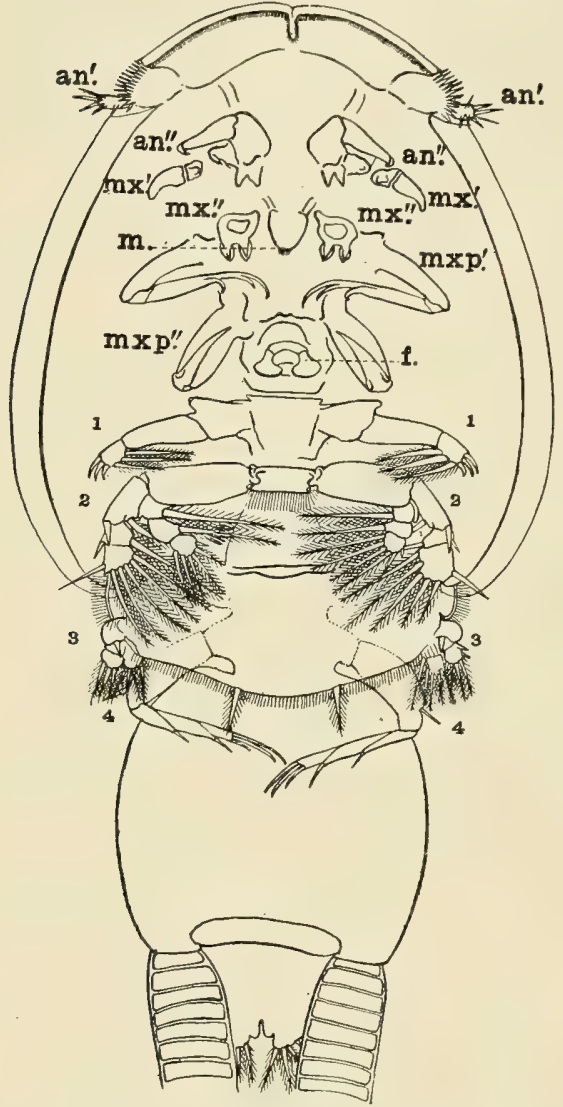

FIG. 4a.-VENTRAL SURFACE AND APPENDAGES OF AN ADULT FEMALE LEPEOPHTHEIRUS EDWARDSI. an'., FIPST ANTENNE; an" ., SECOND ANTENNE; f., FUROA; m., MOUTH; $\mathrm{Mx}^{\prime}$, FIRST MAXILLE; $\mathrm{mx}^{\prime \prime}$., SECOND MAXILLE; $\operatorname{mx} \rho^{\prime}$., FIRST MAXILLIPEDS; $m \times p^{\prime \prime}$., SECOND MAXILLIPEDS; 1,2 , 3, AND 4, SWIMMING LEGS. less club-shaped and furnished with short and sharp spines at and near its tip. These antennæ should be very highly sensitive, if their innervation is any criterion, for a large nerve enters each from the supra-œsophageal ganglion, and, dividing and subdividing, sends a branch to the sucking disk of the basal joint, to each plumose seta of the median joint, and each spine of the distal joint.

The second antennæ $\left(\mathrm{an}^{\prime \prime}\right)$ are attached to the ventral surface just posterior to the bases of the first. They are each two-jointed, the basal joint being short and stout and plentifully supplied with strong muscles. The apical joint is modified into a stout prehensile claw, which fits into a cup or socket hollowed out of the ventral surface of the carapace near its front margin. In the genera under discussion these antennæ have become entirely prehensile in function, and, with the second maxillipeds, they are the chief organs of attachment in places where the skin is accessible (fig. 5).

The mandibles are wholly inclosed within the mouth tube; they are very slender, stylet-shaped and usually four-jointed.

The apical joints are visible through the mouth opening; they curve in toward each other and are either serrated or crenated along their inner edges, the number of teeth being twelve to sixteen.

In Leperphtheirus the outer margins are smooth, but in Caligus they are sometimes cut into very small acute teeth, eighteen to 


twenty in number (fig. 6). The hases of the mandibles are attached just inside the lateral chitin rods of the lower lip, and are connected with the rentral surface of the carapace by stout muscles. There are no traces of mandibular palps.

The first maxilla ( $\mathrm{mx}^{\prime}$, figs. 4 and 5) are situated near the lateral margin of the carapace, just ontside of, and a little posterior to, the bases of the sccond antenna. Each consists of a single joint in most of the species, hut of two joints in a few species of Caligus according to the descriptions given. In both sexes they are swollen at the base and taper toward the tip; in the female they are short and blunt and apparently of no service.

In the male they are much longer and taper to a slender, sharp point at the apex; each maxilla is also curved over toward its fellow on the opposite side and thus forms a claw similar to that on one of the second antennæ (fig 5). And their function would seem to be similar, although we must remember that they are shorter and weaker than both the second antenne and the second maxillipeds and so could not reach the host's body until after these others had been buried in the skin. Possibly they may serve in both sexes to irritate the wound and so stimulate the How of blood. In some species of (irliglus and Leperphlitheirns two minute setre are attached to the basal part of each max-

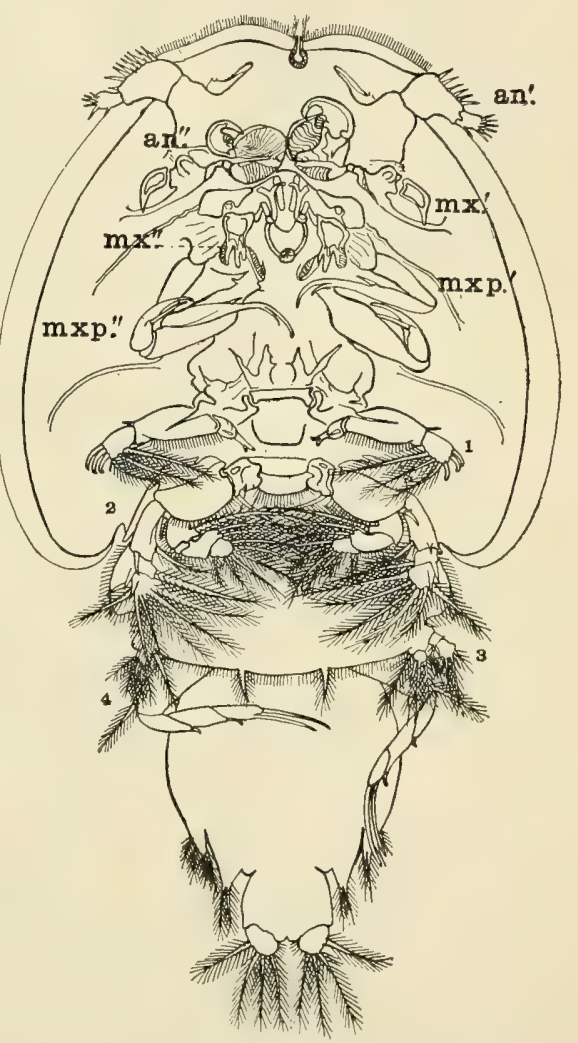

Fig, 4b.-Tentrat surface and appendages of $A N$ ADUlT MALE LEPEOPHTHEIRUS EDWARDS. (For lettering see Fig. 4a.)

illa which $A$. Srott considers to represent the exopodite or palp (é, tig. i).

The serond maxilla (mx", fig. 4) are placed at the sides of the mouth just outside of the suctorial tube. Fach is made up of a single joint, stout at the base and slender toward the tip.

In Califus and closely allied genera the terminal portion is undivided while in Leperpletherim and its near relatives it is bifurcated. 
This terminal portion represents the exopod and in many species of both Caligms and Lepoplitheims there is also a distinct endopod

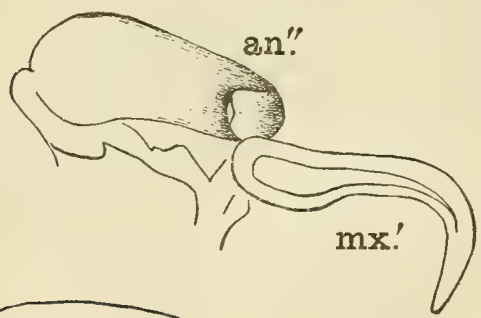
( $\mathrm{e}^{\prime \prime}$, fig. 7), with two setæ on its apex attached to the base of the exopod (Lepeophtheirus pectoralis, Caligus rapax, etc.).

The mouth opening is terminal or termino-ventral and may be either circular in outline (Caligus Jonito, Lepeophtheirus edwardsi), transversely elliptical ( Caligus rapax), or even strongly lunate (Caligus curtus, Lepeophtheirus pectoralis).

Whatever its shape it is always surrounded by a fringe of long hairs. Often in the incision at the center of the under lip is a small tuft of hairs considerably longer yet. In living specimens these hairs are seen to be motile and they must assist in drawing the Fig. 5.-The second antenxe axd the first blood up the mouth tube by makMaxille of the adULt Caligus Bonito. [PPER FIGLRE, THE MALE; LOWER, THE FEMALE. ing the joint at the mouth opening tighter.

The framework of the mouth is quite complicated and consists of two sets or series of rods running lengthwise, connected by others
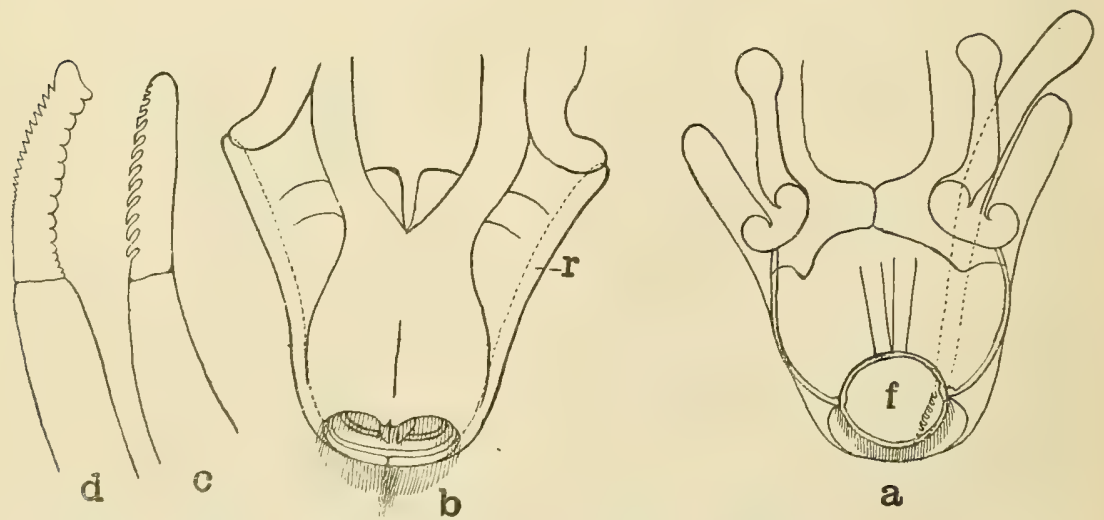

FIG. 6.-MOUTH PARTS. a, DORSAI, SURFACE OF MOUTH TUBE OF LEPEOPHTHEIRUS HIPPOGIOSSI; b, VENTRAI, SURFACE; $c$, MANDIBLE; d, MANDIBLE OF CALIGUS BONITO; f, FLEXIBIE FIAP AT ANTERIOR END OF TPPER IIP: T, ROD ON I.ATERAL MARGIN OF FRAMEWORK OF LOWER IIP.

which are transverse. There is first a long rod on either side, running the entire length of the framework along the lateral margins and furnishing the requisite support for the whole mass (r, fig. 6 . and $r^{\prime}$, 




fig. 10). These rods are inclined toward each other as they proceed away from the rentral surface; their proximal ends are bent sharply and sometimes carried a short distance along the ventral surface of the (arapace as in Culigus curtux. They are articulated at the bend thus made and anain near the tip, making them three jointed. At the basal joint they are also articulated with the ventral surface of the carapace, and the muscles which elevate or lower the whole mass are fastened here.

The short terminal joints curve inward and nearly meet at the mid

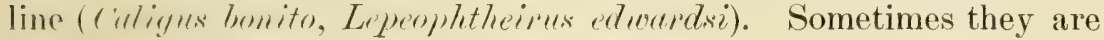
reenforced here at the tip by other small rods which run in toward the

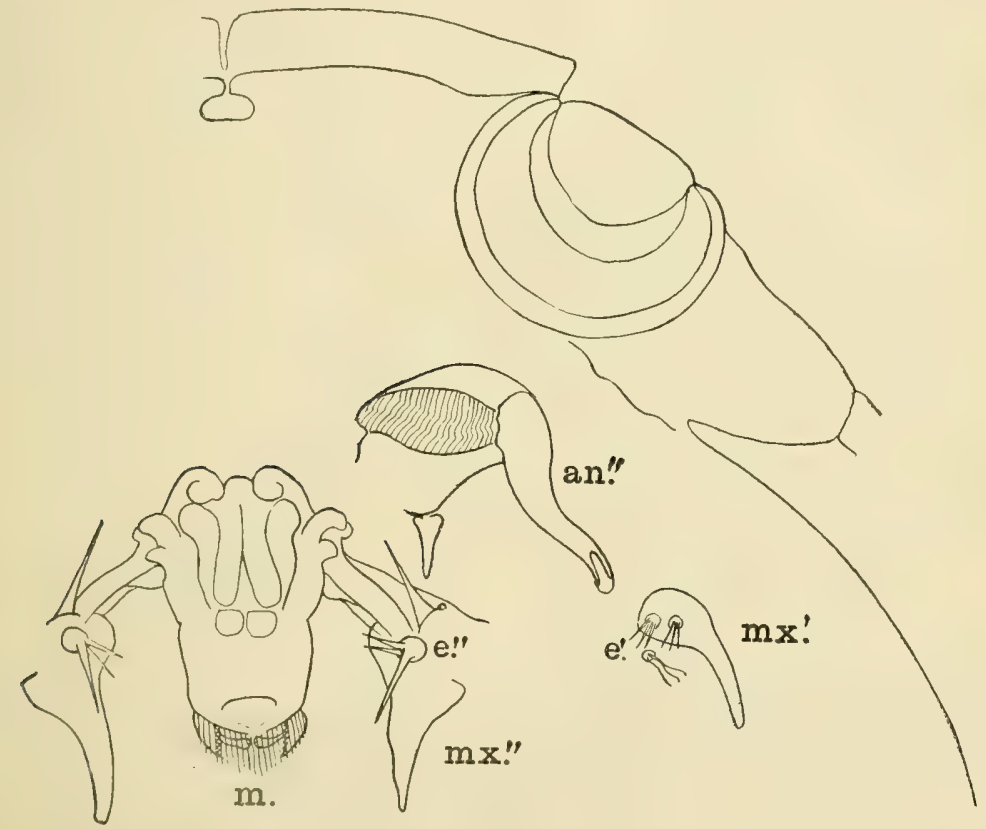

Fig. 7.-SECOND ANTENNE, FiRst AND SECOND MAXIILA AND MoUTh TUBE OF ADULT CALIGUS RAPAX, HIGHLY MAGXIFIED TO SHOW EXACT POSITION, RELATIONS, AND STRUCTURE, an"., SECOND ANTEXNE; $e^{\prime}$. FXYPOI OF FIRST MAXILLE; $e^{\prime \prime}$, ENDOPOD OF SECOND MAXILLE; M., MOUTH; MX'., FIRST MAXILI.E: $m x^{\prime \prime}$., SECOND MAXYLLA.

mid line parallel with the first (culigus artus). The lower lip is stretcherl over this framework from side to side and projects somewhat in front of the small anterior rosk. It is divided at the center, and the extges thus formed are fringed with a tuft of hairs fully twice the length of those which fringe the rest of the mouth opening (fig. 6). In $1 /$ hoim there is a slit at either side instead of a single slit at the center, and the fringe is not much lengthened.

In the membrane of the lower lip, between the marginal rods just described. lises a complicated jointed framework of short rods which help support the rembrane. 'Their' number, arrangement, and shape 
varies greatly in the different species as well as in the genera. In Caligus curtus there is a long rod on either side of the mid line, the two being approximately parallel to the rery tips where they bend in suddenly together and are united for a short distance along the mid line (m, fig. 8). Connected with this united portion are three short transverse rods (t). All of these rods are narrow and cylindrical in shape (Pickering and Dana, 1838).

In Caligus rapax there is a large $V$-shaped rod at the base of the lips $\left(v^{\prime}\right)$, and another $\left(v^{\prime \prime}\right)$ at the tip, the bases of the two $V s$ being toward each other and their sides being connected by a series of short, almost spherical rods (s, fig. 9). The $V$-shaped pieces are strongly flattened

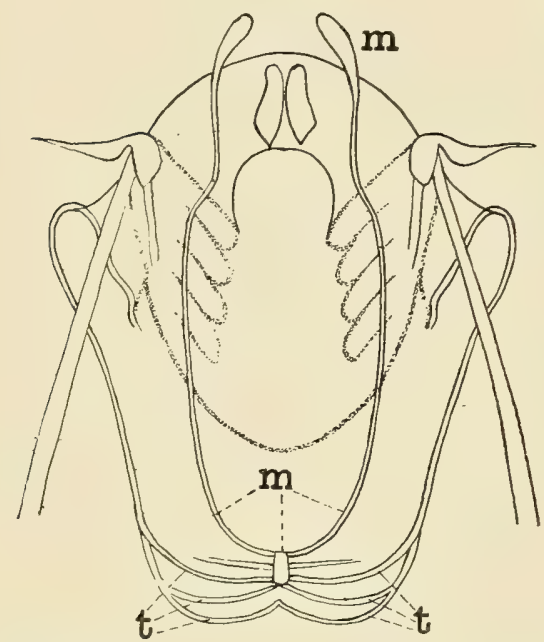

FIG. 8.-VENTRAL SURFACE OF THE MOUTH TUBE OF aN adult Caligus curtus. (After Pickering AND DANA.) $m$, LONGITUDINAL CENTRAL RODS IN FRAMEWORK OF LOWER LIP; $t$, TRANSVERSE RODS.

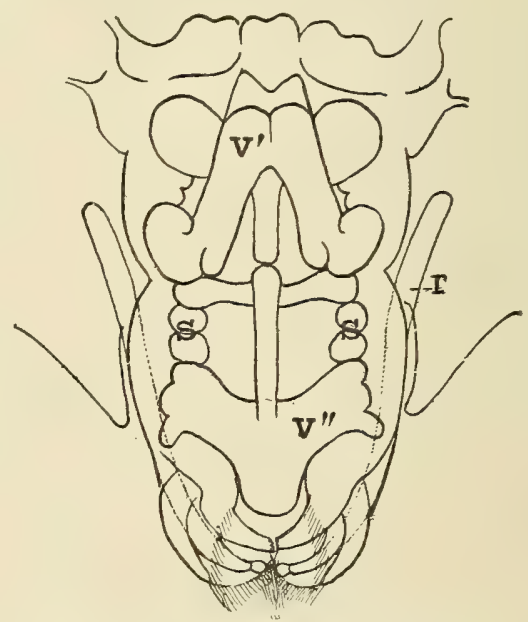

Fig. 9.-VEntral View of THE MOUTH TUBE OF CALIGUS RAPAX IN A LATE CHALIMUS STAGE. r, ROD ON IATERAL MARGIN OF LOWER LIP; $\mathrm{S}, \nabla^{\prime}, \nabla^{\prime \prime}$, SHORT RODS FORMING THE FRAMEWORK OF THE LOWER LIP.

and much wider than thick, and might well be called laminæ instead of rods.

The membrane forming the upper or dorsal portion of the mouth tuhe may be called the upper lip. Like the lower lip, it has a chitin $\operatorname{rod}\left(r^{\prime}\right.$, fig. 10$)$ along either lateral margin, but in this instance, instead of being connected at the tip by short transverse rods, the chitinous edge is continuous around the anterior margin (fig. 6).

The proximinal ends of the rods are enlarged and flexed, but not as sharply as those of the lower lip, and to them are attached muscles for moving the lip. There is no central framework in this dorsal membrane, but the latter is stretched from one marginal rod to the other. In Caligus curtus and Lepeopletheirns edurerdsi the anterior portion of the chitinous margin is bent back in the form of a semicircle, into which fits a more or less circular flap (f) of soft membrane whose front 


edge is crenated and fringed with long cilia (fig. 6, a). This flap is flexible and capable of more motion than the remainder of the lip, but to call the latter "immoval,e" (Pickering and Dana) is certainly misleading. The whole mouth tube moves together and freely, and certainly the dorsal portion of it is as movable as the ventral. In Caligus repar the anterior portion of the chitinous margin, instead of being coneave, is convex like the lower lip, and projecting in front of it is a narrow flexible membrane flap, with its front edge incised at the center and fringed throughout with cilia (fig. 10).

The statement of Pickering and Dana that the mouth "appears to be composed of the upper and lower lips, united with the different parts of a pair of maxillæ" $(1838$, p. 73) can not stand. Those authors made no attempt at any explanation of the position or connection of the maxillæ referred to, except to state that they corresponded to the first pair of maxillæ in decapod crustacea. And even this was not stated directly, but in a roundabout fashion, for they found a single pair of appendages which they said corresponded to the second maxillæ in decapod crustacea, but which they called the first maxillipeds. They proved to be in reality the second antennæ; it must have been, therefore, the first maxillæ which they thought were combined with the upper and lower lips. But we have alreacly seen that both pairs of maxilla are fully accounted for

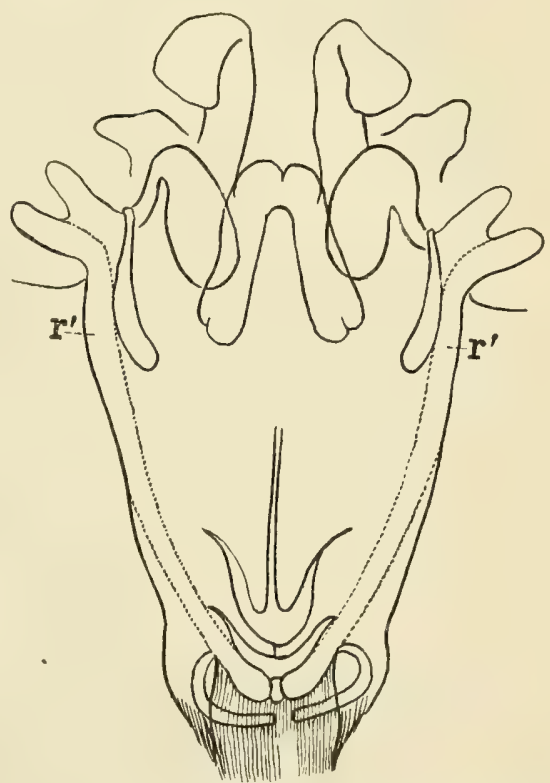

Fig. 10.-DORSAT SURFACE OF THE MOUTH TUBE OF CALIGLS RAPAX IN AN ADVANCED CHALIMUS STAGE. $r^{\prime}$, ROD ON LATERAT, MARFIN OF FRAMEWORK OF UPPER LIP. ontside the buccal tube. And A. Scott has shown by the innervation in Leperplitherims perctoralis that the claws which Pickering and Dana consilered as appendages of their "first maxillipeds" are really the first maxillæ.

Of the two pairs of maxillipeds, the first are situated about halfway between the apex of the mouth and the lateral margin of the carapace. Earh one of this pair is two-jointed, the basal joint moderately stout while the longer terminal joint is very slender and terminates in two or three short and stout spines. Their function is probably that of keeping the mouth clean of foreign matter by a sort of combing motion (fig. 11).

The second maxillipeds arise near the mid line, a little posterior to 
the first. Each is made up of two joints, the basal of which is much swollen and liberally supplied with stout muscles, while the apical one is a powerful claw curved orer inward and carrying a spinc on its inner margin (fig. 12).

These are the chief organs of prehension,

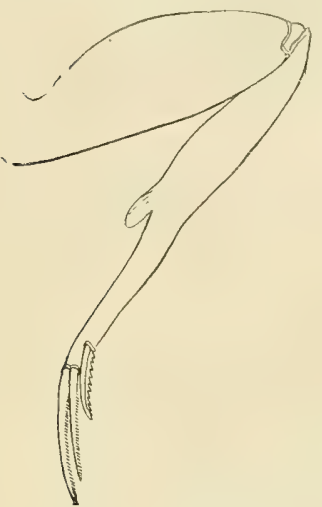

FIG. 11.-FIRST MAXILLIPED OF LEPEOPHTHEIRUS EDWARDSI. as already noted, and are usually much larger in the male. Their relative size, however, varies greatly in the different species and genera; in one they are evidently the chief reliance for clinging to the host or to the female; in another the second antennæ are so much enlarged and the first maxillæ in the male are so stout that these maxillipeds evidently share the honors at the least.

Lepeophtheirus innominatus is a good example of the former, the basal joints of the second maxillipeds being so large as to fill the central portion of the carapace (Plate XXVIII). And Caligus schistonyx is-a good example of the latter, the terminal claw of the second maxillipeds being small and very weak while the second antennæ are large and stout (Plate VI).

In many other species the two are just about equal in strength and efficiency.

Between the swollen basal joints of the second maxillipeds arises the furca or sternal fork, which consists of a stout chitin plate whose tip is bifid, much like an old-fashioned bootjack.

It varies considerably in form and relative size in the different species, and for some authors it serves on this account as a secondary basis of classification. It is frequently of considerable service in this direction, and in one or two cases

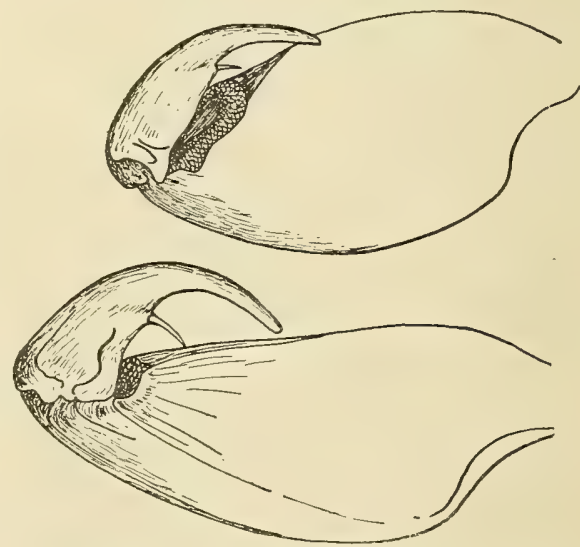

FIG. 12.-THE SECOND MAXILltPEDS OF THE ADULT CALIGUS BONITO. UPPER FIGURE, THE MALE, WITH A LARGE BONY PLATE ON THE BASAL JOINT; LOWER FIGURE, THE FEMALE.

is sufficiently different to serve as the distinguishing characteristic of the species. Witness the double hifurcation in Lepeopletheims lipproglosisi and L. Tifurcutus, and the peculiar form in the genus.Gloioprotes and in Culigus platytursi, and the entire absence of this appendage in the genus Aleliom. (see Plates XX, XXIII). Several uses have been suggested for the appendage. I. C. Thompson thinks that it 


may act as a support or cruteh on which to raise the body of the parasite high enough from its host to render the use of the swimming fert and mouth organs possible. But there are sereral considerations which render such a function quite improbable. In the first place the parasite uses its feet when on its host simply to keep the water beneath the calapace agitated for purposes of respiration; and there is space enough for this, ordinarily, without raising the carapace at all. Again, the raising of the carapace and balancing it upon this fork would weaken the parasite's hold enough to render any sudden or unlooked for friction dangerous. And then, if the fork were to function as a support there would certainly be need of some muscular arrangement to adjust, hold, and remove it, as occasion demanded; but there are no such muscles in connection with this fork, and, so far as can be determined, no means of adjustment whatever.

And, finally, there would be rery little demand for such a support, because when the terminal claws of the second maxillipeds are driven into the skin of the host the parasite's body is ordinarily raised to a greater distance than the length of the sternal fork, and hy straightening the basal joints of the same appendages it can be raised still farther without in the least loosening its hold.

A. Scott, in the memoir already referred to, writes that the function of the furca is unknown. But it seems at least possible that it may be used for the purpose already suggested, to prevent any slipping backward upon the host when the parasite has loosened its claws and is moving about over the host's body.

It would thus correspond in function as well as position with the papillated area and the spines upon the basal joints of the second maxillipeds in the Argulidx. Its position between the bases of the second maxillipeds, its backward inclination, and the entire absence of spines or papilated areas upon the maxillipeds themselves give at least a probability to this view.

Of the swimming legs the first and fourth pairs are uniramose in nearly all the genera while the remaning pairs are biramose. The gemus . Ilefiom has the legs all bilamose, but the fourth pair are rudimentary. As will be seen from the key there are several other genera not represented in North Amerían waters which have all four pairs

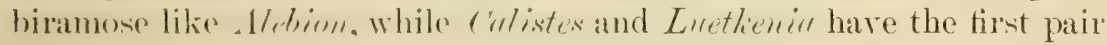
only uniramose, the other three being biramose.

In the first pair the hasipod is simple and considerably larger than the terminal joints, except in / alignles, where it is the same size. It frepuently arries upom its posterior ventral surface one or two spines whose bases ale enlarged and which are inclined batekward (fig. 13). The exopod is well dreveloperd. two-jointed and in line with the hasipod. The terminal joint is often appropriately called the " hand" on areount. of its shape. 
It carries on its outer margin three claws of about the same length, at the outer posterior corner a long plumose seta or a spine longer than the claws, and on its posterior border three stout plumose setw. Occasionally one of the terminal claws is developed at the expense of the others, as in Lepeophtheims monacanthus and L. quadratus and Caligodes megacephalus.

In the genus Gloiopotes two of the claws are curiously modified into a three-pronged fork.

One or two species have been reported in which there were no plumose setæ upon the posterior border (Caligus hxmulonis and $C$. productus).

The endopod of these first legs is rudimentary and is represented in some species by a minute joint bearing setæ (Lepeopletheimes pectoralis) and in others simply by the seta (Caligus rapax and $C$. bomito).

In the second pair of legs both exopod and endopod are well developed, two- or three-jointed, and plentifully supplied with plumose setæ.

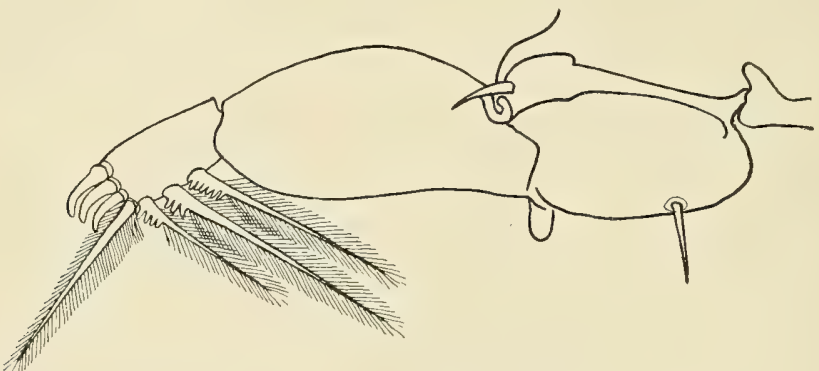

Fig. 13.-First swimming leg of adult female Caligus bonito, ventral view.

These latter point inward on either leg and are often long enough to overlap on the mid line, thus forming a very effective swimming lamina. These legs are almost exactly alike in all the genera. The large basipod carries on its posterior margin a stout plumose seta, inclined backward and inward at an angle of about $45^{\circ}$. The basal joint of the exopod is longer than either of the other two joints and carries a plumose seta on its inner margin and a stout spine at the outer distal corner (fig. 14). The second joint is short, with a plumose seta on the inner margin and a spine at the outer distal corner. The terminal joint is almost circular in outline and carries a row of six plumose setæ around its edge and a spine at the outer corner.

This exopod is in nearly the same line as the basipod, but the endopod is bent inward until in Caligus and Lepeophtheirus it is at right angles to the basipod, while in Gloiopotes and Alebion it is nearly parallel with it, but running in the opposite direction. The basal joint of this enclopod is short and carries a single plumose seta on its inner margin. The second joint is the longest of the three and usually the widest, and carries two plumose setæ at its distal end. The circular 


terminal joint is set into the outer distal corner of the second joint, which is much narrowed at the end for this purpose, and it carries a row of six plumose seta around its margin. The endopod is never armed with spines, like the exopod, in any species.

In the third pair of legs the basipods are widened out into a broad lamina, those from either leg meeting and fusing at the mid line into a single solid apron the entire width of the thoracic area, and often nearly equaling the width of the carapace (fig. 15). This forms a powciful swimming organ and at the same time assists greatly in prehension by closing the posterior edge of the carapace and enabling it to act as a large sucking disk. In addition to these two functions, the lamina is also inclined backward, and being stiff it must make a powerful prop to assist in the prevention of slipping backward. The exopods and endoports of this pair of legs are rery small and are attached to

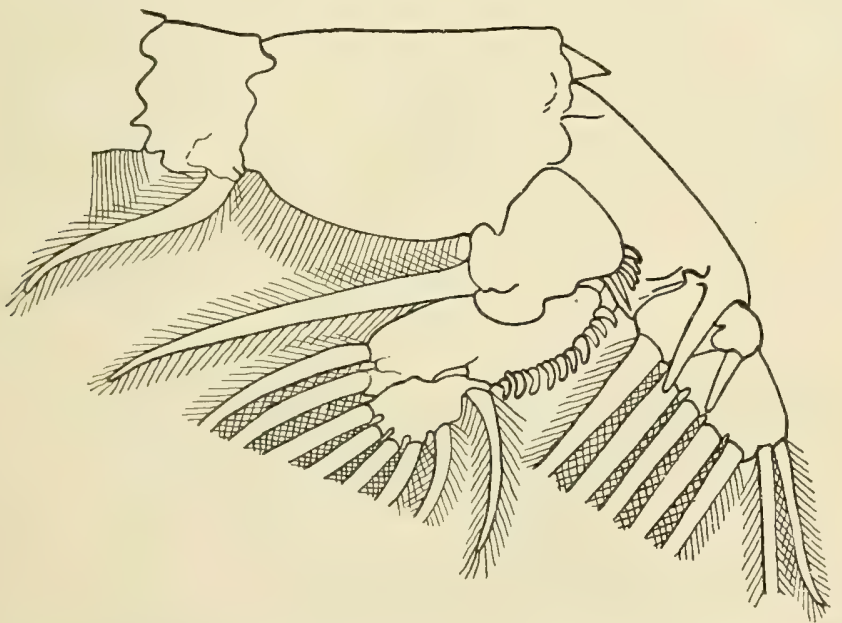

Fig. 14. Second swiming leg of adutt female Caligus bonito, ventral surface.

the outer margin of the basipod lamine, usually some little distance apart. In some species, howerer, they are so close together as to be almost fused. The endopod is one or two jointed, the basal joint being rery short and almost hidden by the edge of the lamina, while the terminal joint is circular. The exopod is two or three jointed, the basal joint amod with a stout claw on its rentral surface, the two torminal joints being the halves of a small ellipse. In some species the two terminal joints are elongated and appresied close to the margrin of the hasal lamina. Both rami are plentifully supplied with plumose setæe and fringed with fine hairs.

These first three pairs of lesw are comnected across the mid line by sternal plates which increase in width from in front backward. 'Those of the second and thirel pairs are fringed with hairs along their posterior margins, while in the first legs this margin is smooth. 
The fourth pair of legs are very different from the others. and they vary greatly in the different species and genera, thus furnishing often a useful means of identification (see Plates). In Caligus, Leperpletheims, and allied genera they consist of a basipod usually as long as all the remaining joints put together, and a one, two, or three jointed exopod with no trace of an endopod.

The exopod is really always three-jointed, but in development the joints often become so thoroughly fused that all trace of the original division is lost. Each exopod joint bears at its outer distal corner a sharp spine, usually straight, and the terminal joint ends in three spines of unequal length, the inner one being the longest. In several species there are short semicircular fringed lamina at the bases of

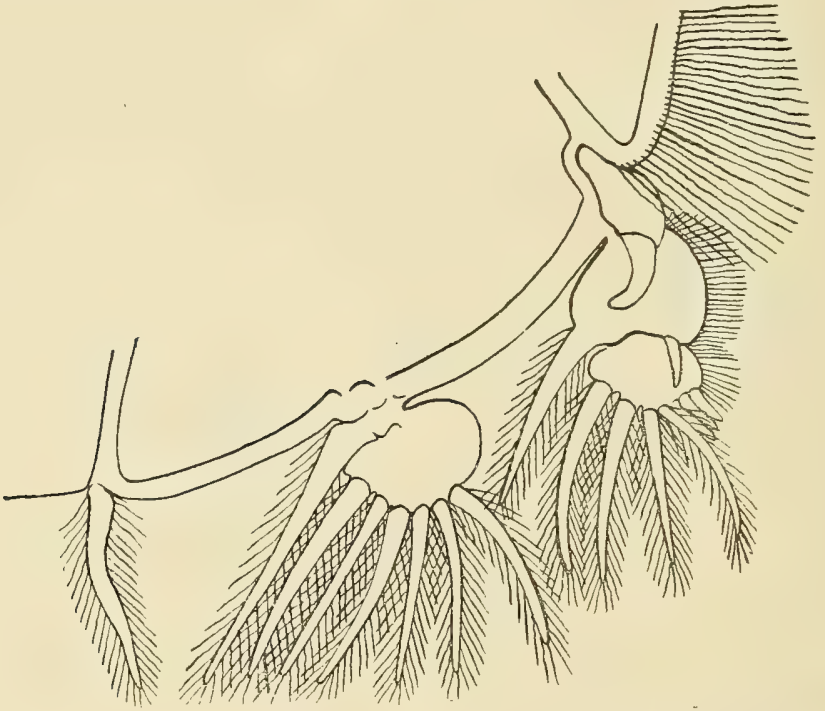

Fig. 15.-Third SWIMming Leg of AdULt Female Caligus Bonito, ventral view.

these spines on the ventral surface (Caligns rapax, teres, mutabilis, etc.). In Gloiopotes there is a continuous fringe of short, stiti spines along each joint, on its outer margin,

The size and length of these legs is even more rariable, and we can find all gradations from the mere rudimentary stunıs in the genera Alebion and Pseudocaligus up to legs which reach far beyond the tips of the anal laminx (Caligus longipes, Lepeophtheims lomgipes, Calinus. namus, etc.). In a few species the spines on these legs are widened and flattened into laminæ covered with hairs (Caligus liementus, C? platytursi).

The fifth legs are rudimentary and are attached to the posterior end of the genital regment. They consist of a short lamellar hasipod, terminated by two or three short spines or sete (5, tig. 1). Thase fifth legs are usually more prominent in the male than in the female, where they are often reduced so much as to be practically lost. 





\section{SUMMARY.}

1. The hody of the Caligids here discussed is made up of three parts or regions-a cephalo-thorax covered with a carapace, a free thorax of two segments the posterior of which is the genital segment, and an abdomen of from one to four segments.

2. The cephalon bears seven pairs of appendages, namely: Two pairs of antenne, one pair of mandibles, two pair's of maxilla, and two paix's of maxillipeds. Each of the five thorax segments carries a single pair of swimming legs, those on the fifth segment being rudimentary in all the genera, while the fourth pair are also rudimentary in Aletrion. and I'sendocaligns. The abdomen has no appendages, but carries at its posterior end the paired anal laminæ.

3. The carapace is oral or elliptical. Articulated with its anterior margin ale the frontal plates or modified basal joints of the first antenna. In six of the genera-Caligus, Psendocaligus, Caligodes, Symestius, Ilomoiotes, and Parapetulus-these frontal plates are provided with lunules or sucking disks. The carapace is divided by grooves or sutures into four areas-the cephalic, the thoracic, and the light and left lateral areas - the principal grooves being arranged in the shape of the letter H. The posterior part of the body is usually much narrower than the carapace.

t. The first antennæ are very fully innervated, and thus become highly sensitive. The second antenne carry hooks or claws on their triminal joints, and are modified into stout prehensile organs, particularly large and strong in the male. The first maxillipeds are weak and apparently useless, unless it be to keep the mouth parts clean. The second maxillipeds are large and well developed, and, with their terminal claws, form the chief organs of prehension for holding the parasite on its host.

5. The eyes are simple and paired, but are fused together on the median line instead of being separate, as in the Argulidie. The mouth parts are modified into a proboscis for sucking up the food; the single pair of mandibles are concealed within this proboscis, while the two pairs of maxille are outside and free from it. The first pair are simple, but rudimentary, and have migrated to a position near the margin of the carapace behind the second antennx. The second maxille are simple in those genera which have lunules on the frontal plates, but are bifurcate in the remaining genera. They are situated close to the proboseis on either side.

6. Situated upon the ventral surface, on the mid line, between the bases of the second maxillipeds and the first swimming legs, is the furca or sternal fork, consisting of a stout chitin plate whose tip is bifid much like an old-fashioned bootjack. It points backward, and its use is probably to prevent the animal from slipping while on its host.

Proc. N. M. vol. xxviii-04-33 


\section{B. INTERNAL MORPHOLOGY.}

Body wall.- The body wall is made up of three layers (1), the outside layer of chitin cells forming the exoskeleton or cuticle (c. fig. 16); (2), the cellular "hypodermis" (h); (3), the connective tissue lamina which lines the entire body wall and supports the alimentary canal and

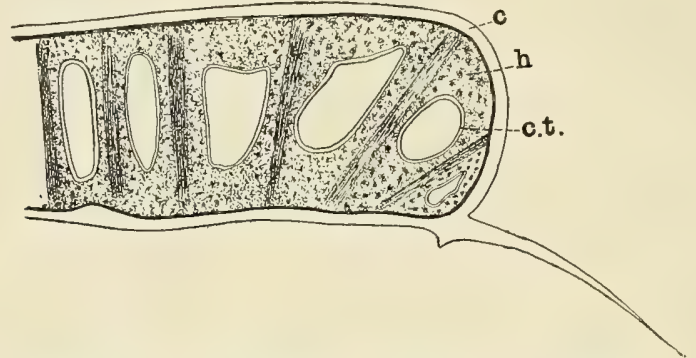

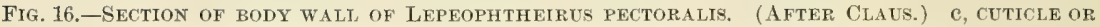
CHITIN EXOSKELETON; c.t., CONNECTIVE TISSUE ENDODERM; h, CEILULAR HYPODERMIS.

other organs (c. t.). There is no continuous body cavity, but only a series of lacuna, through which the colorless blood is driven in spasmodic currents. Furthermore these lacunæ are so situated that no extensive circulation is anywhere possible, but there is instead a series of limited circuits which interlace with one another.

\section{ALIMENTARY CANAL.}

The mouth opens directly into a short, curved resophagus, which passes backward between the supra and infraøsophageal ganglion, along the dorsal surface of the latter, and enters the ventral surface of the stomach a little behind its anterior end. It is very narrow throughout its entire length and is easily overlooked in both longitudinal and transverse sections (oe. fig. 17). The stomach is many times the width of the cesophagus, but is only a little wider than the intestine. It is situated close to the ventral surface of the carapace and stretches from just behind the eyes backward along the mid line at least to the center of the thoracic area (st.).

It is somewhat wider in front than posteriorly, and is also raised away from the ventral surface above the posterior end of the infracesophageal ganglion. This raised end is produced into a median lobe or cæcum, reaching forward over the resophagus and between the oraries or testes. The stomach taper's uniformly toward the posterior end, where it opens directly into the intestine (i). There is a constriction at this point like the beginning of a sphincter muscle, but the opening can not be closed. The intestine, therefore, is a direct continuation of the stomach; it enlarges considerably just back of the stomach, then contracts in the fourth thoracic segment, enlarges again in the 


genital segment, contracts as it enters the abdomen, enlarges in the abdomen, and contracts finally to form a short rectum in front of the

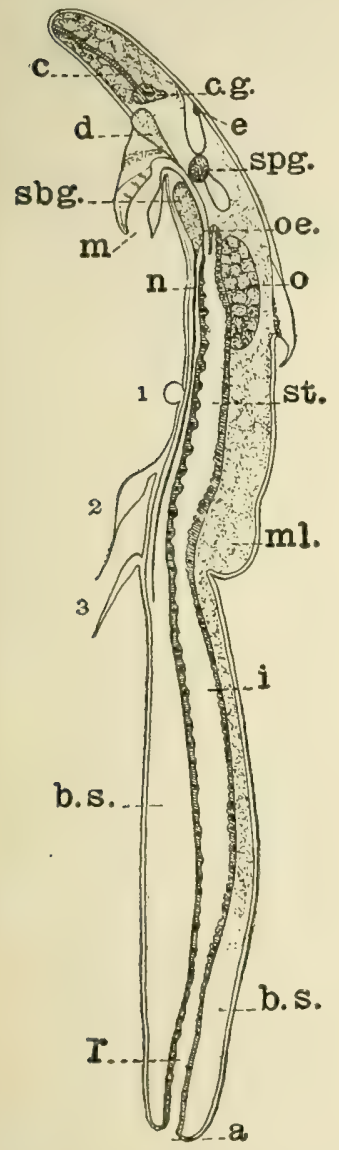

Fir. 17.-LovgitudiNal SECTION OF LEPEOPHTHEIRES SHOWING RELATION OF INTERNAL ORGaNs. (AFTER A. SCOTT.) a, ANUS; b. S., BLOOD SPACE; C, FILAMENT DUCT; e. g., FILAMENT GLAND; d, DUCT OF DIGESTIVEGLAND; $\mathrm{e}$ EYE; i, INTESTINE; M, MOUTH; Ml., MUSCLE; II, VENTRAL NERVE; O, OVARY; DC., CESOPHAGUS; r, RECTUM; sbg., SUBESOPHAGEAL GANGLION; Spg., SUPRAGSOPHAGEAT GANGLION; st., STOMACH. anus. The latter is terminal and situated between the anal laminæ (fig. 18).

At the anterior end where it leaves the stomach the intestine is on the ventral sur-

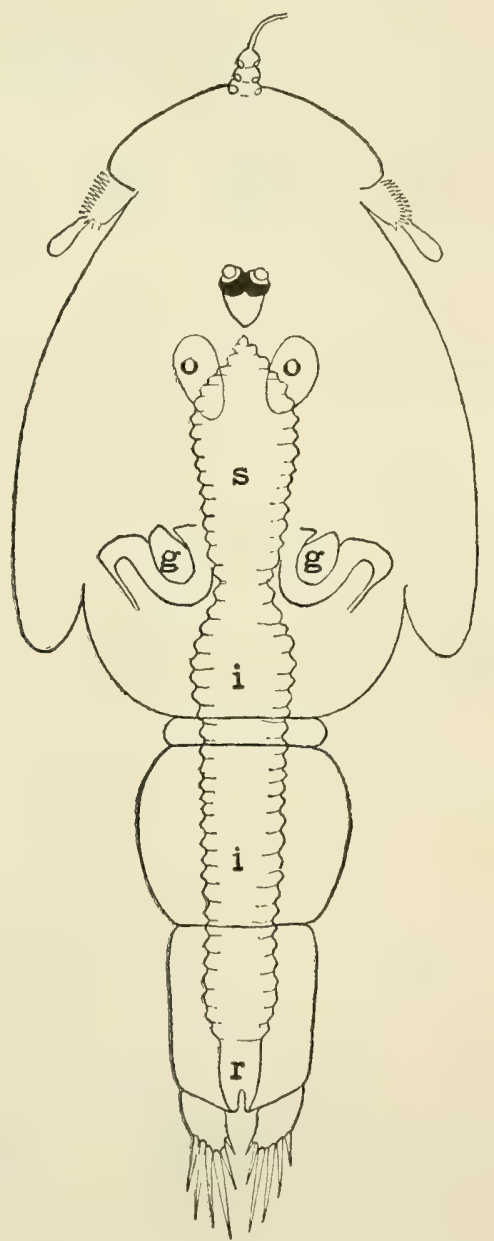

Fig. 18.-The Digestive system OF CALIGUS RAPAX; CHALIMUS FULLY GROWN. $g \mathrm{~g}$, DIGESTIVE GLANDS; i, INTESTINE; o, OVARY; r, RECTUM; S, STOMACH.

fare and it remains there till it passes into the genital segment. Here it lies close to the dorsal surface and remains there until after it enters the abdomen, where it turns downward and occupies the center of the body.

In transverse sections of young males and females the stomach and 
intestine appear circular in outline. But as development progresses and the reproductive organs mature, they gradually encroach upon the digestive tube and compress it. The ovaries or testes being located above the anterior part of the stomach, push the latter together sidewise and also push it downward, the result being that it assumes the

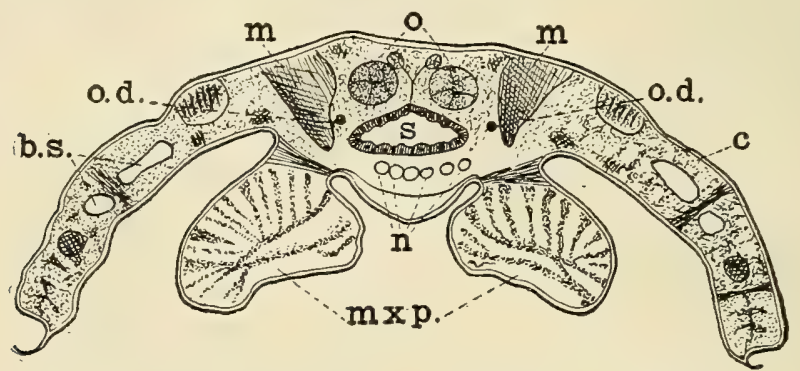

Fig, 19.-TRANSVERSE SECTION OF LEPEOPHTHEIRUS IN THE REgION OF THE SECOND MAXILLIPEDS. (AFTER A. SCOTT.) b. S., BLOOD SPACES; c, ChITIN EXOSKELETON; M, MUSCLE; mXP., MAXILLIPEDS; I, VENTRAL NERVES; o, OVARY; o. d., OVIDUCT; s, STOMACH.

form of a triangular prism, with one of the angles toward the dorsal surface (fig. 19).

In the genital segment, on the contrary, the convolutions of the oviduct are below and outside of the intestine, and consequently push it together sidewise and upward. The result is again a triangular prism, but this time one of the angles points downward and a flat side is in contact with the dorsal surface (fig. 20). By the time the sexual organs are fully mature there has been a strong compression of the digestive organs.

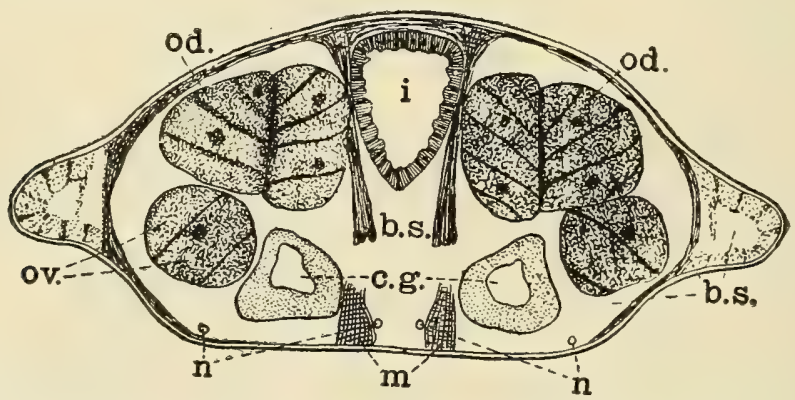

Fig. 20.-Cross section of the genttal SEgment of a Lepeophtheirus. (After A. Scott.)

b. S., BLOOD SPACE; c. g., CEMENT GLAND; i, INTESTINE; m, MUSCles; n, NERVES; od., OVIDUCT; ov., OVA.

The wall of the digestive canal is not smooth, but is constricted transversely at fairly regular intervals. When examined in the living animal this wall is seldom at rest, but shows a series of peristaltic movements passing intermittently along from the stomach to the intestine, or vice versa. The action usually continues in the same 


direction for some time and is then reversed. Under its influence the contents of the stomach and intestine are thoroughly mixed and brought in contact with every portion of the digestive surface. As there is no valve between the stomach and intestine, the contents of the two can pass back and forth without hindrance.

The alimentary canal is lined with endoderm, which is continuous with the ectoderm at the mouth and anus. While the general structure of this endoderm is distinct from that of the ectoderm, there does not seem to be very much differentiation in the different body regions. It is almost exactly alike in structure throughout its entire length. But in both the stomach and intestine it is thrown up into longitudinal folds which increase the digestive surface.

In both Caligus and Lepeophtheirus these folds increase in size as they pass backward from the anterior end of the stomach and attain their maximum in the genital segment, after which they decrease toward the rectum. Connected with these folds and usually most abundant alongside their crests are numerous gland cells, which, doubtless, secrete a digestive juice, since they stain differently from the remainder of the endoderm.

Connected with this alimentary canal are two pairs of digestive glands, which probably function something like the salivary glands and the liver in higher animals. The first pair is situated in the anterior part of the carapace and is made up of three portions. The smallest of these is median, and

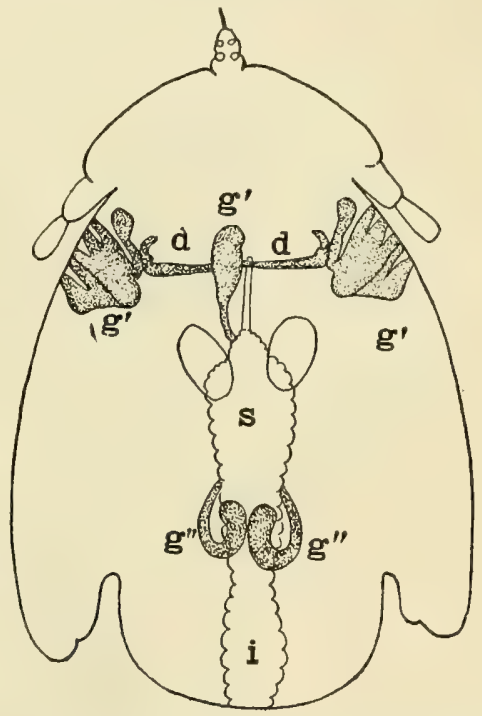

Fig. 21.-DIGESTIVE GLANDS IN LEPEOPHTHEIRUS. (AFTER A. SCOTT.) d, DUCTS; $\mathrm{g}^{\prime}$, ANTERIOR GLANDS; $\mathrm{g}^{\prime \prime}$, POSTERIOR GLANDS; i, INTESTINE; S, STOMACH. situated just in front of the mouth tube. The other two portions are larger, and are located sometimes close to the lateral margin of the carapace, just behind the first antenne (Lepeophtheimes pectomelis, $\mathrm{g}^{\prime}$, fig. 21), sometimes much nearer the median line (c'aligus bonito). A duct (d) extends from the anterior portion of each lateral division acrosis to the side of the median division, and the latter gives off at its posterior end, just below the asophagus, a third duct, which passes backward and enters the anterior end of the stomach.

The second pair of digestive glands ( $\left.\mathrm{g}^{\prime \prime}\right)$ is situated at about the renter of the thoracic area, on either side of and close to the median line, and about opposite the posterior end of the stomach. 
Both pairs of glands are dark brown in color, but while the first pair are partially or wholly concealed among the muscles and appendages of that portion of the carapace, the second pair stand out conspicuously in dorsal view, since they are close to the dorsal surface. In some species they are quite small and shaped like a comma, the large, rounded body lying upon the upper surface of the intestine, while the curved tail bends around laterally to the ventral surface of the intestine, where it gives off a duct leading to the posterior end of the stomach.

This is the condition in Lepeophtheirus pectoralis, while in Caligus repar the gland is much larger, horseshoe-shaped, and entirely free from the intestine, though lying close to it. The duct here is given

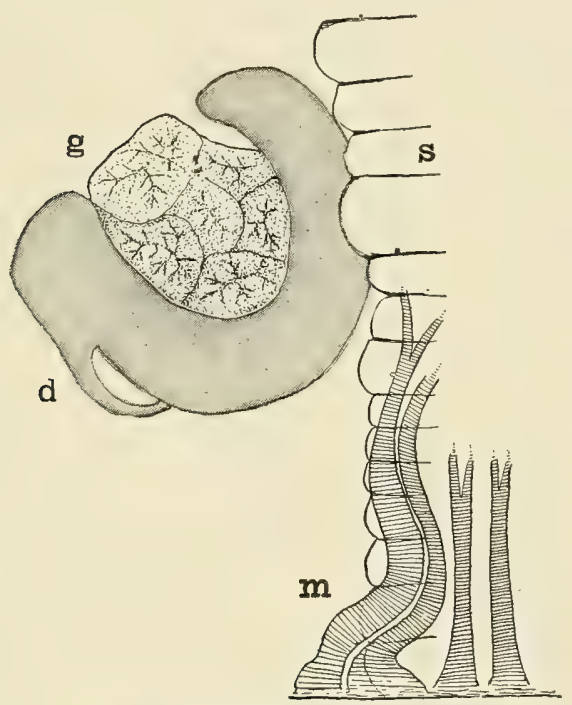

Fig. 22,-Posterior DTGESTIVE gLands OF CALIGUS RAPAX. d, DUCT; g, GLAND; m, MUSCLES; S, STOMACH. off from thé outer arm of the horseshoe, turns downward and then forward to enter the stomach (fig. 22).

In many of the other species and genera these glands are of a decidedly different shape if the brown bodies visible in the thoracic areas are any criterion. Thus by a reference to the plates of the new species here published it will be seen that in Lepeophtheirus edwardsi, L. Tongipes, L. chitensis, and L. parviventris as well as in Caligus pelanydis these brown spots show as quite regular oval or elliptical bodies flattened on the inner sides. In Gloiopotes omatus they are very regular ellipses without being flattened at all. In Caligus bonito they are very small and seem fused on the mid line into a bean-shaped body. In three species of Caliguslatifroms, exilis, and aliuncus - they are comma-shaped with the small end pointing forward, and in the last species also outward. In Caligus mutabilis they are even unlike in the two sexes, having a club-shape in the male, the two clubs being strongly curved with their small ends toward the front and their concave sides toward each other. In the female they have the shape of a spherical triangle, the apices pointed backward, with a small spherical enlargement on the outer side at about the center.

In Lepeophtheims lippogloss they have the form of paragraph marks placed back to back. In the male of Caligus sclistrmyx they show up as hatchet-shaped bodies, widely separated, and the handles 


pointing diagonally outward. And finally in cirligns teres and Lepechelithrimes diswimulatus they appear to be made up of two parts, differing considerably in size, the smaller part being anterior in the Caligus and posterior in the Lepermletheirus species. A section of one of these glands shows it to be divided into small lobules much like a pancreas, and in the center of each lobule (an be seen the divisions of the duct for collecting the secretion.

\section{TIE BLOOD AND CIRCULATION.}

The hlood is made up of a colorless fluid in which floats numerous corpuscles also colorless. These corpuscles are of different sizes and shapes and are even capahle of being changed in shape to accommodate the diameter of the spaces through which they pass. There is no heart nor blood ressels of any sort. The circulation is entirely lacunar, and consists of an irregular pulsation or streaming of the blood hack and forth through the spaces left around the internal organs and muscles, and between the bands of connective tissne in the body wall. The propelling agent of these blood streams seems to be the peristaltic morements of the alimentary canal and the respiratory morements of the rectum. And since the peristaltic movements pass from the anterior to the posterior for a portion of the time and then are reversed, so in like manner the blood streams continue to flow in one direction for a short time and then slacken and reverse. And, again, since the movements of neither the intestine nor the rectum are uniform or continuous, so those of the blood current are spasmodic and irregular. Often also, particularly at the times of slackening prior to reversal, the motion consists of a simple oscillation back and forth, without any definite movement in either direction.

The course of the blood streams varies so much in the different species that it would be necessary to describe each separately. The only descriptions given are for Caligus ruptus by Pickering and Dana (1838), and for Leperphlitlerims pertormlis by $A$. Scott (1901), and these vary in many essential particulars.

The following general statements will apply to all the species so far observed. There is a central current along the median line under the alimentary camal. A pair of lateral currents start from the region just behind the eyes, and each flows outward and backward to the tip of the lateral lobe on its side. It then turns forward along the lateral margin of the earapace till it reaches the muscles connected with the mandibles where it turns toward the median line.

A serend pair of lateral currents start from nearly the same region, course Inckward through the thoracie area and the free segment into the genital segment. IIere they turn outward, following the reproductive organs to the posterior end of the segment, where they turn 
around inward and meet on the median line beneath the intestine. The general course of these main currents is the same, but the details differ greatly. As Pickering and Dana well say, they "are merely main directions, and the blood flows into them or from them through all their extent." The points where the main currents break up into smaller currents and the courses of the latter also vary greatly. Pickering and Dana describe in Caligus curtus two points upon the median line where there is a valvular action, functioning somewhat as a heart in this circulation.

One of these is situated at the apex of the posterior thoracic joint; there are here three valves, one in the center ventrally and one on either side dorsally, the dorsal and ventral valves opening alternately. The pulsations are regular, and from 30 to 40 a minute. The second point is between the basal joints of the second antennæ. (Pickering and Dana call them the first maxillipeds.) Here there is a single membranous valve playing back and forth and thus preventing the return of the blood that has passed it in either direction.

It must not be inferred that these two descriptions are characteristic of the two genera and that Caligus species have the valves while Lepeophtheirus species do not. This would not be true; the descriptions merely serve to indicate the amount of diversity to be found in the details of circulation.

After examining a larger number of species while alive it may be found advantageous to publish these details in a future paper.

\section{RESPIRATION.}

There are no independent organs of respiration, but Hartog, in 1880 , described the anal respiration in Cyclops, Canthocamptus, and allied genera, and suggested that the blood of these parasites may be aerated in the same way. That this is the actual condition the present author has proved in several instances. And first, as noted by A. Scott (1901, p. 21), the chitin exoskeleton is so thick over nearly all the body that very little aeration could be effected through it, while the endoderm lining the rectum is thin enough for this purpose.

Then there are the necessary muscles for such respiration, dilators running from the abdomen wall to the rectum, while the peristaltic movements, common to the rectum as to the rest of the alimentary canal, serve for the contraction. These dilator muscles are figured by Claus (1864) for Leperphtheims thompsoni (which he calls Caligus branchicilis) in Plate XXXIII, fig. 5 of his memoir. They are said to be present in Lepeophtheims pectoralis by A. Scott $(1901$, p. 21), and they have been observed by the present author in Lepeoplitheims edwardsi and in Caligus rapax (fig. 23) and C. bonito. These facts create a strong presumption in favor of the existence of such respiration, and it was only left to actually observe it in the living animal. 



Such observation has been made in the three species last named and the respiration was seen to be exactly like that described by Hartog: for Cyclops, save that it was not as regular.

It can be secn to best advantage in late chalimus stages, in which the walls of the abdomen are usually very transparent, while the movement itself seems more vigorous.

When the rectum contracts during peristaltic movements there is left only a linear cavity along the mid line. Then the dilator muscles immediately pull the rectum out to its full width, at the same time opening the anal valves for an instant. This action fills the rectum with outside water, which then operates by endosmose through the thin rectum wall.

This same method of respiration is as normal to the nauplii of these parasitic forms as it is to those of the free-swimming genera, and the author has repeatedly observed it also in the metanauplius of Caligus rapax and in the chalimus of the same species, as well as those of Catigus curtus and Lepeophtheirus edvardsi. The fact that it

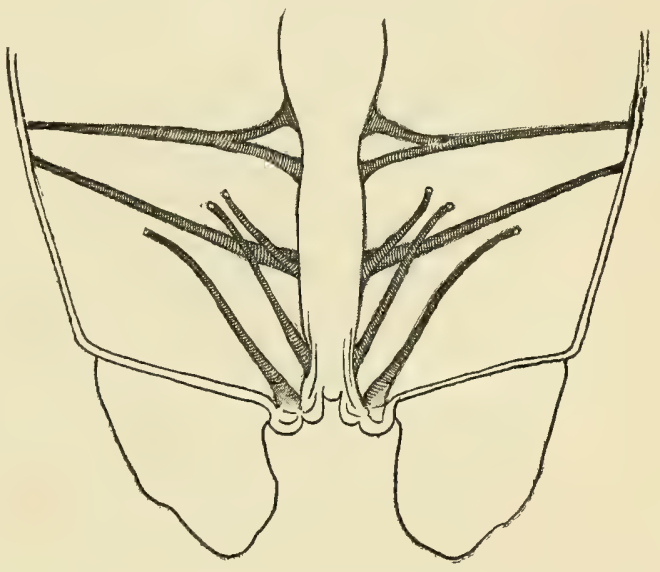

Fig. 23.-OBLIQUE MUSCles Which OPERATE THE RECTUM IN CALIGUS RAPAX DURING RESPIRATION.

is thus the only method of respiration throughout the period when the legis are as yet undeveloped, and that all the muscles concerned in it remain in the mature form, furnishes strong circumstantial evidence that it is the method also in the other forms here described, but in which it has not as yet been actually observed.

\section{MUSCULAR SYSTEM.}

Copepods helonging to the genera here considered are as a general rule so transparent that their musculature can be determined with very little effort. And then the muscles are so plainly striated that there is very little danger of mistaking them for any other tissue. Indeed, the striation in the muscles of Califus antus were among the very first observed in any animal, and their discovery here by Pickering and Dana was about contemporaneous with that in human muscle by Doctor Hodgkin. (Pickering and Dana, 183s, p. s1, footnote.)

The frontal plates are flexed by two short and slender muscles, situat al in nearly the same place in all the genera, directly behind the lunules, attached to the posterior portion of the plates, and rumning 
backward and inward. They bend the frontal plates downward, and thus assist in attaching the lunules (a, figs. 24 and 25 ).

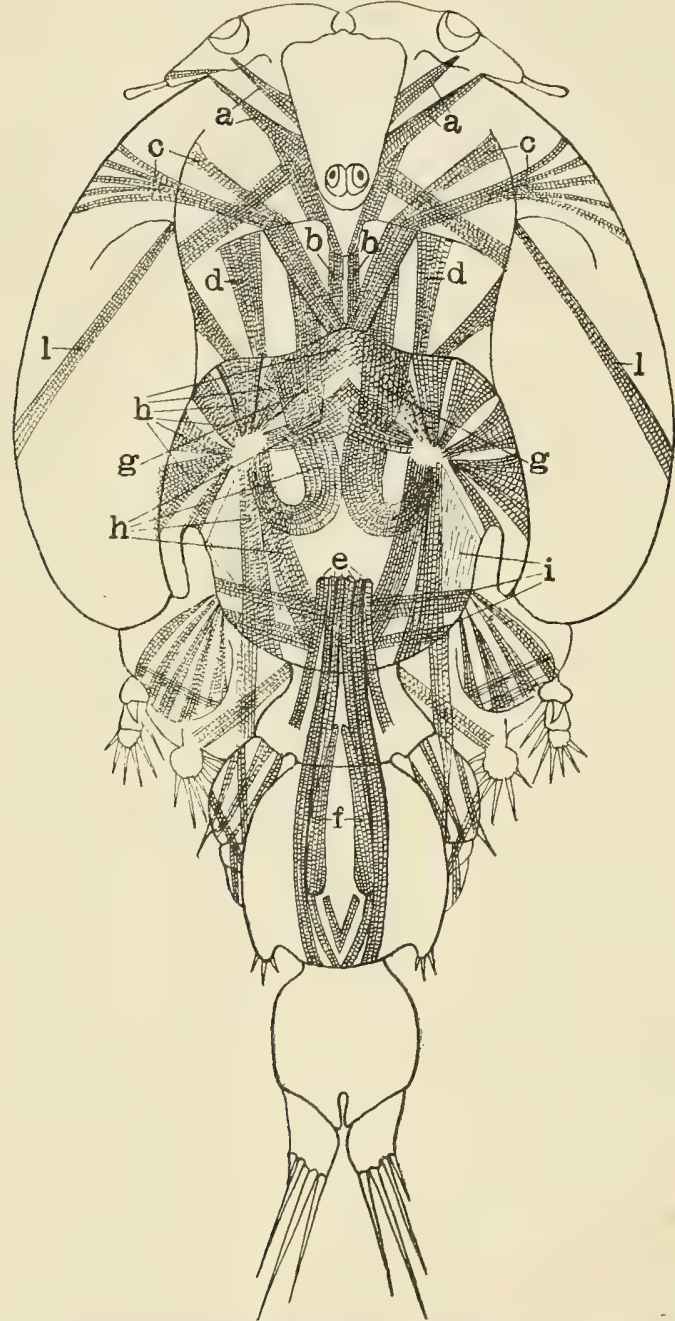

Fig. 24.-Musculature of a male Caligus curtus, (AFter PICKERING AND DANA.) a, FLEXORS OF FRONTAL PLATES; $b$, c, d, MUSCLES PRODUCING FLEXION BETWEEN THE CEPHALON AND THORAX; e, EXTENSORS OF FREE SEGMENT, GENITAL SEGMENT AND ABDOMEN; $f$, EXTENSORS BETWEEN THE GENITAI SEGMENT AND ABDOMEX; g, PRODUCE FLEXION BETWEEN THOPACIC AND LATERAL AREAS; h, i, MOTOR MUSCLES OF THE SECOND AND THIRD LEGS; 1, MANDIBLE MOTORS.

There are three pairs of muscles which operate in producing flexion between the cephalon and the thorax along the cross-bar of the $\mathrm{H}$-shaped groove already described. The shortest of these three pairs are the nearest to the median line and nearly parallel with it (b). The second pair are very much larger and extend from the middle of the cross-bar frontward and outward, at an angle of 45 degrees, to the very edge of the carapace (c).

The third pair are again nearly parallel with the mid line but much farther away from it than the first pair (d).

The muscles for the extension of the free (fourth) thorax segment, the genital segment, and the abdomen arise side by side in pairs near the median line in the posterior portion of the thoracic area (e). The outer pair are the shortest and terminate near the center of the fourth segment, controlling the movements of that segment. The pair next inside of these are the longest and extend through the genital segment and into the abdomen.

The third or inner pair terminate in the genital segment.

In connection with these we find shorter muscles farther back arising near the center of the genital segment and terminating in the 


alodomen (f). These of course produce flexion between the two segments in which they are situated.

The combined action of all these muscles produces a lateral motion of the posterior wegments of the body, flexion, extension, or a telescopic contraction of the different body regions. In addition to these muscles the thoracic area on either side of the mid line is provided with a

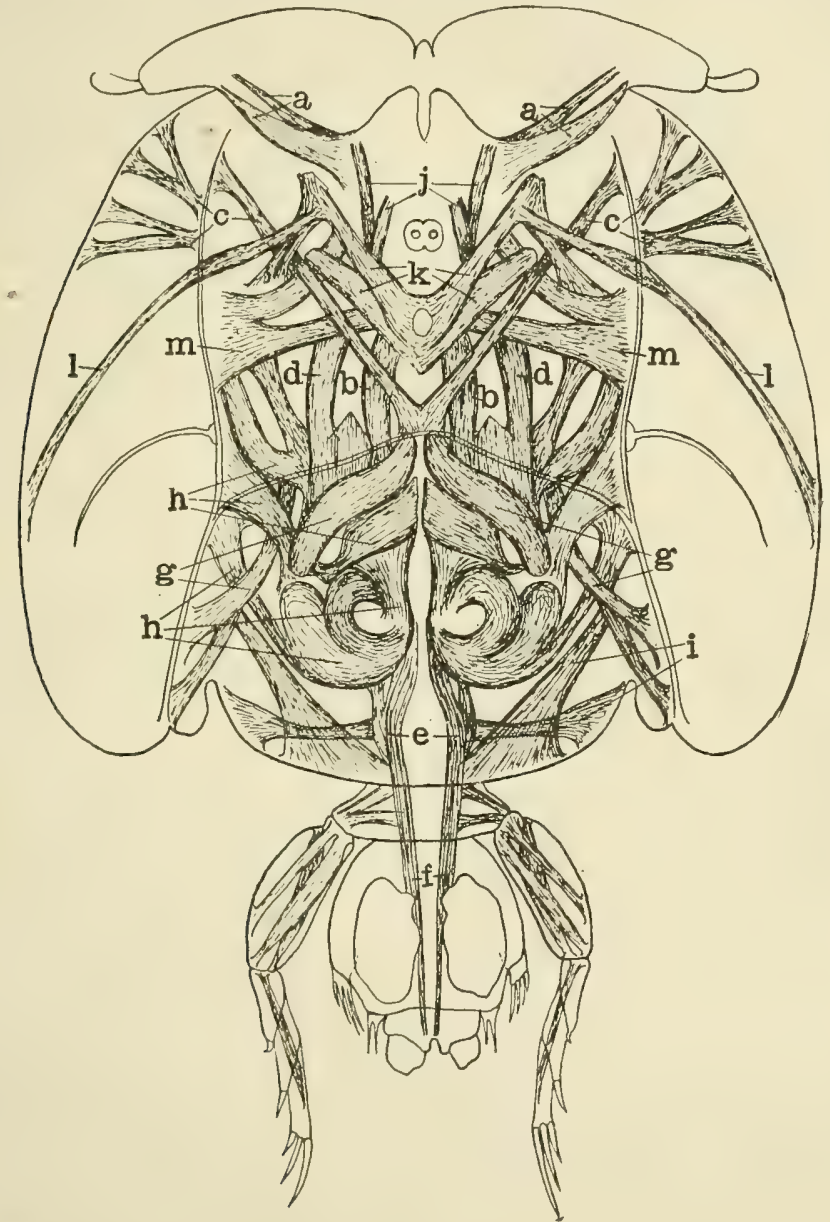

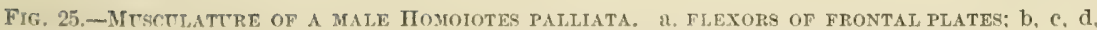
MLACLE PRODUCING FLEXION BETWEEN THE CEPHALON AND THORAX; E, EXTENSORS OF FREE SEGMENT, GENITAL SFGMENT AND ABDOMEN; f, EXTFNSORS BETWEEN THE GENITAI, SEGMENT AND ABDOMEN; g, PRODICE FLEXION BETWEEN THORACIC AND LATERAL AREAS; h, i, MOTOR MTSCILS OF THE RECOND AND HIRD LEGS; $j$, ELEVATORS OF THE MOUTH TUBE; $k$, MOTOR MUSCLES OF MOUTH TUBE; 1. MANDIBLF MOTORS: M. MOTURS OF SECOND MAXIILF.

number of muscles, some extending forward, other's backward, and still others laterally. I few of these are for produeing fle xion between the thoracie and lateral areas and assisting the three pairs already deseribed in Hexing the thorax on the cephalon (g). It is the combined action of these muscles which arehes or depresisen the arapace, and which makes of it an organ of prehension in the form of a large. suck- 
ing disk. But by far the larger portion of these thorax muscles are the powerful locomotor agents which operate the second (h) and third (i) swimming legs and make of them the chief propelling organs.

Each of the appendages and the mouth tube are also plentifully supplied with muscles, both flexors and extensors, and a good idea of the service performed by each may be obtained from an examination of its muscle supply. The anterior antennæ have two extensors and one flexor. The powerful muscles used in the second antennæ for clasping are quite similar to those in the second maxillipeds (fig. 26) and nearly fill the basal joint.

They are much larger and stronger in the male than in the female. We have already seen that the appendages themselves are larger in the male and form the chief organs for clasping.

There are four short and narrow muscles attached to the base of the

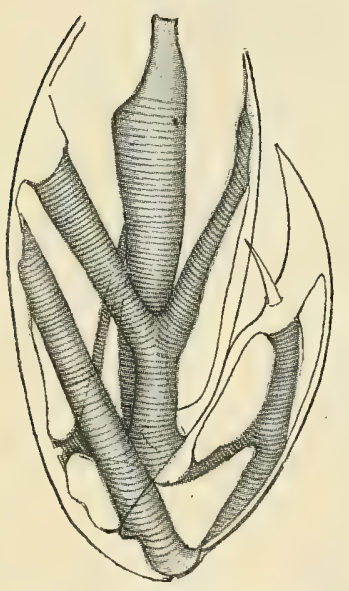

Fig, 26.-Musculature of THE SECOND MAXILLIPEDS OF CALIGUS RAPAX. proboscis framework by means of which the latter may be elevated to a right angle with the ventral surface $(\mathrm{j})$. Other muscles extend posteriorly and laterally and assist in the elevation or depression of the tube when sucking up food (k).

The muscles controlling the mandibles are surprisingly large and strong and fairly prove that these appendages are vigorously used in the process of eating, which is hardly conceivable if the creature feeds on mucus. They extend outward and backward obliquely to the very margin of the carapace about opposite the first pair of legs (1).

In the female the muscles of the first maxillæ are as small and degenerate as the maxillæ themselves; but in the male they are much better developed and must give these appendages a strong clasping power. The muscles of the second maxillæ are better developed than those of the first, and they are larger and stronger in such genera (Lepeophtheirus, etc.) as have these appendages bifurcate $(\mathrm{m})$.

The muscles of the first maxillipeds are very meager in both quantity and quality, and, with the weak structure of the appendages, show plainly that they are not of much service to the animal. And Pickering and Dana are probably right when they bestow upon them the appellation "rudimentary." A good idea of the musculature of the second maxillipeds can be obtained from fig. 26 . These are the principal clasping organs, and the muscles which operate them are both large and stout, particularly the flexor of the terminal claw. The first three pairs of feet possess a complicated musculature, as is well shown in fig. 25, which makes them powerful propelling organs. 


But the fourth pair, even in those species in which they are relatively large (Leperpletheirus longipes, ete.), are notably defective in muscles. Hence, they can be but little used by the copepod, and the genera (Psendocalignes, Alelion), in which they are reduced to mere rudimentary stumps, can not suffer wuch inconvenience from their loss. The muscles of the alimentary canal and those used in respiration have been already described.

\section{NERVOUS SYSTEM.}

The nervous system is composed of two central ganglia and the paired nerves which arise from them. One ganglion lies above the æesophagus and the other below it, but the lateral commissures connecting the two are so large that it would be more strictly correct to speak of the ganglia as fused together with a small opening through the center for the passage of the esophagus (Pickering and Dana, p. 89). The upper, supraœsophageal ganglion or brain, is about half as large as the lower and gives off from its anterior end three pairs of nerves (fig. 27 ).

The first or inner pair (1) are optic nerves and arise from a small optic lobe produced on the dorsal surface of the ganglion.

They are very short and their roots cross so that each eye is supplied by fibers from both sides of the brain.

In Lepeophtheirus the second pair (2) arise just outside the first and go to the first antennæ. They are much larger than the preceding pair and subdivide into a number of branches, which supply both the plumose setre upon the basal joint and the simple tactile setie upon the

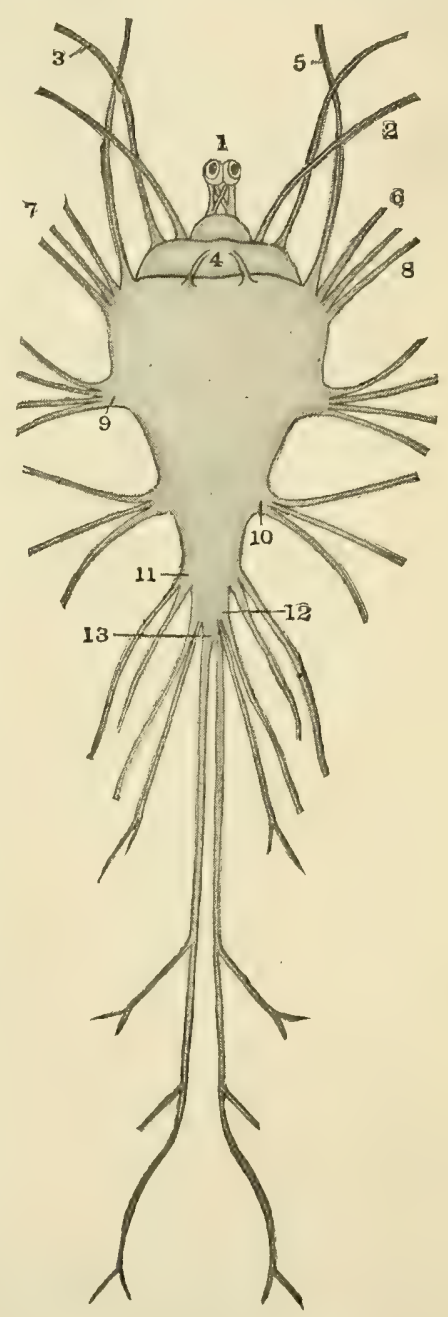

FIG, 27,-NERVOIS STETEM OF A LELEOPHTHIIRLS. (AFTER A. SCOTT.

terminal joint. From the size of this nerve and the detail with which every seta is innervated it is rery evident, as A. Soott has well stated, that these first antenne are important sensory organs. A branch from this second pair of nerves extends inward to the gland which secretes the filament for attachment during the chalimus stage. This branch is not noted by Scott, but is mentioned by Pickering and 
Dana; but the latter are, of course, mistaken in interpreting the gland itself as nerrous tissue. Furthermore, the second nerves in Caligus curtus (fig. 28, 2), which Pickering and Dana are describing, go, not to the terminal joints of the first antenna, but to the frontal plates, and thus correspond with the fifth pair described by Scott. The present author has not had an opportunity to examine either of the species

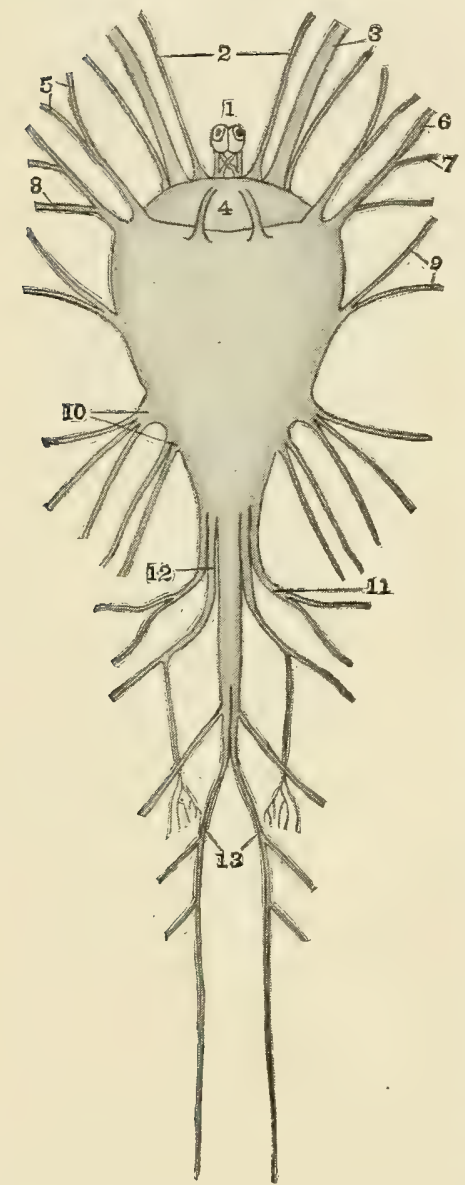

Fig. 28.-Neryous Systen OF a CALigus

(After Pickering and DaNa.) described by these authors, but from an examination of other species of both genera it is fairly certain that the branch spoken of comes from the second pair of nerves, although its destination may vary slightly in different genera. The remaining third pair of nerves (3) arise from the angles of the ganglion outside the second pair and pass to the second antennæ. They are larger than the second pair, which would seem to indicate the importance of these second antennæ as organs of prehension. In their passage to the second antennæ these nerves pass under the second pair.

These are all that are given off by the upper ganglion. From the frontal and lateral margins of the lower ganglion arise seven pairs of nerves, while three other pairs are given off from the posterior end and form a sort of spinal cord, thus making thirteen pairs in all (fig. 28). The ten pairs from the lower ganglion supply the remainder of the appendages and the body muscles. The first of them, the fourth pair (4) in sequence, arise near the center of the anterior margin, and pass along the muscles of the œsophagus until they reach those of the mandibles near the base of the mouth. We have already stated that the mandible muscles were surprisingly large. These nerves are also of good size.

The fifth pair (5) have their origin near the anterior angle of the ganglion and pass forward to innervate the frontal plates, running under the nerves going to the first and second antennæ.

Three other pairs, the sixth, seventh, and eighth, arise close together in Lepenplethripes at the anterior angle just outside the fifth pair. The sixth pair (6) innervates the first maxilla, the seventh (7) the 


second maxilla, and the eighth (8) the muscles of the lateral area of the carapace.

The ninth nerves (9) arise from the anterior lateral margin as a single pair, each of which soon subdivides into four branches which go to the first maxillipeds and adjacent muscles.

The tenth pair (10) have their origin in the posterior part of the lateral margin and, subdividing into three branches, pass to the second maxillipeds. These nerves are very large and indicate again the importance of the appendages to which they go as prehensile organs.

At the posterior end of this rentral ganglion are given off the eleventh, twelfth, and thirteenth pairs. The eleventh pair (11), which are on the outside, go to the first legs and adjacent muscles. The twelfth or middle pair (12) innervate the second legs and the muscles of the thoracic area of the carapace. The thirteenth or inner pair (13) are so close together as to be distinguished with some difficulty. They extend backward side by side along the mid line of the body, through the free segment and into the genital segment, where they separate considerably, passing into the abdomen at about the centers of the right and left halves. Each nerve gives off a branch to the third and fourth swimming leg on its side, a large branch in the genital segment, which courses along the lateral margin and terminates in the fifth leg, and on entering the abdomen divides into two branches, one passing to the anus and the other to the anal lamina.

In Coligns the structure and arrangement of the ganglia and their nerves is almost identical with that in Lepeophtheires, but the distribution as given by Pickering and Dana for $C$. curtus differs in several particulars.

(Of the three pairs given off by the superior ganglion the first is the same, but the second goes to the frontal plates, while the third goes to the terminal joints of the first antenne. On the inferior ganglion an extra par arise close beside the fourth pair, which innervate the proboscis. The fifth pair go to the second antenna instead of the frontal plates. All the other pair's are identical, save that the sixth, seventh, and eighth pairs are united at their roots and appear as branches of a single nerve rather than three separate pairs. There is also an extra pair close to the tenth which help to innervate the second maxillipeds. Thus, out of thirteen pairs ten are identical in the two genera, while the other three innervate the same regions but are interchanged, the nerve antering the frontal plates being first in collignes and last in Lepeopletheirus.

It must be remembered that l'ickering and Dama mistook the nature of areral of the appendages, notably the antenna. They understood that the first antemad. or their rudiments, were situated in the central incision of the frontal plates, while the actual first antema they considered as the second. and they called the second antenna the first 
maxillipeds. Their judgment of the course taken by the several nerves may well have been biased by these mistakes. The present author' has had no opportunity of verifying or disproving their statements by an examination of the same species.

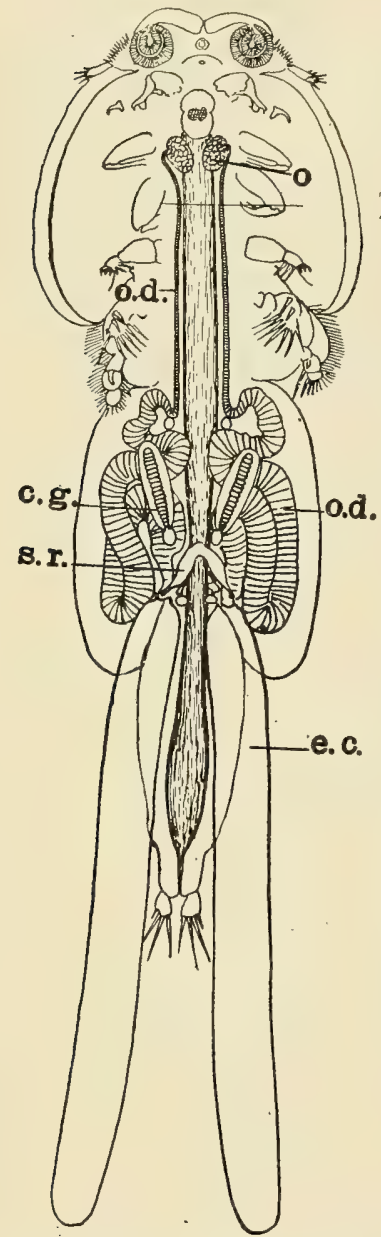

FIG. 29.-FEMALE REPRODUCTIVE organs OF CALIGUS BoNito. (DRAWN BY EMERTON.) c. g., CEMENT GLAND; e. c., EXTERNAL EGG CASES; o, OVARY; o.d., OVI-

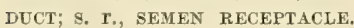

The similarity in the structure and use of the appendages of all the genera here considered renders it probable that their innervation is practically the same, differing only in minor details.

\section{REPRODUCTIVE ORGANS.}

These consist in the female of a pair of ovaries, a long, more or less convoluted oviduct connected with each, a pair of semen receptacles, glands for secreting the material of the external egg cases and these cases themselves (fig. 29).

The ovaries (o) are large oval or kidneyshaped bodies situated on either side of the anterior portion of the dorsal surface of the stomach. When fully developed they extend from the first swimming legs to the base of the second maxillæ and can be plainly seen through the carapace in dorsal view. Each gives off an oviduct (o. d.) from the ventral surface at the anterior margin (fig. 30). This duct runs backward in nearly a straight line through the thoracic area, the free segment, and into the genital segment. As soon as it enters the latter it increases quickly in size and also becomes convoluted. The number and arrangement of the convolutions vary considerably in the different species as well as the genera, as may be seen by consulting figures.

In general, the convolutions attain their maximum number and size just before the extrusion of the external egg cases, and as soon as the latter. are fully formed the oviduct has become nearly straight. This condition is retained at least for some time subsequent to the hatching of the eggs and the throwing off of the egg tubes, since the adult females are often found in the condition shown in fig. 31.

On the rentral surface of the convolutions can be found an oblong, nearly transparent gland, closed at the anterior end, and at the poste- 




rior end connected with the oviduct just in front of the external opening. This organ is a cement gland (c. g., fig. 29) and secretes the material forming the external egg tubes.

This is undoubtedly "the flat, cylindrical organ, usually as broad as the external oviduct, and lying along the central portion of the abdomen," referred to by Pickering and Dana, and whose function they could not interpret.

Its shape differs considerably in the different genera and species, and will be described for each, so far as known.

The general features, however, are the same for all species. It consists of a long and flattened tube, which is decidedly club-shaped in most species rather than cylindrical. It is usually inclined inward toward the mid line

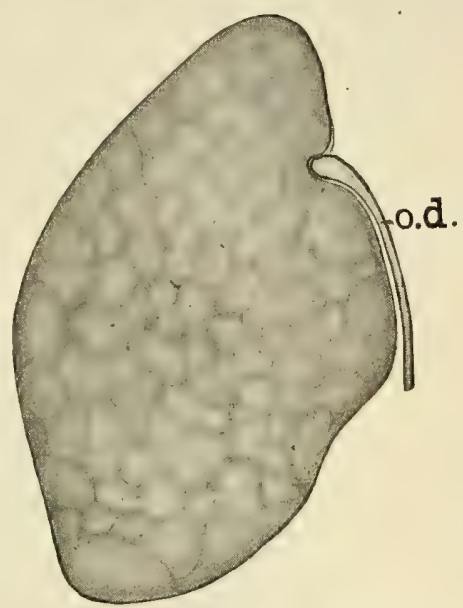

Fig. 30.-OVary of Caligus bonitu ENLARGED, o. d., OVIDUCT. and reaches forward nearly to the anterior margin of the genital segment.

The lumen of the tube is narrow and surrounded by a very thick

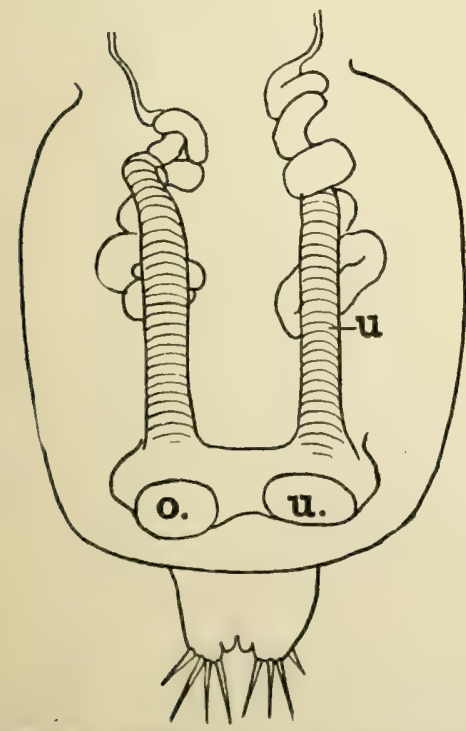

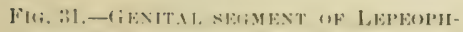

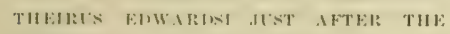
11ATCHING OF THE FGES AND THF

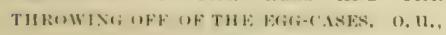
OS UTERI; U., UTERUS. and transparent wall. It is further divided into flattened cells by transverse partitions, the cells being strongly rounded at the edges and thus looking very similar to the eggs. So great is this resemblance that the glands, though perfectly visible in many species, are easily mistaken for a part of the convolutions of the oviduct. But they can be easily distinguished by the fact that in most species the central lumen is considerably narrower than the oviduct, while in all species the anterior end is closed.

In sections the ovary is seen to be made up of a long, narrow tubule coiled up into a dense snarl or skein. The tubule is made up of a structureless membrane lined with germinal epithelium. The latter gives rise to the eggs, which are formed in the lumen of the tubule, and which, when sufficiently developed, break through the walls and pass into the oviduct. 
At first they are rery small, simply nucleated cells, transversely oblong, and not quite filling the lumen of the narrow portion of the duct (c, fig. 32). As they pass backward they increase in size and gradually acquire a vitelline membrane somewhere in the posterior thoracic area. The cell contents also become finely granular with yolk particles, so that on emerging into the genital segment and suddenly increasing in diameter, the cells fuse somewhat and appear as a continuous granular mass in which it is practically impossible to distinguish either cell walls or nucleus (g, fig. 32). Very quickly, howerer, this

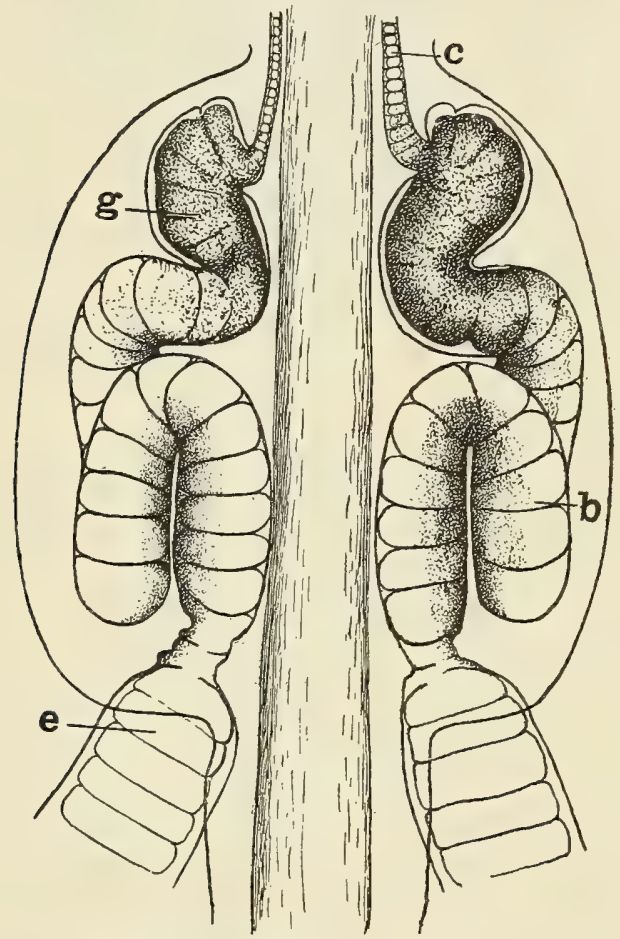

Fig. 32,-GENital SEgMent of CALIGUS RAPAX, b, EGGS FULLY FORMED AND READY TO BE PUSHED OUT INTO THE EGG CASES; C, EGGS AS SIMPLE NUCLEATED CELLS WITHOUT ANY YOLK; e, EGGS AFTER EXTRUSION AND FERTILIZATION; g, EGGS FUSED TOGETHER JUST AFTER ACQUIRING THE YOLK PARTICLES. mass begins to differentiate again into separate eggs, in each of which the yolk or nutrient material separates from the white or animal material. The eggs are now flattened together more and more strongly through the pressure generated by their growth and finally become biscuit-shaped as they approach the external opening (b). This posterior portion of the oviduct is called by Rathke the uterus ( $u$, fig. 31 ), and Claus remarks that the name is well applied, since the eggs remain here a long time. The oviduct is considerably narrowed just before reaching the external opening, and the eggs must be altered in shape as they pass through. During the passage each egg is fertilized by sperm from the sperm receptacles, whose duct opens into the

oviduct very close to the external opening.

This opening of the oviduct to the exterior, which to follow out the nomenclature of Rathke and Claus might well be called the os uteri (o. 1u., fig. 31) is situated on the ventral surface of the genital segment very close to the posterior end, and usually just above the rudimentary fifth legs.

On emerging to the exterior the eggs suddenly widen to nearly twice their former diameter, and are correspondingly diminished in 

length (e., fig. 32). In addition to forming a eylindrical tube in which the egges are arranged like a roll of lozenges, the cement gland also pour's out a layer of its secretion between every two adjacent eggs. This forms a membranous partition and divides the egg tube into a sories of narrow compartments, in each of which is a single egg, which does not quite fill the space, leaving room for the subsequent development of the larva.

The spermaries or sperm receptacles (s. r.) consist of a sack on either side extending from the os uteri obliquely inward and forward to the median line where it joins its fellow from the opposite side (fig. 33). A canal, the ragina (va.), leads diagonally backward and inward from the center of the posterior margin of each sack and opens to the exterior on the posterior margin of the genital segment along-

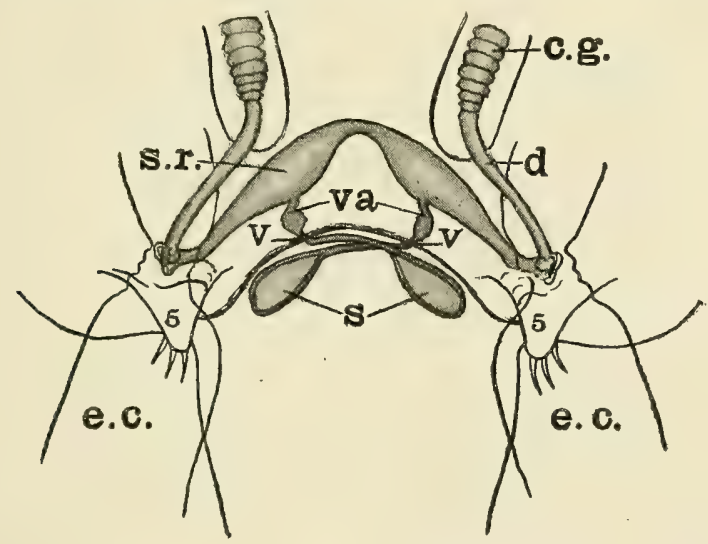

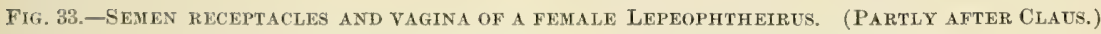
e. g., CEMENT GLANDS; d, CEMENT GLAND DUCT; e. c., EGG CASES; $\$$, SPERMATOPHORES; S. r., SPERMARIES; V, VULYA; Va., VAGINA; 5, FIFTH LEGS.

side the mid line. This is the vulva or sexual opening (v.) and just inside it the ragina is enlarged considerably for the reception of the spermatophores (s.). These spermatophores are white in color for nearly all the species. They do not always enter the rulva, but may often be found upon the external surface, usually in the immediate vicinity of the vulva but sometimes elsewhere. On species like Lepe-

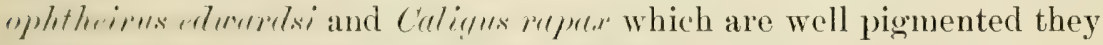
show up rery prominently against the dark background.

A single copulation takes place just after the close of the chalimus stage, and at that time these semen receptacles are filled by the male. Their contents probably suffice for the fertilization of all the eggs the female lays, during her entire life.

The sexual organs of the male are very similar in position and arrangement to those of the female (fig. 3t). They consist of a pair of 
testes, a long vas deferens leading from each, and a pair of spermatophore receptacles in the genital segment. The testes (t.) are ovate or conical bodies situated in positions corresponding exactly to those of the ovaries.

They are considerably smaller than the ovaries and each gives off from its anterior end a duct, the vas deferens (v. d.), which leads directly backward without any convolutions into the genital segment. Here it enters the outer border of the spermatophore receptacle (s. r.)

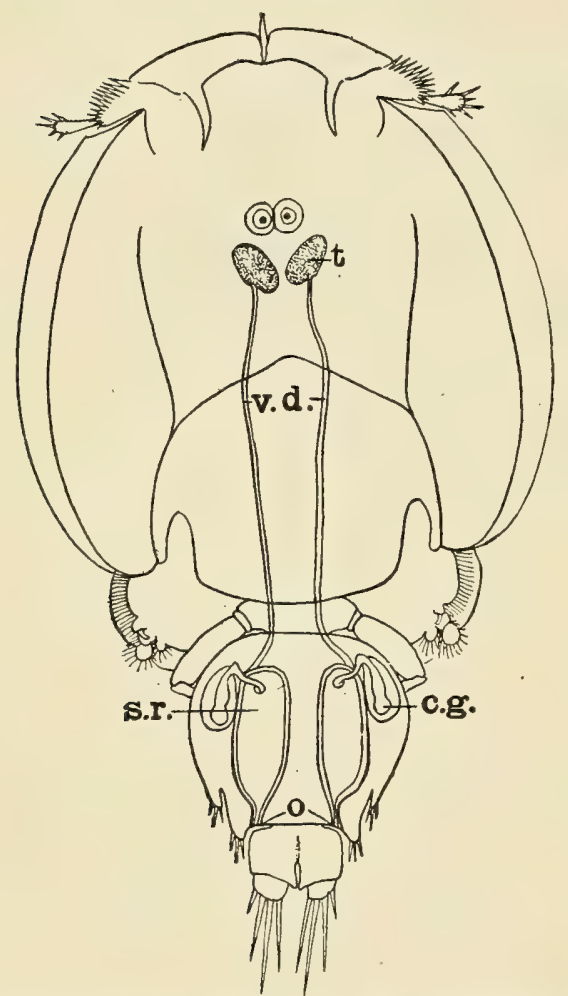

FIG. 34.-SEXUAL ORGANS OF A MALE LEPEOPHTHEIRUS EDWARDSI, C. g., CEMENT GLAND; O, OPENING OF THE SPERMATOPHORE RECEPTACLE, S. T., TO THE EXTERIOR; $t$, TESTIS; v. d., VAS DEFERENS. at or posterior to its center. Each receptacle is oval or elliptical in shape, situated about in the center of its own half of the genital segment, and opens to the exterior near the posterior angle of the segment. On the ventral surface of the receptacle, or a little to one side of it, is a small cement gland (c. g.) which secretes the viscid substance composing the covering of the spermatophore.

In the receptacles the sperms are gathered into oval spermatophores, each of which is covered by the viscid secretion from the cement gland, in which condition they are pushed out of the receptacle and into the vagina of the female. As A. Scott remarks, the spermatophores do not always reach the vagina, and being viscid they stick to the female's body wherever they may touch it. We thus often find them scattered in little bunches or clusters in various places all over the ventral surface in among the appendages. This was probably what the earlier observers mistook for eggs, after they had decided that the true egg sacks were antennæ.

\section{SUMMARY.}

1. The body wall is made up of three layers, the outside cuticle, the median cellular tissue, and the inner connective tissue which forms a lamina supporting the various organs.

2. The alimentary canal is practically a straight tube running from the mouth to the anus, with the regions but slightly differentiated in 

structure. 'It is made up of a narrow resophagus, a very much wider' stomach, a long and wide intestine, and a short and narrower rectum. Comnected with the canal are two pairs of digestive glands, one pair in the anterior portion of the carapace near the margin, and the other in the thoracic area near the mid line.

3. The alimentary canal is constricted at fairly regular intervals, and in the living animal is in almost constant peristaltic movement, the waves passing alternately backward and forward.

4. There is no heart nor any organs of circulation. The blood is driven about through the lacuma between the internal organs by the peristaltic movements of the alimentary canal just referred to, and by the respiratory morements of the rectum. In Culigus cmrtus Pickering and Dana discovered valvular action at two points, the apex of the posterior thoracic joint and between the basal joints of the second antennz. No valves have been thus far seen in other species.

5. Respiration is anal, the posterior portion of the rectum being supplied with the necessary muscles for the pulsating movement.

6. The muscular system is very highly developed, and can be seen clearly through the transparent covering. All the muscles are plainly striated.

7. The nervous system consists of a supra- and an infra-nesophageal ganglion connected by stout commissures, and the paired nerves arising from them. There is no spinal cord nor any ventral chain of ganglia.

8. The female reproductive organs consist of a pair of ovaries situated on either side of the dorsal surface of the stomach. From each an oviduct leads back in nearly a straight line into the genital segment where it is strongly convoluted, and finally emerges to the exterior at the posterior margin of the segment. The oviduct is narrow at first and the eggs are simple nucleated cells. On entering the genital segment the duct widens suddenly and its contents become finely granular with yolk particles, and more or less fused. But the eg's quickly separate and clear in the convolutions, and finally emerge in a long, single row of lozenge-shaped forms, each occupying an apartment of its own in the external ego cases. The eggs are fertilized as they issue from the genital segment hy sperm from a pair of sperm receptacles situated in the posterior part of that segment.

9. The male reproductive organs consist of a pair of testes smaller than the ovaries, but situated in an exactly similar position. From each a vas deferens leads back into the genital segment, and there enters one of a pair of spermatophore receptacles situated in the center of each half of the segment.

Here the sperms are gathered into bunches or spermatophores, corred with a viscid substance, and in this condition they are subsequently squeezed out of these receptacles into the vagina of the female. 


\section{SYSTEMATIC.}

HISTORICAL.

The first which can really be called a classification of the parasitic copepods was made by Burmeister in 1833 and included only 23 out of the 80 and more genera known at the present day.

The group was divided into families on the basis of the presence and structure of the antennæ and segmented feet.

Each family was divided into genera upon a different basis, that for the Caligide consisting in the presence or absence of eyes and the structure of the fourth thóracic feet.

The next important classification was by Milne Edwards in his great work on the Crustacea in 1840. He raised the number of genera of these parasites to 35 and divided them first according to the fusion of the head and thorax, and the structure of the antennæe. They were then subdivided by the presence or absence of dorsal plates on the free thoracic segments, while the Caligidæ were classified by the structure of the fourth legs. This resulted in throwing all the forms with dorsal plates on the thorax into the Pandarinæ, irrespective of their relations in other particulars.

As there were only 9 genera known at that time in the Caligidæ, 2 of which, Chalimus and Nogagus, were spurious, such a division answered well enough, and it located each genus just where it stands at the present time.

A third classification was published by Steenstrup and Lütken in 1861, and by Nordmann in 1864, the two being identical.

They increase the number of genera to 68 , of which 20 belong to the Caligidx; they divide them first according to the structure of the egg sacks and the arrangement of the eggs.

The second subdivision is on the basis of the degree of fusion between the head and thorax, and on the presence or absence of a carapace. In the family Caligida the classification is based on the structure of the fourth feet, the presence of dorsal plates on the free segments of the thorax, and the presence of lunules on the frontal plates.

Heller, in 1865, adopted practically the same classitication, but gave a much more elaborate analysis of the genera belonging to the Caligidæ, which he increased to 26 in number.

For this analysis he makes use of (1) the structure of the rostrum and "palps" (second maxillæ); (2) the degree of fusion between the head and thorax; (3) the presence of dorsal plates on the free thorax segments; (4) the presence of lunules; (5) the structure of the fourth thoracic feet.

In the following year, 1866, there appeared the first number of Bronn's Thierreich, in the fifth volume of which, under the Copepoda, 


Gerstaecker published several years later another attempt at the systematization of this group). II is classification is based almost entirely upon the structure of the appendages and the genital segment, and has remained the accepted classitication up to the present time. For the paper published hy Bassett-Smith in 1899 ('an scarcely be called a classification; it is rather an enumeration of species with portions of the synonyms.

In Gerstaecker's work there are certain errors which can be corrected, and additions which must be made in order to bring the group I1) to date. The latter is aspecially true of North American genera and species, several of which were omitted by Gerstaecker through lack of identification.

The name also, Nogagina, which he suggests for his second subfamily, is rery unfortunate since the genus called by older zoologists Vrogagus is really mate up entirely of the males of other genera. Hence it has no right to he continued at all, much less to be taken as the type of a subfamily. Any attempt to preserve this old genus must be really the introduction of a classification based entirely upon males into the midst of another which considers both sexes equally.

Furthermore it does not seem that Gerstaecker's arrangement shows as clearly as might be done the gradual transition from non-degenerate form like cilligus and Leperplitheirus through those which show the beginnings of degeneration, like cloiopotes and Alebion, down to

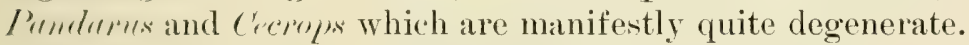

The monograph published by J. D. Dana in 1852 on the Crustacea of the Wilkes Exploring Expedition contains the only attempt at a clasification of the parasitic copepods thus far made by an American. He dirictes the group into three tribes according to the structure of the crphalothorax, the presence of a carapace, and the structure and arrangement of the thoracic legs. He separates the second of these tribes. the ('aligoidea, into three families according to the segmentation of the first antemne and the structure of the maxillipeds. The serond family, the Caligida, he sublirides into four subfamilies on the structure of the mouth part and the external egg tubes.

The rassification here presented, like all its predecessors, appropriates the best in those which have gone before, especially that of Cierstareker, adds the new genera and species up to date, and such Nonth American forms as have been omitted. It can not cam origimality since it differs chiofly in arrangement, but it is hoped that this change in arrangement will show better than heretofore the relationships between the genera. 


\section{FAMILY CALIGIDA.}

Carapace broad and usually compressed. Cephalothorax incompletely segmented, the free thoracic segments often partially overlapped or hidden by dorsal plates. Anterior antennæ short, clubshaped, with two or three free joints, their basal segments anchylosed with the anterior border of the carapace. Posterior antennæ in the form of a simple hooked claw, not extending beyond the carapace. Mouth in the form of a more or less elongated suctorial beak, formed out of the upper and under lips and inclosing the toothed mandibles. Maxillæ free, both pair's rudimentary, the first pair sometimes lacking. Maxillipeds also free and in the form of hooked claws, the first pair weak, the second much stronger and used for prehension. First four pairs of thoracic legs usually biramose, but the first and fourth pairs frequently uniramose; the fifth pair rudimentary and often invisible dorsally or entirely lacking. Two simple eyes fused on the median line, often lacking. Generative organs paired in both sexes; females with two cord-like egg tubes, usually quite long; eggs in a single row. Male usually smaller than the female and both sexes permanent parasites upon fish.

1. Three anterior segments of thorax fused with the head; fourth and genital segments free . . . . . . . . . . . . . . . . . . . . . . . . . . . . . . . . . . . . . . . . 2 .

1. Two anterior thoracic segments fused with the head; third, fourth, and genital segments free .................................... Subfamily Trebine.

1. First thoracic segment only fused with the head, the others free; one or more of them with paired dorsal plates; all four pairs of legs biramose............... 3 .

2. Fourth segment without dorsal plates or any appendages except the fourth

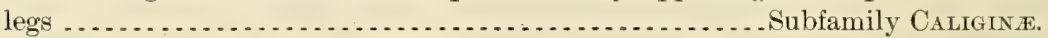

2. Fourth segment with a pair of dorsal plates which usually overlä the genital segment .................................. Subfamily EurYPHORINæ.

3. Frontal plates distinct; egg cases visible their entire length.

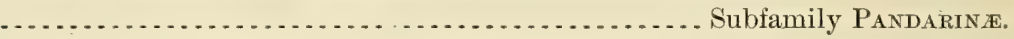

3. Frontal plates fused with the carapace; egg cases convoluted, entirely hidden. . . Subfamily Cecropin..

The genera belonging to the Caliginæ are discussed in the present paper; those belonging to the other subfamilies are left for subsequent papers.

Subfamily CAIIGINAE.

Carapace broad and always flattened dorso-ventrally; free thorax segment without plates or appendages of any sort except the fourth pair of legs. Genital segment enlarged, but usually smaller than the carapace; never much larger except in the genus Echetus. First and fourth thoracic legs uniramose, second and third biramose; fifth pair rudimentary but often visible as a pair of small papillæ at the posterior corners of the genital segment. Adults active, most of the females as well as the males capable of swimming about freely. 




KEY TO THE GENERA.

1. First and fourth thoracic legs uniramose; second and third pairs biramose .....2.

1. First legs only uniramose; second to fourth biramose; frontal plates without lunules........................................ Calistes (Dana, 1852).

1. Fourth legs only uniramose; first to third biramose; no lunules; genital segment with two horny, dentate processes, as in the genus Pandarus.

Calina (van Beneden, 1892).

1. All four pairs of thoracic legs biramose; rami two-jointed; no lunules.

Dysgamus (Steenstrup and Lütken, 1861).

2. Frontal plates provided with lunules; second maxillæe simple, spine-like _ _ 3 .

2. Frontal plates without lunules; second maxillæ bifurcate or simple . . . . . . . 7 .

3. Genital segment simple, without plates or processes, and not elongated _ 4 .

3. Genital segment without plates but prolonged posteriorly into processes nearly as long as the abdomen .............................. 6.

3. Genital segment surrounded by a two-lobed membranous wing; abdomen with wings also............. Parapetalus (Steenstrup and Lütken, 1861).

4. Free segment short; genital segment usually smaller, never much larger, than carapace, and flattened . . . . . . . . . . . . . . . . . . . . . . . . . . . . . . .

4. Free segment produced into a long neck; genital segment many times larger than carapace, cylindrical ......................... Echetus (Kröyer, 1863), p. 611.

5. Fourth legs normal; furca and first maxillæ present and well defined.

Caligus (Müller, 1785), p. 555.

5. Both furca and first maxillæe wanting; host, the mollusk Nautilus.

subgenus.. Anchicaligus (Stebbing, 1901).

5. Fourth legs rudimentary, consisting of basal joint only, no exopod.

subgenus.. Pseudocaligus (A. Scott, 1901).

5. Carapace proportionally very small; genital segment elongated; abdomen longer than rest of body; second maxillipeds large and massive.

subgenus. . Sciznophilus (van Beneden, 1852).

6. Four of these processes; the free segment short.

Synestius (Steenstrup and Lütken, 1861).

6. Only two processes; the free segment prolonged into an elongate neck.

Caligodes (Heller, 1865), p. 608

7. Genital segment simple, without plates or processes....................... 8.

7. Cienital segment without plates, but prolonger posteriorly into two processes twice as long as the segment itself; second maxille simple; no furca.

Diphyllogaster (Brian, 1899).

7. (ienital segment covered with a fuser dorsal plate extending backward orer part of the abdomen .............................. Homoiotes, new genus, p. 661 .

8. Carapace horizontal, not folded; abdomen normal.

Lepeophtheirus (Nordmann, 1832), p. 615.

8. Carapace normal, not folded; abdomen entirely wanting.

Anuretes (Heller, 1865), p. 647.

8. Carapace deeply incised at the center anteriorly; the two sides folded together ...................................... Hermilius (Heller, 1865).

\section{ONTOGENY.}

The life history of the various genera here included is practically identical, so far as it is known. The development of the egg up to the time it is extruded has already been given, and we have seen that each egg was fertilized as it passed out. 
Since the egg tube is secreted only as there is a demand for more space and is extended by the pressure of the issuing eggs, it follows that this pressure, acting always along the axis of the egg tube, flattens the egg at right angles to that axis. Each egg assumes a biscuit shape, with the exception of the one first extruded, which is hemispherical.

The form is usually fairly symmetrical, the pressure being equally distributed, but sometimes an egg will get flattened on one side more than the other (see fig. 2).

The germinal area is about in the center of the proximal side of the biscuit in the great majority of cases. But here again there are exceptions and occasionally an egg is reversed as

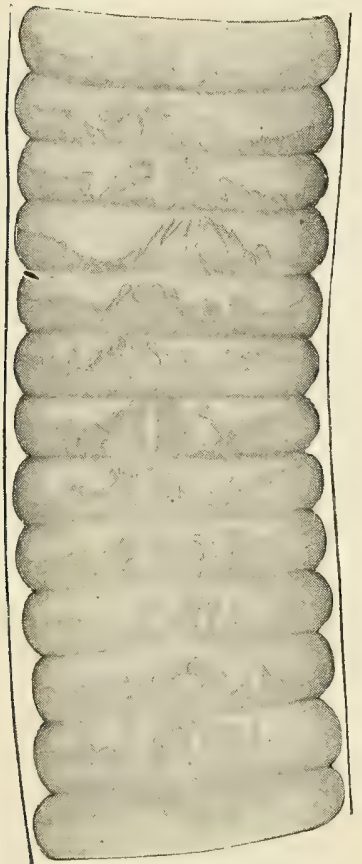

Fig. 35.-PORTION OF AN EGG-STRING OF Caligus Bonito. (Highly MAGINIFYED.) it issues and the germinal area appears at the center of the distal side. From this center the embryo spreads gradually until it covers the flattened side and extends down over the edge of the biscuit, so that in advanced development the appendages can be distinctly seen on the edges of the eggs under a high power (see fig. 35). Not only are the germinal areas thus all upon the center of the proximal sides of the eggs, but the symmetry is carried still farther in the fact that the longitudinal axes of the embryos are very closely parallel. This brings the corresponding appendages of the different embryos in longitudinal rows along the sides of the egg tubes.

The eggs also change in color with advancing development. At first colorless or with a yellowish tint, they gradually assume the color of the pigment which is to distinguish the nauplius when it finally becomes free.

This color varies in different species and is readily visible to the naked eye against a white background for some time previous to hatching. If the living copepod be placed in a porcelain dish and examined with a hand lens the color shows to good advantage. It is so constant in the same species and so distinct in many of them as to afford a good supplementary evidence of identity in females carrying fully developed eggs.

There is no regular breeding season. Females with fully dereloped eggs are found alongside those with egg strings only partially extruded or with none at all. And oftentimes a single fish will yield these different adult forms and several chalimus stages. But while there is this great irregularity in the breeding season of different individuals, 


the period of incubation is approximately the same for all members of the same species. And so far as known it does not vary much in different species, although no judgment of value can be drawn on this point without more extended observations. Eight weeks is recquired in culigus mpar, and from eight to ten weeks in Leperoplitheirus pectoralis.

Hence while the stage of derelopment reached by the rarious individuals found on any given fish may be widely different they are just as likely to correspond closely. And there are certain times when a given stage of development is more likely to be found than at others. Nearly all the chalimus stages used in the present paper were obtained from common flounders aught between the middle and the last of August at Casco Bay on the Maine coast. The season would be a little earlier in the vicinity of Woods Hole.

Again the whole of the embryos in the egg tubes of a given female hatch at practically the same time, only an hour or two between the first and the last. This greatly facilitates the rearing of the embryos through successive moults, as the material requires very little sorting.

If a female is captured with eggs nearly but not fully ripe it is practically certain that the embryos will issue before the mother's death. But of course in such cases the percentage of survival is extremely limited. If it is desired to rear the embryos females should be selected whose egg tuhes have the deepest color, and an almost total failure may be simply due to the immature condition of the eggs and not to the environment.

U'sually each egg ruptures separately, and the inclosing membrane of the egg tube splits opposite the egg, allowing the nauplins to wriggle out. There is thus a break in the tube for each of the eggs and nearly all the breaks are on one side, but in spite of this the empty rases are usually left still attached to the female after the last larva has escaped. But sometimes, in the haste preceding the death of the mother. when there is scant time for the hatching, or when the eggs lack considerahly of being fully ripe, the result is rery different.

The struggles of the nauplii in freeing themselves first break the tubes off from the genital segment of the mother and then tear them all in pieces, leaving nothing but fragkents seattered far and wide.

As soon as they are fully free the nauplii swim to the surface and towarl the light. Each has the typical nauplius form, ovate or elliptieal in ontine, strongly flattened dorso-rentrally, and with three pairs of appendages representing the first and second antenne and the mandibles (fig. 3iti). The body is very simple and without segmentation, heing made up of a cellular exterior surrounding the general body cavity, through the center of which passes the primitive digestive tube.

The latter consists of a mouth opening on the ventral surface just behind the bases of the first two pairs of appendages, and a straight tube with no differentiation of parts. 
In the body cavity is a fluid representing the blood which circulates somewhat. On the dorsal surface close to the anterior margin is the median eye and the first traces of the nerve ganglion. Both the eye and the dorsal surface of the ganglion are well pigmented. This ganglion represents practically only the future supra-cesophageal one and the esophagus does not pass through it. The infra-cesophageal portion of the ganglion (see p. 552) appears with the development of the appendages.

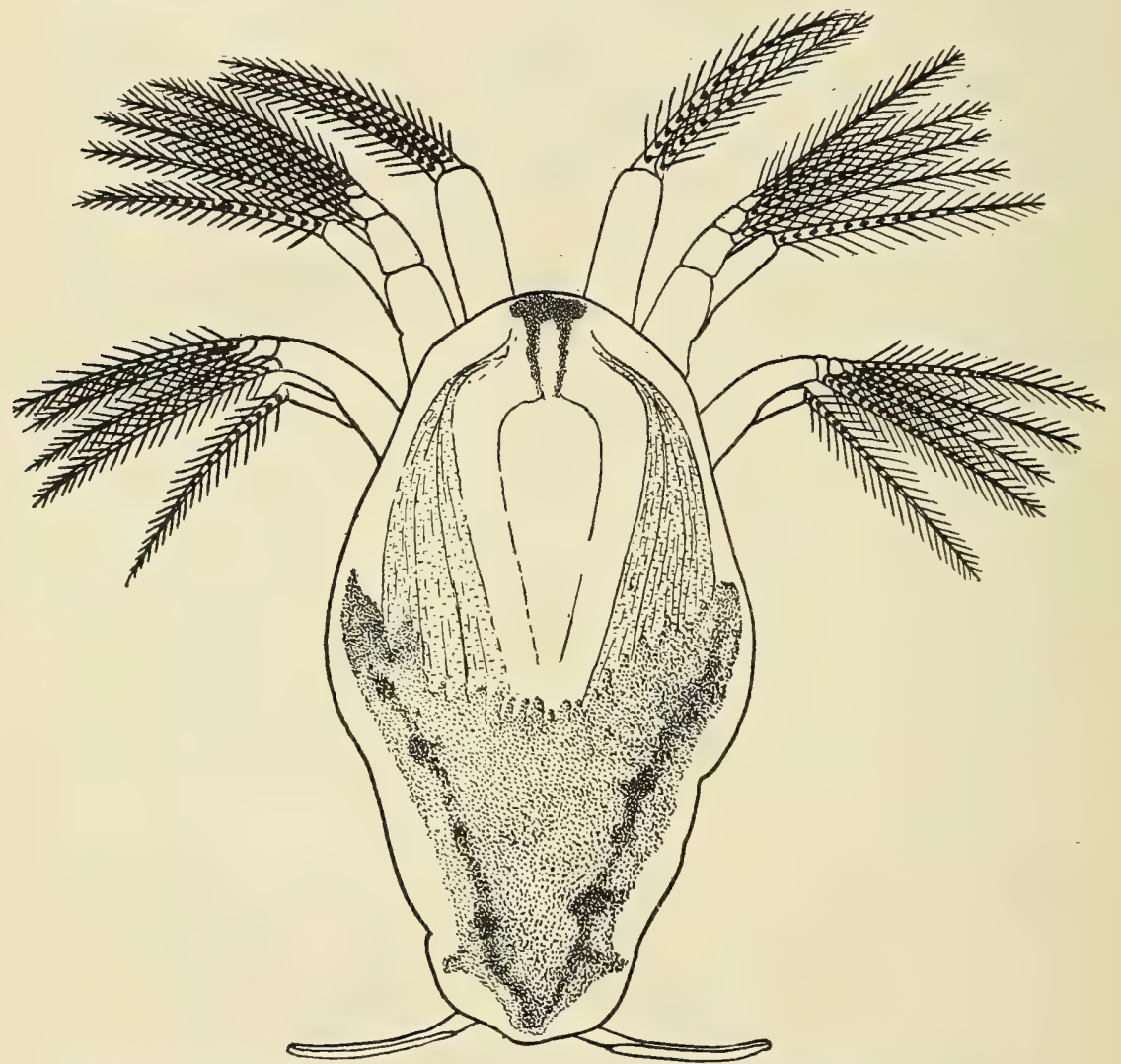

Fig. 36.-Newly hatched NaUplius of Caligus Rapax, PigMent of BRIgHt RUST Color.

The anterior part of the body is transparent and through it can be seen the muscles which move the appendages. They extend backward obliquely on either side from the bases of the appendages to the median line a little back of the center. They are faintly striated and very well developed, furnishing powerful motors for swimming.

The posterior portion of the body, a little less than half, still retains much of the nutritive material from the egg, by means of which the nauplius is to be nourished during several moults until it can seek a host and get its own food. These yolk granules make this portion of the body opaque and nothing of the internal structure can be seen 


through them. On either side at the center are two large spots of the pigment, which characterizes the particular species. This varies decidedly in color and pattern in the different species thus far examined and will probahly furnish a useful means of identification.

There are other much smaller spots of the same pigment, which vary somewhat in location in the different species, but are usually found, one on either side, close to the posterior end of the body, and a median unpaired spot just above the eye.

Of the appendages the first antennæe are uniramous and terminate in two long plumose sete. They are often carried close together and pointing straight forward in front of the nauplius. The second

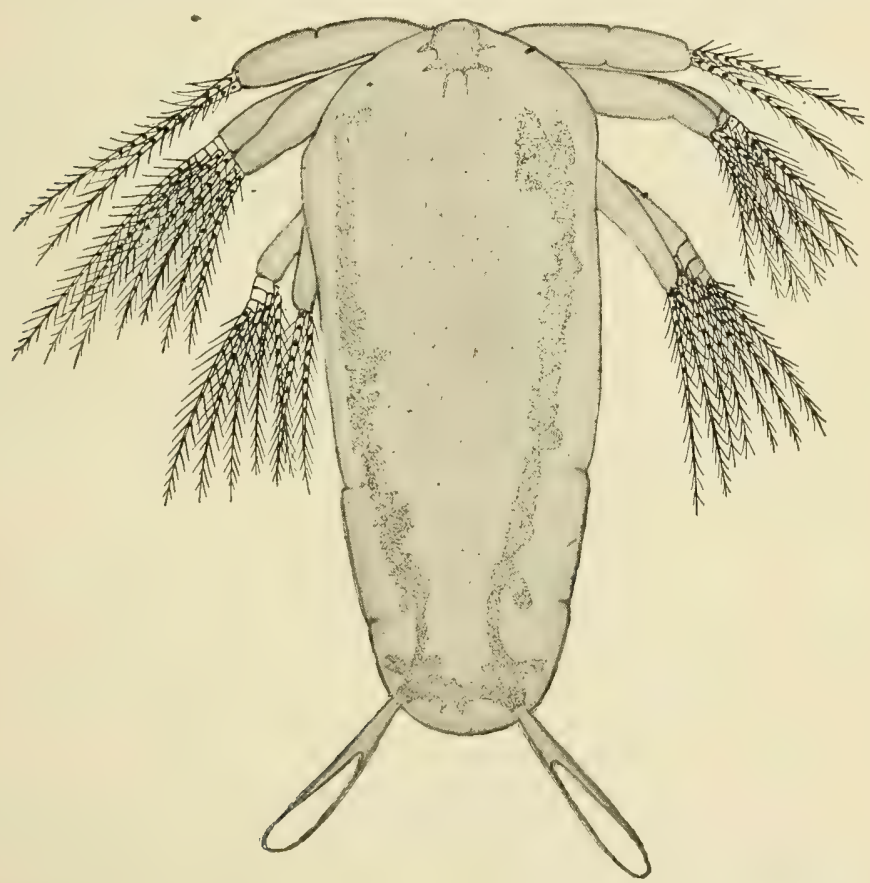

FIG. 37.-EARLY NAUPLIUS OF CALIGUS BONITO, DORSAL VIEW; PIGMENT CINNAMON BROWN IN A CONTINUOUS LINE AROUND THE MARGIN OF THE BODY.

antennar and mandibles are biramous, the exopod four-jointed, each joint bearing a long plumose seta, the endopod with a single joint terminating in two similar setax. These three pairs of appendages propelled by the powerful muscles already noted make efficient locomotor organs, and the nauplii move rapidly. And even at this early stage some difference can be seen between the nauplii of the different species. Those like cialigns mpun, which are very active in the adult form, begin this activity in the early nauplius, while others appear comparatively sluggish.

Near the posterior end of the body there is a pair of appendages 
which usually point obliquely backward, and are of peculiar shape. Cylindrical at the base for about one-fifth of their entire length they then tlatten antero-posteriorly and broaden slightly into the shape of a spatula or paper cutter.

They are not segmented and not readily movable; they seem to be used as a kind of balancing organ when the nauplii assume an upright position in the water on coming to rest.

The uniformity in the shape of these balancers as well as that of the body of the nauplii and the three pairs of appendages is good evidence of the close relationship of the genera here considered.

If a female be captured with eggs nearly or quite matured it is an easy matter to secure nauplii by keeping her over night in cool water. But to rear the nauplii suceessfully is a very different matter for many reasons.

In the first place they are extremely sensitive to even a slight rise in temperature and of course can not be kept in an aquarium of running water, and as they advance toward the chalimus stage they require freshly aerated watex far more than in the nauplius stage, which it is exceedingly difficult to supply properly. A great many different methods have been tried, but the best success thus far has been obtained by keeping the larve in floating aquaria or bags of cheese cloth, immersed in the ocean. The mouth of the bag is open and it is floated at a sufficient height above the surface of the water to prevent the washing out of the larva.

As the latter naturally swim at the surface, this insures just the right temperature. And if they eat any thing prior to the metanauplius stage, which is very doubtful, apparently enough food gets in through the meshes of the cheese cloth to keep them alive. In this way the nauplii of two species of Caligus, $C$. rapax and $C$. bonito, and one species of Lepeoplutheirus, $L$. edwurdsi, have been carried through several moults.

But of course when they reach the stage at which they would ordinarily fasten upon some host, all artificial methods fail, and we must depend for further material upon a careful examination of the fish's body. To achieve any success demands a knowledge of two things, the particular host or hosts preferred by any given parasite and the time of breeding. By securing a plentiful supply of the host just after the parasite's eggs have hatched one may be reasonably sure of finding some larvæ attached to them.

But obviously the securing of these early stages will require a very minute examination of every part of the fish's body, since the larva apparently fastens itself to the first place it happens upon, and may show no indications whatever of a preference for particular localities, which later in life becomes very marked. Especially is this true of such species as frequent the mouth and gill cavity. Caligus bonito in 

the arlult stage is never found on the outside surface of the body or on the fins, hut those are the very places most easily accessible to the young metanamplius and where conseguently it must be sought.

And then the larve are so small as almost to require a hand lens for reeognition, and their color is so similar to that of the fish's body as to afford them ample protection.

Ahout the only way to detert them in most eases is to take the fish directly from the water, and while it still retains a film of water over the entire outside of the body hold it up to the light in such a way as to oret the rays reflected from the surface. The larva, being attached loosely, stands off from the surface and hreaks the reflection. If the

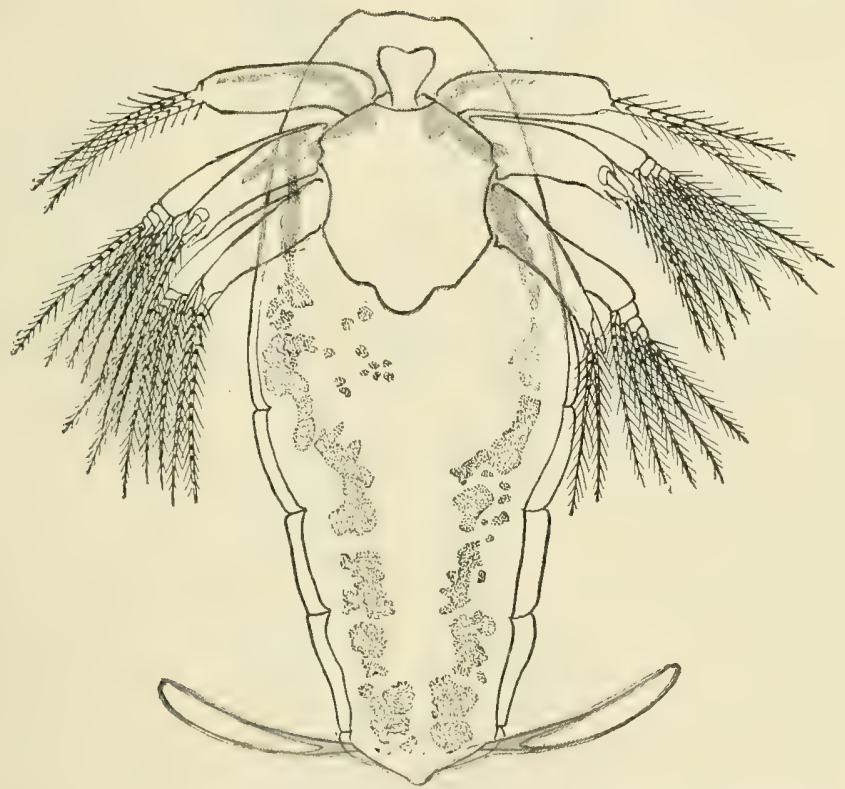

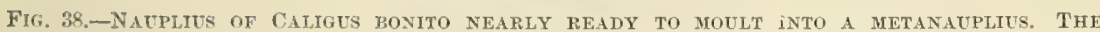
PIGMENT, WHICH AT FIRST WAS IN A CONTINUOUS RING, IS NOW BROKEN UP. VENTRAL VIEW, SHOWIXG IABRUM.

fish has been dropped to the ground or into the bottom of a boat there is very little use to search it for development material.

In riew of these difficulties it is not surprising that so few larval stages have been secured hitherto, or that investigators overlooked all but the largest and most advanced embryos.

As has been stated the nauplius at first is entirely unsegmented, with the thres pairs of appendages grouped around the mouth near the anterior end of the body. The first moult occurs during the first thirty-six hours, usually in the night; the nauplius emerges with its body comsiderably olongated and with the evident beginnings of segmontation posteriorly. The division between heal and thorax is plainly indicated in the clear edge which borders the carapace (fig. 37 ). 
Behind this are two other sutures indicated in the same manner and also by perceptible grooves in the body wall itself. There are also traces of another joint farther back, very close to the halancers on either side. The pigment, which is characteristic of the species, and which at first was gathered more or less in the regions indicated, now spreads along the sides of the body, while the two spots near the anus fuse across the mid line.

The condition of this pigment as to whether it is a continuous line or a series of irregular spots varies greatly even in the same species; now the one condition prevails, now the other.

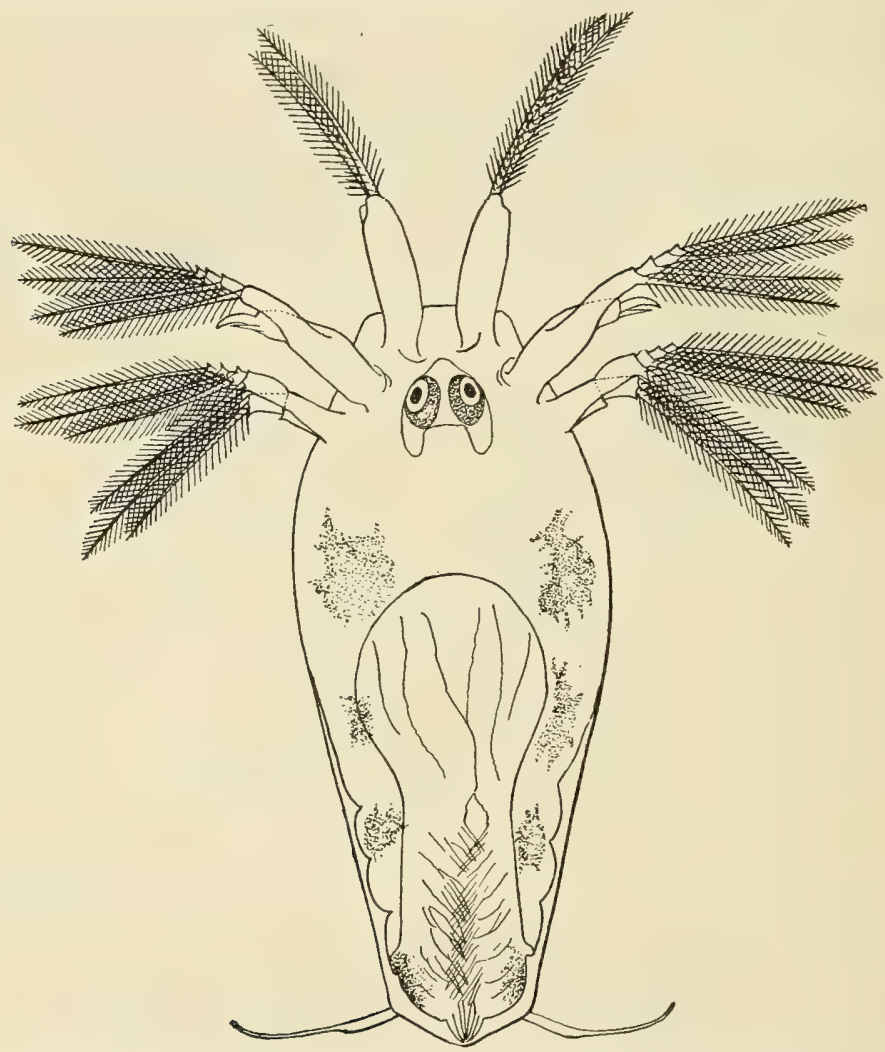

Fig, 39.-A NAUPLIUS OF Lepeophtheirus EDWARDSi JUST READY TO MOULT INTO A METANAUPLIUS THE NEW APPENDAGES CAN BE PLAINLX SEEN AT THE POSTERIOR END OF THE BODY.

The appendages remain unchanged, but between their bases on the ventral surface the huge shield-like labrum becomes more prominent. The spines alio near the tips of the endopods of the two posterior pairs of appendages are larger than before the molt, and they show up plainly in a ventral view (fig. 38).

Hitherto the larva has been very active, but on getting ready for the second moult it becomes more sluggish and moves about slowly. It also pays less attention to the light and gradually seeks the bottom of 



the aruarium. At the same time the first antenne begin to show signs of segmenting into two joints, and upon the ventral surface of the posterior part of the body numerous fine lines appear curving from the outer edge inward and backward toward the anus (fig. 39).

These represent the sete of the new appendages which are to appear with the second moult. This moult occurs during the second thirty-six hours and the larva comes forth radically changed in many particulars. The body has elongated more than 50 per cent, while it has broadened scarcely half that amount, with the result that it appears much narrower than before (fig. 40). The pigment now covers a wider space along the margin and is more uniformly distributed. The median nauplius eye has disappeared and instead we find the pair of simple eyes fused on the median line which are to characterize the adult. They are situated farther back in the earapace and in front of them a large mass of pigment extends the entire width of the carapace. This latter is much more clearly defined and now covers about two-thirds of the entire body. There are two free thoracic segments, each bearing the rudiments of a pair of swimming legs, and each more or less fused with the head.

They are followed by a third segment, and this in turn by an abdomen. The

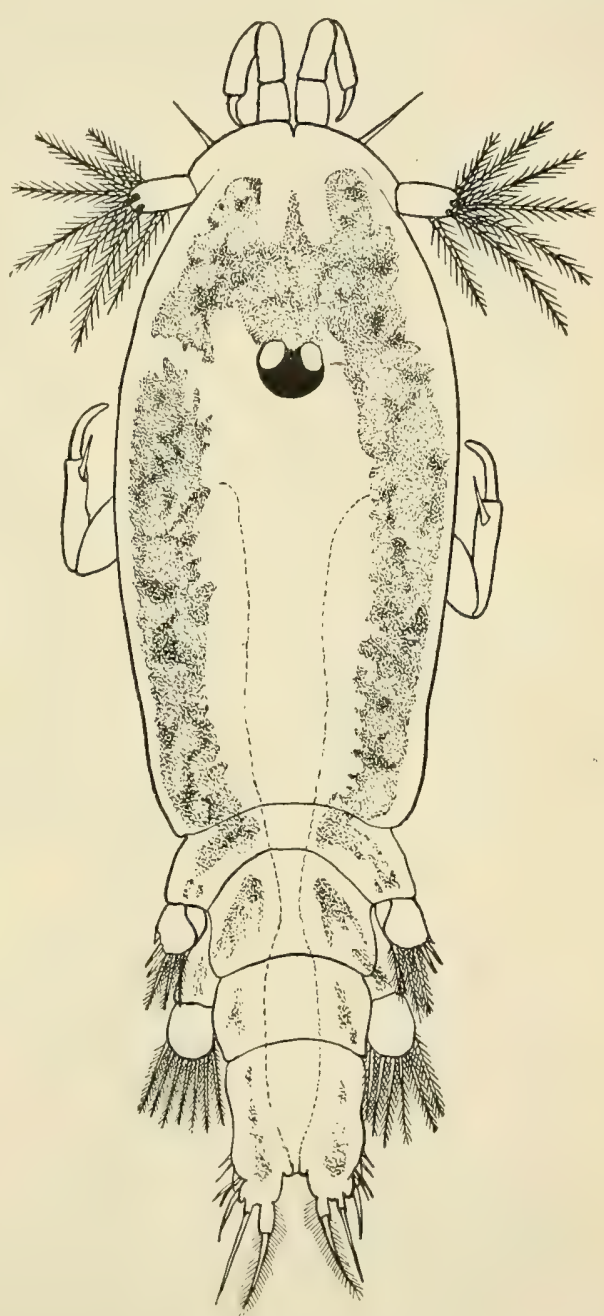

Fig. 40.-THE METANAUPLITS OF CALIGUS BONITO, DORSAI VIEW. PIGMENT UNEVEN AND A RUSTY-BROWN COLOR. latter is short and terminated by a pair of blunt anal lamine (fig. 41). Each lamina carries on its inner margin a stout two-jointed seta. The shorter hawal joint has a row of delicate hairs upon its inner margin, while the longer distal joint is plumose. Opposite this seta on the end of the lamina there is at long slender spine, and on the outer margin are three shorter curved spines. 
This alters the appearance of the larva completely, but the greatest change has taken place in the appendages. The locomotor organs of the nauplius have entirely disappeared, and in their place stand append-

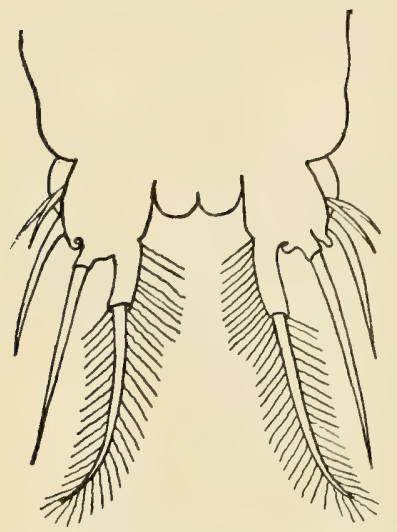

Fig. 41.-ANAL LAMINE OF THE METANAUPLIUS OF CALIGUS BONITO. ages which are evidently the rudimentary forms of those found in the adult.

The first antennæ are now distinctly twojointed, the basal joint carrying a single seta at about the center of its anterior margin, while the terminal joint is tipped with from seven to nine short plumose setæ irregularly arranged (fig. 40). Furthermore, instead of projecting directly forward in front of the body, as they did in the nauplius, these appendages are now appressed close to the anterior margin of the carapace. Their basal joints lie in exactly the position afterwards occupied by the frontal plates, and are already partially fused with the carapace. The terminal joints, which are somewhat elongated, project at right angles to the body axis in the same position which they occupy in the adult.

The second antennæ have changed even more. They still retain their biramous character, but have become prehensile organs instead of locomotor (fig. 42). Each consists of a long and very stout basipod from which project the shorter terminal segments.

The latter are fused for a distance and then separate at nearly right angles. The exopod is considerably the shorter of the two and is terminated by a short rudimentary spine.

The endopod is much stouter and terminates in a single curved claw, nearly as long as the endopod itself, and bent over ventrally until its tip points in toward, and nearly touches, the ventral surface of the basipod. These are manifestly intended for clasping organs and in furtherance of that design they extend forward in nearly the same position as that

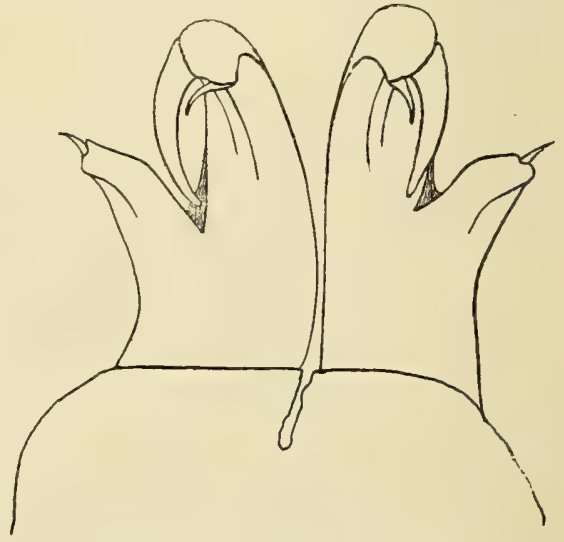

Fig, 42.-THE SECOND ANTENNÆ OF THE METANAU. pliUs of Caligus Bonito. occupied by the first antennæ of the nauplius. Moreover, the larva keeps snapping them viciously, giving a forward and downward rake in the evident endeavor to hook them into something. They must be 


the organs by means of which the larva is to obtain its first hold upon its host.

Just posterior to their base is the mouth, which possesses the same framework and mouth parts as in the adult, although the mouth parts are not yet fully developed. On either side of the mouth, close to its hase, are the second maxille, which are also very rudimentary (mx.", fig. 4i3). There is no basipod; the endopod consists of a single conical mpine, longer and more slender than in the adult, while the exopod is made up of two small circular chitin plates close to the base of the spine.

The first maxille can scarcely be distinguished as minute protuberances close to the margin of the carapace opposite the mouth. The first maxillipeds (mxp.') are much shorter and stouter than in the adult, especially in the terminal joint. They are tipped with three strong spines or claws arranged in a row, the two inner ones being pectinated like the hind toe of a night-hawk's foot.

The second maxillipeds, on the contrary, are much longer and more slender than in the adult, and again this ditference is most marked in the terminal joint and claw (mxp."). They are so much elongated that they project far beyond the edge of the carapace and stand out prominently in a dorsal view.

The claw, even at this early stage, is furnished with the small accessory spine on its inner margin, which is found in the adult.

Evidently these appendages are to serve with the second antennæ as pre-

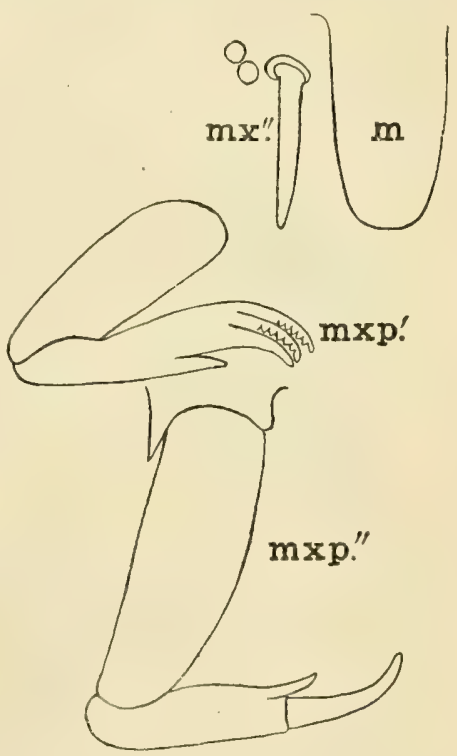

FIG, 43.-MOETH-PARTS OF THE METANAC PLIT'S OF CALIGLS BONITO. M, MOCTH; $\mathrm{mX}^{\prime \prime}$., SECOND MAXILLE; $\mathrm{mxp} \mathrm{p}^{\prime}$., FIRST MAXILLIPEDS; mXp", SECUND MAXILLIPEDS.

hensile organs. They are especially serviceable in this elongated state during the chalimus stage, as will be noted latex. (See p. 546.)

Each of the two free segments of the thorax hears a pair of rudimentary, hiramous appendages whose terminal joints are fringed with plumose setie. It was these seta seen through the skin of the nauplius which gave rise to the long curved lines on the ventral surface at the posterior and of the body just prior to this thixd stage. The appendages represent the first and second pairs of swimming legs of the adult, but differ much from their ultimate form. The basipods are very short and stout, wedge-shaped or ohlong, and armed with short spines at their distal ends. The tirst pair are united across the mid line by a wide and 
strong sternum, which is thickened along its anterior edge (fig. 44). The sternum uniting the second pair is very short and is made up of two heart-shaped plates inclined toward each other and united at their tips and for some distance along their adjacent sides (fig. 45).

The endopods and exopods of the two pairs of legs are quite similar and each consists of a single joint, broadly lamellar and fringed distally with six large plumose setæ, making them strong swimming

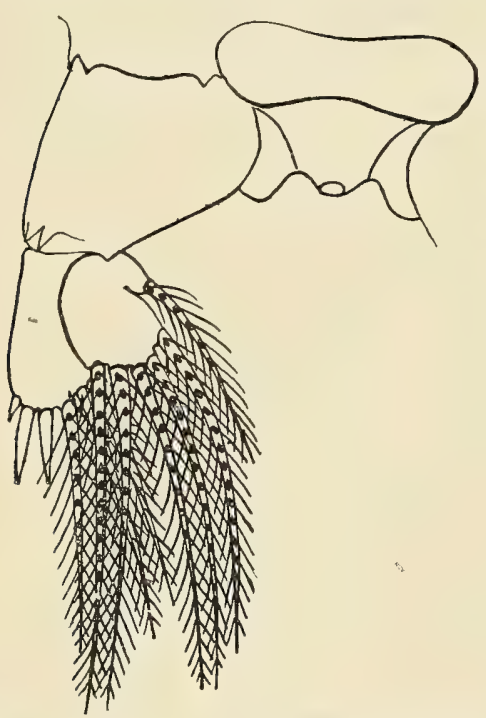

Fig. 44.-First swimming Legs of metanaUPLIUS OF CALIGUS BONITO. VENTRAL VIEW, SHOWING CONNECTING VENTRAL PLATE.

At the third moult, which occurs after about the same interval as the others, there is little advance save in a few changes toward the adult form. The firstantennæ now become three-jointed, the basal joints long and narrow and turned back on and articulated with the anterior margin of the carapace.

It is plainly evident that they are to become the frontal plates. organs. In the arrangement of these setæ may be seen an indication of the future segmentation of the appendages. Upon the third free segment may be found a pair of small projections, unsegmented and unbranched, which are the rudiments of the third pair of legs. Each carries at its distal end several short spines.

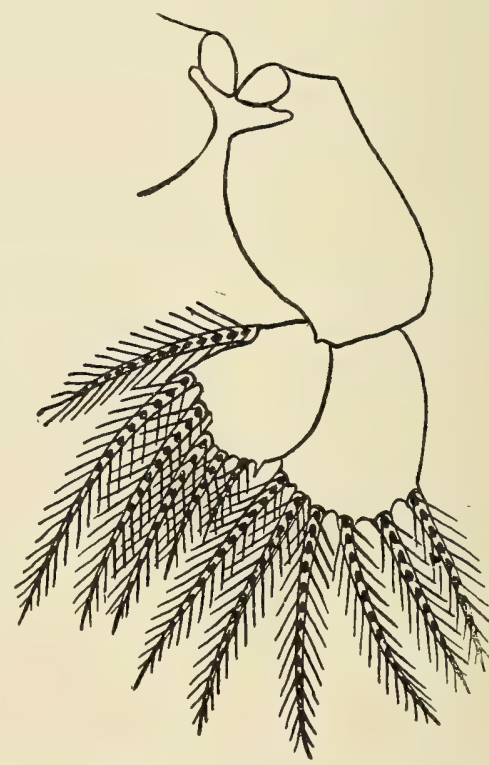

FIG. 45.-SECOND SWIMMING LEGS OF METAnauplius of Caligus bonito. Ventral VIEW, SHOWING CONNECTING VENTRAL PLATES.

Between them, in the very front of the head, there appears a large median gland which secretes the material for attachment during the following chalimus stage. (See fig. 46.) This gland is heart-shaped, the larger end being anterior, and is close to the dorsal surface of the carapace. A duct leads from the gland to a point at the very tip of the carapace between the bases of the first antennæ. 
The second antenna and second maxillipeds retain their prehensile function and have changed but little.

There has been a fusion of the first and a partial fusion of the second thoracic segments of the previous stage with the cephalo-thorax. The third segment has elongated; the rudimentary third legs have developed into a pair quite similar to the first and second pairs of the previous stage. Upon the posterior end of this segment appear another pair of rudimentary protuberances which are to develop into the fourth legs.

The genital segment still remains fused with the abdomen, and the two have increased considerably in size.

The time has now arrived for the larva to seek its host, and, when once found, it fastens immediately to the host's body. Just how the host is found remains a mystery, but certain facts are self-evident.

In the first place the nauplii and metanauplii swim freely at or very near the surface, while the fish which are to serve as their future hosts do not frequent the surface. None of the surface fish when examined are found infested with parasites of the genera here considered, with one or two exceptions. And these are forms which are peculiar to the fish on which they occur.

There is nothing, therefore, in the nature of an intermediate host; the larva does not fasten itself upon the fish which is nearest at hand and remain until it can seek its proper host.

It finds in some way at the very first the fish it wants and upon which it is to be found when fully developed.

Most of the genera here considered

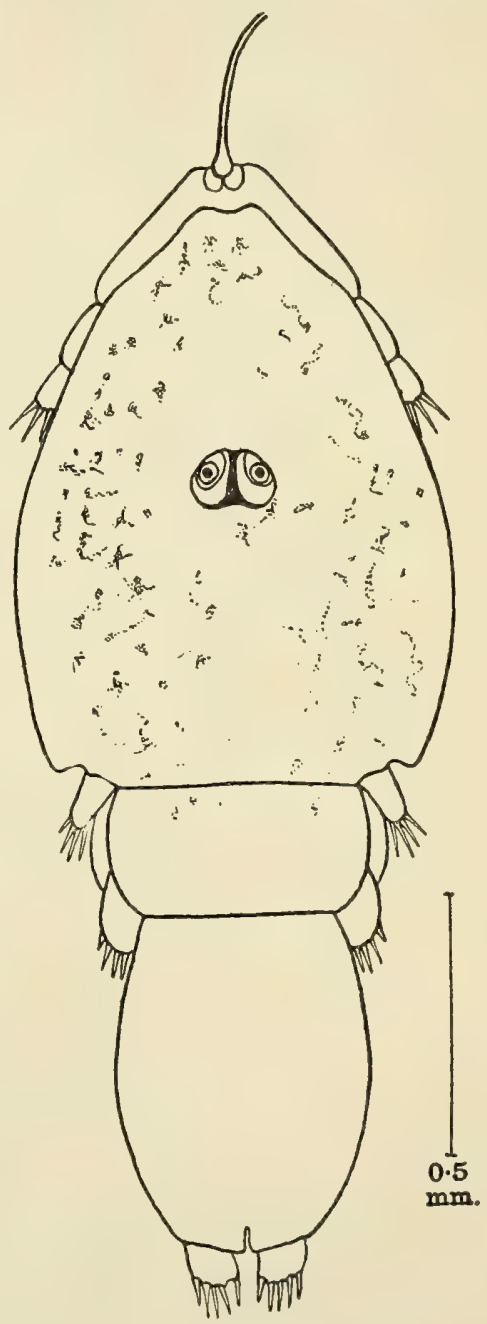

Fig. 46.-A YOUNG CHALIMUS OF CALIGUS RAPAX. infest fish which live at or near the bottom, the Gadida, Pleuronectida, ete. And every form of development from the earliest metanauplius stage through to the sexually mature adults may be found upon the same species of fish by careful search at the right season.

At some time, therefore, during the two metanauplius stages the 
larva must leave the surface and seek the bottom, remaining there until it can fasten itself to a host.

The passage from the surface to the bottom must form one of the critical periods in its existenc , and even after it gets there the chances

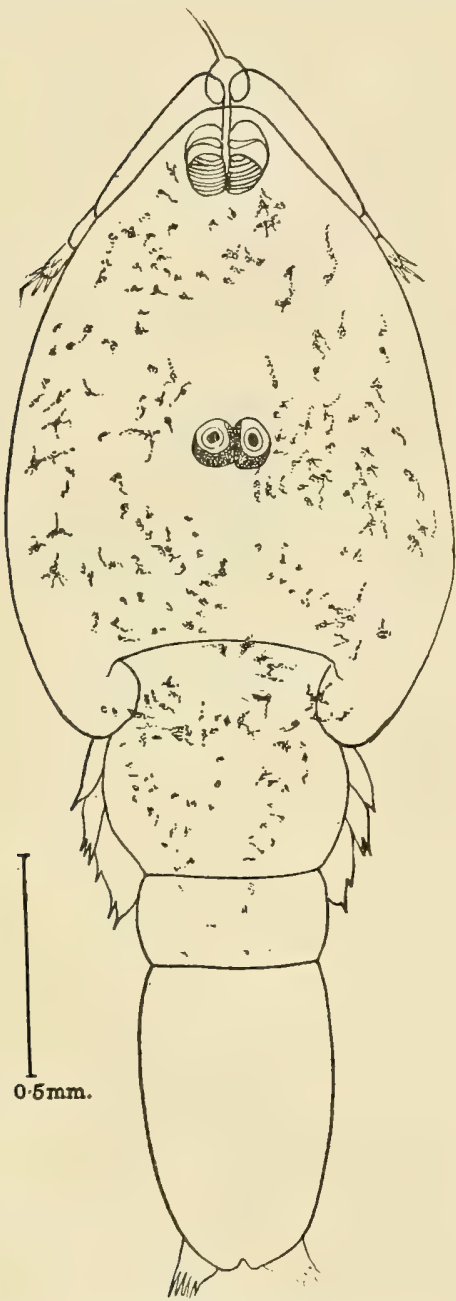

Fig. 47.-Chalimus of Caligus rapax. ('I'HE NEXT MOULT AFTER FIG. 46.) are not very favorable for finding a suitable host within the brief time necessary.

These metanauplii seize the fish with their second antennre, stretching them forward side by side and driving the terminal claws deeply into the fish's flesh through its skin.

The antennæ are so long and the hold obtained is so firm that the larva stands out from the surface of the skin in a manner very suggestive of the chalimus stage with its long frontal filament. Furthermore the antennæ, being very close together and along the median axis, allow almost as much freedom of motion as a single filament.

After one or two moults in this stage the larva emerges as a chalimus and puts in operation the median frontal gland with its secretion, which has been developed as a means of attachment. The way in which the larva handles this gland, produces the filament, and fastens itself to its host has never been directly observed. But the author was fortunate enough to see a young chalimus refasten itself after being torn away from the tail fin of a flounder. In all probability the original method was very similar, if not identical. The larva seized the fin with its second antennre, piercing the skin and obtaining a good hold on the fin ray. The posterior part of the body was then raised upon the second maxillipeds, depressing the anterior margin until it touched the fin at the point where the duct from the median gland opens. The gland then poured out its secretion, which was thick and riseid, and stuck firmly to the fin ray. The carapace was moved about in such a way as to spread the secretion over a larger surface. The larva then released its hold with the antenna and at the same time 

seemed to push itself brekward with its maxillipeds. In this way the secretion was pulled out into a long slender rod or cord, nearly as long as the body of the larva.

The secretion seems to harden instantly and furnishes a strong and very flexible means of attachment during the moults which intervene before the adult stage is reached.

If one of the fin rays be examined under the microscope the filament can be seen to penetrate the skin and to be attached along the side of the ray for some little distance, as noted by Scott (1901). Often the tip of the filament is spread out into a broad disc, giving it a firmer hold around the ray.

Iust how the secretion is brought in contact with the fin ray could not be determined, but it has already been noted that the second antemna, in grasping the fin, penetrated the skin and took hold on the ray. It seems probable that in spreading the secretion about some of it may enter the openings thus made and come in contact with the ray. Its own adhesiveness would be sufficient to fasten it securely on hardening.

In all the specimens collected the tip of the filament has been so firmly fastened to the host that it could not be detached. In every instance the tilament either broke at the center or was torn out of the chalimus's carapace when an effort was made to detach it. And the only way to obtain the fastening intact is to cut off the ray and preserve it with the chalimus still attached.

The larva is frequently attached to a scale rather than a fin, and in such cases the filament pierces the cutis covering the scale and is flattened into a disk upon the surface of the scale itself. The idea in every instance seems to be the attachment of the distal end of the filament to something that will not give way. In rare instances the young may be found attached elsewhere upon the host, or even to some portion of the body of an adult parasite, as noted by Hesse (1858).

The chalimus can pull itself down to its host at any time by means of its long maxillipeds, and in this way obtain its food. The stage is one of great interest, both on account of this peculiar means of attachment and also historically.

Originally discopered by Burmeister, it was described by him in $16: 31$ as a new genus of the Caligidax, and several species were afterwards added by the wame and other authors. But the more careful observers were quick to suspect its real relation to other members of the family, and Kröser very arly suggested that it was only the young of cilligus, or some closely related form. Müller (185*) and stein $(15.5)$ soon proved this satisfactorily, and subsequently

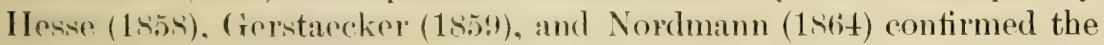
conclusion.

Of these writers Hesise had the notion that the mother voluntarily 
attached the young to her own body, in order to render them material assistance. He describes the "filet" which fastens the embryo to its mother, and designates it as the "cordon frontal." It is long and flexible enough to allow the young an independent action and to permit it to apply itself to the fish upon which both the mother and the young live.

It is a very curious and interesting spectacle, says Hesse, to see these embryos, especially those of Trebius and Caligus, which swim with considerable facility, following the evolutions of their mother, like a small boat towed by a large ship. This liason of the two individuals ceases as soon as the young are able to procure their own nourishment, the rupture taking place about the time of the second or third moult.

This idea of voluntary attachment was strongly denied by Gerstaecker and Nordmann, while Stein, who wrote six y ears before Hesse, and whose work the latter entirely overlooked, also contended that such attachment is purely accidental. That this is the true interpretation is evident from many considerations.

In the first place the larvæ hatch as free-swimming nauplii, positively heliotropic, and therefore frequenting the surface, while most of the fish which are to serve as their hosts live at or near the bottom, as already noted. We have also seen that the larvæ moult at least three times before entering the chalimus stage, leaving the surface and becoming negatively heliotropic after the second moult. Hence each of them must seek out its own host, and there is not one chance in a thousand that it will find the same host upon which it was born.

And the probability of finding its own mother still upon that host would be even less. Indeed the finding of its own mother under any circumstances after a free-swimming period, no matter how short that period might be, presupposes, if the union is to be voluntary, an ability on the part of either mother or offspring to recognize the other! Such recognition would be at least an anomaly among parasitic crustacea.

But even if we grant that the larva might find its own mother, still the act of attachment can not be performed by the latter; it is wholly the work of the larva itself, as we have just seen, and must be controlled by instinct. And it could hardly be claimed that instinct guided the larva to the body of its parent, since this would necessitate some advantage to result from the union. Such an advantage would be difficult to prove, and even if it were established we should still have to explain the fact that only one or two larvæ out of thousands followed their instinct and availed themselves of the advantage. We can only conclude that such a union by no means proves a close relationship between the adult and the larva; that it is purely accidental and of rare occurrence. 






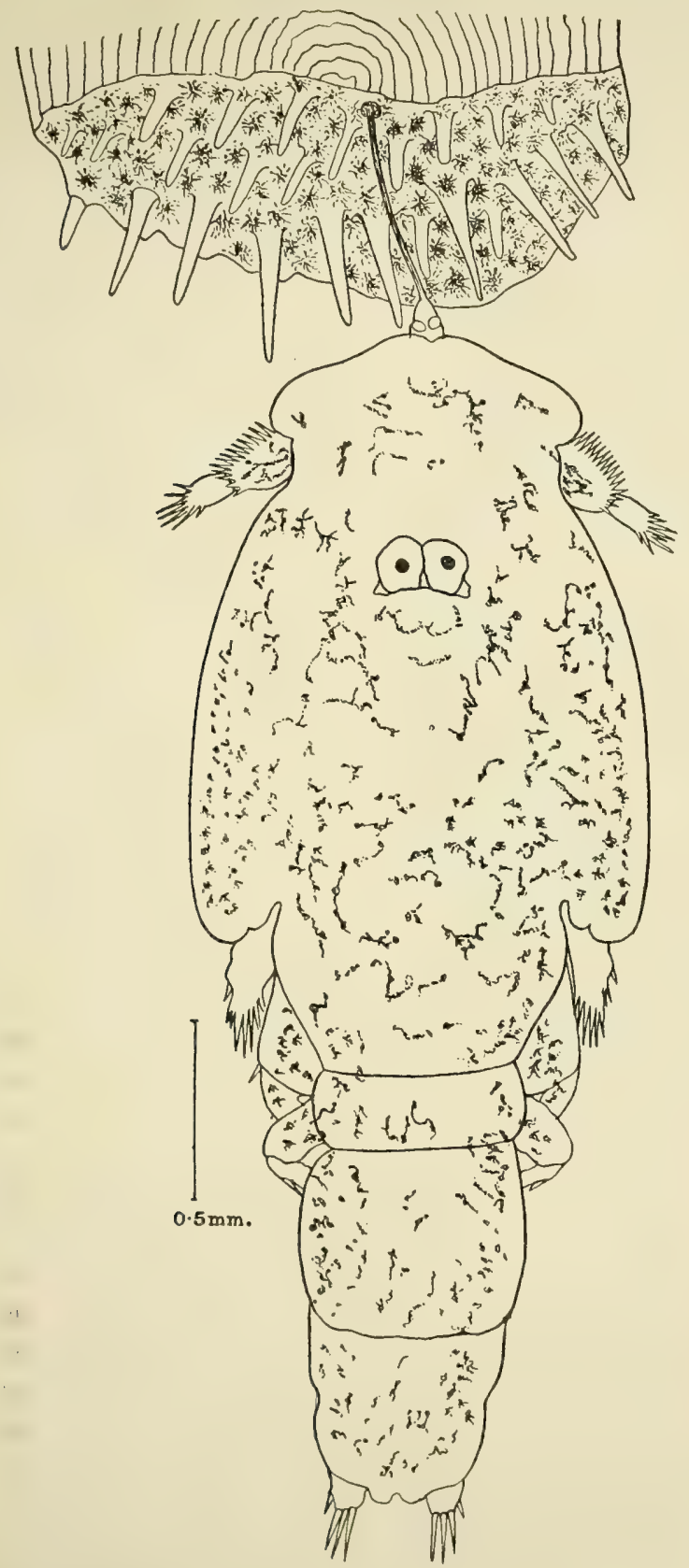

Fig. 48.-Chalimos of Caligts rapax. (ONe motlt later than fig. 47.)

The changes which take place during this fourth moult and those which subsequently occur in the sereral moults of the chalimus period are very suggestive in many ways. 
The carapace, which is at first squarely truncated posteriorly (fig. 46) and decidedly spindle-shaped, gradually develops a lobe on either side and widens considerably into a form which is obovate or elliptical (fig. 48). The first three segments of the thorax fuse completely with the head and the sutures, which

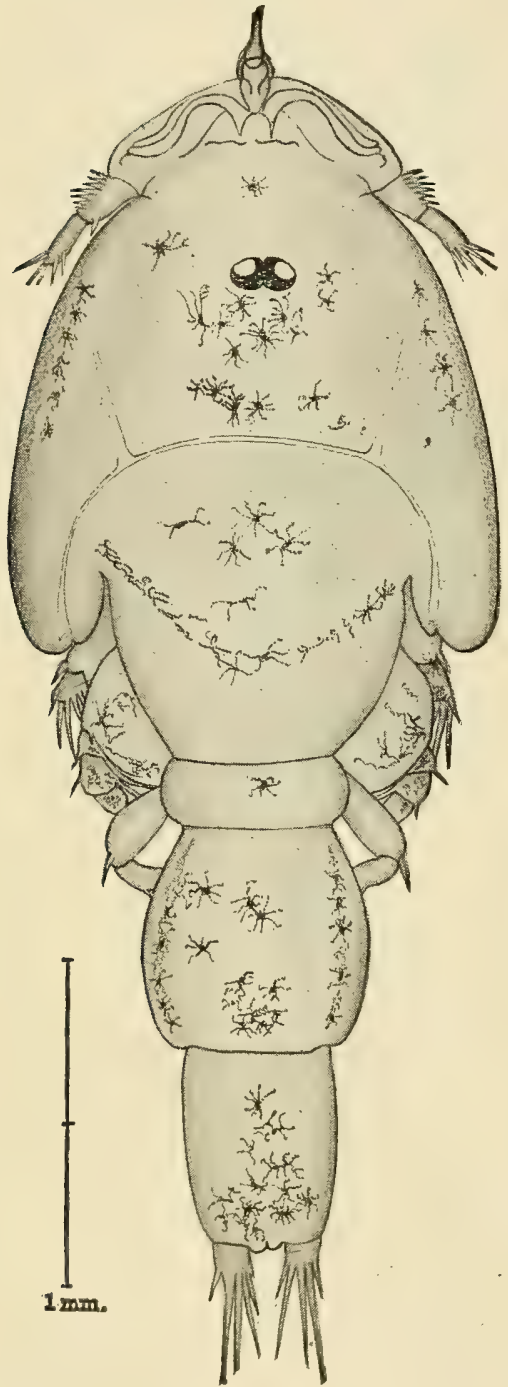

Fig. 49-Fully DeVeloped CHALIMUS OF FEMAIE CALIGUS RAPÁX FROM FLOUNDER. DORSAI VIEW. subsequently separate the regions of the carapace, appear and become fairly well developed. The free segment of the thorax is still very long in the early chalimus stage, but rapidly shortens with every moult. The genital segment and the abdomen begin to separate by the second chalimus moult, the abdomen at first being several times the larger (fig. 47). But before the close of the chalimus stage the genital segment has increased until it is the larger, while the abdomen has narrowed somewhat, and the anal papillæ with their setæ have lengthened considerably (fig. 49).

The eyes in the early chalimus stages are relatively large and situated far back in the carapace, nearly at its center. They move steadily forward with every moult until they reach the adult position at a point about one-third of the length of the carapace from its anterior edge. But the appendages move forward at the same time so that the eyes remain all the while just above the mouth.

The first antennæ still remain three-jointed, and in the later chalimus stages lunules gradually develop upon the basal joints in such species as are to possess them. This is the final proof that these basal joints become the frontal plates.

This fact, which has all along needed the testimony of development in order to demonstrate it fully, now that it is established, entirely changes the homology of the antennre. So long as the frontal plates were regarded as a portion of the carapace, no homology in structure or function between the antennæ of Culigus and those of Argulus was 

possible. But as soon as we recognize in the frontal plates the basal joints of the first antennæ, such a homology becomes not merely possible but very complete and significant. In both families the first antenne are three-jointed, the basal joint being enlarged and modified to serve a prehensile function, while the two terminal joints are much smaller and wholly tactile. In Argulus the prehension is accomplished by means of a stout hook developed at the distal end of the basal joint, while in Caligus the same result is attained hy a sucking disk or lunule.

The second antenna in Argulus are largely tactile, only the hasal joint being prehensile in function, and even these have nothing but stout spines to assist in preventing the copepod from slipping back-
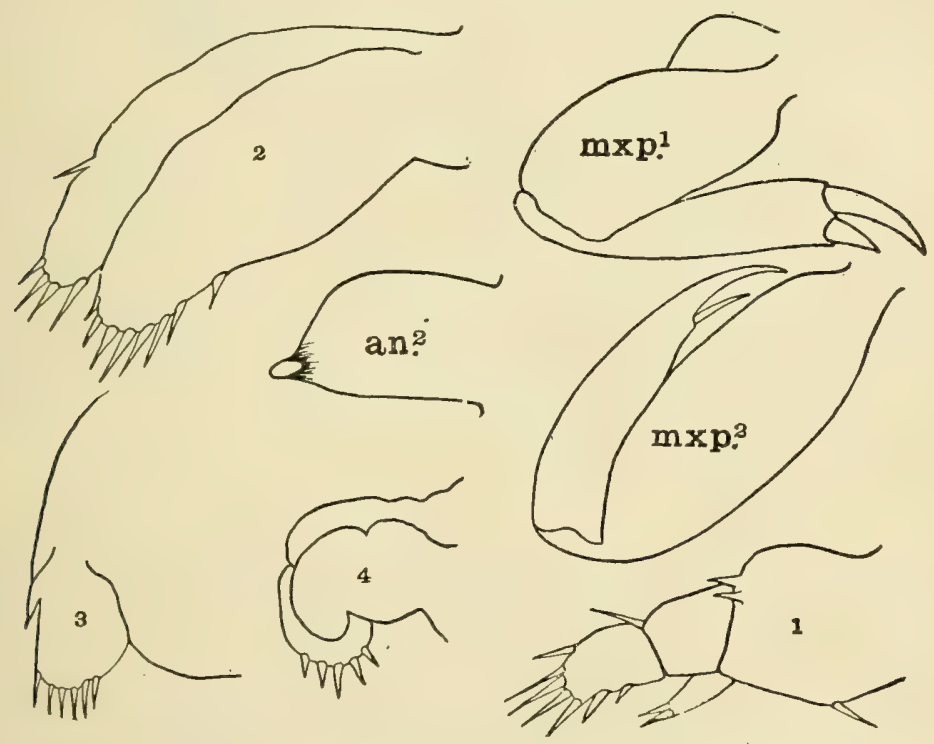

FIG. 50.-APPENDAGES OF THE EART.Y CHALIMUS STAGE SHOWING MODE OF DEVELOPMENT. an²., SECOND

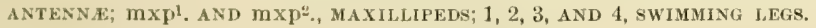

ward. But in Culligus the entire second antenna becomes prehensile (fig. 50, an²), the basal joint with a stout spine pointing backward, as in Argulus, while the terminal joint is developed during the chalimus period into a strong sickle-shaped claw, operated by powerful muscles, and fully capable of rendering material assistance to the maxillipeds in piereing the skin of the host and obtaining a firm hold.

Both Baird (1 15.01$)$ and Pickering and Dana (1838) described these sorend antenne as the first pair of foot-jaws, the former without making any comparisons, the latter claiming that they corresponded to the second maxilla in decapod crustacea, a manifest error.

The first and second maxillie develop soliewhat toward the close of the chalimus period, but as they are rudimentary eren in the adult no marked development is possible in the larva. 
The other mouth parts and the four pairs of swimming legs develop steadily toward the adult form, with no marked changes at any one moult. The only features worthy of note are in the development of the first and fourth pairs of swimming legs.

In early stages the first pair (fig. 50,1) have a well-defined endopod, much smaller than the exopod to be sure, and consisting of but a single joint terminating in two small setæ. Later this rudimentary endopod almost entirely disappears, its place in the adult being indicated by a long, slender seta.

The fourth legs are made up at first of two short and very broad disk-like segments, totally unlike the long and slender adult form (4). Furthermore, there are no setæ anywhere upon them except at the tip of the terminal joint where four very short and stubby ones stand in a row. With almost the first chalimus moult, however, the nature of these legs changes radically, and they quickly narrow and elongate, at the same time acquiring setæ upon all the joints.

With the beginning of the chalimus period the digestive organs change into the adult form, and the reproductive organs appear. The latter grow rapidly in the male and have attained their full development by the close of the chalimus period, but in the female they remain rudimentary until fertilization, which takes place only after the larvæ have become free swimming. The genital segment in the female remains small, deeply lobed posteriorly, and with the fifth legs showing prominently for quite a long time after the close of the chalimus period.

The nervous system starts in a large ganglion just beneath the dorsal surface of the carapace, posterior to the eyes. This ganglion is elliptical in shape, the eyes being situated just above its anterior end. A pair of nerves, corresponding to the first pair in the adult, extend from the anterior end of this ganglion to the eyes. From the posterior end in early chalimus stages two or three pairs of slender nerves extend a short distance backward but do not reach beyond the carapace. This one ganglion evidently corresponds to parts of both the supra- and infra-œsophageal ganglia in later development. As the young copepod grows by successive moultings, and the various appendages appear in regular order, the nervous system also develops. In this way for each of the appendages there appears at the proper time the pair of nerves which are to innervate their muscles until the whole system is completed. After a study of these forms extending over several years it may be stated with a fair degree of accuracy that this period of attachment to the host lasts from four to six weeks. During that time, to judge from the material collected, there are at least five moults, if not more.

At the close of the period the appendages have become fully developed, and with the last moult the filament separates just at the 


frontal margin of the carapace, leaving a notch where it emerged, and usually a portion of the tilament itself projecting from the base of the notch and extending backward into the carapace to the gland. These remains persist all through the adult life and are an abiding evidence of the relation between chalimus and adult.

\section{SUMMARY.}

1. The eggs as they are extruded to the exterior in the egg tubes assume a biscuit shape with the germinal area at about the center of the proximal side. The embryos develop until they cover this side and extend down over the edges of the biscuit, their longitudinal axes being closely parallel.

2. As the embryos develop they become pigmented, the pigment varying in color and arrangement in different species, and in this way affording good supplementary evidence of identity.

3. Each egg ruptures separately, and the membranes of the egg tube split just opposite the embryos, allowing the latter to wriggle out, and leaving behind the membranous framework of the egg tubes the same size and shape as before and still attached to the female, but empty.

t. The nauplii swim to the surface and toward the light as soon as they are free. Each has a typical nauplius form, ovate or elliptical in outline, strongly flattened dorso-ventrally, and with three pairs of appendages representing the first and second antennæ and the mandibles.

5 . The first antennæ are uniramous and terminate in two long plumose setre. The second antennæ and mandibles are biramous, the exoporl four-jointed, each joint bearing a long plumose seta, the endopod with a single joint terminating in two similar setæ. Near the posterior end of the hody is a pair of spatula-shaped balancers.

6. The first moult occurs during the first thirty-six hours, usually at night; the nauplius emerges with its body considerably elongated and with the evident beginnings of segmentation posteriorly. The appendages remain unchanged.

7. The second moult occurs during the second thirty-six hours, also at night; the nauplius emerges radically changed. The median eye has disappeared, and instead we find a pair of eyes fused on the median line, an in the adult. The carapace is more clearly defined, and covers about two-thirdis of the body; there are two free thoracic segments, each bearing the rudiments of swimming legs, followed by a third segment with even more rudimentary appendages, and this in turn by the fused genital segment and abdomen, the latter terminated by a pair of blunt anal papillar armed with setie. For appendages this larva possesses first and second antennae, first and second maxillax, 
mandibles, a mouth tube or probocis, first and second maxillipeds, and three pairs of rudimentary swimming legs.

8. The third moult occurs at about the same interval as the others. The first thoracic segment has been entirely, and the second partially, fused with the head. The third segment has elongated and the rudiments of the fourth thoracic legs appear upon its posterior ventral surface. The genital segment still remains fused with the abdomen, but the two have increased considerably in size. The first antennæ have become three-jointed; the other appendages remain unchanged, save that the swimming legs advance toward the adult form.

9. The larva now seeks its host and moults again into what is known as the chalimus stage, the chicf characteristic of which is the development of a long cord or filament by means of which the young are attached to their host. This filament is made out of the material secreted by a median gland situated just in front of the eyes.

10. The changes which take place during this fourth moult and those which subsequently occur in the several moults of the chalimus period are in the line of gradual development toward the adult form. The carapace, at tirst squarely truncate posteriorly, gradually develops a lobe on either side and widens. The first three thoracic segments fuse with the cephalon, and the sutures on the dorsal surface of this cephalo-thorax appear and become well developed. The genital segment and the abdomen separate at the second chalimus moult, the abdomen at first being several times the larger. The eyes more steadily forward with each moult, but as the appendages on the ventral surface move forward also the relation of the two remains unchanged.

11. The only appendages worth noting are the first and fourth swimming legs. In the early chalimus stages the first pair have a well-defined endopod, consisting of a single joint terminating in two small setæ. Later this disappears and its place in the adult is indicated, if at all, by a long seta. The fourth legs are made up at tirst of two short and broad, disk-like segments, without setw or spines. With successive moults they narrow and elongate into the adult form, and acquire both spines and setæ.

12. This attached stage lasts from four to six weeks, and the larva moults at least five times. At the close of the stage the male is practically fully developed, but the female remains immature, so far as the reproductive organs are concerned, until fertilization has been effected and the ova begin to descend the oviducts. With the last chalimus moult the connecting filament separates just at the frontal margin of the carapace and the copepod enters upon its free adult existence. 




\section{GENUS CALIGUS Müller.}

Carapace large, shield-shaped. Basal joints of the first antennæ provided with lunules; two terminal joints free, heavily armed with setæ. Mandibles often toothed along both margins. Second maxillæ simple, spine-like. First and fourth thoracic legs uniramose, second and third biramose. Fourth thorax segment without dorsal plates; genital segment simple also, without plates or processes. Abdomen one to many segmented. The young of both sexes with a frontal filament for attachment during the chalimus stage. Anal lamellæ strongly flattened and armed with long plumose setæ.

(Caligo, obscurity, darkness.)

ARTIFICIAL KEY TO THE SPECIES.

The relative length of the different body regions is the most constant character available for classification of species.

Both sexes are here included, since they usually exhibit radical differences, and they must be sexually mature, although the presence of egg strings in the female is not necessary. When the fifth legs are spoken of as visible or invisible it means in dorsal view only, and has no reference to a microscopical examination of the ventral surface. All measurements of length include the anal lamellæ, but not the plumose setie upon them. Differences of length must amount to eight per cent or ten per cent; otherwise they are considered as "about equal." In any case where there might still be danger of mistake after this liberal allowance the species has been inserted twice. This key includes all valid species known at the present time. The anthority for each species is here given, and the reference can be found in the bibliography on p. 666.

There have been eliminated the following species:

First, those which subsequent examination has shown to belong to other genera. Here are included bicolor (Lamarck, 1818), which is a Pandarus; branchialis (Steenstrup and Lütken, 1861), a Lepeophtheirus; breripedis (B-Smith, 1896), a Pseudocaligus; crassus (Ahildgaard, 1794), an Anthosome; gracilis (v. Beneden, 1851), hippoglossi (Kröyer, 1837), molrax (Latreille, 1825), nordmannii (M-Edwards, 1840), obscurus (Baird, 1850), ornatus: (Nordmann, 1832), pacificus (Gissler, 1883), pectoralis (Müller, 1785), phuruonis (Nordmann, 1832), sulmonis (Kröyer, 1837), sturionis (Kröyer, 1837), stromii (Bairl, 1850), and respa (M-Edwards, 1840), all of which belong to the genus Loprophtheirus. Imbricutus (Risso, 1816) is an Anthosoma; oblongus (Abildgaard, 1794) is a Dichelestium; paradoxus (Otto, 1828) is a Demoleus, and smithii (Lamarck, 1818) is an Anthosoma.

Seroml, those which have proved to be synonyms of species already described. Here are includerl aglefini (Kröyer, 1863), a male curtus; americumus (Pickering and Dana, 1838), also a curtus; bengoensis (T. Scott, 1894), a young male coryphxnx; bicuspidulus (Nordmann, 1832), a curtus; carangis (Kröyer, 1863), an alalongr; dirphamus (Baird, 1850), a curtus; elegans (v. Beneden, 1851), a curtus; elongatus (Norduann, 18:32), a rapar; leptochilus (Leuckart, 1847), also a mpax; longicaudus (B-Smith, 1898, a), a trichimri; mulleri (Leach, 1816), a curtus; scombri (B-Smith, 1896), a productus; rissoniams. (M-Edwards, 1840), a curtus; scutatus (M-Edwards, 1840), a comphisen.

Third, forms of which no figure has ever been published and which were so poorly describer as to make their identification impossible. Here are included affinis (Heller, 1866), put into the key provisionally; kroyerii (M-Edwards, 1840), piscinus 
(Guerin, 1817), platesse (v. Beneden, 1870), and the following which were simply named by Richiardi in 1880, fissus, lepidopi, petersii, serrani, smaris, and trachuri; and lessonianus (Risso, 1816).

Gayi is here included from a printed figure, the description not having been seen. And finally, the author has been unable to secure either the figures or deseriptions of heptapus (Otto, 1821) or hyalinus (Czerniavski, 1868).

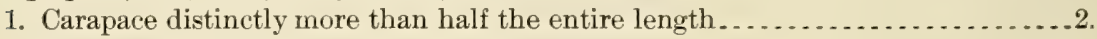

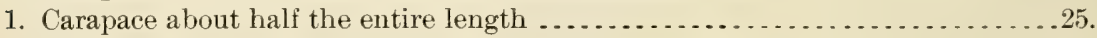

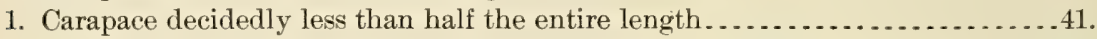

2. Abdomen four-jointed and shorter than genital segment; the latter quadrate. aliuncus, new species, p. 576 .

2. Abdomen two-jointed and longer than genital segment; all males.......... 3.

2. Abdomen two-jointed, the same length as genital segment ............. 5 .

2. Abdomen two-jointed, shorter than genital segment.....................

2. Abdomen one-joinfed, longer than genital segment..................... 12 .

2. Abdomen one-jointed, the same length as genital segment............. 13 .

2. Abdomen one-jointed, shorter than genital segment.......................

3. Abdomen joints about equal ....................... bonito, new species, p. 589.

3. Abdomen joints unequal, the first much the shorter ......................

4. Genital segment oblong, no wider than abdomen; fifth legs invisible dorsally. stromatei (Kröyer, 1863).

4. Genital segment quadrate, three-quarters wider than abdomen; fifth legs visible, large......................... rufimaculatus, new species, p. 561.

4. Genital segment barrel-shaped, one-third wider than abdomen; fifth legs visible, small .................................

5. Males, fifth legs plainly visible dorsally ........................ 6.

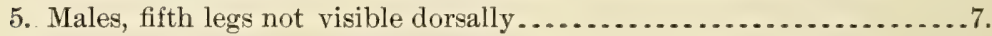

5. Females, fifth legs not visible dorsally ..........................

6. Genital segment quadrate, half as wide as carapace; fourth legs large, all their spines serrate and a large plumose seta at the tip of the basal joint.

coryphænæ (Steenstrup and Lütken, 1861).

6. Genital segment quadrate, half as wide as carapace; fourth legs weak, no serrate spines, no setæ. ... . . . . . ..........................thymni (Dana, 1852) p. 603.

6. Genital segment oblong, one-quarter as wide as carapace; abdomen almost the same width, joints equal...................... diaphanus (Nordmann, 1832).

7. Genital segment oblong, no wider than abdomen .....................

7. Genital segment obovate or spindle-shaped, from one and a half to twice wider

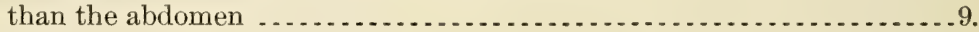

8. First abdomen joint one-third the second; fourth legs short, just reaching the abdomen . . . . . . . . . . . . . .

8. Abdomen joints the same length; fourth legs reaching beyond tips of anal laminæ. longipes (B-Smith, 1898, c).

9. Free segment narrower than genital segment; frontal plates narrow, lunules

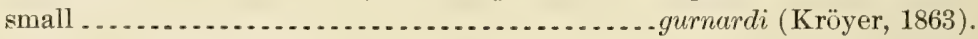

9. Free segment same width as genital segment; frontal plates prominent, lunules large ............................. $\operatorname{rapax}($ Milne-Edwards, 1840), p. 568.

9. Free segment wider than genital segment; third and fourth legs large and stout . . . . . . . . . . . . . . . . 573.

10. Genital segment rectangular, wider than long; fourth legs very short; furca double ..................................... fallax (Kröyer, 1863).

10. Genital segment obcordate, deeply lobed; fourth legs reaching beyond tip of

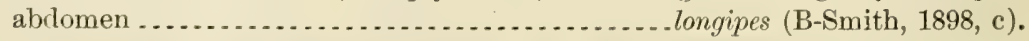

11. Males, genital segment subquadrate; fifth legs visible dorsally. 




11. Males, geniital segment elliptical; fifth legs not visible dorsally.

infestans (Heller, 1865).

12. Genital segment barrel-shaped, longer than wide, sides strongly curved; fifth

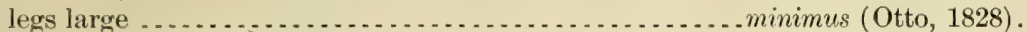

12. Genital segment quadrate, much wider than long, emarginate posteriorly; fifth

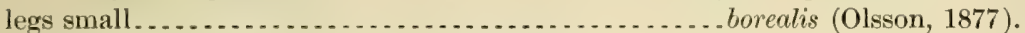

13. Males, fifth legs plainly visible dorsally ......................... 14 .

13. Females, fifth legs plainly visible dorsally . . . . . . . . . . . . . . . . 15.

13. Females, fifth legs not visible dorsally . . . . . . . . . . . . . . . . . . . . . 16.

14. (ienital segment semilunar, deeply lobed; free segment very short, almost concealed dorsally ............................... centrodonti (Baird, 1850), p. 652.

14. (ienital segment acom-shaped, deeply lobed; twice as wide as free segment; lobes acute . . . . . . . . . . . . . . . . balistre (Steenstrup and Lutken, 1861), p. 601.

14. (ienital segment oblong, no lobes; narrower than free segment; fourth legs very long . . . . . . . . . . . . . . . . . . . . . . . . . . . . . . . . nanus (Kröyer, 1863).

14. Genital segment obcordate, lobes short; three times as wide as free segment. parvus (B-Smith, 1898, a).

15. Genital segment acorn-shaped, rounded posteriorly; furca long and narrow. borealis (Olsson, 1877).

16. Genital segment oblong, widened posteriorly; abdomen much longer than wide. dubius (T. Scott, 1894).

16. Genital segment quadrangular, corners square; abdomen the same length and width .... . . . . . . . . . . . . . . . . . . . . . . . . . gracilis (Dana, 1852).

17. Abdomen more than half the length of genital segment .............. 18 .

17. Abdomen much less than half the genital segment . . . . . . . . . . . . . . 23 .

18. Males, genital segment, but little wider than abdomen ..................... 19.

18. Females, both the fifth and sixth legs visible dorsally . . . . . . . . . . . . . . . 20.

18. Females, only the fifth legs visible dorsally . . . . . . . . . . . . . . . . . . . . . . 21 .

18. Females, neither fifth nor sixth legs visible dorsally ...................... 22.

19. Genital segment spindle-shaped; fourth legs with three saber-like spines.

labracis (T. Scott, 1902).

19. Genital segment orbicular, as wide as long; fourth legs with one toothed spine ....................................... curtus (Müller, 1785), p. 578.

19. Genital segment cylindrical, sides parallel; fifth legs invisible dorsally. cheilodactyli (Kröyer, 1863).

20. Genital segment triangular ....... . isonyx (Steenstrup and Lütken, 1861), p. 602.

21. Genital segment obcordate, lobes large; abdomen club-shaped, narrow. minimus (Otto, 1828).

21. Genital segment rectangular, no lobes; abdomen as wide as long.

labracis (T. Scott, 1902).

21. (ienital segment acorn-shaped, no lobes; abdomen spindle-shaped, longer

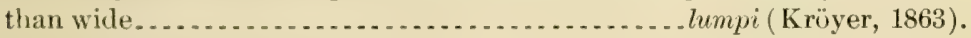

22. Genital segment oblong, no lobes; fourth legs only reaching its center.

curtus (Müller, 1785), p. 578.

22. Cienital segment obeordate, as wide as long, with short lobes; fourth legs reaching abdomen .................................... gurnardi (Kröyer, 1863).

22. Cienital segment barrel-shaped, wider than Jong; lobes short; toothed plates on fourth-leg spines ..................................teres, new species, p. 649.

22. (ienital segment ovate, no lobes; whole borly covered with spots of rust color. rufinaculatus, new species, p. 561.

22. (ienital segment harrel-shaped, wider than long; no lobes; abdomen narrow; body highly colored . . . . . . . . . . . . . . . . . . . . . . gayi (Nicolet, 1849):

22: (ienital segment elliptical, lobes short; terminal claws on first legs bipartite. schistonyx, new species, p. 564 .

Proc. N. M. vol. xxviii-04-36 
23. Fifth legs visible dorsally; males or females; genital segment subquadrate. abbreviatus (Kröyer, 1863).

23. Fifth legs invisikle dorsally, all females. . . . . . . . . . . . . . . . . . . . 24 .

24. Genital segment rectangular, much longer than wide, no lobes; sides nearly parallel . brevicaudatus (A. Scott, 1901).

24. Genital segment rectangular, much wider than long, no lobes; sides nearly parallel parrus (B-Smith, 1898, a).

24. Genital segment obovate, as wide as long, sides strongly curved; small plates on free segment............................centrodonti (Baird, 1850), p. 652.

24. Genital segment obovate, deeply lobed; lobes acute, conical; free segment narrow and long................. balistre (Steenstrup and Lütken, 1861), p. 601. 25. Abdomen three-jointed; genital segment flask-shaped, truncate posteriorly. anyustatus (Kröyer, 1863).

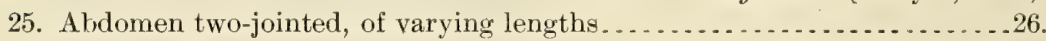

25. Abdomen one-jointed, of varying lengths ... . . . . . . . . . . . . . . 34.

26. Abdomen longer than the genital segment, males or females . . . . . . . . . . 27.

26. Abdomen about the same length as the genital segment. . . . . . . . . . . . . . 28.

26. Abdomen half as long as the genital segment or more ................... 31 .

27. Males, genital segment quadrangular; free segment as wide as long.

hirsuius (B-Smith, 1898, a).

27. Males, genital segment narrow spindle-shaped; free segment four times as wide as long. ............................. bonito, new species, p. 589.

27. Females, genital segment acorn-shaped; free segment twice and a half as

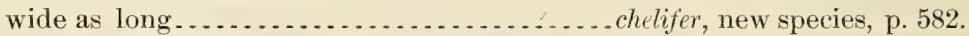

28. Males, fifth legs visible dorsally; genital segment acorn-shaped; first abdomen joint smaller................................. robustus (B-Smith, 1898, b).

28. Males, fifth legs invisible dorsally . . . . . . . . . . . . . . . . . . . . . . . 29 .

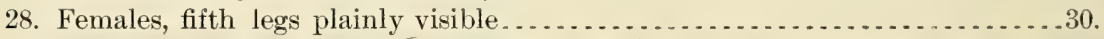

28. Females, fifth legs invisible dorsally; genital segment oblong; basal abdomen joint the longer ..................................... 29. Genital segment barrel-shaped, only a little longer than wide, corners angu-

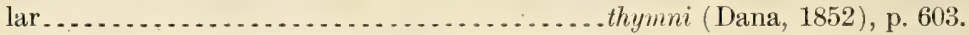

29. Genital segment narrow, elub-shaped, twice as long as wide, corners rounded. trichiuri (Kröyer, 1863).

30. Genital segment obcordate; basal abdomen joint four times the terminal. robustus (B-Smith, 1898, b).

30. Genital segment oblong, widest posteriorly; terminal abdomen joint much the

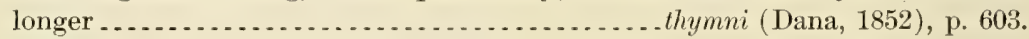

31. Males, fifth legs not visible dorsally . . . . . . . . . . . . . . . . . . . . 32.

31. Females, fifth legs not visible dorsally . . . . . . . . . . . . . . . . . . . . . 33.

32. Genital segment orbicular, half as wide as carapace; basal abdomen joint short and wide........................................

32. Genital segment elliptical, one-third as wide as carapace; basal abdomen joint quadrangular .........................hæmulonis (Kröyer, 1863), p. 606.

33. Genital segment oblong, narrowed anteriorly; deeply emarginate posteriorly; lobes long................................ infestans (Heller, 1865).

33. Genital segment flask-shaped; slightly emarginate posteriorly; lobes short and broad............................ belones (Kröyer, 1863), p. 586.

33. Genital segment orbicular, as long as wide, evenly rounded; basal abdomen

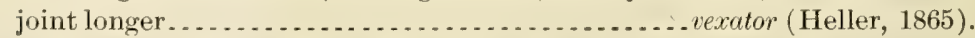

34. Abdomen obconical, longer than the genital segment; the latter flask-shaped; males ..................................... phipsoni (B-Smith, 1898, a).

34. Abdomen same length as genital segmenit; the latter oblong; fourth legs short and weak; females............................... dubius (T. Scott, 1894). 

34. Abrlomen half the length of the genital segment or more ......................

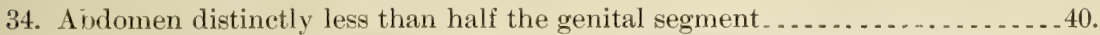

35. Males, genital segment narrow cylindrical, no wider than abdomen; fifth legs invisible... . . . . . . . . . . . . . . . chorinemi (Kröyer, 1863).

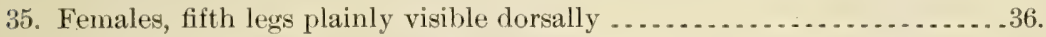

35. Females, fifth legs not visible dorsally . . . . . . . . . . . . . . . . . . . 37 .

36. Genital segment elongate-ovate; fifth legs close to the base of the abdomen.

gurnardi, var. (Kröyer, 1863).

36. Cienital semment hroad acom-shaped; fifth legs at comers; fourth legs reaching

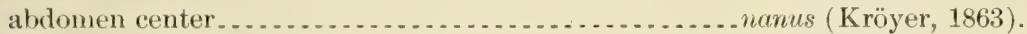

36. (ienital segment acorn-shaped, fourth legs not reaching its center; fifth legs at

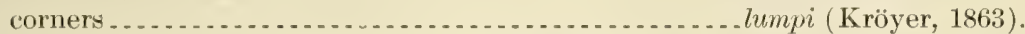

37. Genital segment distinctly more than half the carapace . . . . . . . . . . 38.

37. Genital segment half as long as carapace or less . . . . . . . . . . . . . . . 39.

38. Genital segment oblong; abdomen club-shaped; free segment much longer than

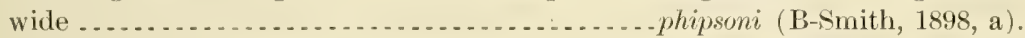

38. Genital segment orbicular, wider than long; frontal plates projecting between the lunules ... . . . . . . . . . . . . . . . hemulonis (Kröyer, 1863), p. 606.

38. Genital segment obcordate, the same length and width; free segment wider than long. . . . . . . . . . . . . . . . . . . . . . . . trachypteri (K röyer, 1863),

39. Genital segment obovate, sides strongly curved; carapace wider than long. cheilodactyli (Kröyer, 1863).

39. Genital segment acorn-shaped, sicles parallel; carapace elliptical; first antennæe hidden .................... . lacustris (Steenstrup and Lütken, 1861).

39. Genital segment acorn-shaped; carapace elliptical; first antennæ large,

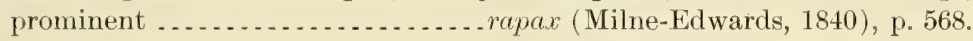

39. Genital segment quadrate; frontal plates wide, lunules large; carapace

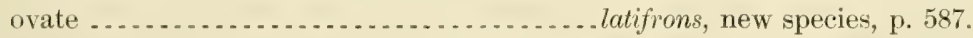

40. (ienital seguent obcordate, posterior lobes large; fourth legs large, stout; fifth

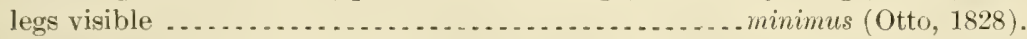

40. Cinital segment tlask-shaped, no lobes, fourth legs short, weak; fifth legs invis-

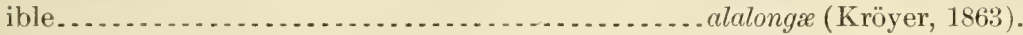

40. Genital segment rectangular, much wider than long, no lobes; abdomen ex-

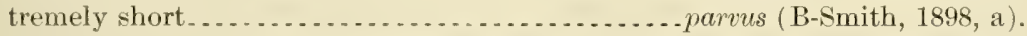

41. Abdomen four-jointed; genital segment wedge-shaped and deeply lobed. coryphanæ (Steenstrup and Lütken, 1861).

41. Abdomen two-jointed, of varying lengths _... . . . . . . . . . . . . . . . 42.

41. Abdomen one-jointed, of varying lengths . . . . . . . . . . . . . . . . . . 54.

42. Abdomen distinctly longer than the genital segment _ . . . . . . . . . . . . . . . 43 .

42. Abdomen about the same length as the genital segment . . . . . . . . . . . . 47 .

42. Abdomen consideraby shorter then the genital segment . . . . . . . . . . . . . . 53.

4i. Males, fifth legs concealed in a dorsal view. . . . . . . . . . . . . . . . . . .

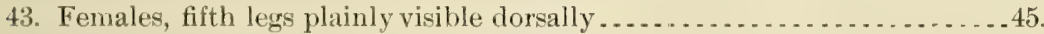

43. Females, fifth legs concealed in dorsal view . . . . . . . . . . . . . . 46.

44. (ienital segment quadrate; first ablomen segment less than half the second.

hirsutus (B-Smith, 1898, a).

44. Genital segment narrow ovate; first abdomen joint twice as long as the second.

trichiuri (Kröyer, 1863).

4i). Genital segment broad ovate; fifth and sixth legs both showing in dorsal view . . . . . . . . . . . . . . . . . . pelamydis (Kröyer, 1863), p. 594.

45. (ienital segment acorn-shaperl; fifth lexs only showing and indistinctly; ablomen twice as long as all the rest of the body _ - macrums (Heller, 1865).

45. Genital segment rectangular, much wider than long; fifth legs only show-

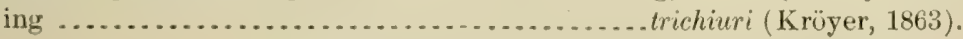


46. Genital segment triangular, much larger than carapace; abdomen longer than rest of body ............................. pharaonis (Nordmann, 1832).

46. Genital segment acorn-shaped; basal abdomen joint three times the terminal. pelamydis (Kröyer, 1863), p. 594.

47. Males, fifth legs not visible in dorsal view ......................... 48 .

47. Females, fifth legs plainly visible in dorsal view . . . . . . . . . . . . . . . . 49.

47. Females, fifth legs concealed in dorsal view . . . . . . . . . . . . . . . . . . 50.

48. Genital segment cylindrical, little wider than abdomen; median carapace lobe projecting its full length behind the lateral lobes. . cossacki (B-Smith, 1898, b).

48. Genital segment obovate, twice as wide as abdomen; median carapace lobe not projecting at all.........................................

48. Genital segment barrel-shaped, three times as wide as abdomen; first abdomen joint the longer . . . . . . . . . . . . . . . . . . . . . . . . . . . . affinis (Heller, 1866').

48. Genital segment oblong-obovate, twice as wide as abdomen; terminal abdomen joint the longer........................... productus (Dana, 1852), p. 597.

49. Genital segment flask-shaped, no lobes; abdomen narrow; joints the same width ............................ diaphanus (Nordmann, 1832).

49. Genital segment obcordate, deeply lobed; basal abdomen joint twice as wide as terminal............................... robustus (B-Smith, 1898, b).

50. Abdomen joints about equal in length .......................... 51.

50. Abdomen joints very unequal in length .......................5. 52.

51. Genital segment acorn-shaped, longer than wide; fourth legs weak, three-jointed. cossacki (B-Smith, 1898, b).

51. Genital segment orbicular, wider than long; fourth legs medium-sized, fourjointed ...................................... torpedinis (Heller, 1865).

52. Genital 'segment oblong, deeply lobed; basal abdomen joint ten times the terminal .................................. arii (B-Smith, 1898, b).

52. Genital segment oblong, slightly lobed; basal abdomen joint three times the terminal ..................................... cybii (B-Smith, 1898, a).

52. Genital segment elliptical, lobes long and very wide; basal abdomen joint three times the terminal ........................ bonito, new species, p. 589.

52. Genital segment flask-shaped, no lobes; basal abdomen joint twice the terminal ........................................ affinis (Heller, 1866).

53. Genital segment elongate-obovate, contracted anteriorly; fifth legs invisible; abdomen joints equal ........................ mutabilis, new species, p. 573.

53. Genital segment broad, acorn-shaped; fifth legs visible; basal abdomen joint three times the terminal ............................. chorinemi (Kröyer, 1863).

53. Genital segment obovate, lobes short; basal abdomen joint four times the terminal ..........................................

54. Abdomen distinctly longer than the genital segment................. 55 .

54. Abdomen about the same length as the genital segment................56.

54. Abdomen considerably shorter than the genital segment. ...............5.

55. Genital segment orbicular, showing both the fifth and sixth legs, female.

stromatei (Kröyer, 1863).

55. Genital segment triangular; only the fifth legs showing; fourth leg spines flattened into laminæ . . . . . . .................... platytarsi (B-Smith, 1898, b).

55. Genital segment obcordate, little wider than abdomen; fifth legs concealed.

hirsutus (B-Smith, 1898, a).

55. Genital segment elliptical, three times as wide as abdomen; fifth legs concealed. productus (Dana, 1852), p. 597.

56. Genital segment elliptical, lobes long and narrow; free segment long and wide. monacanthi (Kröyer, 1863) 607.

56. Genital segment oblong-obovate; lobes short and broad; free segment short, narrow ....... . . . . . . . . . . . . . . . .... productus (Dana, 1852), p. 597. 


56. Genital segment rectangular; no lobes; free segment short and wide. dakari (van Beneden, 1892).

57. Females, both fifth and sixth legs visible; genital segment acorn-shaped.

isonyx (Steenstrup and Lütken, 1861), p. 602.

57. Females, no legs visible on genital segment ............................. 58 .

57. Males, fifth legs concealed; genital segment narrow ovate, well lobed; emarginate posteriorly .............................................

58. (renital segment oblong, four times as wide as abdomen; no lobes; frontal plates projecting .......................... murrayanus (T. Scott, 1894).

58. Genital segment elliptical, twice as wirle as abdomen; no lobes; free segment long, narrow.............................. trachynoti (Heller, 1865).

58. (renital segment narrow obovate, well lobed; free segment short and broad. tenax (Heller, 1865).

58. Genital segment oblong; lobes short, blunt; abdomen club-shaped; freesegment long, narrow . . . . . . . . . . . . . . . ... phipsoni (B-Smith, 1898, a).

CALIGUS RUFIMACULATUS, new species.

Plate V.

Female.-Carapace more than half the entire length, elliptical, distinctly longer than wide, and scarcely narrowed anteriorly (fig. 51).

Frontal plates large and wide, nearly straight along their anterior border, and deeply incised at the center, where may nearly always be found the remains of the frontal filament projecting from the incision. Lunules large, almost circular, and widely separated, but not projecting very much. Posterior sinuses wide and inclined to the central axis, leaving the meciian lobe more than half the entire width and projecting considerably beyond the lateral lobes. Lateral lobes narrow and curved inward at the tip. Free thorax segment small and narrow, not distinctly separated from the genital segment, the dividing groove being little more than a notch in either side, just back of the fourth legs. Genital segment obovate, as wide as long, narrowed anteriorly, with smooth, rounded outlines, and without appendages or setre visible dorsally.

Abdomen short and one-jointed, three-fourths the length of the genital segment and about twice as long as wide; sonewhat swollen at the center into a spindle-shape. Anal lamine large and stout. Egg cases nearly as wide as the abdomen and about as long as the carapace, 35 or 40 eggs in each.

Anterior antenna large and stout, the two joints about the same length and heavily armed with plumose seta and spines. Posterior antenna rather slender, but long, and with the terminal hook sharply bent near the tip); a short and stout accessory spine present posterior to the basal joint. First maxillae small and nearly straight, with a swollen hase. Second maxille also nearly straight and ahout as long as the rostrum; rather stout and blunt and considerably widened at the base. 
First maxillipeds with a rather stout basal joint and the usual slender terminal joint, the two joints in this species being about the same length. The two terminal claws are fringed with hairs and look more like plumose setre than like claws, and there is also a small protuberance on the inner margin near the tip which carries a tuft of hairs. The second maxillipeds have a stout basal joint, but a very weak terminal claw, the tip of which is abruptly narrowed at the junction of the accessory spine on the inner margin. Furca peculiar; branches about the same length at the base, both increasing in width from the center, giving the whole structure somewhat the outline of an hourglass. Branches flattened dorso-ventrally, as wide at the tip as at the base, and considerably divergent; lumen broad, triangular. First legs with three weak terminal claws, a long and slender plumose seta at the posterior corner, and the usual three plumose setæalong the posterior border of the terminal joint. Second and third legs large and stout; the spine on the last joint of the exopod of the second legs is noticeably slender and weak, while that upon the basal joint of the exopod of the third legs is stout and as wide at the tip as at the base. Rami of the third legs well separated, large and prominent. Fourth legs small and weak, not reaching the posterior margin of the genital segment; three-jointed with five spines, the terminal ones graded in length from without inward, the inner one three times as long as the outer. Fifth leg's very rudimentary, scarcely visible in ventral view.

Male.-Carapace the same shape as in the female, but relatively much larger. Free thoracic segment much more distinctly separated from the genital segment and nearly as wide as the latter (fig. 52).

Genital segment very much smaller than in the female, being only a quarter the length of the carapace; fifth legs showing plainly on the lateral margins about one-third the distance from the posterior end. Abdomen little more than half the width of the genital segment and about one-fifth longer; two-jointed, the basal joint less than half the length of the terminal. Anal lamine much larger than those of the female and armed with longer setx. The chief differences in the appendages are found in the second antenne, the first maxillæ, the second maxillipeds, the furca, and the third and fourth swimming legs.

The second antennæ are larger and stouter than those of the female and are branched as is usual in the males of this genus.

The first maxille are fully twice as long as in the female, and are strongly curved, evidently serving as secondary clasping organs. The second maxillipeds are much, enlarged in both the hasal and terminal joints. In the center of the basal joint on the inner margin, opposite the base of the accessory spine, there is a large swelling capped by a small hemispherixal plate with a roughened surface. This aids in the prevention of slipping, and shows that these maxillipeds with the second antenna are manifestly the chicf organs of prehension (fig. 57 ). 

Furca much narrower than in the female, branches close together and nearly parallel, destroying the hourglass outline.

Third legs larger than in the female, attached nearer the posterior border of the carapace, and projecting laterally to the edge of the carapace, and posteriorly to the center of the genital segment. The hasal joint of each is fully as large as the genital segment, and being transparent the longitudinal fibers of the muscles show through plainly and give the central portion a striated appearance. The fourth legs are relatively much longer than those of the female.

Total length, female $3.63 \mathrm{~mm}$.; male $3 \mathrm{~mm}$. Length of carapace, female $2 \mathrm{~mm}$.; male $1.9 \mathrm{~mm}$. Length of genital segment, female 0.84 mm.; male $0.5 \mathrm{~mm}$. Length of aldomen, female $0.65 \mathrm{~mm}$.; male 0.6 $\mathrm{mm}$. Length of egg strings $1.9 \mathrm{~mm}$.

('hulimus.- Carapace considerably more than half the entire length, ovate, strongly narrowed anteriorly. Frontal plates large and well defined. Posterior sinuses narrow and nearly parallel, the median lobe proportionally a little wider and more squarely truncated posteriorly than in the adult (fig. 53).

First antenne large, prominent, and well armed with plumose setæe and spines. Free segment very short, but as wide as the genital segment. The latter is barrel-shaped, one-quarter wider than long with evenly rounded sides and squarely truncated anterior and posterior border's.

The two abdomen segments are about the same relative size as in the adult, but compared with the genital segment they are much wider, in fact almost as wide as the genital segment itself.

The anal lamina are smaller than in the adult and their plumose setie are shorter. The appendages appear about the same with the exception that the second, as well as the third swimming legs show posterior to the carapace in dorsal view. Total length $1.75 \mathrm{~mm}$. Length of calapace $1 \mathrm{~mm}$.; width of the same $0.8 \mathrm{~mm}$. Length of genital segment $0.3 \mathrm{~mm}$. Length of abdomen $0.4 \mathrm{~mm}$.

Color, pale straw yellow. covered on both the dorsal and ventral surfaces with scattered spots of a rusty brown pigment. In some specimens these spots are few in number and not noticeable, but in the great majority of instances they are quite numerous and at once eatch the eye, particularly on the dorsal surface of the genital segment.

(mifus, rust color; maculatus, spotted.)

specimens belonging to this species were obtained by the author from Fundulus majalis and $F$. heteroclitus.

They are more often found upon the former but are not at all common, a careful examination of tive hundred of these minnows yielding barely half a dozen sperimens. The National Museum collection also includes three specimens taken by Vinal N. Edwards, one from a mullet (Mugil apherelus), and the other two from the surface at the Fish 
Commission, Woods Hole. The fact that these two were captured in surface skimmings is an indication that this species swims about freely at the breeding season.

As the measurements indicate they are very small and well suited to parasitism upon such small fish. They are also very transparent and might well have been named diaphanus had not that name already been preoccupied. Consequently it makes an excellent species for study, since the internal anatomy can be plainly seen without dissection, and the small size is to its advantage when examined under a high power. It is a very lively species and moves about freely over the body of its host. Like the Argulus found upon the same minnows, this species occasionally forfeits its life when the fish get hungry, and the author lost a fine lot of males and females which were being kept upon Fundulus in an aquarium, the fish catching them as they were swimming about.

CALIGUS SCHISTONYX, new species.

Plate VI.

Female.-Carapace one-sixth longer than the rest of the body, about as wide as long, ovate, strongly narrowed anteriorly. Frontal plates wide and prominent; lunules large, almost circular, slightiy projecting. Posterior sinuses rather narrow and somewhat inclined to the median axis; median lobe less than half the entire width and projecting but little beyond the lateral lobes; the latter broad and well rounded (fig. 66).

The carapace is very peculiar in its grooving; the thoracic area is almost quadrilateral and is about three-fifths of the length and width of the carapace. From each of its anterior corners a pair of parallel grooves extend diagonally forward and outward to the very edge of the carapace. These grooves are close together and each makes a break in the continuity of the carapace margin. This is the only instance within the author's experience, in which any of the carapace grooves actually reach the margin, and it is very noticeable for that reason.

Taken in connection with the groove along the anterior border of the thoracic area it forms a joint extending the entire width of the carapace and separates the head as completely from the thorax as the latter is separated posteriorly from the abdomen.

The central portion of the thoracic area is raised considerably, leaving a very narrow depressed border around the posterior margin. The line of demarcation between the raised and depressed portions is not parallel with the carapace margin, but on either side forms a straight line inclined toward the central axis and in direct continuation of the posterior of the two inclined grooves already noted. The combination of this line of demarcation and the grooves thus produces a 



trapezium or wedge which stands out very prominently upon the dorsal surface of the carapace, Furthermore, the transparent border surrounding the carapace, instead of being more broadly rounded than the lateral lobe at the posterior extremity of the latter, the condition which prevails in all other species, comes to a sharp point, giving the carapace a peculiar angular appearance.

The free thoracic segment is very short and narrow, about threefifths as wide as the genital segment. Genital segment oblong, with well-rounded corners, half as wide as the carapace, with short and blunt posterior lobes between which the posterior margin is concave. Abdomen four-fifths as long as the genital segment and somewhat less than half as wide; sharply contracted where it joins the genital segment and slightly swollen at the center. Anal papillæ large, well separated, and somewhat eurved inward at the tips, bearing plumose setre which are very long and slender. Egg cases three-quarters as wide as the abdomen and a little longer than the carapace; about 60 eggs in each. Anterior antenne short and stout, the basal joint very plentifully supplied with plumose sete along its anterior and lateral margins; terminal joint club-shaped.

Second antennæ with a stout basal joint reinforced by a short, blunt spine posteriorly; terminai joint long and slender, with an abrupt curve. First maxillæ short, blunt, almost straight, and considerably swollen at the base.

Second maxillie simple, unbranched, nearly as long as the rostrum, slightly curved if at all, and acuminate.

First maxillipeds with a stout basal joint and a long slender terminal joint; the inner terminal claw twice the length of the outer; a short spur on the inner margin of this joint near the distal end. Second maxillipeds with a stout and swollen basal joint and a very weak and slender terminal claw, the disproportion between the two being quite noticeable.

The claw is only half the length and not more than one-fifth the width of the hasal joint, and its terminal portion beyond the base of the accessory spine is scarcely larger than the spine itself. The inner margin of the hasal joint is raised into a slight knob opposite the base of the accessory spine, but the flimsy little terminal claw does not look as though it could hold down very much against this knob. Furea long and narrow, with branches about the same length and width as the baval portion; considerably narrowed at the center, like an hourglas.s. The divergent branches curve inward toward each other, while the sides of the hase curve outward away from each other, but only slightly in either ase. Often the branches are somewhat swollen at the tips.

The first legs are short and stout, with two spines on the posterior border of the basal joint and a single small spine at the distai end of 
the second joint, at the anterior corner. The terminal claws on these legs are peculiar in that they are all three biramose, the division extending well beyond the middle of the claw. Of the two branches the endopod is nearly straight, while the exopod is strongly curved. Furthermore, the appendage at the inner corner, between the terminal claws and the posterior plumose setæ, instead of being a smaller plumose seta, as is usually the case, is here a long and stout claw, unbranched and curved over strongly ventrally (fig. 75).

This peculiarity of the terminal claws has given the species its name. The other legs are like those ordinarily found on Caligus. The spines upon the last two joints of the exopod of the second legs are very small and insignificant, while that upon the basal joint of the exopod of the third legs is large and stout. The rami of these third legs are widely separated and the endopod has but a single joint.

The fourth legs are very slender and weak, three-jointed, with the basal joint as long as the other two. The second joint has a spine at its distal end and another small one on its outer margin. The terminal joint has the usual three terminal spines, of which the inner one is fully twice as long as the second, and a small spine on its outer margin.

The fifth legs are so far reduced as to be invisible except by very careful scrutiny upon the ventral surface.

Male.-The sides of the carapace are not arched as in the female but are nearly straight lines, and the anterior contraction is much more decided. The posterior sinuses are a very broad U-shape, throwing the tips of the lateral lobes outward away from the median lobe. This, together with the sharp angles of the transparent border, gives the carapace a marked trapezoidal form, the anterior and posterior sides parallel, the former only two-fifths the length of the latter, while the right and left sides are equally inclined. The trapezoid formed upon the dorsal surface by the grooves between the different areas is the exact reverse of this formed by the margin, and is not as clearly defined as in the female. The thoracic area is more nearly semicircular in outline than quadrilateral (fig. 65).

The large basal joints of the third legs project from either side of the median carapace lobe and do not orerlap the lateral lobes, nor even reach them. The genital segment is very small, scarcely wider than the abdomen, as wide as long, with evenly rounded sides. The fifth legs appear as very small papilla upon the lateral margins near the posterior end of the segment. The abdomen is two-jointed, the joints of the same diameter but the terminal one four times the length of the basal.

Anal papillæ very large and foliaceous, with long and slender plumose setæ.

The only appendages which are at all worthy of special mention are 


the second antennie and the second maxillipeds. The second antennæ are very much enlarged and three-jointed. The two basal joints are stout and swollen, while the terminal joint is considerably smaller and terminates in a short, stubby claw. The ventral surface of the second joint is parted for a little distance from the distal end by a deep groove, which, starting at about the center of the distal margin, curves around inward in a broadsweep and disappears quickly upon the ventral surface. Along either side of this groove the chitin integument is raised in transverse folds whose anterior edge overlaps the posterior one of the fold next in front, thus giving a rasp-like surface which must be of great aswistance in the prevention of slipping. The line of folds along the inside of the groove extends backward, following the sweep of the groove, across the ventral surface to the proximal end of the joint. The folds along the outer side of the groove stop with the groove itself. The terminal joint is exceptionally peculiar. It is about as wide as long and consists essentially of a very stout claw which is blunt and strongly curved at the tip. But upon the ventral surface of this claw near the posterior margin are two stout accessory spines, each arising from a raised base. And in the center of the basal portion of the claw is a circular, raised area with its surface thrown into longitudinal ridges or folds, which project considerably. This, like the rasp-surface on the second joint, must assist in obtaining a firm hold, and are the more needed in the male since these antennæ are used for clasping organs.

The second maxillipeds are much larger than those of the female hut ot herwise like them, and they evidently serve as accessory clasping organs.

Total length of female $4 \mathrm{~mm}$.; length of carapace $2.1 \mathrm{~mm}$.; width $2.1 \mathrm{~mm}$.: length of genital segment $1 \mathrm{~mm}$.; length of the abdomen $0.5 \mathrm{~mm}$.; length of egg-strings $3.5 \mathrm{~mm}$. Total length of male $3 \mathrm{~mm}$.; length of carapace $1.75 \mathrm{~mm}$; wilth $1.66 \mathrm{~mm}$.; length of genital segment $0.4 \mathrm{~mm}$. ; length of abdomen $0.62 \mathrm{~mm}$.

color a dark yellow, inclining toward brown in many specimens. (schistrmyx, $\sigma \chi i \xi \omega$ to cut or divide, and "ovvE a claw.)

The National Museum collection includes five lots from the common

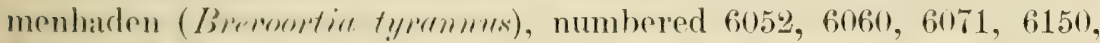
615. (Of these, the first three contain but a single female each, while the last two contain thirteen specimens, two of which are males. They were all obtained from the outside of the body. There is a single female. numbered 6151, from the outside surface of the blue-fish (Imurefomms sulfutrir), and nine lots obtained from the tow. Of these

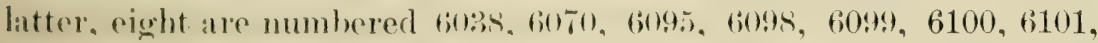
8111, while the ninth is without a number. The first of these lots contains four males, the other cight lots are made up of a single specimen each and evenly divided between the sexes. 
This distribution shows two facts rery plainly. First, the menhaden is evidently the host of the species, the presence of a single specimen on the blue-fish being easily explained by the fact that the latter feeds upon the menhaden. And then such a large percentage taken in the tow indicates that this species is very active, as much so as $C$. rapax, although its hosts are nowhere near as numerous as those of the latter species.

There is also a strong suggestion that these parasites are not likely to change their depth very materially; those which frequent surface fish stick to the surface even when they are swimming about freely. And probably the same can be said of those which are parasitic on fish that frequent the botttom.

This species is not very abundant, as the paucity of specimens clearly shows. As they were all taken in the latter part of August and the first of September, this period is probably the height of the breeding season.

The species can be recognized easily by the sharp angles at the posterior corners of the carapace and the general trapezoidal appearance of the latter. The diagnosis can then be verified by an examination of the claws at the tips of the first swimming legs.

\section{CALIGUS RAPAX Milne Edwards.}

Plate VII, figs. $3,7,9,10,18,22,23,26,32,36,46,47,48,49,50$ in the text.

Caligus elongatus Norduann, 1832, p. 24.

Caligus elongatus KRöY ER, 1837, p. 201.

Caligus rapax Milne Edwards, 1840, p. 453, pl. xxxviII, figs. 9-12.

Caligus elongatus Milne Edwards, 1840, p. 454.

Caligus leptochilus Frey and LeUckart, 1847, p. 165.

Caligus rapax Baird, 1850, p. 270, pl. xxxir, figs. 2 and 3.-White, 1850, p. 119.-Steenstrup and Lütken, 1861, p. 359, pl. II, fig. 4.-KröYer, 1863, p. 71 - Olsson, 1868 , p. 8.-Macintosh, 1874, p. 262.-Sмith, 1874, p. 575 .Richiardi, 1880 , p. 148.-Bassett-Smith, 1896 , p. $156 ; 1899$, p. 448.-Brian, 1898 , p. 10 , pl. II, fig. 6 ; 1899 , p. 2.-T. Sсотт, 1900 , p. 148, pl. v, figs. 13-19.

Female.--Frontal plates wide; frontal margin slightly rounded; lunules large, orbicular, and projecting considerably. Carapace ovate, longer than wide; posterior sinuses narrow, of medium depth, and with approximately parallel sides; thoracic area broad, three-fifths of the entire width, well rounded, and projecting posteriorly about the depth of the sinuses beyond the lobes; lobes narrow, short, slightly wider at the tips (fig. 79).

Free thorax segment very short, only three-tenths as wide as the carapace. Genital segment large, more or less quadrilateral, with rounded corners, slightly wider than long, seven-tenths the width of the carapace. Abdomen unsegmented, varying considerabiy in length (from 0.5 to 0.8 the length of the genital segment), about half as wide as the genital segment; anal sinus scarcely perceptible; anal laminæ of 


good size, terminated by one short and three long plumose setæ, the longest about three times the length of the laminæ.

First antenne large, their tips nearly equaling the extreme width of the carapace; terminal segment about the same length as the basal, one-quarter as wide as long.

Second antennæ close together and rather weak, with a small supplementary hook on the posterior margin of the basal joint. Mouth with a somewhat quadrilateral opening fringed by long setx; margin of the upper lip incised at the center; mandibles stout, strongly curved, and toothed along their inner border.

First maxillæe small, short, and slightly curved; second maxillæ slender, nearly straight, and acuminate.

First maxillipeds with a very slender terminal joint about half as long again as the basal joint, the two curved claws at the tip very unequal. Second maxillipeds fairly stout, the basal joint and the terminal claw of about the same length, the latter with a small curved spine on its inner margin.

Of the swimming legs the first pair is three-jointed; the basal joint is swollen and armed with two spines on its outer margin, and a chitin plate carrying a spine on its posterior margin.

The plate is transversely elongated and has a large blunt projection near its distal end.

The fourth swimming legs are three-jointed; the triangular second joint terminates externally in a long spine; the terminal joint has a stout spine on its external margin, and three long and one short (the inner) spine at the tip.

Total length $5-7 \mathrm{~mm}$. Length of carapace $2.6-3.6 \mathrm{~mm}$.; length of genital segment $1.5-2.2 \mathrm{~mm}$. ; width of carapace $2.4-3.4 \mathrm{~mm}$.; length of abdomen 1-1.5 mm.; length of egg-strings $2.6-3 \mathrm{~mm}$.

Nule.-Carapace about as broad as long and relatively wider anteriorily than in the female; the posterior sinuses are also much wider and their sides are flaring instead of parallel. The thoracic area is only one-third the width of the carapace, and it scarcely projects posteriorly at all; the lobes are much wider than those of the female and are well rounded. The free thoracic segment is considerably longer and narrower than in the female, while the genital segment is pearshaped. only one-third the width of the carapace and well rounded posteriorly. The abdomen is about the same length as the genital segment, two-jointed, with the first joint one-third as long as the second (fig. 80).

The anal lamina are long and large, and are attached to the outer posterior corners of the abdomen; the plumose seta are fully twice as long as in the female.

On the ventral surface the second antenne and second maxillipeds are stouter than in the female, and the small spine on the side of the 
latter is much larger. In the fourth swimming legs the terminal joint is longer, and the spines and setre differ slightly in their relative length and arrangement. In both the male and female the bases of these spines are reinforced by semicircular plates fringed with small hairs.

Total length 4-5 mm. Length of carapace $2.35 \mathrm{~mm}$; width of same $2 \mathrm{~mm}$. ; length of genital segment $0.75 \mathrm{~mm}$; length of abdomen $1 \mathrm{~mm}$.

Nauplius larva.-Body elliptical, widest at about the center; width to the length as 3 to 5 . Appendages projecting far beyond the body margin and typical in form (fig. 36, p. 536).

First antennæ uniramous, terminating in two plumose setæ; second antennæ and mandibles biramous; exopod four-jointed, endopod twojointed; each joint of exopod bearing a long plumose seta, while the terminal joint of the endopod carries two setæ.

The median eye is placed very far forward and concealed beneath a spot of pigment. The anal setre are flattened spoon-shaped, of good length, and they project sidewise from the body instead of diagonally backward. The color is a pale yellowish, with rust-colored pigment distributed in five spots, a small area over the median eye anteriorly, a large area on either side at the center, and a small area on either side just in front of the anal setæ or balancers. The pigment is comparatively faint and scarcely appears under a low power as it does in other species. The anterior half of the body is very transparent and shows the internal structure plainly. Total length, $0.4 \mathrm{~mm}$. Width, $0.23 \mathrm{~mm}$.

Chalimus stage.-Carapace elongate-ovate or spindle shape, narrower anteriorly; frontal plates narrow and inclined backward along the front margin of the carapace. Posterior lobes small, turned inward strongly, and with scarcely any sinus; posterior margin of carapace squarely truncate. Eyes a little behind the center of the carapace, large and prominent; frontal gland very large and occupying the whole of the anterior angle of the carapace. Free segment much larger than in the adult, one-third the length, and more than half the width of the carapace, its sides strongly convex. Genital segment and abdomen at first fused and about the same width as the free segment, but separating with the first moult, the abdomen several times the larger. Anal laminæ short and wide, and projecting diagonally sidewise rather than straight backward; the plumose setre very short and stout. Both pairs of antenne and all the mouth parts present but somewhat rudimentary, especially the second antennæ, whose terminal joint is little more than a small spine on the tip of the large basal joint (figs. 46-50).

The first two pairs of swimming legs are the only ones developed in early chalimus stages, and they are worthy of notice from the fact that the first pair is hiramose; but the endopod is made up of a single joint, which is very small and quickly disappears. Color the same as 

that of the adult, except that the pigment spots are much fewer in number and more widely separated. Length $2 \mathrm{~mm}$, increasing gradually to $3.5 \mathrm{or} 4 \mathrm{~mm}$. Width of carapace $1 \mathrm{~mm}$., increasing to $2 \mathrm{~mm}$. Width of free segment $0.55 \mathrm{~mm}$, length $0.55 \mathrm{~mm}$. Length of abdomen $0.8 \mathrm{~mm}$.

\section{(rapax, rapacious, greedy.)}

This is the most common species of the genus on the northeastern coast of the United States, having been taken from more than twentyfive different kinds of fish by many collectors working in the interests of the United States Fish Commission.

The author, following the example of Mr. Richard Rathbun, as expressed in some very valuable manuscript notes, the substance of which is here presented, has been liberal in his interpretation of specific chararters. In consequence, there are included under this species individuals which some investigator's would probably subdivide into several lots. But after a very careful comparison the differences observed are really too obscure to be of much value for classification. The variation does not extend far in any one direction, and there is comparatively little difference in size. The detail of the appendages agrees very closely in all the specimens, and careful comparisons have been made in every instance with authentic specimens from Europe. Specimens from the mackerel present perhaps the most marked differences in structure, but they vary among themselves and many are perfectly normal. These differences concern chiefly the fourth pair of legs. Sometimes the second of the terminal spines, counting from the proximal end of the terminal joint, is wanting. Again, the ultimate and penultimate joints are relatively shorter and stouter than in normal specimens; or the three successive spines on the outer margin may orerlap one another; or the fringed disks at the bases of these spines may be so little developed as to be overlooked. In specimens from other fish the furca may have shorter and stouter branches, while on the common flounder individuals may be found with the abdomen so much shortened as to appear like those of $C$. curtus. But in all these instances the other appendages are perfectly normal, and it does not seem as if these differences were worthy of creating even a well-marked variety, to say nothing of a distinct species.

They must be mentioned, however, to show that they have been noted and given the proper attention.

Both sexes are usually found upon the same fish and occur anywhere upon the external surface, often showing a preference for the pectoral fins. Upon the flounders and skates they are commonly on the upper or pigmented surface, but also occur on the unpigmented rentral surface. Here again, as in the case of the Arguli, when we reflect that these fish frequent the bottom, and that they often bury themselves in the sand or mud, we can appreciate better the effectiveness of a 
prehensile apparatus which holds the Caligus securely to its host, even in the presence of so much friction.

Of course the color of the Caligus harmonizes better with the pigmented side of the fish; on the under surface the copepod stands out in strong contrast with its surroundings.

The egg strings in this species are comparatively short, and this gives the female greater freedom of motion. Both males and females are more lively than most species, and they manifest this activity frequently by leaving their host and swimming about freely. This happens more often at night than during the daytime, and several investigators have recorded the capture of both sexes in the tow along with free forms.

Such a habit possibly helps in explaining their presence upon so many different kinds of fish. Many of the latter, no doubt, are mere temporary makeshifts to tide over a necessary interval and to keep the copepod supplied with food until it can return to its regular host.

Associated with its distribution among so many hosts is a considerable variation in the color pattern. Most specimens have a pale orange tint and are more or less transparent, but it can be readily seen that those obtained from dark fish or from the darker pigmented surface are themselves of a deeper color and more opaque than others from light fish or from a nonpigmented surface. The difference is due to an increase or decrease in the number of pigment spots and not to any fundamental change in the pigment itself. Each spot consists of an uniformly colored center as if washed in with water color, and long irregularly radiating filaments. The spots are thickest along the margin of the carapace where the filaments are interwoven into a dense, narrow band, close to the margin. Similar but much wider bands are found along the sides of the genital segment and the abdomen. There is also a spot of pigment just dorsal to the furca, and another upon either side on the basal lamina of the third pair of legs, showing dorsally between the carapace and abdomen. The frontal plates, the region over the eyes, the whole of the thorax, including the segments fused with the head, and the center of the genital segment and abdomen are ordinarily free from pigment.

This species has been secured from the following fish on the North American coast, mostly by the United States Bureau of Fisheries. The numbers are those given to the separate lots in the National Museum. From the common flounder (Iseudopleuronectes americanus), lots 1267 and W. 18; from the four-spotted flounder (Paralichthys oblongus), lot 12607; from the cod (Gadus morltua), lots 8112, 8115, 12635, 12636, $12638,12640,12641,12662,19893$; of those collected and numbered by Vinal N. Edwards, V. N. E. $1405,1412,1413,1417,1420,1423,1462$, 1466 ; of those collected and numbered by the author, W. 8, 10, 16, 22; from the haddock (Melanogrummus rglefinus), lots 12611, 12626, 12640, 


and W. $x$; from the pollack (Iollechins rirens), 12609, 12625, W. 1, 5, and 8; from the hake (Uropleycis clurss), 12628, 12640, W. 2 and 23; from the hake (Uropluycix temuis), 6094, 6161, 6165; from the lumpfish (cycloptems lumpus), 12617; from the mackerel (Scomber scombrus), 12620, 12621, 12622; from the scup (Stenotomes chrysops), 12630, W. 21); from the striped bass (Rrecus lineatus), 12613; from the alewife (c'lupere vernulis), 12624; from the sturgeon (Acipenser sturio), 12623, W. 21; from Acipenser brevirostmen, 12610, 12615, 12618, 12629; from the sting ray (Dusyatis centmra), 6188; from the skate (Raic lixvis), $6163,12618,12633,12637,126 \pm 2,12643$; from Raia ocellate, 6065, 6104, 6112; from Revire erinacet, 1399, W. 14 and 24; from the spiny dogfish (Squelus acenthices), 12639; from different sculpins, 8114; from the whiting (Menticimplus saxatilis), 6164; from the shad (Alosa sapidissima), 12612; from the swordfish (Xiphias gladius), W. 12; from the rudder fish (Tiyphoses sectatrix), taken in floating gulf weed, W. 11; from the sand shark (Carcharias littoralis), W. 9; from the remora (Remorn remora), W. 13; from the crevalle (Caranx crysos), W. 15; from the cutlass fish (Trichium lepturus), W. 19; from the sand launce (.1mmorlytes (mericunus), one unnumbered lot. There is also a single specimen of the chalimus stage still attached to a small Monacanthus and numbered W. 20. Other specimens of the chalimus are numbered 6110, 6148, 6191, and W. 1. From the surface were obtained lots $6097,6197,8110,12614,12616,12619$, and $W .3$, some of which contain several specimens. The National Museum also possesses a fine series of specimens from the Durham coast, England, contributed by the Rer. A. M. Norman, numbered 12906. These have been taken as the types of the species, and with them all the American forms have been carefully compared.

\section{CALIGUS MUTABILIS, new species.}

Plate VIII, fig. 2 in the text.

Frmall.-Carapace about three-sevenths the entire length, as long as wide, not narrowed anteriorly. Frontal plates well defined, but less than half the width of the carapace; lunules large, circular, and projerting. Posterior sinuses wide and slightly inclined away from the entral axis. Median lobe much less than half the entire width and projecting only a little beyond the lateral lobes; the latter blunt and well rounded (fig. 90).

Thoracic area medium size, the anterior groove almost a perfect simicircle. Free thorax segment short and narrow, about one-fourth the width of the carapace, and contracted into a much narrower neck just in front of the bases of the fourth legs. Genital segment rery variable, aceording to the age of the individual as well as the developmental stage of the eggs. In young females and in the adults before 
the protrusion of the egg cases this segment is a broad flask shape, a little wider than long, with well-rounded sides, and a squarely-truncated posterior border. Its width under these conditions is fully threefourths that of the carapace and sometimes more.

But after the protrusion of the egg cases it assumes an elongated spindle shape, wider posteriorly, and with a somewhat emarginate posterior border. In this condition it is about one-fifth longer than wide and narrows toward either end, its extreme width being less than twothirds that of the carapace.

It is always contracted into a short, narrow neck where it joins the free segment, and is wrinkled across this neck as though segmented. The abdomen is short, but little more than half (0.64) the length of the genital segment in females with egg cases, and about one-third its width. It is two-jointed, the joints approximately the same length, but the anterior one a little wider.

Anal laminæ small, well separated, and somewhat curved in toward each other. Egg cases short, half the length of the body, but about as wide as the abdomen, and each containing 50 eggs.

Anterior antennæ short and closely appressed to the carapace; posterior antennæ stout, with a swollen basal joint bearing an accessory spine and a strong terminal hook.

First maxillæ medium size with a blunt point and an enlarged base; sacond maxillæ very long and slender with an acuminate point. First maxillipeds with an exceptionally stout basal joint, which is fully three times the diameter of the terminal joint, this latter being the usual weak type, a little shorter than ordinary and tipped with two strongly curved claws. Furca a rounded $Y$-shape, the base being the same length as the branches, but much narrower, while the branches are stout, blunt, and strongly curved. First swimming legs short and stout, with the usual terminal claws, the small seta at the corner, and the three large plumose setæo on the posterior margin of the terminal joint. But these plumose setæ differ from those in most species in that the basal third is swollen in diameter and bordered not by plumose hairs like the tip, but with spine-like projections. The seta nearest the distal end has them on the outer margin only; the middle seta has about half as many on the inner as on the outer margin, while the inner seta has them on both margins equally.

The basal joint of the second legs is very much swollen, while the two branches are short and stout. The spines on the endopod are slender and acuminate. The rami of the third legs are large and stand out prominently from the edge of the basal lamina. The spine at the base of the exopod is also large, well curved, and blunt. The fourth legs are short and weak, not reaching to the center of the genital segment, three-jointed, with five spines of about the same length situated close together along the outer margin. The two terminal joints are 


about the same length and diameter as the basal joint. At the bases of the spines are small semicircular lamine fringed with hairs like those in c. rapare and several other species. The fifth legs are not visible dorsally.

Total length $5.6 \mathrm{~mm}$. Length of carapace $2.3 \mathrm{~mm}$.; width of carapace $2.2 \mathrm{~mm}$.; length of genital segment $1.9 \mathrm{~mm}$.; length of abdomen $1.1 \mathrm{~mm}$.; length of egg tubes $2.5 \mathrm{~mm}$., 50 eggs in each.

Male.-Carapace a little more than half the entire length, longer than wide, otherwise similar to that of the female (fig. 91).

Free thorax segment bearing the same relation to the carapace as in the female, but being wider than the genital segment, owing to the diminution of the latter.

Genital segment a very nariow spindle shape, less than one-fourth the width of the carapace, and three fifths as wide as long.

It is wrinkled where it joins the free segment just as in the female, but is narrowed almost none at all, for it is already much narrower than the genital segment in consequence of its spindle shape. Abdomen the same length as the genital segment and two-thirds as wide, made up of two joints, of which the anterior is considerably shorter than the posterior and subspherical in shape. Anal laminæ very large and foliaceous. Appendages as in the female except that the posterior antenne are branched, while the first maxillæ are elongated into a long, slender hook, evidently used in prehension. The second maxillipeds are enlarged and form the chief organs of prehension. The fourth legs are relatively large and overlap somewhat the basal joint of the abdomen.

Total length $3.4 \mathrm{~mm}$. Length of carapace $1.85 \mathrm{~mm}$.; width of carapace $1.7 \mathrm{~mm}$.; length of genital segment $0.7 \mathrm{~mm}$.; width of same $0.43 \mathrm{~mm}$.

Color a light horn yellow, delicately pencilled with pigment spots of pink and red, which are most prominent along the central axis of the carapace and in the posterior lateral angles.

(mintulilix, changeable, referring to the shape of the genital segment at different times.)

This species angees some what with a variety of $C$. gumardi figured by Kröyer (1s(i⿱⺈, pl. II, fig. $3, g)$, hut the carapace is proportionally shorter and broader, the lunules are larger, and the furea is much more slender. The species irrituns described by Heller (1865, p. 177, pl. $x y$, figs. 7 and s) has similar large lunules, but a much narrower carapare and a very different furca. The species isony, steenstrup and Lütken (1sti1, p. 358, pl. mi, fig. 5), has very much the same proportions, but differs markedly in structural details.

It can be readily distinguished from other American forms by the simple fact that it is the only one having the abdomen about the same length as the genital segment and two-jointed. 
It is not a rery lively species, and thus far has a limited number of hosts. The National Museum collection includes several lots of specimens taken at different times, but all, with two exceptions, from similar hosts-the sea basses. As the scientific name of the host is not recorded in most of the instances, it can not be determined whether these hosts were all the same species or not. Lot 6155 , consisting of ten males and females from the mouth of Centropristes striatus, is taken for the types of the new species. There is another lot, 6119 , from the mouth of a "sea bass," and six unnumbered lots, all from the mouths of "sea bass" at or near Woods Hole, except a single female from the mouth of a pollock and another from the mouth of a bonito.

\section{CALIGUS ALIUNCUS, new species.}

Plate IX.

Female.-Carapace ellipitical, one-fifth longer than wide. Frontal plates distinct and very wide, not emarginate at the center; frontal margin nearly straight. Lunules large, semicircular, prominent. Posterior sinuses narrow and quite deep, leaving the median lobe nearly two-thirds the entire width; lateral lobes narrow and curved inward. Thoracic area very large, half the length of the carapace and more than two-thirds of the width (fig. 103).

Free thorax segment transversely linear, nearly as wide as the genital segment, but very short. Genital segment quadrangular, twofifths as long as the carapace, a little wider than long, with short and blunt posterior lobes.

Abdomen one-fifth shorter than the genital segment, but more than half as wide, made up of four segments, of which the two end ones are about equal and considerably larger than the middle ones.

The terminal segment is deeply hollowed on either side posteriorly for the reception of the small, lateral anal laminæ.

These latter are nearly spherical and do not reach beyond the tip of the abdomen; they each carry three long plumose setæe posteriorly and a much shorter one on the outer margin.

Egg cases narrow, scarcely more than one-third as wide as the abdomen; eggs small and numerous.

The first antennæ are a little longer than the frontal plates, the two joints about the same length, but the terminal one very much the narrower. Second antenna short and stout, with a broad terminal claw and no accessory spine. No trace could be found of the first maxillæ. Second maxillæ stout, broadly triangular, and nearly as long as the mouth tube.

'The latter is broadly U-shaped, a little more than half as wide as long, and abruptly rounded at the tip.

Furca $Y$-shaped, the base longer than the branches and considerably constricted; branches thick, blunt, and divergent. 


Claw of the second maxilliped less than half the length of the hasal joint, slender, and strongly curved at the tip.

First thoracic legs tipped with the usual three claws but lacking the seta at the inner distal corner between the three terminal claws and the three posterior setie. The claws are short and stout, all of the same length, and all fringed on either side from the base nearly to the tip with a lamina or wing which is sharply serrate (fig. 109). Second legs ordinary, save that the large spines upon the exopod are each fringed with a serrate wing like those on the claws of the first legs. Rami of the third legs quite widely separated; claw on the exopod very large, nearly straight, and with a wide, nonserrate wing along either side, giving it a broadly spatulate outline.

Fourth legs large, reaching about to the posterior margin of the genital segment, four-jointed, with the usual five spines; but the spines upon the second and third joints are much larger and longer than usual, and, together with the three curved terminal spines, are fringed with a wide serrate wing along either sicle from the tip nearly to the hase. There is in addition a peculiar appendage upon the onter distal margin of the basal joint. This consists of a thread-like or whip-like projection longer than the second joint, very pliable, and apparently muscular rather than chitinous. It is tipped with a long plumose seta and is evidently tactile, but what other function it may serve is a question. The fifth legs are situated just ventral to the hases of the egg cases, are very small, and do not project beyond the posterior border of the genital segment.

Total length $7 \mathrm{~mm}$. Length of carapace $4 \mathrm{~mm}$.; width of same 3.3 mm.; length of genital segment $1.5 \mathrm{~mm}$; width of same $1.7 \mathrm{~mm}$; length of abdomen $1.23 \mathrm{~mm}$. Egg strings broken so that their length can not be determined.

Unfortunately there is but a single specimen - a female-as the exponont of this species. This specimen was taken at the surface under the attraction of an electric light. The label is one of the United Sitates Bureau of Fisheries steamer Albutrose labels, but no locality is griven. But the specimen differ's in so many particular's from other speries of culigus as to leare no douthe of its validity. There is only onr other species of caligus known, (. comyphene, in which the abdomen has four joints, and in that species the size and proportions of the free and genital segment are entirely different. The winged margins on the claws and spines is anotber distinctive feature, and is the one which has suggested the specific name.

(aliuncus-ala, a wing, and uncus, a claw.) 


\section{CALIGUS CURTUS Müller.}

Plate X, figs. $8,24,28$ in the text.

Caligus curtus MÜLleR, 1785, p. 130, pl. XXI, fig. 1.-SMITH, 1874, p. 575.-RATHBUN, 1884, p. 486.

Caligus mulleri LeACH, 1816, p. 405, pl. xx, figs. 1-8.—DANA, 1854, p. 1352.

Caligus bicuspidatus Nordmann, 1832, II, p. 17.

Caligus americanus Pickering and Dana, 1838, p. 65, pls. III, iv, v.-Dana, 1854, pl. XCIII.

Caligus diaphanus BAIRD, 1850, p. 269, pl. xxxII, fig. 1.

Caligus elegans van Beneden, 1851, p. 91, a male.

Female. - Carapace somewhat longer than the rest of the body, obovate. Frontal plates distinct, the anterior margin well rounded and incised at the center. Lunules large and circular, not very widely separated and not projecting. Posterior sinuses narrow, shallow, and with nearly parallel sides; the median lobe less than half the entire width, projecting for two-thirds of its length beyond the lateral lobes; the latter broad and well rounded (fig. 113).

Thoracic area quadrilateral, comprising about one-third of the carapace; its anterior groove nearly straight. Eyes small and situated far forward. Free segment short and very narrow, not more than half the width of the genital segment, and spindle-shaped. Genital segment oblong, half as long as the carapace, with parallel sides and wellrounded corners. There are no lobes on this segment and the fifth legs are not visible dorsally. Abdomen short, half as long as the genital segment, often slightly swollen at the center. Anal lamina rather small with very long setæ; egg strings wide and about as long as the entire body.

Anterior antennæ large, the basal joint much longer and wider than the terminal and both joints plentifully supplied with setæ and spines. These antennæ stand out very prominently from the carapace. Second antennæ stout, with a long accessory spine on the inner border of the terminal claw, near its base.

First maxillæ of good size and situated close to the edge of the carapace, the terminal portion strongly curved and the base considerably swollen. Second maxillæ broadly triangular with curved sides, abruptly narrowed near the tip into an acuminate spine. This represents the endopod of the appendage, while upon the ventral surface of the base of the triangle is the rudimentary exopod, consisting of a long, slender spine and three or four small setæ. This exopod is articulated with the base of the endopod and is capable of considerable motion.

The mandibles are curved inward and dentated along the inner edge, the number of teeth being about fourteen.

First maxillipeds very slender and weak, the terminal joint much longer and narrower than the basal, with a short spine on its inner margin near the distal end. The two claws at the tip of these append- 


ages are doubly edged with a finely pectinated membrane. Second maxillipeds large and stout, the basal joint much swollen and at least a third longer than the terminal claw. Furca short and very stout, the base longer than the branches, which are straight and slightly divergent, the same diameter throughout and very blunt at the tips.

Of the swimming legs the three terminal spines at the tip of the first pair are short, obtuse, and about the same length.

The seta at the outer corner is also short and naked; the plumose setre on the posterior margin are large, with very short pinnules on the outer margins, but of the usual length on the inner.

The rami of the third leg's are large, well separated, and closely approximated to the margin of the basal apron, the claw at the base of the exopod being of medium size and rather blunt.

The fourth legs are three-jointed, with four spines, one at the extremity of the second joint and three at the tip, all well curved. The first three are small and of approximately the same size, the fourth (the inner terminal) one is nearly three times as long and toothed on its outer margin. The two short terminal spines are edged along either side with a pectinated membrane. There is also a short semirircular membrane with a sharply serrated margin projecting like an epaulette over the base of each of these three spines.

The fifth legs are so small as to be invisible dorsally. Total length s-12 mm. Length of carapace $6.1 \mathrm{~mm}$.; width of same $5.9 \mathrm{~mm}$; length of genital segment $2 \mathrm{~mm}$.; length of abdomen $1.2 \mathrm{~mm}$.; length of egg strings $14 \mathrm{~mm}$.

Color a uniform transparent horn color, often marked in older individuals with numerous dendritic delineations of an ocher yellow. A short time after death the copepod assumes an entire change of color, becoming a deep rose red. This new color is disposed in dendritic delineations corresponding to those of the ocher yellow and in all probability the yellow is changed into the red during dissolution (curtus, shortened.)

Mule.-Carapace hroad orate, as wide as long, strongly narrowed anteriorly. Posterior sinuses inclined toward the central axis; median lobe wider than in the female; lateral lobes plump and well rounded. Free segment as wide as the genital segment, but with the same spindle shape as in the female. Genital segment orbicular with well-rounded sides and posterior margin, a trifle wider than long, with the fifth legs showing prominently at the posterior corners. It is much smaller than in the female, being only one-third the length of the carapace.

The abdomen is a little longer than the genital segment, contracted whore it joins the latter, and considerably swollen at the center. Anal laminæ very large and foliaceous (fig. 112).

Of the appendages the second antenne and second maxillipeds are the only ones requiring special mention. 
The second antennæ are much longer than in the female and threejointed; the basal joint is broad and oblong and is attached to the ventral surface by its long posterior side. At its inner extremity it turns upward to receive the following joint. The secoud joint is broad and well rounded; its entire inner and ventral surface is covered by a swollen pad formed of chitin ridges overlapping one another like clapboards on a house, giving an admirable rasp-like surface for the prevention of slipping (fig. 123).

The terminal joint is obliquely articulated with this second joint and is much smaller and shorter. It terminates in two stout claws, widely divergent and quite strongly curved.

There is a slender seta on the outer margin and another on the inner surface near the base.

The second maxillipeds are much enlarged, the basal joint being swollen with a width considerably more than half its length (fig. 124).

The terminal claw is less than half the length of the basal joint, but is stout and furnished with powerful muscles. Its tip shuts into a socket formed at the base of a large spine on the ventral surface of the basal joint, affording a strong grip. Between this spine and the base of the terminal claw there is another shorter and smaller spine with an acuminate tip. This shuts in past the side of the terminal claw when the latter is closed and thus strengthens the bold. The other appendages are like those in the female.

This species is one in which the males are larger than the females, as can be seen in the following measurements:

Total length 13-20 mm; length of carapace 7.5-12 mm.; width of same 7.4-11.5 mm.; length of genital segment 2.5-4 mm.; length of abdomen $2.5-4 \mathrm{~mm}$.

Chalimus, later stages.-Carapace narrow ovate, much longer than wide, about 0.64 of the entire length, contracted considerably through the frontal plates. Posterior sinuses narrow and slit-like; median lobe projecting nearly its entire length behind the lateral lobes (fig. 115).

Posterior portion of the body very narrow and of nearly the same diameter throughout. Free segment of good length and well rounded at the sides; genital segment also well rounded, with the fifth legs showing on either side near the posterior end.

Abdomen a little narrower, but with well-rounded sides; anal laminæ large and broad.

The lunules appear early upon the frontal plates and are large and semicircular in outline. The eyes are small, highly colored, and placed relatively much farther back of the frontal margin than in the adult. The appendages are nearly the same as in the adult.

Cherlimus, ererly stages.-Carapace, a still narrower ovate, becoming sharply pointed in front. This latter is due almost entirely to the frontal plates, whose width is more than one-third the length of the 


carapace. They taper forward to a sharp point at the base of the frontal filament as though pulled out by the latter. The two terminal joints of the first antenna are attached to the posterior border of the frontal plates, giving them the appearance of being attached to the lateral margin of the carapace, well back toward its center (fig. 114).

The eyes are so far back as to be a little behind the apparent center, though they are not far from the actual anterior margin of the arapace. There are no posterior sinuses, the third thorax segment not having yet fused with the head. This leaves the posterior margin of the carapace concave, the posterior corners projecting somewhat. The third thorax segment is separated by a well-defined groove from the carapace; it is a little wider, but only half as long as the fourth segment, and from its well-rounded sides project the third swimming legs.

The latter have not yet acquired their broad basal apron, but are almost exactly like the second pair, and the exopods can be plainly seen in dorsal view. The fourth segment is long and large, with wellrounded sides; the fourth legs are attached near its posterior margin and are quite rudimentary.

The genital segment and abdomen are still fused, though the line of separation is indicated by a deep indentation on either side.

The anal lamine are small but the plumose setre are long and stout.

The total length of the earliest stages is only a trifle over 2 millimeters, of which the carapace, including the frontal plate, makes up about four-serenths.

This species occurs very frequently and often in great abundance upon the codfish of our coast, but has been rarely ohserved on other specins of fish. Most of the specimens in the collection of the National Muserm agree closely with the Culigus americamus, so well described by Pickering and Dana (1838).

But there are a few lots of females in which the abdomen is broader and mole nearly quadrangular. A careful examination of these specimens, however, fails to reveal the slightest differences in the appendages and hence they can not be regarded as even a variety. This is one of the species upon which Mïller founded the genus ('aliyms in 175.), and is the only one of the types which has proved to be a real (iblingr, the others helonging to other genera. Hence the present species is left as the sole type of the genus.

Many lots of specimens have been obtained by the United States Fish (ommision from rodtish taken along the New England coast from Maine to New York, and on the offshore fishing banks. They are excedingly abundant during the atumn of the year when the shoal-water tish are lorought into the local markets, and they gradually diminish as the season alvances. They are most numerous on halffrown lish and may be found anywhere upon the external surface or the fins. They are also raxely taken in company with $($. Inpure in the 
mouth, but never, to the author's knowledge, within the gill covers. They are not as active as repar, but upon occasion can move about with equal speed and facility. They live but a short time after being taken from their host since they exhibit to a marked degree the pernicious habit of crawling up out of the water and remaining there until dead. They are also very susceptible to a slight rise in temperature; Pickering and Dana say (p. 67) that "when the temperature has been as high as $60^{\circ} \mathrm{F}$., they have generally died in the course of a short time." The author's experience has been similar, although no actual temperature tests have been made.

Being susceptible to so slight a rise it becomes extremely difficult to handle them during the summer months, when most of the research work is being done at the Marine Biological Laboratories. It is not surprising, therefore, that so little has been ascertained in regard to their habits and development, even though they are so common.

The Museum collection includes the following:

From the codfish (Gadus morhua) of Woods Hole and the immediate vicinity four lots numbered 11618, and one each 12305, 12649, 12650, Acc. no. 19893, and the following collected by Vinal $\mathrm{N}$. Edwards, 1301, 1384, 1393, 1417, 1423, 1463, 1466, 1485. These lots include something like 250 specimens. From codfish off the coast of Maine, chiefly near Casco Bay, lots 8022, 8023, 8024, 8025, 12646, $12653,12654,12655,12660,12661,12907$, nearly 200 specimens more. From codfish in Massachusetts Bay lots 12656, 12657, 12658. From other localities, chiefly stations of the U. S. Bureau of Fisheries vessels Albatross and Grampus, lots 1664t, 12645, 12647, 12648, 12671, 12672 , 12673, and W. 31. From the haddock (Melanogrammus xeglefinus) lots 12307, 12651, 12659, W. 25, W. 26, W. 41. From the hake (Urophycis tenuis) lots 8026, 13203, W. 30. From the halibut (Hippoglossus hippoglossus) 12631. From the pollack (Pollachius virens) W. 27, W. 28, W. 29. From the barn door skate (Raia lavis) 858, 6162. From the surface 12908 and W. 32. Specimens of the chalimus of this species are included in lots W. 36 from the tomcod; W. 37 host unknown, and 8116 from fin of codfish.

CALIGUS CHELIFER, new species.

Plate XI.

Female.-Carapace ovate, a sixth to a quarter longer than wide, considerably narrowed anteriorly. Frontal plates well detined; lunules large, close together, nearly circular, and prominent (fig. 126).

Posterior sinuses wide and nearly parallel; median lobe half the entire width, projecting considerably, and contracted into a narrow neck where it joins the free segment.

Thoracic area two-thirds the width and one-half the length of the carapace, subquadrilateral. Free thorax segment very short, a little 


wider than the neck of the median carapace lobe which joins it anteriorly, and passing insensibly into the genital segment posteriorly. Genital segment arorn-shaped, the anterior and posterior margins straight and parallel, the former about half the latter, contracted strongly where it joins the free segment. In the alcoholic specimen the dorsal surface of this genital segment has a row of three pits or depressions on either side of the midline, the two central ones being comnected across the midline by a groove which is convex anteriorly, while the two anterior ones are joined similarly by a straight groove. In the living specimens obtained by the author these pits and grooves were almost invisible and would never have been noticed had not the alcoholic specimen been studied first.

Abdomen narrow and two-jointed, four times as long as wide, the terminal joint two to two and a half times the length of the basal. The latter is enlarged where it joins the genital segment and tapers somewhat toward the distal joint which has parallel sides. The posterior end of this distal joint is wedge-shaped and the anal laminæ are attached to the sides of the wedge. They are long and narrow, cylindrical in form, and curved in toward each other at the tips, while the plumose setre which they carry are fully as long as the entire abdomen.

The egg cases are the same width as the abdomen and about half the length of the entire body. The eggs are quite thick and number 45 or o0 in each case.

Of the ventral appendages the anterior antennæ are small, with the two joints about the same length. The posterior antennæ are slender, the terminal claw being but little longer than the basal joint. The arcessory spine behind the base of this antenna is long and sharp.

The first maxillix are small, only slightly enlarged at the base and with a blunt tip. The second maxillæ are simple, quite long and nearly straight; each carries upon its base a raised papilla from whose summit project two divergent setre representing the exopod of the appendage as in $C$. rupar and several other species. First maxillipeds of normal size and structure, bearing a small spine on the anterior margin of the distal joint near the tip, and terminating in two curved and winged rlaws of unequal length. The second maxillipeds are peculiar. The hasal joint is very large and as wicle as it is long. It sends out two protuberances on the inner margin, a large one at the base which is hemispherical in form with a tlattened tip, another still lateger at the distal end. This latter is broad and finger-like and extends outward along the inner curve of the terminal claw, forming an inarticulate half of a large chela, very similar to those borne by other crustacea. It is notehed at the tip where it is also covered with short and stiff spines, making a rough surface admirable for retaining a firm hold. The terminal claw is about two-thirds the length of the basal 
joint, very stout, and furnished with a short accessory spine on the ventral surface (fig. 130).

This claw is operated by powerful muscles contained in the basal joint and it must make an effective prehensile organ.

Furca long and narrow, the base longer than the branches, the latter of a broad U-shape with the sides nearly parallel.

The first thoracic legs are so small and weak as to appear shriveled; this is especially noticeable in the plumose setre along the posterior margin of the terminal joint, which are scarcely longer than the diameter of the joint. In the alcoholic specimen taken from the menhaden the two posterior of the three terminal claws are branched, the branches being straight, longer than the tips of the claws, and inserted nearly at right angles to the axis of the claw (fig. 133). In the living specimens obtained by the author from the sword-fish the claws are mostly unbranched, but are of the same relative size as in the menhaden specimen.

In all the specimens the appendage at the inner corner of the joint is a long, strongly curved claw instead of a plumose seta.

This is similar to the condition in schistony $x$, but the relative size of the claws and the seta is entirely different in the two species. The second legs are large, of normal structure, and armed with long acuminate spines. The rami of the third legs are well separated, the claw on the basal joint of the exopod is large and slightly curved, while. the endopod is one-jointed.

The fourth legs are three-jointed, long and slender, the basal joint as long as the other two. This leg carries five spines, one at the distal end of the second joint, one on the outer margin of the terminal joint and three at the end.

Of the latter the inner one is about twice as long as the outer.

The fifth legs are not visible dorsally.

Total length in menhaden specimen $5 \mathrm{~mm}$. Length of carapace 2.5 mm.; width of same $2.1 \mathrm{~mm}$.; length of genital segment $1 \mathrm{~mm}$.; length of abdomen $1.4 \mathrm{~mm}$.

Total length of swordfish specimens $6-6.5 \mathrm{~mm}$. Length of carapace $3 \mathrm{~mm}$.; width of same $2.3 \mathrm{~mm}$.; length of genital segment $1.6 \mathrm{~mm}$.; length of abdomen $1.45 \mathrm{~mm}$; length of egg strings $3.2 \mathrm{~mm}$.; 45 or 50 eggs in each.

Color a transparent yellow, very thickly spotted on both the dorsal and ventral surfaces with branching pigment dots of a rusty brown. These spots are quite similar to those on $C$. rapax in shape and arrangement, but the resultant color is a sober gray brown quite different from the bright red tint of rapax. In fact, there is enough difference in the color alone to distinguish the two species when taken together on the swordfish. 

(chelifir, chele, the pincher-like claw of crustacea, and fero, to bear or carry.)

The National Museum collection when sent to the author contained but a single specimen, a female, of this species. It was numbered (6079, and was olstained from the external surface of a menhaden at Woods Hole by the United States Fish Commission. The characteristics of this specimen, especially the pincher-like claw, were so different from other species that it was decided to make it the type of a new species. Much to the author's gratification he was fortunate enough to obtain sereral living females from swordfish captured off Gay Ilead, Marthas Vineyard, in July, 1904. They were found on the external surface in comnection with $C$. rapax, but were not nearly as numerous as that species, only five being obtained from four swordfish.

A single female taken from the cutlass fish (Trichiums lepturus) on September 16, 19(13, by V. N. Edwards, was afterwards placed in the anthor's possession. From the living specimens several facts were ascertained, which have been incorporated in the previous description. In addition it may be said that the species is almost as lively as rapare, swimming about restlessly when kept in an aquarium. That it has nevel been captured in the tow is probably due to the fact that its rhief host, the swordfish, is an off-shore fish. So far as known this is the only instance of a Caligus having anything which may fairly be called a chela. Many other species have protuberances of various sorts on the inner margin of the basal joint of the second maxillipeds, but they are simple protuberances and do not in any way extend outward alongside the terminal claw and in opposition to it. Here, on the contrary, it is to be noted that the conditions reproduce exactly those in higher crustacea. The outer, swollen branch of the chela is articulated at its base, while the inner, larger branch is inarticulate and forms a part of the preceding joint. In place of the rounded teeth so commonly found on this part of the chela we have here short and stiff spines. In the living specimens the chela was frequently opened and closed, the tip of the claw, in the latter instance, folding down orer the end of the protuberance so tightly that the two seemed all one piece.

The comparative measurements of the menhaden and swordtish specimens fumish a good ohject lesion on the shrinkage which results from preservation in alcohol.

(One of the sperimens was a female without egg-strings, and in this condition the genital segment becomes so rounded anteriorly and posteriorly as to be nearly a perfect cirele in outline. The species may he casily peoognized by the shape of the anal lamina and the length of their plumose setex. An examination of the tips of the second maxillipeds will then rerify the diagnosis beyond a doubt. 


\section{CALIGUS BELONES Kröyer.}

Plate XII, figs. 135-139.

Female.-Carapace about half the entire length, a little longer than wide. Frontal plates prominent, the anterior margin almost straight, with very little incision at the center. Lunules large and widely separated, strongly inclined toward the mid line, and subprominent. Posterior sinuses wide and shallow, leaving a median lobe less than half the entire width, and projecting but little behind the lateral lobes. Thoracic area about half the dorsal surface of the carapace, well rounded anteriorly. The digestive glands in this area are pear-shaped and inclined toward each other anteriorly.

Free segment short and strongly contracted where it joins the carapace. Genital segment elliptical, one-third the entire length, emarginate posteriorly, with short and blunt lobes. Fifth legs not visible dorsally.

Abdomen elliptical, less than half the width of the genital segment, nearly twice as long as wide. It is contracted to almost half its width where it joins the genital segment. Anal sinus broad and deep. Anal laminæ large, one-fourth as long as the abdomen, sublateral, with long plumose setæ.

Egg tubes half the width of the abdomen and a little longer than the carapace, 30 or 40 eggs in each.

Anterior antennæ short, the two joints about the same length, but the terminal joint very slender and closely appressed to the frontal margin. The basal joint is plentifully supplied with plumose setæ and the terminal one with spines.

Second antennæ small and short; basal joint nearly as long as the terminal, the angle in the latter very close to the tip.

Accessory spine large and stout. First maxillæ long, slender, and well curved; second pair little more than half as long as the mouth tube, rather slender and blunt at the tip, but much widened at the base. Mouth tube quite stout, a little longer than wide, well rounded at the tip. First maxillipeds slender, the two joints almost equal in length; second pair stout, with a short and blunt terminal claw. Furca long and wide, the base elongate, very narrow, and about as long as the branches, the latter stout and curved into the shape of a horseshoe, of the same diameter throughout.

Rami of the third pair of thoracic legs well separated, large and prominent; the spine at the base of the exopod slender and nearly straight. The fourth legs are half the length of the genital segment, three-jointed with four spines; basal joint stout and as long as the two terminal joints, which latter are very slender. Second joint longer than the third, with a slender terminal spine; the three ter- 


minal spines on the last joint graded in size, the inner one twice as long as the outer.

Total length $5 \mathrm{~mm}$. Length of carapace $2.6 \mathrm{~mm}$; width of same $2.3 \mathrm{~mm}$; length of genital segment $1.4 \mathrm{~mm}$.; length of abdomen $1 \mathrm{~mm}$; length of egg strings $3 \mathrm{~mm}$.

Color a light yellowish brown without pigment (in preserved specimens).

(belomes, generic name of one of its hosts.)

The National Museum collection includes a single lot of this species from the body of a small dolphin (Coryphone equisetis), without a number, and with the locality not given.

But as the label bears the signature of Mr. Vinal N. Edwards, and was given to the author with other material collected at Woods Hole, it is probable that the dolphin was caught in the North Atlantic. The lot includes two females which resemble Kröyer's species so closely as to leare no doubt of the identity. Kröyer states that in his specimens the abdomen was indistinctly segmented, but these two show no sign of segmentation. The furca on these specimens is also somewhat different but not enough so to warrant specific distinction. In all other particulars the two lots agree perfectly. 'The present host, the small dolphin, is a new one, this species having been found previously upon Belone vulgaris, on what Kröyer calls the "Hornfish," and on what Olsson designates as the "Beak fish." It is more of a tropical than a northern species.

\section{CALIGUS LATIFRONS, new species.}

Plate XII, figs. 140-149.

Frmale.-Carapace half the entire length, a little longer than wide, considerably narrowed anteriorly. Frontal plates very wide and prominent; lunules large, almost circular in outline, and projecting far in front of. and laterally over the bases of, the first antenne. Eyes large and situated far forward close to the anterior margin of the carapace. Posterior sinuses wide and oblique, leaving a median lobe tiveeighths the width of the carapace and quite squarely truncated posteriorly. Lateral lobes narrow and eurved inward at the tip. Thoracic areat seren-eighths the entire width of the carapace and almost exactly one-half the length, the anterior groove flattened similarly to the posterior margin of the median lobe.

Free thorax segment two-thirds as wide as the genital segment, abruptly narrowed in front of the fourth legs.

Genital segment nearly quadrate with well-rounded corners, a little more than half as long as the carapace and not quite half as wide. Ahdomen about four-fifths the length of the genital segment, one-half longer than wide, swollen at the center, and narrowed at either end. 
Its posterior margin is wedge-shaped so that the small anal lamina are joined sublaterally.

Each of these latter carries four plumose setæ which are small and short. No egg strings present in this female.

Of the ventral appendages the first antennæe are elongate, with the longer terminal joint very slender. Both joints are turned backward and closely appressed to the anterior margin of the carapace. The second antennæ have a long and slender terminal claw and a rather small basal joint.

Posterior to the base of these antennæ is a stout accessory spine which is relatively larger than in most species.

The first maxilla are small and almost straight, with the base enlarged scarcely at all; the second maxilla are elongate, stout and blunt at the tip. Furca large, the base about the same length as the branches and nearly square, with a transversely semilunar foramen. The branches are slender, blunt, and curved in toward each other. Second maxillipeds stout, the terminal claw about four-fifths as long as the basal joint, the latter not swollen. The accessory spine on the terminal claw is short and weak. First swimming legs stout, with a long plumose seta on the distal end of the basal joint and a short spine on its posterior border near the proximal end.

On the terminal joint the three claws are about the same length and not very strongly curved. The outer one is smooth and nonserrate; each of the other two is branched at about its center on the inner side. The branches are more slender than the tips of the claws and extend some little distance beyond them. They are also perfectly transparent, while the claw itself is more or less opaque. The plumose setæ on the posterior border of this joint and the seta at the inner distal corner are like those in other species.

The spines on the exopod joints of the second legs are long and acuminate and are bent inward at nearly right angles to the outer margin; the basal joint of these legs is strongly flattened and is relatively wider than in most species.

The rami of the third legs are widely separated, the exopod being turned inward along the posterior border of the basal joint.

The claw on this exopod is large and stout, about the same diameter throughout, with straight sides.

The fourth legs are long and stout, the basal joint nearly as long as the two terminal ones. There are five spines-a large one at the tip of the second joint, a much smaller one on the outer margin of the terminal joint, and three at the tip-increasing in size from without inward, the inner one more than twice the length of the outer. There are foliaceous projections fringed with long hairs at the bases of the first, second, third, and fifth spines and at the inner distal corner of the terminal joint. These are almost cxactly like those on $C$. rapax, 


but are arranged differently. The fifth legs are so small as to be invisible in dorsal view.

Total length, $4.9 \mathrm{~mm}$.; length of carapace, $2.46 \mathrm{~mm}$.; width of same, $2.2 \mathrm{~mm}$.; length of genital segment, $1.25 \mathrm{~mm}$.; length of abdomen, 1 mm.; egg strings not present.

Color of specimen preserved in formalin a pale dusky yellow with a large brown area in the center of the dorsal surface of the genital segment, and the two glands in the thoracic area also brown.

(latifroins, latus, wide, and frons, forehead.)

This species resembles rapax very closely in its general appearance, but is clearly distinguished from it by the size and shape of the furca, hy the relative width and length of the median carapace lobe and the free thorax segment, and by the details of the first swimming legs, particularly the divided claws. From schistonyx, which has the claws divided, this species is distinguished again by the size and shape of the furca, by the great difference in the relative size of the terminal claw on the second maxillipeds, and by the detail of the exopods of the third and fourth legs.

From chelifer, whicb also has the claws divided, it is easily told by the simple fact that its abdomen is unsegmented, while that of a female chelifer is two-jointed. There is also a very essential difference in the structure of the second maxillipeds, in the furca and in the fourth legs. In spite of the fact, therefore, that the collection includes but a single female for which neither the host nor the locality is given, there must be established for it a new species.

\section{CALIGUS BONITO, new species.}

Plate XIII, figs. 150-153; figs. 5, $12,13,14,15,29,30,35,37,38,40-45$ in text.

Female.-Carapace orbicular, with the sides somewhat flattened, the same length and width; posterior sinuses shallow, slightly curved and enlarged at the base. Thoracic area broad, more than half the entire widtb, somewhat flattened posteriorly and scarcely projecting beyond the lobes; the latter narrow and curved inward (figs. 150, 151).

Free thoracic segment short and very narrow; much constricted in front of the fourth legs. Genital segment elliptical, two-thirds as wide and nearly as long as the carapace, projecting posteriorly in the form of a blunt, conical lobe on either side of the abdomen. Abdomen somewhat spindle-shaped, more than three times as long as wide, and two-jointed; the joints about equal in immature females, and presenting a very close resemblance to that of the males, but the basal joint three times as long as the terminal in fully developed individuals and the segmentation very indistinet.

Anal sinus searcely perceptible; anal lamine of good size, quadrangular in outline, each terminated by five plumose setæ.

Proc. N. M. vol, xxviii- $04-38$ 
Of these the outer and inner ones are very short, while the three central ones are of the same length, which is nearly three times that of the papillæ.

First antennæ short, particularly the basal joints; frontal plates wide but not very long; lunules orbicular, close together on either side of the median line, projecting considerably, and occupying nearly the whole of the frontal plates. The median joint has nearly the outline of an equilateral triangle, while the terminal joint is slender and club-shaped.

Second antennæ stout, the terminal joint a long, sickle-shaped hook attached nearly at right angles to the basal joint (fig. 5, p. 500).

First and second maxillæ comparatively rudimentary, the former with a slightly swollen base. Mouth tube broad, with the opening elongated transversely and densely fringed with hairs. Mandibles with a row of rounded teeth along the anterior and posterior margins for some distance back from the tip.

Furca stout, with an accessory spine on either side at the base. First maxillipeds long and slender; second pair of medium size, the basal joint much longer than the terminal, the latter consisting of a stout, curved claw, with a slender spine at about the center of its inner margin (fig. 12, p. 504).

First swimming legs with a stout basal joint whose ventral surface is nearly covered by a broad chitin plate. From the posterior margin of this plate project a slender acuminate spine at about the center and a stout blunt papilla at the outer corner (figs. 13-15).

The endopod is represented by a small, slightly curved spine. The second joint is long and considerably swollen at the center.

The terminal joint carries three plumose setæ in the usual position on the posterior margin, the bases of the setæ being pectinated. The three terminal claws are the same length, while the seta at the corner is plumose and three times as long as the claws.

The second swimming legs are not noticeable except for a row of short, pectinate spines along the outer margin of the two proximal joints of the endopod. The third swimming legs have a particularly large and stout curved claw at the base of the exopod. The fourth legs are large and strong for so small a copepod; the distal joint bears three long curved spines at its tip and a smaller one upon its posterior margin; the penultimate joint carries a single stout spine at its distal end on the posterior margin.

The rudimentary fifth legs are not visible dorsally in either male or female.

Total length, $8.3 \mathrm{~mm}$.; length of carapace, $3 \mathrm{~mm}$.; width of same, $3 \mathrm{~mm}$.; length of genital segment, $3 \mathrm{~mm}$.; length of abdomen, $2.3 \mathrm{~mm}$.; length of egg strings, $8 \mathrm{~mm}$. 


Color a pale transparent yellow without any pigment, except at the tips of the lateral lobes and the adjacent thoracic area, which are thickly spotted with light, rusty brown.

The copepod thus appears as if it had two large brown eyes, one on either side of the body at the posterior end of the carapace, and it may he readily recognized by these, since no other species is marked similarly.

\section{(bonito, the name of its host.)}

Mule.Considerably different from the female. The carapace is more nearly orbicular, while the thoracic area is much narrower (fig. 152).

This gives the posterior end of the carapace a rounded appearance quite different from the truncate look of the female.

The free thoracic segment is much wider posteriorly than anteriorly, and projects so far beyond the sides of the genital segment that the fourth legs are attached to its posterior rather than its lateral margin. The genital segment is but little wider than the abdomen and quite fusiform, the anterior end being usually well wrinkled. The abdomen is the same length as the genital segment and is jointed once near the center.

These alterations in shape produce equally marked changes in the proportions of the various parts. Whereas in the female the proportion in length between the cephalothorax and the remainder of the hody (exclusive of the egg strings) is as 7 to 10 ; in the male the same proportion is as 7.5 to 6.5 . This change is far more than usual. The first antenna are relatively larger and longer than in the female, this heing particularly true of their basal joints with the lunules.

The second antenne are not as stout as those of the female, but the first maxilla are nearly three times as large. This makes the two appendiges in the male nearly the same size, the maxillre being a trifle longer but not as stout.

In the recond maxillipeds the basal joint is reinforced at its distal end by a thick, bony plate on the inner side. 'The powerful terminal claw, folling down against this plate, makes a very effective clasping organ.

Total length, $5.5 \mathrm{~mm}$. Length of carapace, $3 \mathrm{~mm}$.; width of same, 2. $4 \mathrm{~mm}$. : longth of genital segment, $1 \mathrm{~mm}$.; length of abdomen, $1.2 \mathrm{~mm}$.

Vinfylims. - The newly hatched nauplii are large and active. They are rather clongate in form, the length being nearly three times the wilth, and the body is bluntly rounded both anteriorly and posteriorly (tigs. 35. 35 in text). The three pairs of appendages have the typical nauplius form. The lablum is oral in outline, with a broad, shallow simus on eithel sirle and in front, but with a wide, blunt projection posteriorly. The body is pigmented with rusty brown in narrow patches all along either side and posteriorly, the patches being irregularly disposed. Sometimes these pigment patches are fused into an 
irregular marginal band. And often the pigment extends out into the antennules almost to their distal end and into the basipods of the other two pairs of appendages. The balancers on either side of the anus are long and stout $(0.12$ by $0.01 \mathrm{~mm}$.), their length exceeding that of the anterior appendages, exclusive of their setæ. They are widest at the center and taper somewhat toward either end. The basal third is cylindrical in shape, while the terminal two-thirds is flattened or compressed into a knife-blade form, the whole resembling in shape the common form of paper cutter made from a cylinder. At the first moult the skin over these anal appendages is shed exactly like that over the others, but at the second moult the entire appendages disappear.

After the first moult also the pigment extends in toward the center of the body, and by the second moult has become quite evenly distributed.

Metanauplius.-Body elongated and narrowed, carapace covering two-thirds the entire length (fig. 40 in text). Carapace ellipitical, well rounded anteriorly, narrowed and emarginate posteriorly. Three free thorax segments and a terminal segment representing the genital segment and abdomen, as yet unseparated. The eyes are placed far back, near the center of the carapace, and are fused on the mid line, as in the adult. The rusty brown color covers a wider space along the margin and is more uniformly disposed than in the nauplius. In place of the three pairs of nauplius appendages there are five pairs of thorax appendages.

Anterior antennæ are two-jointed, bearing long setæ on the terminal joint, irregularly disposed; basal joint closely approximated to the anterior margin of the carapace.

Second antennæ biramous; exopod short and rudimentary, ending in a short spine; endopod longer and stouter, terminating in a curved claw nearly as long as the endopod itself, and bent over ventrally until its tip nearly touches the básipod (fig. 42 in text).

First and second maxillæ very rudimentary, the former a mere protuberance near the margin of the carapace, the latter consisting of a single conical spine at the side of the mouth (fig. 43).

First maxillipeds shorter and stouter than in the adult, tipped with three strong spines or claws, the two inner of which are pectinated. Second maxillipeds longer and more slender than in the adult, projecting far beyond the edge of the carapace, the terminal claw with an accessory spine on its inner margin.

First two pairs only of the swimming legs present on the first two free thorax segments; both pairs rudimentary, biramous, the terminal joints fringed with plumose setæ (figs. 44, 45). Total length, 0.67 mm. Length of carapace, $0.42 \mathrm{~mm}$; width of same, $0.22 \mathrm{~mm}$.

This small species is very abundant upon the common bonito (Gymnosarda pelamis Linnæus), but has not been found thus far upon any other fish. It frequents both the mouth and the gill cavity, more com- 
monly the latter, and in extremely rare instances may be found upon the external surface near the head.

While bonito are frequently taken upon which not even a single specimen of this parasite can be found, there are just as often others which fairly swarm with the diminutive pests. As many as one hundred can sometimes be secured from a single large fish.

They are very lively and scuttle about rapidly over the inside surface of the gill eavity and the mouth, while the sucking disks are so large that they can be removed only with considerable difficulty. They move about constantly when put into sea water, but have two pernicious habits. The first is one common to many species of this genus and quickly results in suicide. It consists in swimming to the side of the dish or aquarium and crawling an inch or an inch and a half above the surface of the water, there to remain until thoroughly dried.

This renders it very difficult to keep specimens alive for any length of time. Indeed it is practically impossible unless they are placed in a wide-mouthed bottle over whose mouth is tied a piece of fine gauze, the whole being sumk beneath the surface of the water in the aquarium.

The other disagreeable habit is confined to the female and consists in sloughing off her egg strings as soon as she is placed in fresh sea water. This renders it impossible to allow the eggs to mature and the larva to hatch. If the eggs have not developed sufficiently for the larve to emerge when, the female is captured, there is practically no hope of maturing them.

If, however, the eggs are just ready to hatch when captured, the female apparently makes an exception of the emergency and retains the egg cases until the larvæ have all escaped.

This species was first obtained at Woods Hole in the summer of 1883 hy Richard Rathbun, who made many drawings and notes upon its habits and anatomy. These, however, were never published, but, together with one or two drawings by Emerton, were recently turned over to the author and have been incorporated in the present account. Mr. Rathbun had named the species Caligus bomito in his manuscript, and this namo has been retained (brmito, the name of its host).

A study of the development of this species is of peculiar interest for the light which it throws upon the morphology of the adult. The nauplius and metanauplius have already been described in detail; the chalimus has not yet been obtained, bet specimens have been secured which had just moulted from the chalimusstage. In them the carapace is proportionally much larger than in the adult, while the genital segment is rory much smaller. Indred, so great is the difference between females in these two stages that the younger immature specimens resemble the males more than they do the alult females, and would 
ordinarily be taken for males. The anterior portion of the grenital segment, where it joins the free segment, is contracted into quite a long neck, well creased with wrinkles.

The body of the segment is not much wider than the abdomen and is almost squarely truncated posteriorly without any lobes at the corners. The abdomen is considerably shorter than in the adult and is plainly segmented at about the center-i. e., it is practically the same as in the male. There is not the slightest doubt that these are really young females, for the egg strings can be seen forming inside the genital segment, and the second antennre and second maxillipeds have the structure of those in the female and differ much from those in the male.

The examination of these developing females led plainly to the conclusion that the abdomen is segmented in the adult, although the segmentation is usually very well concealed.

Accordingly a large number of adults were carefully examined with the result that two were found which showed a segmented abdomen very plainly. As development proceeds the genital segment widens and lengthens, sending out large lobes from the posterior corners; at the same time the abdomen lengthens, the increase taking place almost wholly in the basal segment.

Thus while in the immature female the segments of the abdomen are about equal, in the adult the basal segment is three or four times the length of the terminal.

This development also suggests an explanation for what have been considered as variations in the species productus. (See p. 600.)

The National Museum collection includes the following lots of this species, all obtained from the same fish and quite constant in their specific characters: 'Two lots, numbered 6035, obtained by Mr. Rathbun at Woods Hole; one lot, numbered 1307, taken by Vinal N. Edwards at Woods Hole; five lots, numbered W 50, W 51, W 52, W 53, W 54, obtained by $\mathrm{Mr}$. Rathbun in Vineyard Sound, in the immediate vicinity of Woods Hole; five lots, numbered W 55, W 56, W 57, W 58, W 59, obtained by the author from Woods Hole and vicinity. The specimens in Mr. Rathbun's collections number nearly 200, while the author obtained almost as many. The species must therefore be regarded as a very common one on the single fish which it frequents.

\section{CALIGUS PELAMYDIS Kröyer.}

Plate XIII, figs. 154-161, Plate XIV, fig. 161a.

Caligus pelamydis KröYer, 1863, p. 50, pl. Iv, fig. 4, a-g.-RichraRdr, 1880, p. 148.-Carus, 1885, p. 357.-Bassett-Smith, 1899, p. 452.-Brian, 1899, p. 2.

Female.-Carapace orbicular, somewhat narrowed anteriorly, the same width and length, which is much less than half the entire length of the body, and with nearly straight lateral margins (fig. 15t). 


Frontal plates narrow, a little more than half as wide as the carapace; lunules large, circular, but almost entirely concealed in dorsal view, appearing only as a slight concavity at the base of the first antenne. Posterior sinuses broadly triangular, the median lobe considerably less than half the entire width. Thoracic area rather small, not quite reaching the center of the carapace. Digestive glands situated at about the center of this area, each in the form of a large rightangled triangle, the perpendicular's parallel with the longitudinal axis, the bases at the posterior ends.

Free thorax segment narrow and short, swollen considerably at the center where the fourth legs are attached. Genital segment broad acorn shape, narrowed into a slender neck where it joins the free segment and squarely truncate posteriorly.

It is two-thirds as wide as the carapace and the sides and posterior corners are symmetrically rounded.

Abdomen as long as the carapace, the length three and a quarter times the width, slightly swollen at the center and constricted where it joins the genital segment. It is two-jointed, the first joint being four times the length of the second.

In living specimens and in material preserved in formalin the joints are distinct, but in material preserved in alcohol they become indistinct. But in all specimens alike the abdomen is abruptly narrowed at the groove between the joints, the terminal joint being considerably narrower than the hasal, and tapering posteriorly. Anal laminæ of medium size, and flattened, with the tips turned in toward each other.

Egg strings wide, considerably shorter than the body, each containing about thirty eggs.

First antenne small, the basal joint short and not very wide, but heavily armed with setr; the terminal joint short, club-shaped, and searcely projecting beyond the edge of the carapace.

Second antenne with a very long and slender terminal claw, and without any accessory spine at the base.

First maxilla rery small with a narrow, blunt tip and a slightly swollen base. Second maxilla long and acuminate, projecting some distance beyond the tip of the rostrum.

recond maxillipeds with a stout basal joint, somewhat swollen, and a much shorter and rather slender terminal claw.

Furea short, the base not more than half as wide as the branches; the latter simple, short, very wide, and curved.

The first natatories have a long plumose seta on the distal end of the basal joint, a short curved claw at the distal end of the second joint, while the terminal joint arries three very large plumose sete on the posterior margin, and the usual terminal claws. The latter are all curved, about the sime size, and close together. In addition there is a tinger-like projection extending from the distal margin in the same 
direction as the claws. It is of about the same diameter as the claws, but considerably longer and carries at its tip a small curved spine.

The rami of the third legs are some distance apart, but as the exopods are closely appressed to the margin of the basal apron, this brings their tips close to the bases of the endopods.

The spines on the exopods of these legs are proportionally larger than usual and parallel with the outer margin.

The fourth legs are short and stout, and made up of four joints; the basal joint is as long as the remaining three. Of these latter the second is the longest and the fourth the shortest.

The latter joint is triangular and so arranged that the three spines which it bears and the two upon the distal ends of the second and third joints are close together along the outer margin. These spines are all the same size and each has a row of hairs along its outer margin. The fifth legs are very minute and situated on the ventral surface just at the base of the egg cases.

Total length, $3.3 \mathrm{~mm}$. Length of carapace, $1.1 \mathrm{~mm}$.; width of same, $1.1 \mathrm{~mm}$.; length of genital segment, $0.9 \mathrm{~mm}$.; length of abdomen, 1.2 $\mathrm{mm}$.; length of egg strings, $2 \mathrm{~mm}$. Number of eggs in each, 30 .

Color, a uniform yellowish white, lighter on the genital segment, which is almost pure white.

(pelamydis, the name of its host.)

In his monograph, published in 1863, Kröyer described (p. 50) two small females of this species which had been found on the common bonito (Gymnosarda pelamis). His description differs in a few particulars from that here given, the most noticeable one being the presence of double papillæ at the posterior corner representing the fifth legs. In the present specimens also the carapace and genital segment are more nearly the same size, but otherwise the two lots are identical.

It would certainly not be feasible to have two species, both from the same host, and resembling each other so closely. The differences, therefore, must be regarded as mere variations, found in many other species also. Richiardi (1880) reports this species from the gill cavity of the mackerel (Scomber scombrus), while Bassett-Smith describes (1896) a species which he calls $C$. scomberi from the gills of the same fish. Again in 1901 T. Scott described and figured a C. scombri, in this case a single specimen adhering to the inside of the gill cover of a mackerel.

Bassett-Smith's description is so meager as to be worthless for identification; in his figures the carapace is long and narrow and the fourth leg's have only three joints. But he has placed five spines in a row upon the outer margin of the last joint and none on the second joint. If this were the correct distribution it would be an anomaly indeed, unlike anything known in other species. Scott does not describe the species at all, but in the figure he has given the fourth legs are four- 


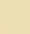





jointer and two of the five spines belong to the second and third joints, respectively. The carapace also is almost exactly as here figured, and the furca differs only in having the base a little longer. Both Scott and Bassett-Smith figure the abdomen as one-jointed, but neither of them makes any statement in regard to it. In both figures, however, the abdomen narrows abruptly near the posterior end at exactly the place where the joint occurs in the present species.

Bassett-Smith makes no statement of the dimensions of the specimens he obtained, but in his explanation of the plate the magnification of the figure is given as 6 . This would give a length of $7 \mathrm{~mm}$. Scott states that the single specimen he obtained was $5.5 \mathrm{~mm}$. In the present species no specimen thus far obtained has exceeded $4 \mathrm{~mm}$.

In view of these meager and conflicting descriptions, together with the contradictions expressed in the figures, it becomes practically impossible to decide just how many species are represented. The size given for $C$. scomber $^{a}$ seems to preclude its identity with petamydis, and yet the two agree in almost every detail as given by the one or the other of the two authors quoted.

It will require a careful comparison of the original types to decide the problem finally.

\section{CALIGUS PRODUCTUS Dana.}

Plate XIV, figs. $162-170$.

Caligus productus Dana, 1854, p: 1354 , pl. xciv, fig. 4.-STEenstrup and LÜTKen, 1861, p. 357, pl. III, fig. 6.-KRöYER, 1863, p. 64, pl. III, fig. 4, a-i.-RATHBUn, 1884, p. 487.-Brian; 1898, p. 10.

Female.-Carapace ovate, much less than half the entire length; as longas wide, narrowed anteriorly. Frontal plates projecting strongly, but not more than three-eighths of the width of the carapace. Lunules small, orbicular, scarcely projecting. Posterior sinuses inclined outward, and of medium width, leaving a median lobe less than half the width of the carapace, and not projecting posteriorly. Lateral lobes broad, well rounded, and turned inward slightly at the tips. Thoracie area small, and contracted anteriorly. Eyes small, and placed well back from the anterior margin.

Free thoracic segment very narrow and spindle-shaped, ahout onefourth the width of the earapace, and contracted into a neck anteriorly where it joins the latter. Genital segment elliptical, with evenly eurved sides, like the free segment contracted anteriorly where it joins that sergment, and expanding abruptly to its full wilth. It is five-eighths as wide, and almost seren-eighthe as long as the carapace.

Ahdomen elongate linear, somewhat swollen at the center, about onefuarter longer than the genital segment, and more than four times as 
long as wide, apparently unsegmented. From a study of the figures given by Kröyer and Steenstrup and Lütken, and from comparison with the developmental history of $C$. bonito it would seen reasonably certain that in the present species there is a similar development. In immature females the abdomen is plainly two-jointed, the joints being fairly equal, but as development proceeds the terminal joint increases faster than the basal. Hence, in mature females the abdomen is probably two-jointed, with the basal joint only one-third or one-fourth of the terminal. Anal laminæ small, foliaceous, and curved in toward each other. The plumose setæ, with which they are armed, are rather small. Egg cases narrow and reaching only to the tips of these setæ, each containing about thirty eggs.

Anterior antennæ with a short, stout basal joint and a very slender terminal joint of about the same length, the whole appendage less than the space between the lunules.

Second antennæ with a stout basal joint bearing a short and blunt accessory spine on its posterior border.

First maxillæ small and strongly curved; second maxillæ narrow triangular with acuminate tips, twice as long as wide and straight.

First maxillipeds slender and of the usual form; second pair large and stout, the basal joint much swollen, the terminal claw small. The claw is scarcely half the length of the basal joint, but is stout and well curved.

Furca slender, the basal portion narrower and shorter than the branches, almost circular in outline, and connected with the branches by a narrow neck. The branches are divergent, rather slender, and blunt.

First swimming legs with the usual armament of three terminal claws graded in size, a long slender plumose seta at the distal corner beside the smallest claw, and three rather small plumose setæ on the posterior margin. The spines on the exopods of the second legs are very long and acuminate; the two on the two basal joints are inclined at an angle of about 45 degrees with the anterior margin, while the one on the terminal joint is nearly parallel with that margin.

The rami of the third legs are well separated, but the two terminal joints of the exopod are turned in and appressed close to the margin of the basal apron. And they reach so far across the intervening space between endopod and exopod that the two rami appear close together. The spine on the basal joint of the exopod is long, slender, and curved into a sickle shape.

The fourth legs are of medium size, but rather short and threejointed, with only four spines, one at the distal end of the second joint, one on the outer margin, and two at the end of the terminal joint. The last three are almost in a row, the outer one being but a little behind the others. All these spines are very long and acuminate; 


the two terminal ones are serrate along their outer margins. Fifth legs invisible.

Total length $6 \mathrm{~mm}$. Length of carapace $2.1 \mathrm{~mm}$.; breadth of same $2 \mathrm{~mm}$.; length of genital segment $1.6 \mathrm{~mm}$.; length of abdomen $2 \mathrm{~mm}$. ; length of egg strings $2.2 \mathrm{~mm}$.; 30 eggs in each.

Mule.-Carapace ovate like that of the female, but narrowed rather more anteriorly, as long as wide; median lobe relatively wider and not projecting backward as far. Free segment shorter and relatively wider. Thoracic area wider than long and evenly rounded in front; lateral lobes narrow and somewhat pointed. Genital segment narroworate, one-third longer than wide, the sides nearly straight.

This segment is much smaller than in the female, being less than one-third the width of the carapace and not very much wider than the abdomen. The fifth legs can not be seen in a dorsal view, and there are no traces of lobes at the posterior corners.

The abdomen is elongate-linear, similar to that of the female, and is made up of two distirict joints, which are about equal in length if we leave out of account the anal laminæ. The latter are small, scarcely any larger than in the female, but the setæ with which they are armed are considerably larger and longer than those of the female.

The appendages are as already described; there is the usual increase in size of the second antennæe and the second maxillipeds. And there is the same absence of plumose setw on the posterior border of the terminal joint of the first swimming legs, which may be taken as characteristic of the species.

The fourth legs are small and hardly reach the posterior border of the genital segment. In other particulars the appendages are like those of the female.

Total length $4.5 \mathrm{~mm}$. Length of carapace $2.2 \mathrm{~mm}$; breadth of same 2.2 mm.; length of genital segment $1.1 \mathrm{~mm}$.; length of ahdomen

\section{$1.1 \mathrm{~mm}$.}

Color a uniform yellowish brown entirely destitute of pigment markings of any sort.

(productus, lengthened or drawn out.)

There is one lot of this species in the National Museum collection, consisting of four females taken from the common dolphin (Cory) hexne liipmums), from the inner side of the gill covers and the outer surface of the body. The tish was captured by the United States Bureau of Fisheries steamer $1 /$ hatms in latitude $35,19,26 \mathrm{~W}$ est and longitude (ix, 20, 20 North. This is the original species described by Dana in 1s.st as occurring on the same dolphin and on trigger fishes (Bulistes) in the West Indies. It was afterwards noted by Steenstrup and Lütken (1stil) as taken from the inside of the opereulum of the "Barracuda"

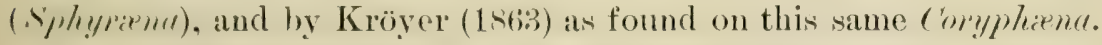

The specimens described by these three authors agree closely in 
general details, but differ in several particulars, as also do the specimens here described. The greatest differences are found in the furca, the first and fourth swimming legs, the abdomen, and the egg strings. In Dana's original species the branches of the furca are longer and more strongly curved, while in the present specimens the base of the furca is larger and the branches are short, straight, and strongly divergent.

All the authors unite in characterizing the species by a complete absence of the setre on the posterior horder of the first swimming legs. In the present specimens they are certainly present, but are unusually small.

Dana's species shows the fourth legs three-jointed, with five spines, all about the same length; in the present specimens there are but four spines, and the inner terminal one is twice the size of the others. All the authors write that the abdomen is obscurely two-jointed, but Kröyer figures the adult female with an apparently one-jointed abdomen, as in the figures herewith presented. Dana states that the egg strings are "longer than the body" (p. 1354); Steenstrup and Lütken figure them as only half the length of the body, but as twice the length of the abdomen, with eggs so large that each tube could contain only twenty.

In the present specimens the egg tubes are but a trifle longer than the abdomen (one-third the entire length), but each contains 40 eggs.

In view of such differences it might seem as if the present specimens constituted a new species, but after careful consideration this does not seem to be warranted. In the first place, they come from the same host as those obtained by the author's mentioned, a good presumption in favor of their identity.

Again, both Kröyer and Steenstrup and Lütken found great differences in their specimens, and they each figure what they call a variety of the species fully as different from the type as the present specimens. Nor do the egg tuhes here shown differ any more from those given by the authorities just quoted than the latter do among themselves. For this reason these specimens have been referred to Dana's species, and possibly the males reported by Brian (1898) may belong: here also.

The foregoing are all the species of Caligus from North American localities which are contained in the collection of the National Museum. But in addition the following species have been reported from the West Indies by various authors. The types of these species have been lost or are contained in foreign museums. In most instances the species are represented hy very few specimens, sometimes only one or two, obtained many years ago, and none have since been found, but this is chiefly, if not wholly, due to the fact that no investigations hive been made in that region since these specimens were found: and there is every reason to believe that a carcul search at the pres- 


ent day would yield some of the same species, as well as many new ones.

The diagnoses of these species and the outline drawings presented with them are taken from the original descriptions as far as possible, and in one or two instances additions have been made from later authors, for which acknowledgment is duly made. Dana's species, $C$. thymmi, was obtained a long distance from the American shore, but as it was found upon the same bonito which serves as host of three other species here described, it is likely to be found here at any time; and then it is really needed for purposes of comparison, and so is here included.

\section{CALIGUS BALIST $\mathbb{E}$ Steenstrup and Lütken.}

\section{Plate XV, figs. 172-177.}

Caligus balistre Steenstrup and LÜtren, 1861, p. 356, pl. I, fig. 1.-BassetTSигтн, 1899, p. 448.

Female.-Carapace elliptical, as wide anteriorly as posteriorly, more than half the entire length. Frontal plates not prominent nor very distinct; lunules small and widely separated. Posterior sinuses shallow and nearly parallel with the longitudinal axis; median lobe about half the entire width and shorter than the lateral lobes; the latter are narrow and somewhat pointed.

Free segment very narrow and long, like a wasp waist, and not much widened at the center through the bases of the fourth legs. Genital segment obovate, well rounded anteriorly, but with a deeply concave posterior margin, leaving the lobes at the external angles short and acute.

Abdomen short and wide, only half the length of the genital segment and somewhat cluh-shaped; anal lamine minute and armed with small setie. Eng strings ahout the same width as the abdomen and as long as the entire body; egg's large and well rounded, about fifty in each string.

First antenne longer and more thickly beset with setre than usual, those at the extremity of the terminal joint being very long. Second antrnne rather weak. Second maxillipeds with a stout basal joint and a slender terminal claw, the accessory spine of the latter being much nearer the tip than usual. Second maxilla slender, curved and acuminate. Furea small, base wide and short, branches very slender, straght, and dirergent, about twice as long as the base. Fourth legs three-jointed, with four spines; the latter slender and very long, all four about the same length; fifth legs invisible dorsally. Total length $4.5 \mathrm{~mm}$. Length of carapare $2.6 \mathrm{~mm}$. ; width of same $2.2 \mathrm{~mm}$. ; length of genital segment $1.4 \mathrm{~mm}$; length of abdomen $0.6 \mathrm{~mm}$.; length of egg strings $4.6 \mathrm{~mm}$. 
Male.-Carapace proportionally very large, twice as long and three times as wide as the rest of the body, slightly narrowed anteriorly; frontal plates small and narrow; free segment even smaller relatively than in the female, which is very unusual; genital segment semilunar in shape, nearly twice the width of the abdomen, with very long and acuminate lobes at the posterior corners. Two pairs of setiferous papillæ, one at the tips of the lobes and the other on the inner margins near the base.

Abdomen the same length as the genital segment and slightly swollen near the tip; appendages as in the female, with the usual increase in the size of the second antennæ and second maxillipeds; fourth legs proportionally longer and more slender than in the female.

Total length $4 \mathrm{~mm}$.; length of carapace $2.68 \mathrm{~mm}$.; width of same $2.35 \mathrm{~mm}$; length of genital segment $0.8 \mathrm{~mm}$; length of abdomen $0.79 \mathrm{~mm}$.

Color not given.

(balistæ, generic name of host.)

Several examples of this species were obtained from the gills and fins of West Indian species of the genus Balistes.

A few individuals in the chalimus stage were also found still fastened by a frontal filament.

\section{CALIGUS ISONYX Steenstrup and Lütken.}

Plate XIV, fig. 171; Plate XV, figs. 184-186.

Caligus isonyx Steenstrup and LÜtren, 1861, p. 358, pl. III, fig. 5.-BAssetTSмiтн, 1899, p. 450.

Female.-Carapace considerably less than half the entire length, as wide as long, narrowed anteriorly; frontal plates not prominent; lunules very small; antenna short; posterior sinuses comparatively deep, with parallel sides; median lobe scarcely one-third the entire width, its posterior margin just even with those of the lateral lobes; free segment narrow, but long and not swollen much at the center; genital segment acorn-shaped, narrowed into a slender neck, where it joins the free segment, the sides symmetrically rounded, the posterior margin squarely truncated. There are two pairs of rudimentary leg papillæ on this segment, one on the lateral margins considerably posterior to the center of the segment, the other at the posterior corners. Abdomen two-thirds the length of the genital segment, quite wide, and enlarged a little toward the tip; anal laminæ terminal, very small, and carrying small setæ; egg strings unknown. Frontal plates emarginate between the lunules; basal joint of first antennæ short; terminal joint much longer, but scarcely protruding beyond the margin of the carapace.

Second antennæ long and slender, with an elongated and narrow terminal claw, strongly curved. 

First maxilla short and strongly curved, the hase only slightly enlarged; second pair longer than the proboscis, straight and acuminate, with a small tooth on the inner margin near the center.

Terminal claw on the second maxillipeds bent nearly into a semicircle. Furca short and wide, the branches longer than the base, straight and divergent. Claws at the tip of the first swimming legs moderately long, and all, together with the seta at the distal corner, the same length. Branches of the second legs longer than usual, the exopod with long and pointed spines. Rami of the third legs large and close together, the spine at the base of the exopod large and strongly curved. Fourth legs four-jointed, with five spines, all slightly curved, the one at the tip of the second joint longer and curved more than the others, the rest about equal.

Total length $4.5 \mathrm{~mm}$. Length of carapace $2 \mathrm{~mm}$.; width of same $1.9 \mathrm{~mm}$.; length of genital segment $1.4 \mathrm{~mm}$.; length of abdomen $0.9 \mathrm{~mm}$.

Color not given.

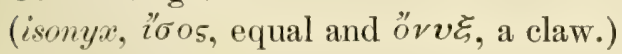

This species is based on a single example, which is evidently a female although it lacks the egg strings. It was taken from the gills of the great barracuda, Sphyræna barracuda (Walbaum), in the West Indies.

\section{CALIGUS THYMNI Dana.}

Plate XV, figs. 178, 179.

Caligus thymni Dana, 1852, p. 56.-DANA, 1852, p. 1353, pl. xcrv, fig. 3, a-c.T. Sсотт, 1894, p. 129, pl. xiv, fig. 21.-Валsетт-Sмith, 1899, p. 451.

Frmule.-Carapace oblong, not narrowed anteriorly, the length one and a half times the width. No emargination at the center of the frontal plates; lunules elliptical and not prominent. A short seta on the frontal margin on either side about half way between the lunule and the center. Eyes deep red on a black background. Free segment short and wide. Genital segment oblong, the sides divergent, widest posteriorly, where it is about twice the width of the abdomen; posterior angles prominent and tipped with sete. Abdomen longer than the genital segment, two-jointed, with the basal joint about half the length of the terminal; anus prominent.

Anal lamine small, filling out the posterior angles and hardly projecting beyond the anus. The three plumose setre which they carry are as long as the last joint of the abdomen, and do not diverge, as is many species, but are parallel.

Egg tubes a little narrower than the abdomen, longer than the entire body, each containing 40 eggs.

First antenne small, terminal joint very slender and tipped with setre as long as the joint itself. Fiecond antenne of moderate size with a 
slender terminal claw but with no spine on the posterior margin of the basal joint.

First maxillæ lacking; second pair stout and broad. First maxillipeds with basal joint about three fourths the length of the terminal; second pair very stout, basal joint subconical in shape, without protuberances, the terminal claw less than half the length of the basal joint. Furca simple, the branches divergent, straight and acuminate. Fourth legs three-jointed with four simple spines, no teeth on the spines nor sheathing setæ at their bases.

Total length $9.7 \mathrm{~mm}$. Length of carapace $4.9 \mathrm{~mm}$; width of same $3.4 \mathrm{~mm}$.

Color not given.

(thymni, the generic name of its host.)

Male.-Carapace elliptical, about one-eighth longer than wide, not narrowed much anteriorly. Frontal plates small, without an emargination at the center and very narrow; lunules small and semicircular. Free segment like that of the female. Genital segment nearly quadrate, the sides somew hat convex, the posterior margin almost squarely truncate, with the posterior angles scarcely projecting at all, but each armed with a bunch of setæe representing the fifth leg of that side.

Abdomen a little shorter than the genital segment, almost as wide as long, two-jointed, the basal joint only about half the terminal as in the female. Anal laminæ as before, but the plumose setæ much longer, as long as the entire abdomen.

The appendages show the usual increase in the size of the second antennæ and second maxillipeds. The former have $\mathrm{a}^{4}$ stout branch on the inner margin of the terminal joint near its center. The fourth legs are longer and more slender than those of the female, and the spines which they carry are longer and weaker.

This species was obtained from the oceanic bonito (Gymnosarda pelamis Linnæus; Thynnus pelamys Cuvier and Valenciennes), and is the fourth species of Caligus to be recorded from that host. The other three species are pelamydis, productus, and bonito. It will be instructive to review here the distinguishing characters of these four species.

They differ, first, in size, and may be arranged in an ascending series, pelanydis, 3-4 mm. long; productus, 5-6.5 mm.; bonito, 7-8 mm., and thymni, 9-10 $\mathrm{mm}$.

Again, they differ considerably in color, although unfortunately the color of thymni has never been given. Pelannydis is a light yellowish white, the genital segment almost pure white without pigment of any sort. Productus is a light dirt-brown, everywhere transparent, except the egg strings; while bonito is a very transparent white faintly tinged with yellow, and with a large spot of rusty-brown pigment in the posterior portion of the lateral area on cither side, like a large lateral eye. 




The genital segment in pelamydis is nearly orbicular, only a trifle longer than wide (one-sixteenth), not narrowed into a neck anteriorly and only slightly emarginate posteriorly.

In productus and bonito this segment is elliptical, narrowed into a rery marked neck anteriorly and with stout lobes prolonged far backward posteriorly on either side of the abdomen.

In thymmi it is trapezoidal, widest posteriorly, with straight sides and short, narrow posterior lobes.

The abdomen is two-jointed in each of the species, but in pelamydis the basal joint is three times the length of the terminal and only onethird as wide as the genital segment.

In bemito the basal joint is about twice the length of the terminal and the abdomen is two-fifths the width of the genital segment. In productus the terminal joint is twice the length of the basal and the abdomen is one-third the width of the genital segment. In thymni the terminal joint is also twice the basal, but the abdomen is fully half the width of the genital segment. In the structure of the abdomen, therefore, the species arrange themselves in two pairs, a large and a small species in each pair, which correspond quite closely.

The fourth legs in pelamydis are four-jointed with five spines, the last two joints very short and squat, bringing the five spines close together in a row. In productus these legs are three-jointed with four spines, the two terminal joints long and slender, the last two spines toothed along their outer margins. In bonito the legs are of medium length, three-jointed with five spines, none of which are toothed. In thymni they are long and slender, four-jointed with five spines, none of which are toothed. All the authors who have hitherto noticed productus are agreed that the first swimming legs have no plumose seta on the posterior border of the terminal joint.

The male of pelamydis is unknown, but in the males of the other three species there is even greater differences than in the females. In productus the free segment of the male is a little narrower than the genital segment, and the fourth legs do not reach its posterior margin. The terminal joint of the abdomen is half as long again as the basal and the anal papilla are small. In the male bonito the free segment is a little wider than the genital segment and the fourth legs reach considerably beyond its posterior margin. The two abdomen joints are about equal and the anal lamine are very large.

In thymmi the free segment is about half the width of the genital segment and the fourth legs just reach its posterior margin. The abdomen is as wide as it is long with the terminal joint nearly twice the length of the basal. These four species are thus well distinguished in both sexes, but more clearly in the males, since there is not as much specific variation in this sex.

Proc. N. M. vol. xxviii-0t-39 


\section{CALIGUS HAMULONIS Kröyer.}

.Plate XV, figs. 180-183.

Caligus hæmulonis KRöyen, 1863, p. 48, pl. Iv, fig. 3, a-d.-BAssetт-Sмiтн, 1899 , p. 448.

Female.-Carapace not quite half the entire length (as 9 to 20), as wide as long. Frontal plates projecting very strongly between the lnnules, with a deep median incision. Lunules themselves large, elliptical and widely separated. Posterior sinuses wide and shallow; median lobe a little more than half the entire width, and projecting but little behind the lateral lobes; the latter broad and well rounded. Cephalic area very much larger than the thoracic; eyes over the base of the proboscis and elliptical. Free segment very narrow and short, standing out in sharp contrast with both carapace and genital segment.

Genital segment orbicular or slightly obcordate, a little wider than long with a shallow posterior emargination. It is one-third shorter than the carapace with symmetrically rounded sides and posterior corners.

Abdomen a little more than half as long as the genital segment and one-third as wide, contracted at its base and unsegmented; anal papillæ small with short setæ; egg strings unknown.

First antennæ small, the joints equal in length; second pair situated so near the posterior border of the lunules as to partially hide them. First maxillæ stout and sickle-shaped; second pair a little shorter than the proboscis, situated far forward on either side of the latter and just reaching its tip.

They are simple, somewhat weak, acuminate and slightly curved. Maxillipeds of the usual form; furca large, base as long as the branches, with parallel sides and an oval foramen; branches stout, acuminate, curved, divergent, the space between them having a width equal to its length. First swimming legs short and thick, the terminal spines all the same length, while the plumose setæ on the posterior border of the terminal joint are entirely lacking. Rami of third legs widely separated, the outer branch long and stout. Fourth legs three-jointed, the basal joint as long as both the others, minus the claws; second and third joints the same length; claws quite close together.

Total length $2.8 \mathrm{~mm}$. Length of carapace $1.35 \mathrm{~mm}$.; width of the same $1.3 \mathrm{~mm}$.; length of genital segment $0.75 \mathrm{~mm}$.; length of abdomen $0.6 \mathrm{~mm}$.

No statement with regard to the color or habits.

Male.-Carapace slightly more than half the entire length; frontal plates distinct, not projecting as in the female, but about as deeply incised at the center. Lunules large and more nearly circular. Posterior sinuses even more shallow than in the female; median lobe con- 


siderably more than half the entire width and quite squarely truncate posteriorly.

Free segment five-serenths as wide as the genital segment, and much swollen at the center through the bases of the fourth legs.

Genital segment ovate, three-sevenths as long as the carapace, with evenly rounded sides; fifth legs not visible dorsally.

Abdomen a little shorter than the genital segment, two-jointed, the terminal joint three times as long as the basal; the latter considerably wider than long; anal papillæ as in the female, but the plumose setæ much longer.

Total length $2.25 \mathrm{~mm}$. Length of carapace $1.25 \mathrm{~mm}$; width of same $1.2 \mathrm{~mm}$.; length of genital segment $0.6 \mathrm{~mm}$.; length of abdomen $0.5 \mathrm{~mm}$.

Three specimens, two females and a male, of this well-defined species were obtained from the gills of Hrmulon elegans Cuvier, in the Danish West Indies. The largest female was full size, with egg strings just hatched.

(hæmulonis, generic name of the host.)

\section{CALIGUS MONACANTHI Kröyer.}

Caligus monacanthi Kröyer, 1863, p. 59, pl. IIr, fig. 2, a-e.-BAssetт-Sмith, 1899; p. 450.

Kröyer obtained what he states to be a male Caligus from the skin of a Monacanthus in the West Indies. There was but the single specimen on which to found this new species.

After a careful examination of Kröyer's figures and a study of his description, it seems to the author that he must have mistaken the sex of his specimen, and that what he really had was a young female Caligus productus.

The general make-up of the creature is that of a female and not a male; the genital segment is very large for a male, and if it were really that sex with lobes at the posterior corners, as indicated, the setæ of the fifth legs would certainly be visible.

But Kröyer states that there are no setæ. Again, if it were a male, with an abdomen as long as indicated, that region would certainly be segmented as in all other known species.

In the description Kröyer does not notice any differences in the second antenne and second maxillie, which are characteristic of all males. On the other hand, his description is identical throughout with that given for the female of productus, and we note particularly the absence of plumose sete on the terminal joint of the first swimming legs, the group of seven or eight pectinate projections on the outer border of the hasal joint of the endopod of the second legs, the widely separated rami of the third legs, while the fourth legs are three-jointed, with four spines, the inner terminal one much longer than the others. In 
view of the marked similarity between this single specimen and the female productus, it will at least be necessary to wait for further specimens whose sex can be established beyond a doubt before admitting it as a new species.

This completes the North American species so far as known at the present time, but there are in the National Museum collection, specimens of another species from South America which seem to be new to science and whose description is here included. (See p. 649.)

\section{Genus CALIGODES Heller.}

Carapace minute, a very small fraction of the entire length. Frontal plates well defined and furnished with lunules. First maxillæ small with a swollen base; second maxillæ simple. Furca large and prominent with the divergent and sharp-pointed branches bent so as to appear like a grapnel anchor in side view. Free segment narrow and somewhat elongated, forming a neck connecting the carapace with the genital segment.

First and fourth legs uniramous, second and third biramous, the fourth pair sometimes partially rudimentary.

Genital segment much swollen and prolonged posteriorly into two processes as long as the abdomen and extending backward nearly parallel with it on either side. Fifth legs lacking.

Abdomen elongate and flattened; anal laminæ linear and minute.

Egg cases long and narrow; eggs as in Caligus.

(Caligodes, Caligus, and odes, a termination denoting likeness or similarity.)

This genus will be distinguished from Echetus under the latter genus (see p. 615), and it only remains to separate it here from van Beneden's genus, Scixnophilus. In the latter the free thorax segment is very short and wider than long, as it is in Caligus, while in the present genus the free segment is much elongated. Again in Scixnophilus the genital segment is without processes or appendages, while here it is prolonged on either side into an appendage as long and as large as the abdomen. In Scixnophilus, also, the second maxillipeds are very large and massive, while here they are of moderate size.

1. Abdomen wide and produced into posterior lobes; fourth legs four-jointed with

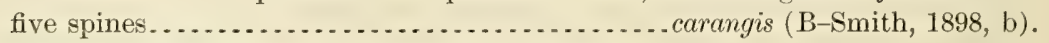

1. Abdomen without lobes or processes, of medium width ...............

2. Processes on genital segment longer than the abdomen; fourth legs inserted close to the carapace, two-jointed with two spines.

megacephalus, new species.

2. Processes on genital segment shorter than the abdomen; fourth legs inserted some distance back of the carapace, three-jointed with one small spine.

laciniatus (Kröyer, 1863). 


CALIGODES MEGACEPHALUS, new species.

Plate XVI.

Female.-Carapace orbicular, a little longer than wide nearly onefourth the entire length. Frontal plates distinct and furnished with small lunules, which are better dereloped than those on Echetus. Frontal margin deeply incised at the center, with the remains of the basal portion of an attachment filament still left in the incision. In this genus, therefore, the development is similar to that of Caligus, and the larva at one period is attached by means of a frontal filament.

Posterior sinuses small, narrow, and inclined toward the central axis; median lobe but little more than one-third of the entire width, projecting half its length back of the lateral lobes. The latter are rather pointed and curved inward at the tips. Thoracic area small, half the width and a third of the length of the carapace. Eyes small and situated far forward. Free segment elongate, a little more than half the length and one-third the width of the carapace, contracted where it joins the latter, but widened through the bases of the fourth legs (fig. 187).

Genital segment also elongate, flask-shaped, produced into a long neck anteriorly, while at the posterior end it extends backward in a narrow lobe on either side of and nearly as long as the abdomen. On the dorsal surface of this segment there is a broad horseshoe-shaped curve, the toe of the shoe formed by a slight projection just over the anus, while the sides of the shoe extend forward in a curve parallel with the margin of the segment. Abdomen elongate, nearly as long as the genital segment, only one-fifth as wide as long, and the same diameter throughout, except at the very tip. It shows no trace of segmentation. The anal papille are very minute and inclined toward each other. The egg cases are narrow, while the eggs are thick and probably not very numerous, although that can not be decided with certainty, since the cases are broken and the posterior portion is lacking.

Of the ventral appendages the anterior antenne are as long as the frontal plates, the terminal joint longer than the basal, and both armed with setre in the usual manner.

Posterior antenne with a short basal joint and a long terminal claw hent into a sickle shape. There is a short and blunt accessory spine at the base of the first joint.

The first maxillie are little more than a swelling on the ventral surface of the carapace. The second maxille are broad and triangular, and as long as the mouth tube. They are removed some little distance from this tube on either side and are rather blunt at the tip.

The first maxillipeds are short and stout, the joints approximately even, the terminal claws short. The second maxillipeds are large and 
strong, the terminal claw three-fourths as long as the swollen basal joint, with a large tooth on its inner margin near the base. Furca small, the base about the same length as the branches. The latter are slender, well separated, and nearly parallel. This furca is reenforced on either side by a stout curved spine, situated about halfway between the furca and the bases of the first legs and a little distance from the mid line.

First legs short and stout, the last joint bearing a single short terminal spine, not curved, and the usual three plumose setæ on its posterior border. There are no terminal claws.

The second legs are like those of Caligus in segmentation and appendages, with the spines on the three joints of the exopod the same size and rather small. Rami of the third legs close together, each twojointed and furnished with the usual setæ and fringe of hairs. Fourth legs two-jointed, the joints the same size and length, the second one terminating in a single spine of medium size. Fifth legs entirely lacking.

Total length, $6.1 \mathrm{~mm}$. Length of earapace, $1.25 \mathrm{~mm}$. ; width of same, $1.1 \mathrm{~mm}$.; length of genital segment, $2 \mathrm{~mm}$. $(4 \mathrm{~mm}$. including the posterior processes); length of abdomen, $2.2 \mathrm{~mm}$.; length of free segment, $0.7 \mathrm{~mm}$.

Color a dark yellowish brown, abdomen and egg strings darker than the rest of the body.

(megacephalus, $\mu \dot{\varepsilon} \gamma \alpha s$ large and $\kappa \varepsilon \phi \alpha \lambda \dot{\eta}$ head.)

There is but a single female of this species in the National Museum collection, numbered 6103 which was taken from the underside of the mouth of a silver gar (Lepisosteus osseus) at Woods Hole. It has apparently shrunk somewhat in the preservative, but as the shrinkage has been uniform it has not affected the proportions of the different parts.

This is of importance, because the details of the appendages in the two species of this genus already described are meager, especially for the species laciniatus, the type. Hence the distinction of species must be based upon the relation of the different parts. This will appear to better advantage in tabular form.

\begin{tabular}{|c|c|c|c|}
\hline Measurements. & Laciniatus. & Carangis. & $\begin{array}{l}\text { Megaceph- } \\
\text { alus. }\end{array}$ \\
\hline Total length............... & $\begin{array}{l}m m . \\
5-5.5\end{array}$ & $\begin{array}{l}m m . \\
11-12\end{array}$ & $\begin{array}{c}m m . \\
\overline{6} .1\end{array}$ \\
\hline 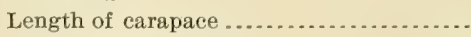 & .75 & $\quad 3.6$ & 1.25 \\
\hline Length of free segment . . . . . . . . . . . . . & 1.3 & .2 & .7 \\
\hline Length of genital segment............... & 2.9 & 6.3 & 4 \\
\hline Width of carapace ....................... & .8 & 1.7 & 1.1 \\
\hline Width of genital segment................ & 1.7 & 1.5 & 1.5 \\
\hline
\end{tabular}



From this table it can be seen that the species carangis is about twice the length of the other two, which are themselves approximately equal. But the carapace in carangis is only one-seventh the entire length, while in megacephalus it is a quarter. The free segment in megacephalus is actually three and a half times as long as in carangis, or proportionately seven times the length, and yet it is only half as long as the free segment in laciniatus. The relative width of the genital segment and carapace also vary greatly in the three species.

And if Kröyer's figure of the ventral surface of laciniatus is to be trusted for details of the appendages, the second maxillipeds in that species have no tooth at the base of the terminal claw, and there are no accessory spines in connection with the furca.

\section{Genus ECHETUS Kröyer.}

Carapace minute, a very small portion of the entire length; frontal plates well defined and furnished with lunules. First maxillæ and furca lacking; second maxillæ simple.

Free thoracic segment very narrow and much elongated, forming a long neck connecting the carapace and the genital segment.

First and fourth legs uniramous, the fourth pair partially rudimentary; second and third pairs biramous. Genital segment swollen sereral times the size of the carapace, without appendages or procexises. Abdomen an elongate spindle attached to the genital segment by a very short and narrow neck; anal laminæ linear, minute. Egg cases a little longer than the abdomen, eggs as in Caligus.

(Echetus, the name of a king mentioned in Odyssey, line 85.)

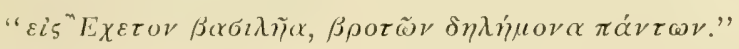

This name is peculiarly appropriate, as can be seen from a translation of the context, "And I shall send you to King Echetus, destroyer of all men, who will eut off your nose and ears with pitiless steel, and draw out your vitals and give them to dogs to eat raw."

Only one species known.

\section{ECHETUS TYPICUS Kroyer.}

Plate XVII.

Female.-Carapace about one-twentieth the entire length, longer than wide. Frontal plates well defined and furnished with small lunules, which are widely separated and not fully visible dorsally. The median incision between the two plates is as deep as the plates themselves, reaching the margin of the cephalic area. In this incision can be plainly seen the remains of the base of an attachment filament similar to those in Caligus. 
This indicates plainly that the genus has a development similar to that of the other members of this subfamily.

Posterior sinuses shallow with divergent sides; median lobe foursevenths the entire width, projecting far behind the lateral lobes, with nearly straight, inclined sides, and an emarginate posterior border. Lateral lobes short and well rounded. Thoracic area very small, the groove which defines its anterior border reaching only a short distance in front of the posterior sinuses, or about one-third the entire length of the carapace.

The longitudinal grooves separating the lateral from the cephalic areas are not well defined and are consequently difficult to trace. Eyes small and situated well forward.

Free thoracic segment cylindrical, about one-fourth the width of the carapace, contracted considerably just before joining the latter and prolonged posteriorly into a narrow, thread-like neck, nearly twice the length of the rest of the body.

The fourth legs are attached close to the carapace just back of the constriction.

Genital segment approximately an ellipsoid, two and a half times as long and twice as wide as the carapace. It is flattened somewhat dorsoventrally and has three lobes on the posterior margin, a short blunt one at the base of each of the egg cases and a smaller median one. The dorsal surface of this segment is marked by two ridges which start from the center of the lateral margins on either side and curve in toward each other and pass backward close together alongside the median line to the posterior median lobe. The areas at the posterior end of the segment outside these ridges are darker in color than the rest of the segment, and their surface is wrinkled irregularly. They contain the ovaries and the internal oviduct.

The abdomen is an elongated spindle, nearly twice the length of the genital segment and half its width, unsegmented. It is contracted into a very narrow wasp-waist where it joins the genital segment and tapers evenly and gradually toward the posterior end. It is attached to the ventral surface of the genital segment, a short distance in front of the posterior end, and in a side view stands out nearly at right angles to the longitudinal axis of the segment.

Anal papillæ linear, almost thread-like, but quite long and tipped with three short setæ. Egg tubes narrow, only one-quarter as wide as the abdomen but about the same length, each containing 40 to 50 eggs.

Anterior antennæ the same length as the frontal plates; basal joints thick, conical, and heavily armed with plumose setæ; terminal joints the same length as the basal, cylindrical, and bluntly rounded at the ends where they show the usual nonplumose setæ.

Frontal plates peculiar in that the outer portion between the lunules 




and the antennie curves forward and projects considerably, looking like the stumps of an accessory pair of antennæ.

Posterior antennæ small, with a stout basal joint and a long slender terminal hook, not bent very sharply. They are situated far forward almost at the very anterior margin of the carapace. No trace could be found of the first maxilla or the furca after the most careful search.

Second maxillie short and wide, triangular in outline with swollen bases, and bluntly rounded at the tip. They are closely appressed to the side of the mouth tube and are about two-thirds its length. The mouth tube is short and wide, almost a semicircle in outline, and flattened against the rentral surface of the carapace. It does not seem capable of being raised any distance from the latter as in Caligus and other genera.

First maxillipeds short and comparatively stout, the two joints about the same length; terminal claws short and stout, the inner one twice as long as the outer. Second maxillipeds greatly enlarged and very strong, evidently serving as the principal organs of attachment to its host. The basal joint is much swollen and furnished with powerful muscles; the terminal claw is two-thirds as long as the basal joint and strongly curved. No accessory spine could be seen upon the specimens examined.

The first thoracic leg's are long and narrow, the second joint five times as long as wide and cylindrical. The terminal joint is also much longer than wide, and armed as in Caligus, with three terminal claws of moderate length, three plumose setre on the posterior margin, and a long slender seta at the corner between the two. Second legs large, with a long basal joint and a three-jointed endopod and exopod, the joints of similar size and shape, and armed with spines and plumose setie, as in culigus. Third leg's also large, the rami close together, each two-jointed and furnished with the usual number of plumose setie. The spine at the base of the exopod is of medium size and acuminate. Outside of the exopod on the margin of the apron is a wide transparent flap, similar to that alound the edge of the carapace, and supported by numerous wavy hair-like ribs. Fourth legs short and stout, two-jointed, the joints about equal. The terminal joint carries three terminal spines and one on the outer margin, all nearly the same size. No trace of the fifth legs can be found.

'Total length, 2:.5 mm. Length of carapace, $1.1 \mathrm{~mm}$; width of sime, $1 \mathrm{~mm}$.; length of free segment, 14 mm.; length of genital segment, $3.1 \mathrm{~mm}$; length of abdomen, $5.5 \mathrm{~mm}$.; length of egg strings, $6 \mathrm{~mm}$.

Color of the carapace, a light yellowish hrown, of the long necklike free segment a dark hrown, of the genital segment a sulphur yellow except in the posterior areas of the lorsal surface outside the ridges, where the yellow is mixed with dark brown; color of the abdo- 
men a brownish yellow, considerably darker than the genital segment; of the egg strings a dark brown.

(typicus, typical, that is, the type of the genus.)

The National Museum collection includes three unnumbered lots collected by Dr. H. M. Smith from the inside of the operculum of the common channel bass (Sciznops ocellatus Linneus) in the fish markets in Washington city.

In 1863 Kröyer published the description of some specimens of female copepods which he had obtained from this same channel bass at New Orleans. He called the fish Convina unimaculata in his manuscript. He states frankly that the parasites had no head and only a portion of the long and slender neck. But they seemed to him so different from any of the others he had examined that he established for them a new genus Echetus, and a new species, typicus. From his figures and description there is no doubt that his specimens were the same as those here described, especially as they were obtained from the same species of fish. The names which he gave have accordingly been adopted, and the genus designation, which has already been explained (p. 611) seems peculiarly appropriate for a creature which burrows into the flesh of its host the entire length of the carapace and long free segment, leaving nothing but the genital segment and abdomen exposed.

So firm is the hold which the creature thus obtains that it is impossible to remove one entire without cutting away the flesh from around its neck and carapace. Those which Kröyer obtained were probably pulled out without cutting the flesh, with the result that the free segment broke somewhere near the center, to judge by the measurements which he gives. For the obtaining of the head intact upon several of the present specimens the author is deeply indebted to the persistent and careful efforts of Doctor Smith. And the result fully justifies the efforts, for the addition of the head changes entirely the systematic position of the genus and its relationships. Kröyer considered that the portion which he obtained indicated considerable degeneration. He states that "the large knobs on the dorsal surface are, as it were, the beginning of a monstrosity of the genital parts observed in Lernæ branchialis and L. cyclopterina, and indicates an approximation to those forms." And in accordance with this view he places the species in a group which he designates as Lernæocerina (Lernæidæ), including the most degenerate forms known. But the general arrangement of the various body regions, together with the details of the carapace and the appendages, show at once that it belongs to the subfamily Caliginæ now under consideration. It thus takes its place among the least rather than the most degenerate forms.

It is most closely related to the genus Caligodes, founded by Heller in 1865. On comparing it carefully with the three species already 


known in that genus, the following differences may be noted. First, the carapace is relatively much smaller here and ovate instead of orbicular. Again, the free segment or neck is nearly twice as long as in Culigodes, and it is the same diameter throughout, instead of being enlarged where it joins the genital segment. The latter is also very different, having no processes of any kind in Echetus, but simply short and rounded lobes, such as are common in Caligus and other genera.

The dorsal surface of this segment is also marked by the ridges alrealy described, in a manner totally unlike Caligodes. Here the abdomen is a symmetrical elongated spindle, while in Caligodes it is broad and Hattened, and in the species carangis is produced into posterior processes, like the genital segment. In this genus also the fourth legs are different from those in the three species of Caligodes, but the latter differ as much from each other, so that this could hardly become a generic distinction.

\section{Genus LEPEOPHTHEIRUS Nordmann.}

Carapace large, shield-shaped. Basal joints of the first antennæ without the sucking dises characteristic of Caligus; the terminal joints free. Mandibles toothed only on the inner margins. Second maxillæ small, bifurcate, the branches acuminate.

First and fourth thoracic legs uniramose, second and third biramose. Free thoracic segment simple, without dorsal plates. Genital segment also simple, without plates or processes. Abdomen one or two segmented. The young with a frontal filament during the chalimus stage, as in Caligus.

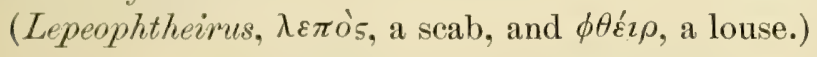

ARTIFICIAL KEY TO THE SPECIES.

This key is hased upon the different body relations, as in Caligus (see p. 555). The same methor of measurement is used as in the former genus, and here also are inclucterl all the valid species known at the present time, with the authority for each. The anthor considers L. obscurus (Baird) to be the male of $L$. hippoglossi, while the sprecimen called by Bassett-Smith (1896, plate Iv, fig. 2) "Caligus obscurus, Baird," is certainly not identical with Baird's species, but is probably $L$. thompsoni (see 1. 622). Three of Kröyer's "new species," gibbus, gracilescens, and rhombi, are considered identical with $L$. thompsoni, as are also Malm's $L$. branchialis and van Benerlen's $L$. gracilis, for reasons stated on page 622 . Of the remaining species which are incluterl in this key there are five which are based on single specimens, namely, cossuphi, longipalpus, molvi, grudratus, and robustus. Another, ornatus, was not very -learly differentiated by Milne-Elwards, and no figure of it has ever been published.

1. Carapace definitely more than half the entire length . . . . . . . . . . . . 2.

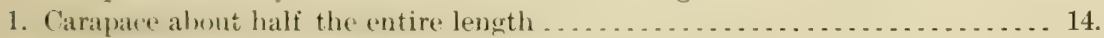

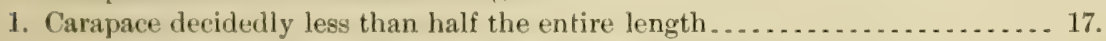

2. Abdomen two-jointed, half as long as genital segment or more......... 3.

2. Abdomen two-jointed, less than half the genital segment........... 4 .

2. Abdomen one-jointed, half the genital segment or more............ 5 .

2. Abdomen one-jointed, less than hali the genital segment ............ 10. 
3. Females, genital segment obovate, longer than wide; lobes long, conical; fourth legs long ............................. longipes, new species, p. 618 .

3. Females, genital segment orbicular, a fourth wider than long; lobes short; fourth legs short ............................... chilensis, new species, p. 658 .

4. Males, genital segment obovate, three-fifths the carapace; fifth and sixth legs separated ....................nordmannii (M-Edwards, 1840), p. 623.

4. Males, genital segment oblong, one-fourth the carapace; fifth and sixth legs close together ............................. ereesoni (Thomson, 1890)

5. Males, both fifth and sixth legs showing plainly ..................... 6.

5. Males, only fiith legs showing, but with a pair of dorsal papillæ at the base of the genital segment ........................................... 7 .

5. Males, only fifth legs showing; no papillie ....................... 8.

5. Females, genital segment without appendages of any sort............. 9.

6. Genital segment barrel-shaped, sides curved; no lobes; fourth legs reach-

ing its center . . . . . . . . . . . . . . . . . . . . . . . pectoratis (Müller, 1776).

6. Genital segment oblong, sides parallel; well lobed; fourth legs reaching

abdomen tip . . . . . . . . . . . . . . . . . . . . . chilensis, new species, p. 658 .

7. Genital segment obcordate, one-third the carapace; fourth legs reaching its center only .............................. appendiculatus (Kröyer, 1863).

7. Genital segment quadrate, one-fifth the carapace; fourth legs reaching fully to its tip..................................... robustus (Kröyer, 1863), p. 646.

7. Genital segment reniform, wider than long; anterior appendages lateral rather than dorsal . . . . . . . . . . . . . . . . . . . . . . . . . . . . . crabro (Kröyer, 1863).

8. Genital segment semilunar, wider than long; fourth legs nearly reaching its tip ............................... rotundiventris (B-Smith, 1898, b).

8. Genital segment diamond-shaped, longer than wide; lobes short, acute; fourth legs short..................................... bagri (Dana, 1852).

9. Genital segment ovate, wider than long; lobes acute, spine-like; fourth legs reach-

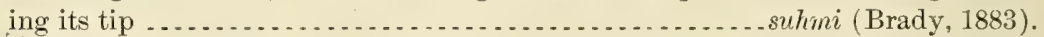

9. Genital segment elliptical, longer than wide; lobes broad, rounded; fourth legs reaching its center ...................nordmannii (M-Edwards, 1840 , p. 623.

9. Genital segment subquadrate, wider than long; lobes broad, rounded; fourth legs reaching abdomen tip ......................erecsoni (Thomson, 1890).

10. Males, both fifth and sixth legs showing plainly ........................

10. Females, only the fifth legs showing dorsally . . . . . . . . . . . . . . .

10. Females, no appendages visible dorsally ......................................

11. Genital segment elliptical; fourth legs reaching abdomen tip; branches of furca bifid . . . . . . . . . . . . . . . . . . . .....hippoglossi (Kröyer, 1837), p. 625.

11. Genital segment ovate; fourth legs not reaching its tip; furca branches flattened,

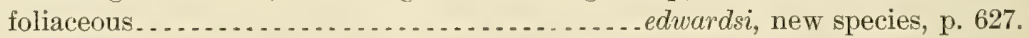

11. Genital segment elliptical; fourth legs medium; furca branches acuminate, close together......................... . . . . . . . dissimulatus, new species, p. 631.

11. Genital segment quadrate; fourth legs medium; furca branches blunt, flanged, widely separated . . . . . . . . . . . . . . . . . . parvicentris, new species, p. 635.

12. Genital segment orbicular; abdomen minute, spindle-shaped, much widened at center . . . . . . . . . . . . . . . . . . . . rotundiventris (B-Smith, 1898, b) .

12. Genital segment broad flask-shaped; fifth legs longer than abdomen.

cossyphi (Kröyer, 1863), p. 644.

12. Genital segment orbicular, wider than long; abdomen nearly covered by it posteriorly . . . . . . . . . . . . . . . . . . . . dissimulatus, new species, p. 631.

13. Genital segment elliptical, longer than wide; lobes short, narrow; furca branches bifid, truncate ... . . . . . . . . ......hippoglossi (Kröyer, 1837), p. 625.

13. Genital segment orbicular, wider than long; no lobes; fourth legs two-jointed with three spines........................... brachyurus (Heller, 1865). 


13. Genital segment subquadrate, as wide as long; no lobes; fourth leg spines all serrate. edwardsi, new species, p. 627.

13. (ienital segment obovate, longer than wide; lobes very wide and blunt; no serrate spines. .parviventris, new species, p. 635.

13. Genital segment obovate, longer than wide; no lobes; furca branches bifid, branchlets acute......................... bifurcatus, new species, p. 637. 14. Abdomen four-jointed, as long as genital segment; the latter trapezoidal. pacificus (Gissler, 1883), p. 642.

14. Abdomen two-jointed, as long as genital segment; latter elliptical; males. pollachii (B-Smith, 1896).

14. Abdomen two-jointed, shorter than genital segment .................... 15 .

14. Abdomen one-jointed, as long as genital segment; latter ovate; lobes short, pointed ............................. molice (M-Edwards, 1836-49).

15. Males, both fifth and sixth legs visible; genital segment narrow-ovate; abdomen joints unequal . . . . .............. . . . . . nordmannii (M-Edwards, 1840), p. 623.

15. Females, genital segment without any visible appendages. . . . . . . . . . . . . 16.

16. Genital segment obcordate; abdomen twice as long as wide; joints equal; free segment as long as wide; fourth legs four-jointed, five spines.

crabro (Kröyer, 1863).

16. Genital segment obcordate; abdomen twice as long as wide; joints equal; free segment three times as wide as long; fourth legs three-jointed, four spines................................. intercurrens (Kröyer, 1863).

16. Genital segment quadrate; abdomen as wide as long; joints equal; fourth legs four-jointed, five spines. . . . . . . . . . . . . . . . pectoralis (Müller, 1776).

16. Genital segment obcordate; basal abdomen joint four times terminal; fourth legs three-jointed, five spines................. grohmanni (Kröyer, 1863).

17. Abdomen two-jointed, longer than rest of body; genital segment triangular, twice

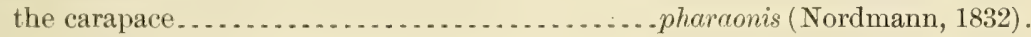

17. Abdomen two-jointed, longer than genital segment; females ................ 18.

17. Abdomen two-jointed, shorter than genital segment...................... . 19.

17. Abdomen one-jointed, three times the genital segment; latter subquadrate, spiny; lobes short. . . . . . . . . . . . . . . . . . . . . . . flores (van Beneden, 1892).

17. Abdomen one-jointed, a little longer than genital segment ... . . . . . . . . . . 22.

17. Abdomen one-jointed, shorter than genital segment . . . . . .

18. Genital segment oblong, half the carapace; basal abdomen joint four times terminal . . . . . . . . . . . . . . . . . .... longipalpus (B-Smith, 1898, b).

18. (ienital sexment whlong, as large as (arapace; basal abdomen joint twice terminal . . . . . . . . . . . . . . . . . . . . . . innominatus new species, p. 656.

19. Females, abrlemen distinctly more than half as long as the genital segment; fifth legrs concealed dorsilly . . . . . . . . . . . . . . . . . . . . . . . . . . . . . 20.

19. Females, abrlomen "learly less than half as long as the genital segment; fifth legs concealerl in rorsal view . . . . . . . . . . . . . . . . . . . . . . . . . . . . 21 .

20. Genital segment ovate; no lobes; fourth legs nearly reaching its tip.

sturionis (Kröyer, 1837).

20. Genital segment elliptical, lobes large; fourth legs not reaching its center. thompsoni (Baird, 1850), p. 619.

20. Cienital segment elliptical; lobs lurmu, hut short; ablomen half its wilth. salmonis (Kröyer, 1838), p. 640.

21. (ienital segment qualrate, as wide as long; joints of the aldomen nearly equal. pectoralis (Müller, 1776).

21. Cienital segment elongate, twice as long as wide; hasal ablomen joint three times terminal . . . . . . . . . . . . . . . . . . . . . . . . . . . bagri (Dana, 1852).

21. Crenital segment tlask-shaped, a fifth longer than wide; hasal abdomen joint the longer .......................................... 186adratus (Krö). 
21. Genital segment oblong, twice as long as wide; basal abdomen joint the wider, but shorter.............................. monacanthus (Heller, 1865).

22. Females, genital segment quadrate, nearly as long as carapace; no lobes. pollachii (B-Smith, 1896).

22. Females, genital segment bell-shaped, half the carapace; lobes long and broad ................................. exculpatus (Fischer, 1860).

23. Females, genital segment elliptical, lobes short and broad; fifth legs concealed dorsally ................................... salmonis (Kröyer, 1838), p. 640.

23. Males, genital segment spindle-shaped; lobes narrow and two-thirds as long as abdomen................................. flores (van Beneden, 1892).

23. Males, genital segment broad acorn-shaped; no lobes; both fifth and sixth legs visible................................ intercurrens (Kröyer, 1863).

LEPEOPHTHEIRUS LONGIPES, new species.

Plate XVIII, figs. 206-211, 222.

Female.-Carapace elliptical, one-seventh longer than wide. Frontal plates well rounded and deeply incised at the center. Posterior sinuses of medium width, with the sides nearly parallel; median lobe rather more than half the entire width and projecting well back of the lateral lobes. Free thorax segment four-fifths as wide as the genital segment, four times as wide as long.

Genital segment oblong, somewhat less than half the width of the carapace, a little wider posteriorly where it is produced into a narrow conical lobe on either side.

Abdomen narrow, oblong, two-jointed, the basal joint somewhat the larger. Anal laminæ long, narrow, and curved inward so much at the tips that the two overlap. Egg strings about the same diameter as the abdomen and three-fourths as long as the body.

Anterior antennæ two-thirds the length of the frontal plates, wellarmed with setæ; posterior antennæ sleıder, the terminal claw much longer than the basal joint and curved nearly a third of its length. Both pairs of maxillæ very slender, the first pair not much curved, the second pair divided about to the center with the branches close together, parallel, and both curved slightly away from the rostrum. Furca narrow and abruptly constricted at the base; the branches very thick and stout, divergent, and much longer than the base.

Second maxillipeds stout, the claw three-quarters the length of the swollen basal joint with an accessory spine longer and stouter than ordinary. The plumose setæ on the first swimming legs are short and weak; the two outer terminal claws are pectinate, while the inner one is smooth. On the second legs the spine at the tip of the basal joint of the exopod is very large, nearly as long as the joint itself, and the spines on the other two joints are also large. There is a curved claw at the tip of the second joint of the endopod of these legs which is totally unlike anything observed in other species. The fourth legs are very large, relatively much longer than in any other species. The 


basal joints are thick and swollen, and they reach nearly to the center of the genital segment, while the three terminal joints, much narrower, extend well beyond the tips of the anal papillæ. There are the usual five spines on these legs, arranged in the customary manner. There are several species (erecsoni, hippoglossi, nordmannii, etc.) in which the fourth legs of the male reach beyond the tips of the anal papillæ, but this is the first instance where the same is true of the female. Furthermore, these legs in the present species are far larger than those of any known male, the basal joint on each leg being actually larger than the entire free segment to which it is attached.

This, therefore, may be taken as the distinguishing characteristic of the species.

Total length $8.5 \mathrm{~mm}$. Length of carapace $4.25 \mathrm{~mm}$.; width of the same $3.6 \mathrm{~mm}$.; length of genital segment $2.1 \mathrm{~mm}$.; length of abdomen $1.25 \mathrm{~mm}$.; length of egg strings $7 \mathrm{~mm}$.; length of the fourth legs 4.2 mm., including the spines.

The color in preserved specimens is a dark yellowish gray, without any pigment visible.

(longipes, longus, long, and pes, foot.)

This species is very clearly differentiated from all other by the size of the fourth legs, by the shape of the furca, and by the curved claw on the endopod of the second legs.

The National Museum collection unfortunately includes only a single unnumbered lot of two females, and there are no data as to the locality or the host from which they were obtained.

\section{LEPEOPHTHEIRUS THOMPSONI Baird.}

Plate XVIII, figs. 212-219.

Leperphtheinus thompsoni BAIRD, 1850, p. 278, pl. xxxiIr, fig. 2.-WHite, 1850, p. 121.-Bassetт-Sнтth, 1899, p. 455.-T. Sсотт, 1900, p. 152, pl. v, figs. 43-45. Caligus gracilis P. J. van Beneden, 1851, p. 90, pl. II, figs. 1-7; 1861, p. 147.RICHIARDI, 1880, p. 148.

Caligus branchialis Steenstrup and Lüthen, 1861, p. 362, pl. II, fig. 3.-Claus, 1864, p. 365, pl. xxxir, figs. $3-7$; pl. xxxrv, figs. 8 and 9.

Lepeophtheirus thombi KRöY ER, 1863, p. 118, pl. v, fig. 5, a-i.

Leprophtheirus giblus Kröyer, 1863, p. 121, pl. xvII, fig. 2, a-i.

Lepeophtheirus gracilescens KRÖYER, 1863, p. 124, pl. vi, fig. 2, a-i.

Lepeophtheirets gracilis Carus, 1885, p. 359.--Brian, 1898, p. 12, pl. I, fig. 5; 1899 , p. 3.

Lepeophtheims obscumes BAsметT-Sмттп, 1896, a., p. 157; 1896, b., pl. iv, fig. 2.

Lepeopletheirus branchialis B AsSETT-Sмптн, 1899, p. 456.

Lepeophtheims obscums T. ScoтT, 1900, p. 153, pl, vi, figs. 16-19.

F'mule.-Carapace obovate, a little wider than long, not much narrowed anteriorly. Frontal plates narrow but distinct, without any incision at the center. Posterior sinuses widely triangular and shallow, leaving a median lohe less than half the entire width and not projecting beyond the lateral lobes. 
Of the grooves separating the carapace areas, the crossbar of the " $\mathrm{H}$ " is much farther forward than in the preceding species, fourninths, or nearly half, the distance from the posterior margin. Moreover, it is strongly curved forward, and, together with the posterior portion of the lateral grooves, it forms a nearly perfect semicircle. The lateral grooves are not parallel with the margin of the carapace, but diverge widely from it. The eyes are smaller than in innominatus, but are situated in about the same relative position.

The free thoracic segment is less than half the width of the genital segment, subtriangular in shape, and narrowed into a neck anteriorly where it joins the carapace. This is in marked contrast with innominatus, the anterior margin of whose free segment is its widest part.

The genital segment has an elongate flask shape, narrowed into a neck anteriorly, and then widening to about two-thirds the width of the carapace. It is one-fourth longer than wide, with a deeply emarginate posterior border and well-rounded lobes at the angles. The abdomen is two-fifths the width of the genital segment and two and a half times as long as it is wide.

It is two-jointed, the basal joint nearly three times as long as the terminal. The abdomen is somewhat swollen at the joint, and then tapers rapidly toward the tip. The anal laminæ are small and widely separated, with the tips curved in toward each other. The setæ are also very small and slender.

The egg strings are only half the diameter of the abdomen and about as long as the entire body. The eggs are thick, and number 125 or 130 in each string.

The first antennæ are relatively smaller than in innominatus, but are as well provided with setæ and spines; the second pair are small, with a short terminal hook.

Both pairs of maxillæ are slender, the second pair divided nearly to their base with narrow, slender, divergent branches.

The furca is relatively large, fully twice the size of that in innominatus; it is strongly narrowed at the base and then widens into a broad $U$-shape, with dilated branches.

The second maxillipeds are large but not to be compared with those in innominatus for size; the terminal claw is nearly as long as the basa] joint, but rather slender and strongly curved.

The first swimming legs have a stout spine on the posterior margin of the basal joint and another at the anterior distal end of the second joint, with the usual setæ and terminal spines on the last joint. The fourth legs are short and small, four-jointed with five spines; but one of the spines is at the outer distal corner of the basal joint and there is none on the second joint. These legs are about one-third the length of the genital segment. The fifth legs are invisible in a dorsal view. 


Total length $8.4 \mathrm{~mm}$.; length of carapace $3.2 \mathrm{~mm}$; width of same $3.4 \mathrm{~mm}$.; length of genital segment $2.8 \mathrm{~mm}$.; length of abdomen 2.1 $\mathrm{mm}$.; length of egg strings $8.5 \mathrm{~mm}$.; 125 or 130 eggs in each.

General color a light yellow, the hard parts turning much darker on preservation.

(thompsoni, to William Thompson, who did much valuable work on the Irish fauna.)

Male.-Carapace elliptical, one-sixth longer than wide, with evenly rounded sides. It is twice as long and nearly three times as wide as the rest of the body. The posterior sinuses are shallow and considerably narrower than in the female, but the grooves and general proportion of the parts are the same.

The free segment is more than half the width of the genital segment and is swollen at the center through the bases of the fourth legs, so that it becomes spindle-shaped.

The genital segment is orbicular, of about the same length and width, one-third the length of the carapace. It carries two pairs of setiferous papille, one on the lateral margins near the posterior corners and the other pair at the corners.

The posterior margin between the latter papillæ is slightly concave. The abdomen is half the length of the genital segment, a little longer than it is wide, and strongly narrowed at the base. The anal laminæ are minute and carry small setr. In the appendages there is the usual increase in the size of the second antennæ and second maxillipeds; otherwise the appendages are like those in the female.

Total length, $4 \mathrm{~mm}$. Length of carapace, $2.8 \mathrm{~mm}$.; width of the same, $2.4 \mathrm{~mm}$.; length of genital segment, $0.7 \mathrm{~mm}$.; length of abdomen, $0.4 \mathrm{~mm}$.

The specimens of this species in the possession of the National Museum were obtained from Rev. A. M. Norman. The lot is numbered 8032 and consists of females only, taken from the turbot, Rhombus maximus, at Cornwall, England.

In all probability this is the species referred to by S. I. Smith (1874, p. 281) as found on the sting-ray (Dasyatis centrura) in Vineyard Sound; but those specimens were not preserved, and none have since been obtained from the same fish.

But during the past season the author received from Mr. V. N. Edwards a single female of this species taken from a goosefish at Woods Hole.

There has been the utmost confusion in the description of the species of Lepeophtheirus infesting the common turbot and brill of European waters. There are no less than seven species of this one genus, all ('laiming to be valid and all infesting the same fish. These seven species are as follows, given in the order of their discovery: Lepeophtheimus thompsoni Baird, 1550; gracilis van Beneden, 1851; branch-

Proc. N. M. vol. xxviii- $04-40$ 
ialis Steenstrup and Lütken, 1861; rhombi, gibbus, gracilescens Kröyer. 1863; obscurus Bassett-Smith, 1896.

The figures given by the various authors all show the same general proportions, body regions, and appendages, especially the small fourth legs. It is obviously impossible that there should be so many species of the same genus on one fish and corresponding so closely. And when we come to examine the figures and descriptions carefully we are at a loss to discover anything of specific value. The differences are all trivial and of no greater value than those recorded under the single species Caligus rapax.

Bassett-Smith in his description of the species which he calls obscurus makes his specimens, which were all females, the same species as Baird's male, which the latter described in 1850.

This decision is based upon the bifurcation of the branches of the furca. If that were correct it would come the nearest to a specific difference of anything connected with the entire seven species. But Bassett-Smith in his first paper (1896) calls this species (obscums) a Lepeophtheirus; in another paper published the same year he labels the figure he presents Caligus, and puts a pair of lunules in the frontal plates; again in 1899 he goes back and calls it Lepeophtheimus.

In the face of such vacillation too much stress can not be placed upon the bifurcation of the branches of the furca, especially as this one detail is all he has ever presented in the way of a description.

Baird himself suggested in his original description that the male he described as obscurus might very well be the male of the species hippoglossi, only the female of which was then known.

If his figure be compared with that given by other authors of a male hippoglossi, the resemblance will be found very close.

Furthermore Bassett-Smith places a question mark in every instance after the name of his species. Until he can give us more convincing proof, therefore, and a better description of his species we are not warranted in accepting its validity.

With reference to Beneden's species it is enough to say that not very much credit can be given to an author who represents the fourth legs as attached to the basal apron of the third legs, while the true rami of the third legs are attached to the lateral lobes of the carapace(!).

A careful reading of Kröyer's diagnosis of the three species rhombi, gibbus, and gracilescens, together with a comparison of the figures he presents, will quickly convince one that the three are identical. All the details which he gives of the appendages show absolutely no differences, except trifling ones of size. The second antennæ, second maxillæ, furca, second maxillipeds, and third and fourth swimming legs are identical. The proportions of the different regions are also very nearly identical, only such slight differences as occur in any species. His specific distinctions, so far as one can judge, rest solely upon the 


size and shape of the carapace and of the genital segment, and he was working entirely with preserved material.

The carapace is the one part of all others to be modified in a preserving fluid, while a candid examination of the genital segment of any common species will show that it is capable of much variation, even in living specimens. We are compelled to the conclusion, therefore, that we have here only a single species subject to local variations, and that the various forms given as distinct species are nothing more than varieties. And of them all Kröyer's gracilescens is the most worthy of separation as a well marked variety.

With reference to Steenstrup and Lütken's species branchialis the figure which they give entire shows a genital segment quite different in shape from that which has been taken as typical of thompsoni. But the detail of the appendages, of which they present most admirable figures, corresponds exactly with thompsomi. And they add a partial figure showing the free and genital segments and the abdomen, which they declare illustrates a common variation, and which corresponds very closely with that here given. Furthermore, they, as well as Claus, give Caligus gracilis van Beneden as a synonym under Caligus branchirtis. The priority of branchiatis presumably rests upon the fact that it is a manuscript name given by Malm, to whom they ascribe the species. But as Malm's manuscript was never published, and hence Beneden's name, gracilis, antedates it by ten years, branchiclis would hare to be regarded as a synonym of gracilis rather than vice versa.

The important fact for us is that the two species are identical, and that the one (branchialis) for which we have reliable details seems to be identical also with thompsoni.

Finally the seven species here discussed agree remarkably in size, the range being from $7 \mathrm{~mm}$. in gracilescens to $8.4 \mathrm{~mm}$. in thompsoni, or less than a millimeter and a half, which is no more than would be expected in so large a species.

\section{LEPEOPHTHEIRUS NORDMANNII Milne-Fdwards.}

Plate XIX.

Calig,"s nordmamii IItLNe-EDWARDs, 1836-1849, pl. Lxxvir, fig. 1; 1840, p. 455.

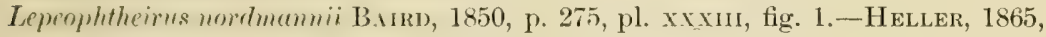
p. 180 , pl. xvi, figs. 1 and 2.-Rathiun, 1884, p. 487.-Thompson, 1895, p. 118, pl. XXvir, fig. 5, a.-T. Scotr, 1900, p. 151, pl. v, figs. 32-37.

Female.-Carapace orbicular, as wide as long, and very squarely truncated posteriorly, or even slightly emarginate. Frontal plates small and narrow and not very well defined; posterior sinuses broad, deep, and well rounded. Median lobe about one-half wider than the lateral lobes, squarely cut or emarginate posteriorly, with sharp corners terminating in short spines. 
Grooves separating the carapace areas considerably different from those in other species. The two longitudinal grooves forming the sides of the "H" are strongly inclined toward each other anteriorly, and there are two crossbars instead of one, dividing the length of the carapace into quite even thirds. Eyes very small and situated just in front of the anterior crossbar. Free thorax segment subtriangular in shape and a little more than half the width of the genital segment.

Genital segment obovate, not quite half as wide as the carapace, with broad and well-rounded posterior lobes. Abdomen spindle shaped, half the length of the genital segment, with a strongly emarginate posterior margin. Anal laminæ large and curved in well toward each other.

The characteristic of the appendages is great length, combined with a reduction in width, making them appear very slender. The first antennæ are somewhat of an exception to this rule; they are slender, but are also very short and hardly show at all on the anterior margin. But in the second pair the terminal hook is nearly twice the length of the basal joint and is bent into an almost perfect sickle shape.

Both pairs of maxillæ are much elongated and narrowed, the branches of the second pair diverging considerably. The terminal claw of the second maxillipeds is longer than the basal joint and strongly curved, but its accessory spine is small and weak.

The furca is much elongated, with widely divergent and slender branches, which are somewhat enlarged at the very tips, but these tips are not acuminate in American specimens, as was noted by Baird in European specimens; they are rather blunt.

The first three pairs of thoracic legs are normal; the fourth pair have a spine at the outer distal angle of every joint and three terminal ones. The two largest of these latter are very distinctly toothed. The fifth pair of legs, which are ordinarily rudimentary papillæ, are in this species quite broadly foliaceous, but they do not protrude far from the ventral surface.

Total length, 10 to $12 \mathrm{~mm}$. Length of carapace, $5.5 \mathrm{~mm}$.; width of the same, $5.4 \mathrm{~mm}$.; length of genital segment, $2.85 \mathrm{~mm}$.; length of abdomen, $1.5 \mathrm{~mm}$.; length of egg strings, $7 \mathrm{~mm}$.

Color a dark yellow-white, without pigment spots of any kind.

Male. - Carapace a little longer than the rest of the animal and itself longer than wide, narrowed anteriorly and quite strongly convex. Frontal plates rather more distinct than in the female; frontal margin slightly rounded with a broad notch at the center. Free segment much longer and narrower than in the female, about one-fourth the length and one-fourth the width of the carapace; considerably widened at the center through the bases of the fourth legs. Genital segment acornshaped, longer than wide, much narrowed anteriorly and deeply emarginate posteriorly; furnished with two acute lobes on either side at the 


posterior corner. Abdomen only one-third the length of the genital segment, but two-jointed, the joints unequal, the basal one wider and the terminal one longer. Anal laminx small, nearly linear, furnished with short setæ.

Of the appendages the second antennæ are branched as usual in males. The first maxille are very long and sickle-shaped. The second maxillipeds have a stout spine or tooth on the inner margin of the basal joint. The other appendages are the same as in the female.

Total length, $5 \mathrm{~mm}$. Length of carapace, $2.75 \mathrm{~mm}$.; width of same, $2.5 \mathrm{~mm}$.; length of genital regment, $1.65 \mathrm{~mm}$.; length of abdomen, $0.75 \mathrm{~mm}$.

\section{(nordmannii, to Dr. Alexander v. Nordmann.)}

This species was first described by Milne-Edwards in 1840, under the genus Caligus. This error was corrected by Baird in 1850, and the species was placed under the genus Lepeophtheirus, which had been founded by Nordmann himself in 1832.

It is apparently confined to the sunfish of our own coast and in European water's, as all the recorded specimens have been obtained from that fish. And it is not very abundant, only a few specimens being obtained from among the many parasites which infest one of these fishes. The National Museum collection includes three lots, 6018, 12667,12668 , the first and last from the vicinity of Woods Hole, the other from Casco Bay.

\section{LEPEOPHTHEIRUS HIPPOGLOSSI Kröyer.}

Plate XX, fig. 6 in the text.

Caligus hippoglossi Kröyer, 1837, p. 625, pl. vi, fig. 3 A. and B.-MrLneEdwards, 1840, p. 456.-RAthke, 1843, p. 102.-Steenstrup and LÜtKen, 1861, p. 355.

Lepeophtheirus hippoglossi BAIRD, 1850, p. 276, pl. XXXII, fig. 12.-KRöYER, 1863, p. 131, pl. vi, fig. 5, a-d.-T. Scotr, 1900, p. 151, pl. v, figs. 38-42; pl. vr, figs. $1-2$

Femele.-Carapace elliptical, widest at the center, one-fourth longer than wide. Frontal plates very distinct, but rather narrow. Posterior sinuses shallow and widely separated, leaving the median lobe fully half the entire width of the carapace. This lobe has a very flat posterior curve and usually overlaps the free segment. The lateral lohes are short and curved inward strongly at their tips.

Free segment one-eighth the length of the carapace and four-fifths as wide as the genital segment, the portion to which the fourth legs is attached projecting strongly on either side.

Genital regment three-fifths the length of the carapace, narrow, elliptical in outline, the length to the width in the proportion of 5 to 4; posterior lobes narrow and pointed. 
Abdomen very small, about one-tenth the entire length, rather conical in shape, and terminating in a pair of small anal laminæ armed with short plumose setæ.

Terminal joints of the first antennæ long and slender, club-shaped, with only a few small setae. Second anterinæ with a stout basal joint and a long and strongly curved terminal claw. Maxillæ relatively very large, the first pair close to the tips of the second antennæ, the second pair in the usual place beside the proboscis. Each of this second pair is fully as large as the entire proboseis, projects far beyond the tip of the latter, and is bipartite for its terminal half. Each branch is the shape of a sharp cone with a wide flange or wing on either side at the center.

The proboscis is short and wide and bluntly rounded at the tip, mouth opening terminal. The mandibles are long and slender, the last joint short, quite strongly curved and toothed along its inner margin. First maxillipeds normal; second pair slender, the terminal claw but little more than half the length of the basal joint; the accessory spine so small as to be easily overlooked. Furea long, narrow at the base but flaring rapidly toward the tip, the prongs strongly flattened, laminate, and each divided nearly to its base by a narrow sinus, leaving the secondary branches with squarely truncate ends and parallel sides. The central sinus is a broad $U$-shape, with a square base and slightly converging sides.

The first swimming legs are stout, the basal joint with a short spine on its posterior margin, the second joint unarmed, the terminal joint as in other species. Third legs with large and powerful basal apron, but with very small and weak rami, scarcely projecting from the fringe along the border of the apron. Fourth legs large and stout, with four joints and four spines, the longest terminal one toothed on its outer margin. Fifth legs situated close to the openings of the oviducts and so rudimentary as to be scarcely visible.

Total length $12 \mathrm{~mm}$. Length of carapace $7 \mathrm{~mm}$; width of same $6 \mathrm{~mm}$; length of genital segment $4 \mathrm{~mm}$.; length of abdomen $1.2 \mathrm{~mm}$.; length of egg strings $15 \mathrm{~mm}$.

Color a light yellow, beautifully marked with spots of pink or red distributed all over the body and the basal joints of the fourth legs in an irregular pattern.

Male.-Carapace orbicular, as wide as long, the posterior sinuses broader than in the female, the median lobe relatively narrower and well rounded posteriorly, the lateral lobes not curved inward at their tips. Free thoracic segment wider than the genital segment and about half as long.

Genital segment small, of about the same length and width, and carrying two pairs of large papillæ. One pair projects backward from the lateral margin about one-third the distance from its posterior 


$$
\text { - }
$$



end; the other pair are situated at the posterior corners. The papillæ are all about equal in size and each is furnished with three small setæ.

The abdomen is rather more quadrilateral than in the female, the anal laminæe are larger, and their setæ are much longer.

The chief difference in the appendages is found in the usual enlarging of the second antenne and second maxillipeds. The fourth legs are also relatively larger and project beyond the tips of the setre on the anal papillie, but their structure is the same as that in the female.

Total length $7.2 \mathrm{~mm}$. Length of carapace $4.85 \mathrm{~mm}$. ; width of same $4.75 \mathrm{~mm}$.; length of genital segment $1.35 \mathrm{~mm}$.; length of abdomen $0.7 \mathrm{~mm}$.

Color as in the female.

(hippoglossi, generic name of its host.)

Like the preceding species, this one was first described by Kröyer and Milne-Edwards under the genus Caligus, and was first recognized as a true Lepeophtheims by Baird in 1850 .

Like nordmannii also it seems to be practically confined to a single species of tish, the halibut, the few specimens obtained from other tish having probably been rubbed off a halibut caught in the same boat, as suggested by various authors.

The National Museum collection includes lots numbered 8031, 12038 , 12631,12634 , and 30044 , all from halibut caught off Greenland, Iceland, and Cape Ann. 8031 are type specimens from Shetland.

\section{LEPEOPHTHEIRUS EDWARDSI, new species.}

Plate XXI; Plate XXII, fig. 258; figs. 1, 4a, 4b, 11, 31, 34, 39 in the text.

Femule.-Carapace orate, widest posteriorly, longer than wide. Frontal plates distinct, strongly curved, not quite half the width of the carapace. Posterior sinuses shallow, wide, and well rounded. Median lobe three-eighths the entire width, squarely truncated postrriorly, and projecting well hack of the lateral lobes. The latter are short, blunt, and straight (fig. 244).

- Free thoracic segment of medium length and about half as wide as the genital segment, contracted anteriorly where it joins the carapace. Genital segment slightly obovate with gracefully rounded sides and angles, contrated to a very short neck before joining the abdomen. 'The latter is one-fifth as long as the genital segment, wider than long, and tapering postriorly. It is made up of a single joint which is cut for one-third of its length at the anus. Anal papilla small, wider than long, with short and stout setae. Hgg tubes nearly as long as the entire body and as wide as the abdomen, each containing 75 to 80 eggs.

Interior antenne of medium size, and well armed with spines and seta; posterior pair rather slender and strongly curved.

All the other appendages are cither lamellate or furnished with lamella somewhere in their structure. 
The two pairs of maxillæ have wide wings along either side of the the central spines; in the second maxillæ, although the spines are well separated and divergent, these wings nearly touch each other at the center. The first maxilliped has a spatulate lamella instead of a spine inserted in the inner margin of the terminal joint near its center.

The second maxillipeds are large and stout, with a swollen basal joint furnished on the posterior ventral margin, where it joins the body, with a stout tongue-like lamella which projects downward at a right angle to the ventral surface. The terminal claw is three-quarters as long as the basal joint, rather slender, and furnished with a very long and hair-like accessory spine on its inner margin. Furea large, the base longer and narrower than the branches, and both base and branches strongly flattened into fan-like lamellæ. The branches are nearly twice as wide as long, with radiating ridges and lines extending outward from the thickened center. The median sinus is triangular, the branches being so widened toward the tip as to nearly meet.

The first swimming legs have a small spine on the end of the basal joint pointing outward, and a much stouter, blunt spine on the posterior border of the same joint pointing backward.

The three claws on the terminal joint are about equal, with serrated lamellæ along their posterior margins. The second legs have a wide, rounded flange or wing along the outer margin of the exopod. The fourth legs are stout and four-jointed; the basal joint is swollen and carries a slender, flexible hair on its outer margin near the distal end.

The short curved claw at the tip of the second joint, and the longer ones on the third and fourth joints, are flanged on one or both sides with serrate laminæ.

The fifth legs are distinct and of medium size, plainly visible ventrally, but not dorsally.

Total length, $7.5 \mathrm{~mm}$; length of carapace, $4 \mathrm{~mm}$; width of same, $3.75 \mathrm{~mm}$.; length of genital segment, $2.25 \mathrm{~mm}$.; length of abdomen, $0.6 \mathrm{~mm}$.; length of egg strings, $5.5 \mathrm{~mm}$.

Color a delicate pinkish yellow, with small pigment spots of a purplish or reddish brown distributed evenly over the entire dorsal surface, so that the color is uniform throughout.

Under strong magnification each spot is seen to be very irregular, and to consist of a dark-blue center bordered with purple, in both of which the pigment is in small granules of uneven size, those in the purple being the larger. From this granular center narrow convoluted processes extend outward in every direction. In these the pigment is dark orange in color and is not granular, but like a watercolor wash. The combination is very striking, and affords the most noteworthy instance of pigmentation thus far found among these parasites. 




Male.-Carapace as in the female, except that it is relatively much larger, five-eighths of the entire length (fig. 245).

Free thoracic segment considerably shortened by the overlapping of the median lobe of the carapace. Unlike the condition in most males this segment is not proportionally wider than in the female. The genital segment and the abdomen together form an almost perfect oval, the widest end being anterior, while it narrows rapidly posteriorly.

The genital segment is one-third the length of the carapace, considerably wider than long, and scquarely truncated posteriorly. It is furnished with two pairs of large papillie - one on the lateral margins, one-third the distance from the posterior end, the other pair at the posterior corners. In both pair's the papillæe are sharply conical and furnished with quite large plumose setæ. The testes are very large, elongate-elliptical in shape, and they fill nearly the entire segment. The semen ducts open on the posterior ventral surface, on either side of the abdomen. The abdomen and the anal papillæ are similar to those of the female. There is the usual difference in the appendages, but, while the second antennæ are increased in size, they are not branched as much as in most species.

Instead, at their bases are two large corrugated ridges of chitin, inclined diagonally outward from the mid line, which serve to prevent slipping.

Total length $3.6 \mathrm{~mm}$. Length of carapace $2.2 \mathrm{~mm}$.; width of same $2.2 \mathrm{~mm}$.; length of genital segment, $0.8 \mathrm{~mm}$.; length of abdomen $0.3 \mathrm{~mm}$.

Color as in the female.

(eduardsi, to Vinal N. Edwards, of the United States Fish Commission at Woods Hole, who discovered the species and collected nearly all the specimens.)

Nenplins.-Body oborate or slightly spindle-shaped in outline, and almost exactly twice as long as wide. The posterior end is quite squarely truncated, while the anterior end is well rounded (figs. 39 and 257).

There are the usual three pairs of appendages, which do not differ in form from those of other nauplii, except perhaps that they are a little stouter. But the balancers on either sicle of the anus are considerably shorter and wider than in most nauplii examined. They are also considerably swollen at the outer ends and somewhat curved.

The pigment is a distinctive bright purple, foreshadowing that of the adult, but it is distributed very sparingly in irregular patches, which vary much in position, size, and shape. Sometimes there are three pairs of patches along the sides of the posterior part of the body, a central patch between the anterior pairs, and an anal pateh, each resembling a piece of tattered cobweh. But more often there is no regularity whatever in the arrangement, the only constant factor 
being that the pigment is confined to the posterior two-thirds of the body, with traces also in the antennules. The eye and brain are distinctly bilobed, each half semilunar in shape, the two convex sides facing each other and fused at their centers, giving the whole very much the shape of a rough $\mathrm{H}$.

Total length $0.5 \mathrm{~mm}$.; width $0.26 \mathrm{~mm}$.

After the first moult the larva becomes decidedly ovate, the pigment increases considerably in area, the eye moves back from the anterior edge of the carapace, and through the skin at the posterior end of the body can be seen the segmentation and the rudimentary legs of the metanauplius stage.

Chatimus. - Carapace elongate and spindle-shaped; frontal plates distinct and projecting strongly, giving the anterior portion of the body a triangular outline; the frontal filament at the apex of this triangle large and strong. The anterior portion of the carapace is considerably narrowed. The posterior sinuses are also narrow and not very deep. The median lobe is seven-tenths of the entire width and projects for three-quarters of its length behind the small lateral lobes. The transverse groove of the carapace is only a short distance in front of the posterior sinuses, leaving the cephalic area much larger than the thoracic, in spite of the great development of the median lobe. Eyes showing yet as two distinct half moons fused on their convex sides, and situated at some distance from the anterior border. Free segment as wide as the segments posterior to it and quite long; genital segment and abdomen fused into an elongate ovoid, showing by a slight constriction near the center where the two are to separate; anal papillæ large and well provided with stout setæ (fig. 258).

Color a pinkish yellow with pigment spots of the same purple as in the nauplius and adult, rather sparingly and irregularly scattered over the posterior two-thirds of the carapace; almost none anywhere else on the body.

Total length $2.55 \mathrm{~mm}$.; length of carapace $1.52 \mathrm{~mm}$.; width of same $1 \mathrm{~mm}$. ; length of remainder of body $1 \mathrm{~mm}$.

This is undoubtedly the species mentioned by Smith (1874, p. 281) as found upon the flounder, Chrnopsetta ocellaris, and which he designates as "a species with a very short tail, and approaching Heller's genus Ameretes." It is fairly common on the four-spotted flounder (Paralichtleys oblongus), but is not often found upon the summer flounder. It affords a notable example of color protection, for the pigment spots with which it is covered give it so nearly the hue of the dorsal surface of its host that it can be distinguished only when in motion.

It is always found upon the external surface, and so far as observed always on the dorsal side of the body. It shows no decided preference 

for any particular locality, but may be found anywhere from the outside of the operculum to the tip of the tail.

When disturbed the males scuttle about over the surface in a lively manner, but the females ordinarily remain quiet. In the aquarium both sexes swim about freely, but the male is the more lively and usually lives longer. They can be kept more successfully than many other species, and do not bother by crawling up out of the water. Females with eggs which are nearly ripe retain the egg strings even under rough treatment, and the nauplii may be reared successfully. The egg cases are separated rather more than usual at their origin in the genital segment. At first they approach each other rapidly until about their own diameter apart, and then extend backward parallel with each other. They are light colored even when well developed, so that it is difficult to judge of their maturity by their color. This is due to the paucity of pigment in the larvæ.

The National Museum collection includes the following lots of this parasite, from the summer flounder (Paralichthys dentatus) 6065, 6081; W. 61; W. 62; W. 65; W. 73, all from Woods Hole and vicinity.

From the four-spotted flounder (Paralichthys oblongus) 1285 (two lots with the same number), 1308, 6040, W. 63; W. 64; W. 67; W. 68, all also from the vicinity of Woods Hole.

. From an unknown host 4403 from Great Egg Harbor, New Jersey, and W. 66 from an unknown locality.

From the horse crevalle (Caran $x$ hippos) a single specimen taken at Woods Hole, W. 69.

From the garfish (Tylosumus marinus) a single male taken at Woods Hole, W. 70, and from the summer skate (Raja erinacer) a single female at the same locality, W. 71.

\section{LEPEOPHTHEIRUS DISSIMULATUS, new species.}

Plate XXII.

Female.-Carapace orbicular, the width and length almost exactly equal; frontal plates large and well defined. Posterior sinuses shallow and broadly triangular; median lobe fully half the entire width of the (arapace, projecting but slightly beyond the lateral lobes and squarely truncated posteriorly, sometimes slightly emarginate. Transverse groove in the center of the carapace, its halves nearly straight lines and inclined toward each other like the sides of a roof. Eyes small and placed well forward. Free thoracic segment short and a little more than one-third as wide as the genital segment, with the base of the fourth legs projecting strongly.

Genital segment a sphere, flattened antero-posteriorly, its diameter a little more than half that of the carapace, its dorsal surface overhanging the ventral posteriorly. From the rounded posterior margin 
of this dorsal surface, opposite each egg tube, projects a short, conical papilla, without setæ or spines.

From the rentral surface on either side of the abdomen and at a little distance from it, a second pair of papillæ project backwards. These are much larger than the first pair, and each of them carries three good-sized plumose setæ. These latter are not arranged in a trio at the tip as usual in this genus, but stand in a row along the outer margin of the papilla, one close to the tip, another near the center, and the third between these two, In the Bermuda specimens there is also a third pair of papillæ, each of which is situated just outside and superior to the base of the large ventral papilla on its side. This third pair is the smallest of the three, and each of its papillæ is tipped with a single long and slender seta. The large ventral pair evidently represent the fifth legs; the other pairs are simply processes without special significance. Abdomen small, less than one-third the length of the genital segment, and attached to the ventral surface of the latter in front of its posterior border, so as to be almost wholly concealed in a dorsal view. It is swollen a little near the base, and then at the base where it joins the genital segment it is abruptly contracted into a short neck of about one-third its full diameter. It is made up of a single segment, three-fifths as wide as long, and terminates in laminæ, which are three-quarters of its own length. These laminæ are half as wide as long, and are armed with four slender plumose setæ considerably longer than both abdomen and laminæ. The egg strings are wide and a little more than half as long as the whole body. Eggs very large, their antero-posterior diameter being often fully half their lateral diameter, and hence only 15 to 25 eggs in each string.

Since the abdomen is thus upon the ventral surface, while the openings of the egg tubes are in the center of the posterior surface dorsal to the abdomen, it follows that the egg strings, when extruded, cover the dorsal surface of the abdomen, and practically complete the concealment partially accomplished by the overhanging of the dorsal surface of the genital segment. This position of the egg strings, dorsal to the abdomen, is very unusual in the genus, the two being exactly reversed in relation in all other known species.

In the appendages the basal joint of the first antennæ is robust and heavily armed with spines along its anterior and inner border. The terminal segment is slender, longer than the basal, and armed with numerous spines toward the distal end, and a single one at the center of the posterior border.

Second antennæ of medium size, with the terminal hook strongly curved. Both pairs of maxillæ consist of single curved spines, the first pair strongly curved, the second pair nearly straight. Terminal claw of the second maxillipeds less than half the length of the basal joint, the latter being fairly stout. 


Furca small with parallel branches separated by a $V$-shaped sinus reaching beyond the center. The shape varies slightly in the specimens from the two localities as indicated in the figures. First swimming legs short and stout, the basal joint with a stout spine on its posterior border, the two inner terminal claws pectinate.

Exopods of the second and third legs armed with long and stout spines. Fourth legs of medium size, the hasal joint about as long as the other three and bearing a single snuall spine on its outer margin near the distal end. A very long and slender spine at the distal end of the second joint, a shorter and stouter one on the third joint, the two inner terminal claws pectinate, the outer one very long and slender. Fifth legs large and well defined as already described, protruding for more than half their length beyond the posterior margin of the genital segment. They are broad at the base, but taper to a narrow tip, with the plumose setre on the terminal half. This arrangement is totally different from that in any other species, except parviventri, and may be used to great advantage in determining the species.

Total length, $3.5 \mathrm{~mm}$. Length of carapace, $2.3 \mathrm{~mm}$.; width of same, $2.3 \mathrm{~mm}$.; length of genital segment, $1 \mathrm{~mm}$.; length of egg strings, 2 $\mathrm{mm}$.; 15 to 30 eggs in each.

Color a uniform dark yellow without pigment spots.

(dissimulatus, dissimulo, to conceal what really exists.)

Hale.-Carapace similar to that of the female. Free thoracic segment relatively much larger, fully as wide as the genital segment and nearly half as long, with the bases of the fourth legs protruding as prominently as in the female.

Genital segment elliptical in outline, about as wide as long, and squarely truncated posteriorly. The fifth legs appear as a pair of prominent papillæ projecting from the posterior lateral margin on either side, each papilla carrying three long spines.

Abdomen very short, wider than long; anal papillæ large and armed with plumose setæ even longer than those in the female.

The second antenne are much longer than in the female and branched several times like a stag's horn; they evidently make effective clasping organs. The other appendages are as in the female, except the fourth legs, which are relatively much larger and stouter.

Total length, $2.5 \mathrm{~mm}$.; length of carapace, $1.7 \mathrm{~mm}$.; width of same, $1.6 \mathrm{~mm}$.; length of genital segment, $0.37 \mathrm{~mm}$.; length of abdomen, $0.2 \mathrm{~mm}$.

The National Museum collection consisted of one lot, 1505, taken from the white-spotted serranus, Evinephelus luthriformis, at Charles Island, one of the Galapagos group. This lot includes a male with ten females, but the latter were not very well preserved, and hence the author was much pleased to receive a second lot of four females, admirably preserved, which had been taken from a red grouper, 
Epinephelus morio, at the Bermuda Islands, by Dr. Edwin Linton, in the summer of 1903. It is from these latter specimens that most of the female characters in the present description are taken. These females resemble those described by Bassett-Smith under the name L. rotundiventris, ${ }^{a}$ but the male is entirely different from the one which he pictures.

If he is right, therefore, in assigning the male and female which he describes to the same species, we have here a markedly different form. But, whether right or wrong, the present species shows enough important differences to leave no doubt of its validity. In this species the second maxilla is much longer than in Bassett-Smith's species and the tip is not bifid in either sex. The furca is cut for three-fifths of its length rather than for one-tenth, as in rotundiventris, and it is widest at the tip instead of at the base.

The detail of each pair of legs, especially the fourth, differs considerably in minor characters. The abdomen in rotundiventris is attached on a level with the dorsal surface, as is usual. It is widest in the center and tapers much toward the tip, where are attached the small laminæ.

In the present species the abdomen is attached on a level with the ventral surface and so far forward that the overhanging dorsal surface nearly conceals it in a dorsal view. It is widest at the base, and then abruptly contracted where it joins the genital segment, and to its tip are attached a pair of laminæ nearly as large as the abdomen itself. In the present species, also, the male's genital segment is radically different from that of the female, and is like that in other species. It is flattened dorso-ventrally, has an acorn-shape, and is furnished with two pairs of papillæ, one on the lateral margins and one at the posterior corners. It does not project dorsally over the abdomen, but the latter is attached to it, as in other species, on a level with the dorsal surface.

The general relation of the different regions in the male would thus correspond closely with that of both sexes in Bassett-Smith's species, but the details of structure are very different.

Another thing which renders the present species interesting is the thickness and paucity of the eggs. In no other species, except bifurcatus, is there any approach to the condition found here. That this is no accidental occurrence, nor the result of immaturity, is shown by the fact that the egg strings of all the females are almost exactly alike. Furthermore, a careful examination of the egg cases at the point of their attachment to the genital segment shows that all the eggs have been extruded, and the cases have been pinched off and closed, as is normally done at the conclusion of egg extrusion.

a He has used the term "ventris" here to express a portion of the thorax; it is the genital segment which is rotund and not the abdomen. 


Such a marked restriction in the number of eggs would lead us to search for some accompanying advantages in the struggle for existen : One thing which suggests itself is a superior activity. All the swimming legs in the adult are powerfully developed, particularly the basal apron of the third pair. This constitutes the chief organ of locomotion as already suggested, but whether there is a similar superiority in all the stages of development only a careful study of the nauplii and chalimus stage can determine.

But the chief interest of the species lies in its morphological relation to such forms as (aligus and Lepeophtheirus on the one side and the genus Ammretes on the other. In the latter genus the anal laminæ are attached directly to the ventral surface of the genital segment, and usually at some little distance from the posterior margin of the latter. It would be diflicult to know just how to account for the disappearance of the abdomen were it not for the present species. But the structure here seems to indicate clearly that, starting from the dorsal surface and of a normal size, the abdomen has retreated gradually, first to the ventral surface, and then away from the posterior margin, diminishing in size all the while, until it has been finally absorbed into the genital segment.

The anal lamina have not participated in the diminution, but, retaining their original proportions, when the abdomen has disappeared they still remain on either side of the anus as morphological indicators of the degeneration which has taken place.

\section{LEPEOPHTHEIRUS PARVIVENTRIS, new species.}

Plate XXIII, figs. 275-284.

Female-Carapace obovate, one-eighth longer than wide, broadest posteriorly. Frontal plates of medium size and well defined; posterior sinuses broad, shallow, and quite widely separated, leaving the median lobe four-ninths of the entire width and rather squarely truncated posteriorly. Lateral lobes broad and well rounded. Free thoracic segment considerably less than half the width of the genital segment, and of medium length. Genital segment a little more than half the length of the carapace, as wide as long, and with nearly parallel sides and broad, well rounded posterior lobes. Abdomen quadrangular and very small, only one-third the length of the genital segment, and wider than long. Anal lanine large and curved outward, each one armed with four long plumose setæ.

The two joints of the first antenna about the same length, and both plentifully supplied with setie. The second antenne short and small, the terminal hook slender and strongly curved.

The first maxille are as large as the claw of the second antenne and as strongly curved. The second maxilla are also large, the branches slighty longer than the basal portion, and curved in toward each 
other. Each branch is slender, conical, and rather blunt, without flanges or wings of any sort.

Between the bases of these maxillæ and those of the second antennæ there is on either side a pair of conical papillæ. The larger of these is in a line between the two appendages mentioned, and is furnished with a stout spine which is inclined strongly backward. The other smaller papilla, which is without a spine, joins the larger one on its outer border. These evidently represent the rudiments of the endopod of the second maxillæ. The first maxillipeds are slender, the terminal joint nearly twice the length of the basal and ending in three long setre, the inner two of which are pectinate. The second maxillipeds are stouter, with the terminal claw nearly as long as the basal joint and acuminate; the accessory spine is long and slender. Furca short and very wide, the branches longer than the base, widely separated, and nearly parallel, with the intervening sinus but little rounded. The branches are short and blunt with a slight flange on the inner side, making them widest at the center.

The first swimming legs are short and stout, the basal joints connected across the median line by a narrow band of chitin, and each of them armed posteriorly with a short, blunt spine. The second joints are fringed with hairs posteriorly and carry a single small spine at the distal end anteriorly. The three terminal claws decrease in size posteriorly, the third one being only half as long as the first. The seta at the distal corner is very small, being no longer than the shortest claw. The second pair of legs are also stout, the basal joints being nearly circular in outline and densely fringed with hairs around their entire margin. The basal joint of the exopod is noticeably long, and the spines are slender and sharp. The rami of the third legs are large and close together, the spine at the base of "the exopod being twisted until it is nearly parallel with the margin of the basal apron. The fourth legs are large and reach back considerably beyond the posterior margin of the genital segment; they are four-jointed, the basal and third joints carrying spines at their distal ends, and the terminal joint ending in three short spines of about equal length. The fifth legs are well defined and their setæ show beyond the edge of the genital segment.

Total length $7 \mathrm{~mm}$. Length of carapace $4 \mathrm{~mm}$.; width of same 3.25 $\mathrm{mm}$.; length of genital segment $2.1 \mathrm{~mm}$.; length of abdomen $0.5 \mathrm{~mm}$.; length of egg strings $6.3 \mathrm{~mm}$.

Color a uniform light yellowish white.

(parviventris, parvus, small, and venter, the abdomen.)

Male. -Carapace elliptical, one-eighth longer than wide, the posterior sinuses very broadly triangular, leaving a well-rounded median lobe and lateral lobes, which flare outward.

Free thoracic segment considerably narrower than the genital seg- 




ment (seven-tenths of it). Genital segment ovate, one-third the width of the carapace, longer than wide, and quite squarely truncated posteriorly. There are two pairs of blunt papillæ projecting backward from the posterior portion of the lateral margins of this segment. The abdomen is quadrangular in outline, wider than long; the anal lamina are very long, while the plumose setæ which they carry are nearly as long as the entire abdomen.

Total length $4.5 \mathrm{~mm}$. Length of carapace $2.8 \mathrm{~mm}$.; width of same $2.4 \mathrm{~mm}$.; length of genital segment $0.8 \mathrm{~mm}$.; length of abdomen $0.4 \mathrm{~mm}$.

This species closely resembles L. lieppoglossi (Kröyer) and L. appendiculatrs (Kröyer), of the latter of which only the male is known. But in both these species the branches of the furca are bifid and close together, while the general proportions of the body and its parts are also entirely different.

The National Museum collection includes several lots of this species taken during the voyage of the United States Bureau of Fisheries steamer Albatross in 1888. They are all from the northern Pacific, a portion of them on the American side and the rest on the Asiatic coast. From Humboldt Harbor, Shumagin Islands, Alaska, an unnumbered lot containing twenty females and ten males, no host given. From Loring Harbor, Alaska, an unnumbered lot taken from the cod of that region, Gadus macrocephahs.

From Chignik Bay, Alaska, another unnumbered lot; also from the cod, Gadus macrocephalus. From the Commander (Kommandorski) Islands, Siberia, ten females and one male taken from Pleurogrammus monopterygius (Pallas). From a halibut taken off Alaska in the summer of 1880, an unnumbered lot of ten females. From station No. $\$ 212$ of the United States Bureau of Fisheries steamer Albatross an unnumbered lot taken from a species of Lepidopsetta.

No specimens of the Caligus curtus or $C$. rapax were obtained from these Pacific cod, as it seems practically certain would have been done had those species been found there.

It would seem, therefore, as if this new species of Lepeophtheirus took the place on the Pacific cod occupied by the two species of Caligus on the Atlantic cod.

LEPEOPHTHEIRUS BIFURCATUS, new species.

Plate XXIII, figs. 285-293.

Fimale.-Carapace elliptical, distinctly longer than wide, and about one-third longer than the rest of the body. Frontal plates well defined with a shallow incision at the center.

Posterior sinuse- broad, well rounded, and slightly inclined away from the central axis, loaving a median lobe considerably less than lualf the entire width and projecting well back of the lateral lobes. 'The latter are broad and well rounded.

Proc. N. M. vol. xxviii-04-41 
Thoracic area considerably smaller than the cephalic and somewhat angular; digestive glands prominent, shaped like a comma, with the convex sides toward each other.

Free segment short and narrow, about one-fourth the width of the carapace, the bases of the fourth legs projecting strongly on either side. Genital segment ovate, considerably more than half as wide as the carapace, and three-fifths as long, with smoothly rounded corners and a slightly emarginate posterior border. Abdomen very small, wider than long, with small, widely separated papillæ. Egg tubes about the same diameter as the abdomen and short, only a trifle longer than the genital segment, each containing but twenty eggs.

Of the appendages the anterior antennæ are stout, the two joints about the same length; the posterior antennæ have a large basal joint supplemented by a short and stout accessory spine, while the terminal joint is long and abruptly bent.

The first maxillæ are very large for a female, strongly curved and blunt at the tip. The second maxillæ are also very large, cut about to the center, the branches thick and stout, and flanged along either side. These branches are widely separated at their bases and diverge considerably, giving the intervening sinus a deep basin shape. The distance from tip to tip of the branches is the same as the entire length of the maxilla.

The proboscis is long and of medium width, with nearly parallel sides. The first maxillipeds are long and slender; the terminal joint carries a small flattened spine on its anterior border at about the center. The two terminal claws are very uneven in length and both have serrated flanges along their sides. The second maxillipeds are small and rather weak; the terminal claw is a little more than half the length of the basal joint and strongly curved, with a small and weak accessory spine on its inner margin.

The furca is very large and wholly unlike that of any other known species. It is almost as wide at the tip as it is long, but is contracted to less than half that width at the base, giving the entire appendage somewhat the shape of a thick-stemmed wineglass. The sinus between the branches reaches nearly to the center and has a broad $U$ shape, with the sides parallel.

The secondary branches are narrow and acuminate, and the sinus between them is triangular and cut in as deeply as the central one. It thus differs markedly from the furea of hippoglossi and appendiculatus, the only other species in which the furca is doubly bipartite. In hippoglossi the central sinus is triangular and its sides approach each other rapidly and almost touch at the tips. The secondary branches are laminate and squarely truncate at the ends. In appendiculatus the secondary sinuses are not more than a very small fraction of the length of the central sinus. 


The first swimming legs of this new species are short and thick, the basal joint with a short spine at the distal end, the terminal joint with the usual spines and setæ.

The second and third legs are slender but otherwise like those in other species. The fourth legs are large and stout, four-jointed, the hasal joint nomewhat swollen and as long as the other three, with a plumose seta at its distal end on the outer margin. The second joint has a very short and strongly curved claw at its tip; the third joint has a much longer one, while the three terminal claws are still longer and increase in size from without inwards. The last four claws are close together and they all have serrate Hanges along their outer margins. At the base of each of the claws on the dorsal surface is a large semicircular lamina made up of radiating thread-like spines, connected by a membrane. The tips of the spines project heyond the edge of the membrane, giving it a serrated appearance. The fifth legs are small and are not visible dorsally.

Total length $4.8 \mathrm{~mm}$. Length of carapace $2.7 \mathrm{~mm}$.; width of same $2.4 \mathrm{~mm}$.; length of genital segment $1.6 \mathrm{~mm}$.; length of abdomen 0.3 $\mathrm{mm}$.; length of egg cases $1.7 \mathrm{~mm}$.; twenty eggs in each case.

Color, a dark-brownish yellow, without pigment spots.

(bifurcatus, forked or divided into two branches, i. e., with a double furca.)

There is but a single lot containing two females of this new species, and the male is unknown. They were taken from one of the common flounders of the Pacific coast, Psettichthys melanostictus, in San Fran-" cisco Bay, California.

This species is distinguished from all others by the peculiar structure of the furca, as already noted. The wide separation of the branches of the second maxilla is another distinguishing characteristic, the sinus between the branches being very much broader than in any known species. The fourth legs furnish a third character in the prominent spiny lamella at the bases of the claws. So far as known these are not present in any other species of the genus. There is but a single female with egg cases from which to diagnose the species, but everything about them seems to point to a very small number of eggs. The thickness of the eggs for any species does not vary appreciably, whether many or few have been extruded, and in this species they are much thicker than ordinary. In fact, the only other species which approaches it in this respect is dissimulutus, which has just been described. 


\section{LEPEOPHTHEIRUS SALMONIS Kröyer.}

Plate XXIV.

Caligus salmonis KröYer, 1838, p. 13, pl. vi, fig. 7 a-e.

Caligus vespa Milne-Edwands, 1840, p. 456.

Caligus stromii BAIRD, 1847.

Lepeophtheirus salmonis BAIRD, 1850, p. 274, pl. XxxIr, figss. 8 and 9.-KRöYER, 1863, p. 137, pl. xvir, fig. 1 a-b.-RathBun, 1884, p. 487.

Lepeophtheirus stromii BAIRD, 1850, p. 274, pl. xxxII, figs. 8 and 9.-BAssETTSмiтн, 1899, p. 455.-T. Sсотт, 1900, p. 152, pl. vi, figs. 3 to 8.

Female.-Carapace orbicular, as wide as long; frontal plates narrow and not well defined; posterior sinuses narrow, shallow, and somewhat inclined away from the median line. Median lobe broad and well rounded, projecting but little beyond the lateral lobes, and often raised posteriorly into a fold or wrinkle, which projects over the dorsal surface of the free segment and hides it.

The grooves separating the carapace areas are well defined; the crossbar of the " $\mathrm{H}$ " is strongly curved, so that it makes a continuous half circle with the lower portion of the sides. The free segment is very short and narrow, less than half the width of the genital segment. The latter is nearly as large as the carapace, fully as long but a trifle narrower, with well-rounded lobes projecting posteriorly on either side of the abdomen. The abdomen is four-fifths as long as the genital segment and narrow, with a clearly marked constriction near the posterior end. Such a constriction is usually good evidence of segmentation, but the most rigid examination of the opaque preserved specimens at the author's disposal fails to confirm the segmentation. It is quite possible, however, that living specimens would show it clearly, and for that reason the present species has been included twice in the artificial key herewith presented. The anal laminæ are enlarged considerably at the tips and curved in toward each other.

The egg strings are fully three times as long as the entire body, and at the same time very narrow, which of course emphasizes their elongate appearance.

Of the appendages the second antennæ are stout, with the terminal hook considerably longer than the basal joint; the latter also lacks a spine on its posterior margin.

The first maxillæ are very long and stout, the basal portion swollen to about twice the diameter of the terminal curved part.

The second maxillæ are of the usual size and shape. The first maxillipeds are stouter than usual, the terminal joint more than twice the length of the basal. The shorter terminal claw is about three-fifths the length of the longer one, and is dentate along its outer margin. In the second maxillipeds the terminal chw is only about half as long at the basal joint, and in all the specimens examined it lacked an accessory spine on the inner margin. The furca is proportionally small, 
, 

with short and blunt branches, which are somewhat divergent. The first swimming legs are short and stout; the basal joint has a short spine at its distal posterior corner, while the second joint has a similar one at the distal anterior corner. The terminal claws are nearly the same length, and the plumose sete on the posterior margin are uncommonly large. Second and third legs as usual. The fourth legs are four-jointed, with four spines; the second joint has an enlarged tip, with rough papillary elevations, hut without a spine. The third joint has a short spine, about as long as the two outer ones on the terminal joint. The fourth or inner terminal spine is fully twice as long as the others. The fifth legs are broadly triangular and terminated by three small spines, but are not visible from the dorsal surface.

Total length $18.2 \mathrm{~mm}$. Length of carapace $6.6 \mathrm{~mm}$.; width of same $6.6 \mathrm{~mm}$.; length of genital segment $6.6 \mathrm{~mm}$.; length of abdomen 5 $\mathrm{mm}$.; length of egg strings $53 \mathrm{~mm}$.; total length including egg strings $65 \mathrm{~mm}$.

Color a dirty yellow brown, the dorsal surface often having a strongly metallic luster, quite different from any other species of this genus.

(salmonis, pertaining to the salmon.)

Mule. Carapace elliptical, one-third longer than the rest of the body, and one-fifth longer than wide. Frontal plates distinct, but not very wide; carapace areas as in the female.

Posterior sinuses much broader than in the female, but shallow and learing the median lobe projecting well beyond the lateral lobes. Free segment long and narrow, only five-sevenths as wide as the genital segment, and swollen at the center through the bases of the fourth legs.

Genital segment elliptical-oblong, slightly narrowed anteriorly and with a shallow emargination on the posterior border, leaving very short and blunt lobes on either side.

Abdomen oblong, a little wider posteriorly, made up of two segments the basal of which is only about one-third as long as the terminal. Anal lamine very large, more than two-thirds as long as the terminal joint and broadly foliaceous, each carrying four long plumose setre.

There is the usual sexual difference in the appendages, but nothing worthy of special note save that the fifth legs are not visible any more than in the female.

Total length $6 \mathrm{~mm}$. Length of carapace $3.45 \mathrm{~mm}$.; width of same $2.9 \mathrm{~mm}$.; length of genital segment $1.1 \mathrm{~mm}$.; length of abdomen $1.25 \mathrm{~mm}$.

This species was first deseribed by Krörer in 1838 under the genus

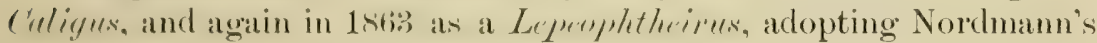


separation of such species as had no lunules. It was also described independently by Baird in $18+7$ under the name Caligns stromii, which he changed in 1850 to Lepeopletheirms stromii. This name of Baird's is the one subsequently retained by Bassett-Smith and T. Scott, the former of which gires Kröyer's name as a synonym under it.

But if the two species are identical, as there seems to be no doubt, then Kröyer's name has a priority of nine years over Baird's, and must be retained.

The species is common upon the salmon of our coasts as well as those of European waters, and often attains a large size.

Some of the females examined by the author measured $22 \mathrm{~mm}$. in length, and that, too, although they had been preserved in alcohol. They can be readily distinguished from other species by the extreme length and slenderness of the egg strings and by the metallic luster so common on the dorsal surface.

The males are very scarce, the material in the entire National Museum collection yielding but a single specimen. So far as known, no figure of the male has ever been published previous to the one here included. The following are the lots in the National Museum collection: Cat. No. 3030, from salmon at the Tyne, England, used for identification of the American specimens. No. 8109 , four specimens, including the single male from the gills of a salmon, locality not given. No. 8117, from the king salmon at Kenai, Alaska. No. 8489 , fifteen specimens, from Ungava, Labrador, found on "salmon and sea trout." No. 12666, from salmon at St. Johns, Newfoundland. No. 36073, from salmon at East Orland, Maine. No.41840, two specimens, from "Dolly Varden trout" in Alitak Bay, Alaska. No. 6017, from Onchorhynchus gorbuscha at Port Chatham, Cooks Inlet, Alaska. An unnumbered lot, from Salmo salar, found at Rigolet, Labrador.

The salmon at East Orland, Maine, must have been from fresh water, and several of the other species mentioned occur as entirely landlocked forms in various localities. There can be very little doubt, therefore, that this parasite is another instance of one which can remain upon its host during the passage of the latter from salt to fresh water. It would be of great interest to ascertain whether it remains upon such forms as have become entirely landlocked.

\section{LEPEOPHTHEIRUS PACIFICUS Gissler.}

Plate XXV, figs. 304-310.

Caligus pacificus Gisster, 1883, p. 885, figures in the text.

Female.-Carapace about half the entire length, elliptical, a little longer than wide; frontal plates short and narrow, but well defined. Posterior sinuses wide and shallow, leaving a broad median lobe, more than half the entire width, and not projecting back of the lateral lobes. Thoracic area relatively small and well rounded posteriorly; 

eyes small and situated far forward in the carapace. Free segment short and narrow. Genital segment quadrilateral, wider than long, widest and somewhat emarginate posteriorly; lobes very short and well rounded.

Abdomen only one-fourth the width of, but slightly longer than, the genital segment, and indistinctly four-jointed. It is cylindrical in form and taper's somewhat toward the tip; the joints also diminish regularly in length, the basal one being about twice the length of the terminal. The anal lamina are large and leaf-shaped, but armed with short setæ.

The egg strings are two-thirds as long again as the entire body, of medium width, and there are between sixty and seventy eggs in each.

The first antenne are short and inconspicuous. with the two joints about the same length; the second antennæ are stout, the basal joint short and wide, and tapering rapidly outward. This joint is provided on its inner surface with a knob-like process of chitin, the surface of which is raised into parallel transverse ridges, overlapping one another. There is thus formed a file-like surface which assists materially in the prevention of slipping. The terminal claw of this second antenna has a long slender spine on its outer margin. The mandibles are three-jointed, the third joint curved in toward its fellow and toothed along its inner margin.

The second maxillse are triangular and bifurcate for about one-third of their length; the branches are narrow and sharp while the basal portion is wide and strong.

The first maxillipeds are very slender, the terminal joint much longer than the basal and armed with a short, sharp spine on the inner margin near the center. The two terminal claws are not as uneven as in many species and both are bordered with a "delicate pectinate membrane" (Gissler). The second maxilliperds are large and stout, the basal joint considerably longer than the terminal claw. The accessory spine on the latter is near the base. The fourth swimming legs are short and weak, four-jointed with five spines, the basal joint as long as the other three, which latter are widened toward the tip.

The spine on the second joint is short and strongly curved, the other four spines are about equal and arranged in a row at the tip of the last joint. This is due to the fact that the second spine at the tip of the third joint is carried out by the elongation of the joint to a level with those on the terminal joint.

Total length $9.5 \mathrm{~mm}$. Length of carapace $4.6 \mathrm{~mm}$. ; width of same $4 \mathrm{~mm}$.; length of genital segment $2.4 \mathrm{~mm}$.; length of abdomen $2.5 \mathrm{~mm}$.; length of egg strings $15 \mathrm{~mm}$.

Color dark rufons on the dorsal surface, lighter below.

(pacificus, of or belonging to the Pacific.)

Twenty-three females of this species were obtained by Gissler from 
a salmon (probably the "blue-back salmon," Oncorhynchus nerka) inhabiting Puget Sound, on the Pacific coast.

They were described by him as a new species." He called the species a Caligus, but that does not seem possible after a careful study of his description and text figures.

There are no lunules on the frontal plates and the second maxillx are bifureated for one-third of their length, both of which are characteristics of the genus Lepeophtheims as distinguished from Caligus.

From correspondence with Gissler it was ascertained that his type specimens had been turned over to the American Museum of Natural History at New York City. Dr. H. C. Bumpus, the director of the museum, very kindly made a careful search for the specimens at the author's request, but they could not be found. The species will have to stand, therefore, upon the original figures and description given by Gissler. Fortunately, these were carefully made and give us definite data to work upon. Nearly everything in the present account and the figures which are herewith presented were taken from Gissler. The species can be readily distinguished by the four-jointed abdomen; no other species in this genus has more than two joints in the abdomen. However, Gissler states that the segmentation is indistinct in fresh material, and only becomes distinct on being treated with acetic acid.

There may be a suggestion in this that some species, like salmonis, just described, in which the abdomen has been hitherto regarded as unsegmented, would show a distinct segmentation if treated in the same way with acetic acid.

The species bears some resemblance to salmonis, but the size and shape of the genital segment are entirely different, as are the details of every one of the appendages given by Gissler, particularly the second antennæ and the fourth legs.

\section{LEPEOPHTHEIRUS COSSYPHI Kröyer.}

Plate XXV, figs. 311-313.

Lepeophtheirus cossyphi KröYeR, 1863, p. 115, pl. viI, fig. 6, a-e.-BAssetT-SмitH, 1899, p. 454.

Female.-Carapace longer than the rest of the body (as 7 to 4), nearly as wide as long, narrowed anteriorly. Frontal plates medium size, not well defined, without any emargination at the center. Free segment very narrow and short, considerably less than one-fourth as wide as the genital segment.

Genital segment half as long as the carapace, a little wider than long, of a broad acorn shape, squarely truncated posteriorly. The corners are well rounded, and to-them are attached the long and slender fifth 




legs. These are conical and three-jointed, with a seta at the end of the first and second joints.

The abdomen is rudimentary, only one-eighth the length of the genital segment, and looking like a knob on its posterior border.

Anal lamina proportionally large, longer than the abdomen, as wide as long, with stout setre three or four times the length of the lamina. Egg strings not present.

Joints of the first antennæ of about the same length and slender; second antennæ of medium size and the usual shape.

First maxilla small and placed close to the second antennæ, the base swollen more than usual, so that they appear two-jointed.

Proboscis small and plump, of the same length and width, and squarely rounded at the end. Second maxilla the same length as the proboscis, tolerably stout; the branches pointed and weakly curved. Eyes small and circular.

First maxillipeds of the usual form; second pair not as large as usual, and lacking the accessory spine on the terminal claw.

Furca small, the base squarely truncate, almost rectangular; the foramen tolerably large and of about the same length and width. Branches not as long as the base, simple, divergent, and pointed, the sinus between them triangular, with the sides almost meeting anteriorly. Rami of the third legs close together, but pointing straight backward. Fourth legs elongate, four-jointed, the basal joint as long as the three terminal ones.

There are five spines, of wnich those on the second and third joints are equal and of medium size, while of the three terminal spines the middle one is more than twice the length of the other two.

Total length $3.35 \mathrm{~mm}$. Length of carapace $2.1 \mathrm{~mm}$.; width of same $1 . i \mathrm{~mm}$; ; length of genital segment $1.1 \mathrm{~mm}$.; length of abdomen $0.125 \mathrm{~mm}$.

Color not given.

(cossyphi, the generic name of its host.)

Kröyer bases this new species upon a single female taken from the gills of the Spanish ladytish or hogfish, Marpe rufi, in the West Indies. But although thus confined to a single specimen, the species presents well-defined characters which serve to distinguish it from all others.

The first of these characters is the relative proportion of the rarious boly regions. The carapace and genital segment are noticeably large, while the free segment and the abdomen are equally small. The genital segment is also of a peculiar shape, and the fifth leg's are unusually prominent.

But the crowning mark of distinction, if we may believe Kröyer's statement, is the fact that these fifth legs are indistinctly three-jointed. In no other known species of c'aligus or Lepeopletheirus is there any 
indication of jointing in these appendages. We thus have here a form in which the fifth legs are less rudimentary than usual, and one which leaves no possible doubt as to their morphological significance.

\section{LEPEOPHTHEIRUS ROBUSTUS Kröyer.}

Plate XXV, figs. 314, 315.

Lepeophtheirus robustus KRöYeR, 1863, p. 135, pl. vi, fig. 6 a-c.-BAsseTt-Sмith, 1899, p. 456.

Male. - Carapace longer than the rest of the body, the proportion about 5 to 2 and strongly arched. Frontal plates weakly developed and not very distinct. Free segment quadrangular in form with rounded corners, a little contracted anteriorly.

Genital segment about one-fourth as long as the earapace, and of the same width and length. On either side anteriorly there is a fold of skin which fills up the space between this segment and the one in front of it. The posterior corners are squarely rounded and the fifth legs appear as stout pointed knobs armed with three or four long setæ.

The abdomen is half as long as the genital segment and of about the same width and length. The anal laminæ are one-fourth as long as the abdomen and a little wider than long. They are armed with setæe which are at least four times as long as they are themselves, and with tufts of hair on either side at the base of the setæ.

The first antennæ are short, with the basal joint somewhat plump and longer than the second joint. In the second antennæ the terminal claw is particularly long and sharp.

The first maxillæ are quite stout, while the second are larger still, and are deeply cleft at the tip into two acuminate branches. The proboscis is plump, not quite twice as long as wide. The first maxillipeds are weak, the inner terminal claw fully twice as long as the outer. The second pair are proportionally larger but with a short terminal claw.

Furca small and somewhat difficult to see; base longer than the branches, squarely truncated anteriorly, with a slender frame and a large, half-moon-shaped foramen. The branches are short and plump and cleft at the ends; the secondary branches are very shott, the outer one much wider than the inner, and turned outward, while the inner one points straight backward.

First swimming legs short and stout, the second joint plump and egg-shaped, with a spine and a rounded protuberance on its anterior border. Second swimming legs characterized by their stoutness; rami of the third legs small and close together. Fourth legs small but stout, four-jointed, with the basal joint as long as the other three; the latter decrease regularly in size in the proportion of 4,3 , and 2 . There are only four spines, the second joint ending in an enlarged and 


papillated prominence instead of a spine. Of the three terminal spines the outer, which is the smallest, has a peculiar knife-blade shape.

Total length $7.875 \mathrm{~mm}$. Length of the carapace $5.5 \mathrm{~mm}$.; width of the same $4.3 \mathrm{~mm}$.; length of genital segment $1.45 \mathrm{~mm}$.; length of abdomen $0.75 \mathrm{~mm}$.

Color not given.

(robustus, stout, strong.)

This species was founded by Kröyer on two male specimens obtained from a species of Raja off the Greenland coast. It is not as well defined as the preceding species, but seems fairly well characterized by the skin protuberances on the genital segment and by the bipartite furca.

\section{Genus ANURETES Heller.}

Carapace large and shield-shaped, as in the preceding genera. Frontal plates well defined, without sucking disks. Second maxillæ small, simple, and straight. Second maxillipeds large and very powerful. First and fourth thoracic legs uniramose, second and third biramose, the rudiments of the fifth pair large and prominent. Genital segment large, well rounded, emarginate posteriorly. Free thorax segment small and without dorsal plates. Abdomen entirely lacking; the anal laminæ only left, attached to the ventral surface of the genital segment. Egg strings as in Caligus.

(Anuretes, av privitive, ovpò, tail.)

$$
\text { KEY TO THE SPECIES. }
$$

Genital segment semilunar, deeply cut posteriorly; fourth legs small, three-jointed, four spines close together at tip.................................heckelii, p. 647 . Genital segment almost circular, with shallow, triangular posterior depression; fourth legs long, first spine removed some distance from the others............ perplexus.

\section{ANURETES HECKELII Kröyer.}

Plate XXV, figs. 316-321.

Lepeophtheirus heckelii Kröyen, 1863, p. 110, pl. viI, figs. 4, a-h. Anuretes heckelii Heller, 1865, p. 186.-Bassetт-Sмith, 1899, p. 457.

Fimale.-Carapace somewhat longer than the rest of the body, about as wide as long. Frontal plates distinct, but narrow and only slightly emarginate at the center. Posterior sinuses broad and shallow; median lobe about half the entire width, projecting scarcely at all beyond the lateral lobes.

Free segment narrow and proportionally long with almost parallel sides. Genital segment two-thirds as long as the carapace and threefourths as wide, its sides strongly curver and projecting backward at the corners as a pair of stout papilla, representing the fifth legs. Between these papillax the posterior border of the genital segment is slightly convex, lut the projecting papilla give this border a deeply 
emarginate appearance. Abdomen entirely lacking, or only appearing in the faintest traces on the rentral surface of the genital segment. Anal lamine as in other genera, not at all degenerate, but attached to the ventral surface of the genital segment owing to the absence of the ahdomen. Their exact position varies considerably in different specimens, but they are usually attached some little distance in front of the posterior border. For this reason they are wholly, or almost wholly, concealed in dorsal view, only their tips or the setæ attached to them appearing beyond the edge of the genital segment.

First antennæ small and plump, the joints about even and armed as in other genera; second pair with a large terminal claw bent at a sharper angle than usual.

First maxillæ rather large and plump, not much swollen at the base; second pair little more than half as long as the mouth tube, separated from it quite a distance on either side, simple and pointed, with a greatly enlarged base.

Mouth tube large, twice as long as wide, and well rounded at the end. Eyes small, situated posterior to the base of the mouth tube, the lenses separated by about twice their own diameter. First maxillipeds with a blunt lobe on the middle of the inner margin of the terminal joint. Second pair very large and strong, the basal segment much swollen but without knobs or spines, the terminal claw stout, bent abruptly, and without any accessory spine on the inner border.

Furca small, plump, the basal part slightly longer than the branches, with a membranous frame and large oval foramen.

The branches are simple, parallel and club-shaped, with obtuse ends; the sinus between them is long and very narrow.

There is no spine at the distal corner of the terminal joint of the first thoracic legs, but only the three terminal claws, the longest of which is about the length of the joint.

Second swimming legs as in Caligus. Third pair different from the genera already described; the basal laminre are larger and the rami are not attached to their posterior horder or at the posterior corners, but high up on the lateral border's and close together so that they partially overlap.

Furthermore the endopod consists of but a single segment, armed with three strongly curved bristles which hardly deserve the name of plumose setæ. The exopod is two-jointed and but scantily armed. The fourth legs are small but comparatively strong, three-jointed, the basal joint as long as the other two. There is a spine at the end of the second joint and three on the terminal joint, all so close together as to form a single bunch or cluster.

The fifth legs appear as a pair of very stont and long papillæ projecting from the posterior corners of the genital segment, each ending in a single stout spine. 


Total length $2.8 \mathrm{~mm}$. Length of carapace $1.53 \mathrm{~mm}$.; width of same $1.6 \mathrm{~mm}$.; length of genital segment $1 \mathrm{~mm}$. Egg strings wanting.

Color not given.

(heckelii, to Prof. Ernst Hëckel.)

This species was founded by Kröyer upon three specimens, all females, two of which he obtained from the Vienna Museum while the third came from Biloxi, near New Orleans, on the shore of the Gult of Mexico. The two Vienna specimens were said to have been found by Hëckel on the gills of an Ephippus gigus from the Brazilian coast. They had been labeled by Kollar Culigus heckeliz and Kröyer retained the specific name of the label but changed the genus. The North American specimen was found on the gills of the same fish (the angelfish or spadefish, Chxtodiptems faber, Broussonet).

This is the only representative of the genus found in North American waters and may be recognized by the entire absence of the abdomen.

\section{NONAMERICAN SPECIES.}

The collection of the National Museum includes specimens of the following species, which have not thus far been found in North American waters. Three of the species are new to science and one of them is made the type of a new genus.

CALIGUS TERES, new species.

Plate XXVI.

Fimale-Carapace one-fourth longer than the rest of the body, about the same length and width, and very strongly ovate in shape, the posterior portion being more than twice as wide as the frontal plates. The latter are well differentiated, with large, almost circular lunules which project strongly in front of the antennæ. The posterior simuses are wide and comparatively deep, leaving a median lobe about half the entire width and projecting considerably behind the lateral bohes. The sinuses are slightly inclined away from the mid line, and the posterior margin of the median lobe is a little concave.

The lateral lobes are broad and well rounded, their thoracic portion being very prominent and projecting considerably behind the rest of the lobes. Thoracic area large and well rounded, embracing half the longth and fully two-thirds the width of the carapace. The crossbar ant the lower portion of the sides of the " $\mathrm{H}$ " make a nearly perfect semicirele.

The free thorax segment is almost half as long as the genital segment, and is strongly narowed in front of the bases of the fourth legs, leaving the sides concave.

The enenital segment has a broarl. harrel shape, with erenly rounded sides; it is two-tifths the length of the carapace, as wide as it is long, 
with an emarginate posterior border and short, well-rounded lobes. The abdomen is three-fifths the length of the genital segment, and like the latter has a broad, barrel shape, abruptly narrowed into a neck, where it joins the genital segment.

The anal laminæ are large and foliaceous, separated more than their own diameter, and armed with large and stout setæ.

The egg tubes are about half as long as the body; each has a diameter a little more than half that of the abdomen and contains 60 eggs. The anterior antennæ are of medium size and very heavily armed with setæ and spines; the posterior pair have a stout basal joint and a long, slender terminal hook. The accessory spines situated just posterior to the base of these antennæ are small and weak.

The first maxillæ are of medium size, slightly curved, and considerably enlarged at the base; the second pair are large and stout, as long as the proboscis, and abruptly curved near the base.

The terminal portion is nearly straight and ends in a rather blunt point. The terminal joint of the first maxillipeds is much longer than the basal and is tipped with two long and curved claws, the inner of which is longer than the outer, and has a serrate lamina along its anterior and posterior margins. There is also a stout curved spine upon the anterior margin of this terminal joint near its distal end.

The second maxillipeds are large and stout, the terminal claw about half the length of the swollen basal joint, with a long accessory spine upon its inner margin close to the tip.

The inner margin of the basal joint is also raised into a slight protuberance just opposite the point of the claw.

The furca is narrow, the base as long as the branches and slightly swollen; the branches are straight, almost parallel, and acute. The three terminal claws on the first swimming leg are long and strongly curved, decreasing in size from the anterior to the posterior. There is no seta at the distal corner, but the three plumose setæ on the posterior margin are of the usual size. The second legs are noticeable chiefly for the spines on the exopod and the curious shape of its terminal joint. There are but two spines, one on the basal joint and one on the second joint; the former is about three times the length of the latter, and stretches across the second joint and projects beyond its inner border nearly a third of its length. The terminal joint of this exopod is shaped like the quadrant of an ellipse, the half of the shorter diameter joining the second joint, while the half of the longer diameter forms the anterior border. The plumose setæe are arranged in a row around the curved posterior margin.

The rami of the third legs are well separated; the exopod has a stout basal joint with a medium-sized claw, and a considerably smaller terminal joint, both joints being appressed closely to the margin of the apron. The fourth legs are long and slender, three-jointed with five 

spines, of which three are terminal. The outer of these terminal three is rudimentary and so small as to be easily overlooked. The tips of the leg's slightly overlap the abdomen, the basal joints, which are the same size throughout, heing about as long as the two terminal joints. On the outer margin of the basal joint near the distal end is a short plumose seta; there is a large spine at the distal end of the second joint, and one on the outer margin of the terminal joint at about its center. At the bases of this last spine and also of each of the three terminal spines there is on the ventral surface a small lamina whose edge is cut into very long and acuminate teeth. The fifth legs are so small as to be wholly invisible dorsally and they can be seen on the ventral surface only with difficulty.

Total length $4.75 \mathrm{~mm}$. Length of carapace $2.6 \mathrm{~mm}$.; width of Same $2.75 \mathrm{~mm}$; length of genital segment $1 \mathrm{~mm}$; length of abdomen $0.7 \mathrm{~mm}$. ; length of egg strings $2.2 \mathrm{~mm}$. Sixty eggs in each.

Male.-Carapace three-fifths of the entire length, and proportionally narrower posteriorly than in the female, but wider anteriorly.

Frontal plates wider and more prominent, and the lunules larger. The eyes appear a little farther back in the carapace, owing to the width of these frontal plates.

Thoracic area as large as in the female and rounded similarly. The glands in this area which show as dark masses through the dorsal integument are of peculiar shape and very similar in the two sexes. Each consists of a large ovate posterior portion and a smaller elliptical or spherical anterior portion, the two being connected by a narrow neck. On the inner side both portions of these glands are flattened against the intestine and present a nearly straight line for their entire length.

The free segment is longer and wider than in the female, and is similarly constricted in front of the fourth legs. It is fully as wide as the genital segment and overlaps the anterior end of the latter on either side by the width of the basal joint of the fourth legs.

The genital segment is oblong, narrowed considerably anteriorly where it joins the free segment, and has a convex posterior margin. On either side near the posterior end is a broad and blunt triangular spine, on the rentral side of which may be found the fifth legs.

The abdomen is about two-thirds the width and seven-eighths the length of the genital segment, two-jointed, the basal joint considerably the smaller, with a strongly convex posterior margin.

The abdomen widens a little posteriorly and the anal lamine are set into the sides as much as the end of the terminal joint. 'They are very large and foliaceous, hut the plumose setae upon them are not much larger than those of the female.

'The appendages are very similar to those of the female, the chief differences being in the enlarged and branched second antenne, the 
enlarged second maxillipeds, and the fourth legs. The latter hare the same detail as in the female, but reach well beyond the posterior margin of the basal abdominal joint.

Total length $3.7 \mathrm{~mm}$. Length of carapace $2.2 \mathrm{~mm}$; width of same 2 $\mathrm{mm}$.; length of genital segment $0.7 \mathrm{~mm}$.; length of abdomen $0.54 \mathrm{~mm}$.

Color, a dark-brownish yellow, without pigment spots.

(teres, smooth, well rounded.)

The National Museum collection includes two lots of this species, one of twenty-five females and two males taken from a Callorhynchus, and the other of about the same number taken from a ray, both at Lota, Chile. The ray and the chimæra were in the same tub of fish, so that it is very possible the parasites may have crawled from one to the other. This is a very clean-looking species, and the roundness of its outlines gives it both grace and symmetry. It may be easily distinguished from other species by the rounded barrel shape of the genital segment and abdomen, and by the concave sides of the free segment. This preliminary diagnosis may then be verified by the presence of toothed laminæ at the bases of the spines on the fourth legs.

In 1849 one Claudius Gay published what he styled Historia fisica y politica de Chile, which was issued at Madrid and contained, among other things, a review of the animal and plant life of the country. The author has been unable to find a copy of the text of this work, but in

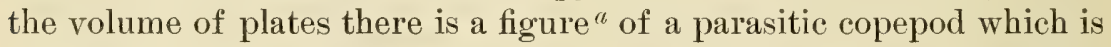
designated Caligus gayi. This was found upon an undetermined fish and resembles the present species in many particulars, but there is still enough difference, particularly in the coloration, to render it certain that the two are distinct species.

\section{CALIGUS CENTRODONTI Baird.}

\section{Plate XXVII.}

Caligus centrodonti BAIRD, 1850, p. 272, pl. xxxII, figs. 6 and 7.-BASsETTSмiтн, 1899, p. 447.

Female.-Carapace considerably more than twice the length of the rest of the body, and quite strongly narrowed anteriorly. Frontal plates large and distinct, with a deep central incision; lunules large, circular in outline, and not projecting much beyond the anterior margin. Posterior sinuses of medium depth, nearly parallel, and well rounded; median lobe a little more than half the entire width, and squarely truncate or slightly emarginate posteriorly. Thoracic area large and very well defined but with indistinct digestive glands.

Ey is situated far forward and entirely separated from each other but very close together, the axes slightly inclined toward each other anteriorly. 
. 



Free segment short and narrow, overlapped by the carapace anteriorly and by the genital segment posteriorly. From either side of this segment there projects over the base of the fourth leg a narrow, blunt plate or spine, about half as long as the basal joint of the leg. This overlying plate, together with the small size of the fourth legs, renders the latter invisible in dorsal view.

Genital segment transversely semilunar in shape, one-third wider than long, the sides well rounded, the posterior angles prolonged backward as stout blunt lobes. The posterior margin between these lobes is deeply concave, being fully one-third of the entire length. The fifth legs are not visible dorsally, but may be distinctly seen upon the ventral surface of the posterior lobes. The abdomen is so small as to be at least partially rudimentary. It is less than one-fourth the width of the genital segment and does not quite reach the level of the tips of the posterior lobes of the genital segment. In shape it is ovate, the base being contracted strongly and joining the genital segment on its ventral surface, a little anterior to its posterior margin. The genital segment thus overlaps and partially conceals the base of the abdomen.

The anal laminæe are proportionally of good size, but armed with small setæ. Egg cases about two-thirds as long as the body, and considerably wider than the abdomen, each containing thirty-five to forty eggs.

Of the appendages the anterior antennæ are short, the two joints about the same length and not very heavily armed with setæand spines. Second antennæ small and without any accessory spine at the base of the proximal joint.

First maxillæ large and well curved, but with very little swelling at the base. Second pair simple, with a wide triangular base and a short blunt tip; they are attached opposite the base of the mouth tube and extend slightly beyond its tip.

The mouth tube is short and evenly rounded, nearly as wide as it is long. First maxillipeds of the usual form; second pair very small and weak, hardly larger than the first pair; the terminal claw is a little more than half the length, and considerably less than half the width, of the basal joint.

The tiny accessory spine is attached close to the distal end of the claw on the inner margin.

The first swimming legs are smaller than usual, with only one of the three terminal claws at all developed, the other two being rudimentary. The plumose setæe on the posterior horder of the terminal joint, however, are full size.

The exopod of the second legs has but two spines; the one on the tirst joint is large and stout, but the one on the second joint is rudimentary. The rami of the third legs are large and well separated,

$$
\text { Proc. N, M, vol, xxviii-04-42 }
$$


but the exopod is turned sidewise and appressed so close to the margin of the basal apron that the latter overlaps it somewhat. This brings the tip of the exopod over onto the endopod, so that the two appear close together. The fourth legs are small and weak, three-jointed with four spines; the first and third joints are about the same length, the second joint is only one-third as long.

The spine at the tip of the second joint is long, slender, and perfectly straight; of the three at the tip of the third joint the inner one is very short and rudimentary; the outer one is about the same length as that on the second joint, and like it slender and straight. The middle claw is much larger, nearly as long as the joint itself and strongly curved.

Fifth legs as already stated.

Total length $4 \mathrm{~mm}$. Length of carapace $2.7 \mathrm{~mm}$; width of the same $2.5 \mathrm{~mm}$.; length of genital segment $1 \mathrm{~mm}$.; length of abdomen 0.4 $\mathrm{mm}$; length of egg strings $3.5 \mathrm{~mm}$.

Color a light yellowish brown without pigment spots.

(centrodonti, the specific name of its host.)

Male.-Carapace as in the female, but proportionally much larger (as 7 to 2); not narrowed as much anteriorly. Frontal plate larger and wider and lunules larger. The median posterior lobe is not quite as large proportionally and is slightly rounded along the posterior margin instead of being emarginate.

Free segment short and almost concealed beneath the carapace and the genital segment. It is proportionally much wider than in the female, and from tip to tip of the lateral plates is five-sevenths as wide as the genital segment.

The latter is narrower than in the female, but is of the same shape. The fifth legs show plainly at the tips of the posterior lobes. Abdomen relatively larger than in the female, with anal laminæ almost as large as itself. The abdomen proper does not reach to the tips of the posterior lobes of the genital segment, but the anal laminæ project well beyond them (fig. 344).

Of the appendages there is no increase in the size of the second antennæ, as is usual, but there is enough increase in the second maxillipeds to more than compensate for this. Instead of the weak and puny appendages found in the female, the male carries a pair of enormous second maxillipeds.

The basal joint is swollen until it is fully as wide as long, and is armed on the inner margin with two large protuberances or papillæ, into the sinus between which the tip of the terminal claw fits snugly. This hasal joint is supplied with very powerful muscles, particularly the one which closes the terminal claw. The latter is three-quarters as long as the basal joint and stout.

The first maxillæ are also very much enlarged, and are bent into a sickle shape, with a slightly enlarged base. 


Total length $3.5 \mathrm{~mm}$. Length of carapace $2.5 \mathrm{~mm}$.; width of same $2.3 \mathrm{~mm}$.; length of genital segment $0.9 \mathrm{~mm}$.; length of abdomen $0.25 \mathrm{~mm}$.

The collection of the National Museum contains one lot of this interesting species sent from England by Rev. A. M. Norman. It is numbered 8105, and was obtained from the gill cavity of Pagellus centrodontus. The species was originally discovered by Baird and described by him in 1850 , and no further description has ever been given. Indeed, so far as known, it was not even noted by any other author until Bassett-Smith in 1899, and he simply gives the name.

The description here given supplements that of Baird in many particulars, especially with regard to the appendages.

Attention should be called to the lateral plates or spines on the sides of the free segment which are not mentioned by Baird, but which are important as a connecting link between this form and those in the following subfamily, the Euryphorinæ. The latter are characterized by the presence of just such plates in all the species, while the Caliginæ, which are here discussed, have no such plates or processes.

In the present species the plates are so small as to be easily overlooked, but if the large aprons at the bases of the second legs be removed and the copepod be then examined the plates appear plainly. Most of the Euryphorine are unable to swim about freely, and with this lack of free locomotion there appear the dorsal plates on the thorax, or abdomen, or both.

It is interesting to find that the beginnings of these plates are found among forms which still retain the ability, if not the disposition, to move about freely.

Another detail of anatomy is equally interesting, and this also was overlooked by Baird. The upper surface of the genital segment projects considerably over the base and sides of the abdomen, so that the latter is partially concealed in dorsal view. But the posterior margin of the genital segment is cut in a deep semicircle, which reveals most of the dorsal surface of the abdomen. We have here, therefore, the initial step in the disappearance of the abdomen; the genital segment is deeply incised to receive it, and it is attached on the ventral surface so as to be partly concealed. The second step is found in Lepeophtheirns dissimmlutus. where the abdomen is attached as far forward on the rentral surface, but the genital segment is no longer incised, and consecquently almost entirely covers the abdomen. The third and last step is the complete disappearance of the abdomen in the genus Anuretes. 


\section{LEPEOPHTHEIRUS INNOMINATUS, new species.}

Plate XXVIII, figs. $345-352$.

Female.-Carapace elliptical, one-eighth longer than wide, equally narrowed anteriorly and posteriorly. Frontal plates small, but well defined with a deep incision at the center.

Posterior sinuses shallow, narrow, somewhat enlarged at the base and inclined diagonally outward. Of the grooves separating the carapace areas that which represents the crossbar of the " $\mathrm{H}$ " is only two-sevenths of the length of the carapace from its posterior margin. Furthermore it is not curved, but is made up of two straight lines meeting at the center like the sides of a very flat roof. This leaves a thoracic area proportionally smaller than in any known species of either Caligus or Lepeophtheirus. The longitudinal grooves are strongly curved, so as to be practically parallel with the margin of the carapace. The eyes are situated well forward and are of good size. The median lobe of the carapace projects backward well beyond the lateral lobes; it is abruptly narrowed at about the center as if jointed, the posterior half being semi-circular and overlapping the free segment a little.

The latter is considerably more than half as wide as the genital segment; is quite short and somewhat crescentic in shape.

The genital segment is fully as large as the carapace, quadrangular in outline, with well rounded corners and a squarely truncated posterior margin. Anteriorly it narrows into a short neck, where it joins the free segment, the neck being considerably narrower than the free segment.

The abdomen is narrow cylindrical, about one-third the width of the genital segment, and nearly four times as long as wide. It is twojointed, the basal joint three times the length of the terminal; the latter joint is also quite a little narrower than the former, but does not taper posteriorly. The anal laminæ are of good size and curve in toward each other at their tips; the plumose setæ are rather short and slender.

The egg strings are two-thirds as wide as the abdomen and fiveeighths the length of the body; the eggs are small, eighty or eighty-five of them in each string.

Of the appendages, the first antennæ are about as long as the frontal plates, the two joints of the same length, and well supplied with setæ and spines. The second antennæ are long and slender, the most of the length being in the terminal claw, which is strongly bent near the tip. The hasal joint is short and stout. The two pairs of maxillæare small and slender, the second pair bifid for only a third of their length, with the branches parallel and close together.

The furca is small, the base and branches about the same length, 


the former slightly enlarged where it joins the vential surface, the latter of a broad $U$ shape, with blunt points.

The second maxillipeds are enormous, the stout basal joints filling the whole central portion of the carapace; the terminal claws are nearly as long as the basal joint and are strongly curved near their tip. The accessory spine is small and weak and is attached near the base of the claw.

There are no spines on the first legs except on the terminal joint, where there are the usual three, and three plumose setre on the posterior border. The three spines on the exopod joints of the second legs are the same size and all very sharp.

The rami of the third legs are close together, with a large spine at the base of the exopod. The fourth legs are long and stout, threefourths the length of the genital segment.

The basal joint is nearly as long as the other three, exclusive of the claws. Of the latter there are five, a tiny, rudimentary one at the enlarged tip of the second joint, a somewhat larger one at the tip of the third joint, and three terminal ones.

These last are graded in size from without inward. The outer one is no larger than that on the second joint, the second one is three times as large, while the inner one is twice the size of the second and is toothed along its outer border.

The fifth legs are invisible dorsally, but are plainly discernible on the ventral surface.

Total length $9.2 \mathrm{~mm}$. Length of carapace $2.8 \mathrm{~mm}$.; width of same $2.5 \mathrm{~mm}$.; length of genital segment $2.8 \mathrm{~mm}$. ; length of abdomen 3.2 mm.; length of egg strings $6 \mathrm{~mm}$. Eighty to eighty-five eggs in each.

Color a dark steel gray, changing but little in alcohol.

(immmimutus, without a name, the one given to it being preoccupied.)

The National Museum collection has a single lot of this species, numbered s(1) 8 , and including three females taken from a salmon at Cornwall, England, by the Rev. A. M. Norman.

These are labeled by Mr. Norman Lepeophtheims gracilis, but that name can not stand, for several reasons. In the first place, P. J. van Beneden described, in 1851, a species which be called Caligus gracilis, but which was really a Lepeophtheirus. If any species of the genus were to preserve the name gracilis, it would of necessity be this one. But even a casual giance at Beneden's figure will suflice to show that he was really describing something very different from the present species.

Again, Beneden's species has been shown by various author's to be the same as $L$. thompsomi Baird, and hence must he included under the srnonyms of that species. Therefore it could not stand for the present species, an entirely different form. 
For these reasons we have considered it necessary to change Norman's label, which has never been published, and leave L. gracitis in its old place as a synonym of $L$. thompsoni.

Under the latter species will be found (see p. 622) a full discussion of these troublesome synonyms. It will suffice here to statrothat the present species can be distinguished at once from $L$. thom psomi, with which it is most likely to be confused, by the equality in size between the carapace and genital segment, by the comparative length of the abdomen (considerably longer than either carapace or genital segment), and by the large size of the second maxillipeds. In the present species, also, the basal joint of the fourth leg reaches well beyond the margins of both carapace and genital segment, while in thompsoni the entire leg, if straightened out, would not reach the margin of the carapace, and the basal joint falls far short of reaching the margin of the genital segment. Finally, the present species was found on a very different host.

\section{LEPEOPHTHEIRUS CHILENSIS, new species.}

Plate XXVIII, figs. 353-364.

Female.-Carapace orbicular, as wide as long, the frontal margin strongly curved and deeply incised at the center.

Posterior sinuses shallow and widely triangular; median lobe about one-half the width of the carapace, and not projecting much behind the lateral lobes. Transverse groove separating the cephalic from the thoracic areas almost exactly in the center of the carapace; lateral grooves nearly straight.

Free thoracic segment short and less than half the width of the genital segment; very prominently widened at the center through the base of the fourth leg. Genital segment half the width of the carapace, one-fourth wider than long, with strongly curved lateral margins and somewhat reentrant posterior margin.

Abdomen half as long as the genital segment and one-fifth as wide, distinctly two-jointed, the joints about equal.

Anal laminæ small and $\cdot$ widely separated, curved in slightly toward each other and armed with small and short setæ.

The anterior antennæ are large, three-fourths as long as the frontal plates with the terminal joint shorter and much narrower than the basal. Both joints are heavily armed with setr, those on the terminal joint being gathered at the tip.

The posterior antennæ are large, the basal joint swollen and with a good-sized spine on its ventral surface. The terminal claw of these appendages is strongly bent in a horizontal direction at the base, and again in the usual vertical direction at the tip. The first maxillæ are close to the tip of these antennæ, are of medium size, and nearly straight. 


The second maxilla are of about the same size as the furca and are 'ut beyond their center with divergent branches, of which the inner one is the larger and curved the more.

The first maxillipeds are of the usual form; the second pair are rather saitl, the basal joint more than twice the length of the terminal claw; the latter is weak and not much curved.

The fura is of medium size and cut beyond the center, making the branches longer than the base. The former are conical and widely divergent; the latter is swollen on either side at the center, giving a spindle shape.

The first swimming legs have a stout spine upon the outer and another upon the posterior margin of the basal joint. The terminal spines are nearly equal and not pectinate, while the plumose setw are rather short. The second legs have large spines upon the outer margin of the exopod; the rami of the third legs are well separated and longer than in most species.

The fourth legs are large and stout, their tips reaching back beyond the genital segment. They are four-jointed, the basal joint only half as long as the other three, including the spines. This basal joint has a stout spine on its outer border at a little distance from the distal end. The third joint is longer than the second and fourth and ends in a short spine. There is no spine on the second joint. The terminal spines are strongly curved and vary much in length, the inner one being nearly three times the length of the outer.

The fifth legs are large and prominent and project beyond the posterior margin.

In young females the free segment and genital segment and abdomen are each of nearly the same size, the fourth segment being the widest and the other's narrowing slightly in order. The fifth legs project as very large papilla from the posterior margin of the genital segment and are much more prominent than even in the adult male. There is no trace of segmentation in the abdomen, but this region is almost exactly like that in the adult male.

Total length $5.3 \mathrm{~mm}$. Length of carapace $3.2 \mathrm{~mm}$; width of same $3.1 \mathrm{~mm}$; length of genital segment $1.2 \mathrm{~mm}$; length of abdomen $0.55 \mathrm{~mm}$.; length of egg strings $3.3 \mathrm{~mm}$.

Color a dull yellow with a slight tinge of brown, with no pigment spots visible in preserved specimens.

(chilensis, of or belonging to Chile.)

Mule.-Carapace twice the length and more than four times the width of the rest of the body, its own length and width being about the same. Posterior sinuses the same as in the female, but the thoracic area is relatively smaller and the digestive glands are larger. The free segment is as wide as the genital segment, one-fifth the width of the carapace, and relatively longer than in the female. The fourth 
legs are attached to its posterior lateral margins, which are much widened through their bases. The genital segment is oblong, with well-rounded anterior corners where it is contracted into a neck on joining the free segment. It carries two pairs of papillæ, one at the posterior corners and the other on the lateral margins just in front of those corners.

The abdomen is small, only half the length of the genital segment, as wide as long, with no trace of segmentation. The anal laminæ are much larger than in the female and their setæ are very much longer and stouter.

The second antennæ are enlarged as usual in this sex into clasping organs, but the branches are reduced to mere knobs. The rami of the third legs are especially prominent and protrude a long distance from the margin of the basal apron.

The fourth legs are relatively much larger than in the female; the basal joints alone reach more than three-quarters of the length of the genital segment, while the tips extend well beyond the ends of the anal laminæ.

Total length $3.3 \mathrm{~mm}$; length of carapace $2.2 \mathrm{~mm}$; width of same $2.2 \mathrm{~mm}$.; length of genital segment $0.58 \mathrm{~mm}$.; length of abdomen $0.3 \mathrm{~mm}$.

Color somewhat darker than in the female.

The National Museum collection includes three lots of this new species, all of which were obtained at Lota, Chile, during the voyage of the United States Bureau of Fisheries steamer Albatross in 1887-88.

The first two lots are numbered 1502 and 1503, while the third lot is unnumbered. No host is given for the first lot; the second, 1503, was taken from a ray, while the third was taken from a species of Sebastes. This third lot includes twenty-five females and two males, which are excellently preserved.

The species resembles parviventris at first sight, but is considerably smaller and the proportions of the various body regions are markedly different. This is seen especially in the general shape of the carapace and genital segment and in the relative size of the two.

The abdomen, also, in this species is relatively longer and is made up of two segments, while in parviventris it is shorter and undivided. The egg strings in parviventris are as long as the entire body, while here they are only three-fifths as long. In parviventris the furca has a broad $U$ shape, the branches widely separate and parallel; here the furca is much smaller, $V$ shaped, with the branches starting close together and diverging rapidly. In this species, also, the second maxillipeds are small and weak, while the fourth legs are very large and strong; in parviventris exactly the opposite is true. 




\section{Genus HOMOIOTES, new genus.}

Carapace large and shield-shaped. Frontal plates without lunules. Mandibles with sharp sawteeth along the inner margins only. Second maxilla small and divided as in Leperphtheimes. First and fourth sivimming legs uniramose, second and third biramose. Genital segment covered by a pair of dorsal plates which finally fuse into one. In the female this plate often grows forward and covers the free segment as well as the genital segment, overlapping the bases of the fourth legs. It extends backward to the center of the abdomen and on either side of the latter sends out a well-rounded, flattened lobe, terminating in a stout blunt spine which reaches even beyond the tips of the anal laminæ. In the male the plate covers only the genital segment and does not quite reach the base of the abdomen. In this latter sex a pair of tifth and a pair of sixth legs are plainly visible on the genital segment, the former very well differentiated.

Abdomen unsegmented, without plates or processes; anal laminæ small, flattened and armed with plumose setæ.

(Homoiotes, óozót $\eta s$, likeness or similarity.)

HOMOIOTES PALLIATA, new species.

\section{Plate XXIX.}

Female.-Carapace orbicular, as long as wide, much narrowed anteriorly and posteriorly. Frontal plates well defined but narrow, completely separated by a central incision, within which can be seen the remains of a frontal filament. Posterior sinuses narrow, of medium depth, and inclined outward, leaving a median lobe fully half the entire width and rather flatly rounded posteriorly. The lateral lobes are narrow, sharply rounded, and curved strongly inward. Thoracic area rather small, the groore which separates it from the cephalic area being made up of two straight lines inclined toward each other like the sides of a roof. The digestive glands in the center of the area show plainly and are semicircular in shape.

The free segment, seen from the ventral surface, is about half the width of the genital segment and less than a third as long. In the adult its dorsal surface is entirely corered by a mantle or lamina which overlaps the bases of the fourth legs on either side and extends back the entire length of the genital segment and half the length of the abdomen.

This lamina belongs really to the genital segment and grows forward over the free segment as can be seen in all young females, all males, and in several of the adult fenales, where the free segment is without any covering. It starts as a pair of small plates, one on either side at the hase of the genital segment. These grow inward toward each 
other, backward, and in the adult females usually forward, until they finally fuse into a single plate or lamina.

The genital segment, seen from below, is about half the width of the carapace, and is ovate in shape, narrowing rapidly toward the posterior end. The sides are very evenly rounded and the dorsal lamina which covers the entire upper surface projects considerably beyond the lateral margins, and extends backward on either side of the abdomen in a broad, flattened lobe. 'These lobes are about one-third the width of the lamina at the point where they arise and each is tipped with a stout spine. The sinus between them is deep and almost a perfect semicircle in outline, leaving exposed the terminal half of the abdomen. 'This latter is small, only one-fourth the length of the genital segment, and composed of a single joint. Its base is concealed beneath the posterior edge of the dorsal lamina, which covers both the free and genital segments, and it tapers strongly posteriorly. It is tipped with a pair of small and narrow anal laminæ, which are well separated and armed with short setæ. The egg strings are a trifle wider than the abdomen and about as long as the carapace; each contains from seventy to eighty eggs.

Of the appendages the first antennæ are large, more than half the length of the frontal plates; the two joints are the same length, the terminal one being narrow and club-shaped.

The second pair are of medium size; the basal joint is not much swollen and is furnished on its dorsal surface, at the inner corner of the distal margin, with a circular plate covered with short and stiff bristles. The terminal claw stands at right angles to the basal joint and is sharply bent near its tip.

The first maxillæ are small, slender, and strongly curved; the second pair are also small and are cut beyond the center, the inner branch being considerably smaller than the outer one. The mandibles are strongly curved at the tip, with about a dozen large serrate teeth along the inner margin of the curve. The first maxillipeds have a small chitin lamina inserted in the inner margin of the terminal joint near its center. They terminate in three claws instead of the usual two; the inner one is considerably longer than the two outer ones, which are about the same length. The outer claw has a pectinate edge along its outer margin.

The second maxillipeds are small, the terminal claw not more than a third the length of the basal joint, with a long and slender accessory spine inserted near its base.

The furca is smail, the base longer than the branches and somewhat swollen, with a large rectangular foramen. The branches are short, well separated, a little divergent, and blunt at the tips.

The first swimming legs have a large plumose seta on the posterior margin of the basal joint and a stout spine at its distal corner. There 


is a slender spine at the anterior distal corner of the second joint and the usual armature on the terminal joint, three plumose setre on the posterior margin, three terminal claws, and a spine at the distal corner.

The second legs are like those of Caligus and Lepeophtheirus. The rami of the third legs are very close together, but are not at all fused. They project well beyond the edge of the basal apron. The exopod is three-jointed and the endopod two-jointed. All the spines and setre are small except those on the respective basal joints.

The fourth legs are large. The basal joint is stout, but is considerably less than half the entire length. The three terminal joints are ahout the same length. The second joint ends in a small and strongly curved claw; the third joint is tipped with a longer and straighter claw, while the fourth joint ends in the usual three claws, graded in size from without inwards.

At the base of each claw is a large lamina tipped with radiating bristles, like those in Lepeophtheirus edwardsi.

Along the outer margin of the two longest terminal claws, and along both margins of the outer shortest claw, is a wide serrated fringe or lamina, again like that in L. edwardsi.

The fifth legs are well defined with long setæ, but are wholly concealed in dorsal view by the dorsal lamina.

Total length $5.3 \mathrm{~mm}$. Length of carapace $3.5 \mathrm{~mm}$.; width of same $3.5 \mathrm{~mm}$.; length of lamina covering free and genital segments $2 \mathrm{~mm}$.; length of egg strings $3.1 \mathrm{~mm}$. Seventy or eighty eggs in each.

Color a light cinnamon brown, the pigment uniformly distributed and not in spots.

(palliata, wearing a cloak or mantle.)

Mule-Carapace more quadrangular than in the female, distinctly wider than long, with the sides somewhat flattened.

Frontal plates well defined, relatively larger than in the female, the joint which separates them from the carapace almost a straight line. In this sex also the plates are completely separated by the deep median incision, in which can be seen the remains of a frontal filament. The posterior sinuses are broadly triangular, leaving a median lobe less than half the entire width. The lateral lobes are broad and well rounded and they do not curve in at all at their tips.

(rrooves and thoracic area as in the female, except that the digestive glands are very pointed anteriorly and much elongated.

'The free segment is as wide as the genital segment, but is quite short. It is constricted anteriorly into a neck, where it joins the carapace, and is comsiderably enlarged through the bases of the fourth legs into a spindle shape.

There is no dorsal plate or lamella, as in the female, but the segment is like that in Caligus and Lepeophtheirus.

The genital segment is quadrangular in outline, slightly emarginate 
posteriorly, with almost straight sides. It is only one-fourth as wide as the carapace, about as wide as long, and carries two pairs of papillaone on the lateral margin and the other at the posterior corners, the two close together.

The first pair, on the lateral margins, represent the fifth legs and are much better developed than in any species of Caligus or Lepeophtheirus thus far observed. On the rentral surface in favorable specimens this pair of legs may be traced to the very base of the genital segment; and they also show an indistinct segmentation, which is very unusual.

The second pair represent the sixth legs, and are in the condition usually assumed by the fifth pair, except that they show only two spines instead of three.

As in the female, the dorsal surface of this segment is covered with a lamina which projects over either lateral margin and covers the bases of the fifth legs posteriorly.

The abdomen is very short, scarcely reaching beyond the tips of the fifth-leg papillæ, and is wider than it is long, with very large anal laminæ, armed with long and stout setæ.

The first antennæ are large and project well beyond the lateral margins of the carapace. The second pair are also enlarged, as usual in this sex, and well branched.

The second maxillipeds are enlarged rather more than usual, and must form powerful prehensile organs.

The basal laminæ, or apron of the third legs, are very large and reach back fully to the center of the genital segment. Being plentifully supplied with powerful muscles, they form a swimming organ of great strength, and must propel the animal through the water swiftly. They must also be equally effective in the prevention of slipping.

The fourth legs are much enlarged and so long that they reach well beyond the tips of the plumose setæ on the anal laminæ. The basal joint on each of them is as large as the entire free segment. They are armed, as in the female.

Total length $2.5 \mathrm{~mm}$. Length of carapace $1.8 \mathrm{~mm}$; width of same $2 \mathrm{~mm}$; length of genital segment $0.35 \mathrm{~mm}$.; length of the fourth legs $1.5 \mathrm{~mm}$.

The National Museum collection includes a single lot of this interesting species; it is numbered W. 75, and was taken from the blue cod, Ophiodon elongatus, locality unknown.

Its chief interest lies in the fact that it forms a connecting link between the subfamily Caliginæ, which is here treated, and that of the Euryphorinæ, their nearest relatives.

By reference to the key on page 532 it will be seen that the Caliginæ are characterized by the entire absence of dorsal plates or appendages on the fourth segment of the thorax, with the exception of the fourth 


\section{•}



legs. The Euryphorine, on the other hand, have a pair of plates on the dorsal surface of the fourth segment which usually overlap the genital segment.

The present species has a pair of dorsal plates which start at the groove between the free and genital segments and, in the female, grow hackward and forward until they fuse and cover both segments. In the male they cover only the genital segment. It would seem at first as if this new genus and species should be placed with the Euryphorine by reason of these dorsal plates. But there are several good reasons for placing it here among the Caliginæ.

First the growth and fusion of the dorsal plates is as unlike the condition which pertains in the Euryphorina as it is unlike that in the Caliginæ. No genus in the former subfamily shows such a fusion of plates, nor do we find it until we come to the Pandarinæ. But in this latter subfamily the character of the appendages has changed materially, and we no longer find anything there which resembles the Caligine. The fusion of the plates then is like Pandarus, but the detail of the appendages is still like that of Caligus Lepeophtheimus in every particular.

Again attention has been called in both sexes to the fact that the remains of a frontal filament can still be seen in the bottom of the incision between the frontal plates.

This shows conclusively that in its development this genus has a stage during which the young are fastened by a frontal filament, exactly like the chalimus of the Caliginæ.

When we come to discuss the development of the Euryphorinæe we shall find that they possess no frontal filament but accomplish their attachment in an entirely different manner.

The present genus, therefore, in the detail of its appendages and in the different stages of its development, is very plainly one of the Caligine. Yet at the same time it possesses a pair of fused dorsal plates, which are developed in a manner similar to that of the Pandarinæ.

Hence it is to be classed with the Caliginæ, but regarded as exhibiting the first signs of that degeneration in structure and function so plainly shown in the Pandarinæ.

In this first beginning the dorsal plates do not stiffen the body enongh, nor is their weight sufficient, to retard the copepod's freedom of motion. If they should offer an impediment in this direction the increase in the size of the apron of the third legs, which is the chief organ of locomotion, would more than offset it.

It is an extremely fortunate circumstance that this single lot of parasites includes well-preserved adults of both sexes and the young in sereral stages of development, so that the foregoing points are clearly demonstrated. 


\section{BIBLIOGRAPHY.}

The following bibliography simply enumerates the papers to which reference is made in the text. The author is compiling an exhaustive bibliography of the entire group of parasitic copepods, which will be published at some future time.

1850. BaIRD, W. The Natural History of the British Entomostraca. Printed for the Ray Society, London.

1896. Bassett-Smith, P. W. Notes on the Parasitic Copepoda of Fish obtained at Plymouth, with Descriptions of New Species. Annals and Magazine of Natural History (6), XVIII, 16 pp., pls. III-vI.

1898a. Bassett-Smith, P. W. Some New Parasitic Copepods found on Fish at Bombay. Annals and Magazine of Natural History (7), I, 17 pp., pls. I-vir.

1898b. Bassett-Smith, P. W. Further New Parasitic Copepods from Fish in the Indo-tropical Region. Annals and Magazine of Natural History (7), II, 22 pp., pls. III-VI.

1898c. Bassett-Smith, P. W. Some New or Rare Parasitic Copepods found on Fish in the Indo-tropical Region. Annals and Magazine of Natural History (7), II, $16 \mathrm{pp}$., pls. $\mathrm{x}-\mathrm{xII}$.

1899. Bassett-Smith, P. W. A Systematic Deseription of Parasitic Copepoda found on Fishes, with an Enumeration of the Known Species. Proceedings of the Zoological Society of London, 1899 , pp. 438-507, pl. xxvI.

1765. Baster, Јов. Opuscula subseciva, observationes miscellaneas de animalculis et plantis quibusdam marinis, eorumque ovaries et seminibus continentia. 2 vols., quarto. Harlem, 1759-1765.

1851. Beneden, P. J. van. Recherches sur quelques Crustacés inférieurs. Annales des Sciences Naturelles (3), XVI, pp. 71-131, pls. II-VI.

1892. Beneden, P. J. van. Quelques nouveaux Caligidés de la Côte d'Afrique, et de l'Archipel des Açores. Bulletins de l'Académie Royale des Sciences, des Lettres et des Beaux-arts de Belgique (3), XXIV, pp. 241-262, pls. I-IV.

1883. Brady, G. S. Report on the Copepoda. Challenger Expedition, VIII, Pt. XXIII, pl. LV.

1898. Brran, A. Catalogo di Copepodi parassiti dei Pesci della Liguria. Atti della Società Ligustica di Scienze Naturali e Geografiche, IX, 31 pp., pls. I-IV.

1899. Brian, A. Diphyllogaster thompsoni, n. gen. di Caligidæ della Dicerobatis giornæ (Günther), idem, X, pp. 5-11, pl. III.

1833. Burmeister, H. Beschreibung einiger neuen oder weniger bekannten Schmarotzerkrebse, nebst allgemeinen Betrachtungen über die Gruppe, welcher sie angehören. Kaiserlich-leopoldinisch-carolinische deutsche Akademie der Naturforscher, Acta, XVII, Pt. 1, pp. 271-336, pls. XxIII-Xxv.

1885. Carus, J. V. Prodromus Faunæ Mediterraneæ, I, quarto, Stuttgart.

1864. Claus, C. Beiträge zur Kenntniss der Schmarotzerkrebse. Zeitschrift für wissenschaftliche Zoologie, XIV, pp. 365-382, pIs. XXXIII-XXXXVI.

1846. Dana, J. D. Notice of some Genera of Cyclopacea. Silliman's American Journal of Science and Arts (2), I, pp. 225-230.

1852. Dana, J. D. Conspectus Crustaceorum quæ in Orbis Terrarum circumnavigatione, Carolo Wilkes e Classe Reipublicæ Fœderatæ Duce, lexit et descripsit Jacobus D. Dana. Pt. 2. Proceedings of the American Academy of Arts and Sciences, Philadelphia, II, pp. 9-61.

1853. IANA, J. D. United States Exploring Expedition during the years 1838, 1839, $1840,1841,1842$, under the Command of Charles Wilkes, U. S. N., XIII, Pt. 2, pp. 1309-1382, pls. XCiv-Xcvi.

1825. Desmarest, A. G. Considérations générales sur la classe des Crustacés, et description des espèces de ces animaux, qui vivent dans la mer, sur les côtes, ou dans les eaux douces de la France. Paris and Strasbourg. 


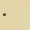



1860. FIs:HER, $S$. Beitrïge zur Kenntniss der Entomostrareen. Abhandlungen der mathematisch-physicalische Classe der Koeniglich bayerschen Akademie der Wissenschaften, Munich, VIII, p. 645, pl. XxIr.

1847. Frex, H., and Leutckart, R. Beitrüge zur Kenntniss wirbelloser Thiere mit hesonderer Berücksichtigung der Fauna des Norddeutschen Meeres. Braunschweig, 170 pp., 2 pls.

1849. (i.ty, C. Historia física y política de Chile. Madrid, quarto. Gives a figure (Crustáceos, pl. III, fig. 12) of Caligus gayi.

1866. Gerstakcker, A. The Copepoda in Bronn's "Klassen und Ordnungen des Thierreichs," V, Pt. 2.

1883. Gissler, C. F. A new Parasitic Copepod Crustacean. American Naturalist, XVII, pp. 885-887, 10 text figures.

1842. Goodsir, H. D. S. On a New Genus and on Six New Species of Crustacea, with Observations on the Development of the Egg, and on the Metamorphoses of Caligus, Carcinas, and Pagurus. Edinburgh New Philosophical Journal, XXXIII, pp. 174-192, pls. II and III.

1865. HeLLER, C. Reise der Österreichischen Fregatte Novara, in den Jahren 1857, 1858 und 1859. Zoologische Theil, II, Pt. 3, Crustaceen. Wien.

1866. Heller, C. Carcinologische Beiträge zur Fauna des adriatischen Meeres. Verhandlungen der Kaiserlich-koeniglichen, zoologisch-botanischen (iesellschaft, Wien, 1866, pp. 723-760.

1858. Hesse, E. Mémoire sur les moyens à l'aide desquels certaines Crustacés parasites assurent la conservation de leurs espèces. Annales des Sciences Naturelles, Zoologie (4), IX, pp. 120-125.

1877. Hesse, E. Remarques sur le Genre Chalime. Annales des Sciences Naturelles (6), Zoologie, V, article 10, $3 \mathrm{pp}$.

1883. Hesse, E. Crustacés rares ou nouveaux des côtes de France. $33^{\mathrm{me}}$ article. Annales des Sciences Naturelles (6), XV, article 3, 48 pp., pls. IV-VI. Closes with a review of the classification of the parasitic Copepods.

1824. Jonnston, G. Notice respecting the Genus Caligus of Leach. Edinburgh New Philosophical Journal, X, pp. 292-294, pl. vir.

1835. Kol,ar, V. Beiträge zur Kenntniss der Lernäienartigen Crustaceen. Annalen des Wiener-Museums der Naturgeschichte, I, pp. 81-92, pls. Ix and x.

1837. Krï̀ner, H. Om Snyltekrebsene, isaer med Hensyn til Danske Fauna. Naturhistorisk Tidsskrift, I, pp. 172-189, pl. II; pp. 203-208, pl. II; pp. 252-304, pls. II and III; pp. 476-505, pl. v.; pp. 605-628, pl. vi.

1838. KröyeR, H. Idem. Idem, II, pp. 7-52, pl. I; pp. 131-157, pl. III.

1863. Ккйкв, H. Birlrag til Kundskab om Snyltekrebsene. Naturhistorisk Tidsskrift, Tredie Raekke, Andet Bind, pp. 75-426.

1818. Lamarck, J. B. P., Chevalier de. Histoire naturelle des animaux sans vertèbres, V, Paris, July, 1818.

1813-1814. LeAch, W. E. Crustaceology. Edinburgh Encyclopedia, VII.

1816. Lек'н, W. H. Annulosa. Encyclopedia Britannica, Supplement I, 1816, p. 405, pl. $\mathrm{xx}$, figs. $1-5$.

1855. LEIDY, J. Contributions towards a Knowledge of the Marine Invertebrate Fauna of the Coasts of Rhode Island and New Jersey. Journal of the Academy of Natural Sciences at Philadelphia, III, pp. 1-20, pls. x and XI.

1889. Lemy, J. A Parasitic Copepod. Proceedings of the Academy of Natural - Sciences at Philatelphia, 1889, p. 95, with figure in the text. A chalimus, probably of Caligus rapax.

1875. McIntosm, W. C. On the Invertehrate Marine Fauna and Fishes of St. Andrews. Annals and Magazine of Natural History (4), XIV, pp. 258-274.

1840. Minn-limwarin, II. IIstoire Naturelle des Crustacés, Paris, III, pp. 432-529. 
1776. UÜLLER, O. F. Zoologiæ Danicæ. Havniæe [Copenhagen], 1776. Introduces the genus Caligus under the name Binoculus.

1785. MüLLER, O. F. Entomostraca seu Insecta Testacea quæ in aquis Daniæ et Norvegiæ reperit. Lipsiæ, 1785. Corrects his previous error and founde the genus Caligus.

1851. MƯller, F. Ueber Caligus appendiculatus, n. s. Archiv für Naturgeschichte, 1851, XVII, Pt. 1, p. 91.

1852. MUthLER, F. Eine Beobachtung über die Beziehung der Gattungen Caligus und Chalimus. Archiv für Naturgeschichte, XVIII, Pt. 1, pp. 91 and 92.

1832. Nordiant, A. VAx. Mikrographische Beiträge zur Naturgeschichte der wirbellosen Thiere, Berlin, quarto, 1832 , Pt. 2 , pls. $\mathrm{I}-\mathrm{X}$.

1864. Norburann, A. van. Neue Beiträge zur Kenntniss Parasitischer Copepoden. Erster Beitrag. Bulletin de la Société Impériale des Naturalistes de Moscou, XXXVII, No. 4, pp. 461-520, pls. v-viII.

1869. Otsson. P. Prodromus faunæ Copepodorum parasitantium Scandinaviæ. Karolinska universitet, Lund, Arsskrift, 1868, p. 36.

1877. Olsson, P. Om Parasitiska Copepoder i Jemtland. Oefversigt af Kongl. Vetenskaps-Akademiens Forhandlingar, XXXIV, No. 5, pp. 75-88, pls. IV-VI.

1828. Отто, A. W. Beschreibung einiger neuen, in den Jahren 1818 und $1819 \mathrm{im}$ Mittelländischen Meere gefundener Crustaceen. Kaiserlich-leopoldinischcarolinische deutsche Akademie der Naturforscher, Nova Acta, XIV, pp. 331-354, pls. xх1-XXIII.

1838. PiCkertng, C., and Dana, J. D. Description of a Species of Caligus, C: americaners. American Journal of Science, XXXIV, pp. 65-106, pls. III-V.

1884. Racubun, R. Annotated List of the described Species of Copepods from American Waters contained in the U. S. National Museum. Proceedings of the U. S. National Museum, VII, pp. 483-492.

1843. Rath ке, M. H. Beiträge zur Fauna Norwegens, Crustacea, mit 12 Kupfertafeln. Kaiserlich-leopoldinisch-carolinische deutsche Akademie der Naturforscher, Verhandlungen, XX, Pt. 1, pp. 98-132, 244-249.

1880. Richtarni, S. Contribuzione alla Fauna d' Italia. Catalogo sistematico dei Crostacei che vivono sul corpo degli animali acquatici. Catalogo degli Espositori e delle Cose Esposte, Espozitione internazionale di Pesca in Berlino, 1880 , pp. $147-152$.

1818. SAY, T. An Account of the Crustacea of the United States. Journal of the Academy of Natural Sciences at Philadelphia, I, Pts. 1 and 2.

1901a. Sсотт, A. Lepeophtheirus and Lernea. Transactions of the Liverpool Biological Society, XV, pp. 188-241, pls. I-V.

1901b. Scotт, A. Some Additions to the Fauna of Liverpool Bay, Collected May 1, 1900, to April 30, 1901. Transactions of the Liverpool Biological Society, XV, pp. 342-352, pls. I and II.

1894. Sсотт, T. Report on Entomostraca from the Gulf of Guinea. Transactions of the Linnean Society (2), Zoology, VI, Pt. 1, 161 pp., pls. I-Xv.

1900. Sсотт, T. Notes on some Crustacean Parasites of Fishes. Eighteenth Annual Report of the Fishery Board for Scotland, Pt. 3, pp. 144-187, pls. v-viI.

1902. Scotr, T. Notes on some Parasites of Fishes. Twentieth Annual Report of the Fishery Board for Scotland, Pt. 3, pp. 288-303, pls. XII-XIII.

1778. SLABBER, M. Naturkundige verlustigingen behelzende microscopise. Waarneemingen van in- en uitlandse Water- en Land-Dieren. Te Haarlem, 1769.

1874a. Surn, S. I. Invertebrate Animals of Vineyard Sound. Report of the Commissioner of Fish and Fisheries for 1871 and 1872, pes, 295-747, pl. vil (parasitic copepods). 



1874b. Smith, S. I. Crustacean Parasites of Fresh-water Fishes. Report of the U. S. Fish Commission for 1872 and 1873, Pt. 2, p. 662.

1901. Steising, T. R. R. On rerustacea brought by Dector Willey from the South

Seas. Willey's Zoological Researches, Pt. 5, pp. 605-690, pls. I-XI.

1861. Steenstrup, J., and J.̈̈Tken, C. Bidrag til Kundskab om det aabne Havs Snyltekrebs og Lerneer. Kongelige Danske Videnskabernes Selskabs Skrifter, 5te Raekke, naturhistorisk og mathematisk Afdeling, V, pp. 343432 , pls. I-Xv.

1762. Strow, H. Physiske og Oeconomisk Beskrivelske over Fogderiet Söndmör, I, Deel, 1762.

1895. Tummpon, I. C. Revised Report on the Copepoda of Liverpool Bay. Report of the Fauna of Liverpool Bay, IV, pp. 81-136, pls. Xv-xxxv.

1889. Thomsox, (․ M. Parasitic Copepoda of New Zealand. Transactions of the New Zealand Institute, XXII, p. 354, pls. Xxv-XxIx.

1890. Thomson, G. M. On a New Parasitic Copepod. Transactions of the New Zealand Institute, XXIII, pp. 227-229, pl. xxuI.

1850. White, A. List of the Specimens of British Animals in the Collection of the British Museum, Pt. 4, Crustacea, London, 1850, pp. 117-132.

1902. Wilson, C. B. North American Parasitic Copepods of the Family Argulidx, with a Bibliography of the Group and a Systematic Review of all Known Species. Proceedings of the U. S. National Museum, XXV, pp. 635-742, pls. VIII-XXVII.

1904. Wilson, C. B. A New Species of Argulus, with a more complete Account of two Species already described. Proceedings of the U. S. National Museum, XXVII, pp. 627-655, text figures.

\section{EXPLANATION OF THE PLATES.}

Plate V. Caligus mufimaculatus, new species. Fig. 51, Dorsal view of female; fig. 52, Dorsal view of male; fig. 53, Dorsal view of a fully developed male chalimus; fig. 54, First maxilla and second antenna of female; fig. 55, First maxilliped of female; fig. 56, Second maxilla of female; fig. 57 , Second maxilliped of male; fig. 58, Second maxilliped of female; fig. 59, Furca and first maxilla of male; fig. 60, Furea of female; figs. 61-64, First, second, third, and fourth swimming legs of female.

Plate VI. Culigus schistom!r, new species. Fig. 65, Dorsal view of male; fig. 66, Dorsal view of female; fig. 67 , Second antenna of female; fig. 68 , First maxilliped of female; fig. 69, First maxilla of male and female; fig. 70. Second maxilliped of female; fig. 71, Second antenna of male; fig. 72, Second maxilla of female; fig. 73, Furca of female; fig. 74, First swimming leg of female; fig. 75, Tip of same enlarged to show the divided claws; figs. 76-78, Second, third, and fourth swimming legs of female.

Plate VII. C'alimps rume. Milne-Whwards. Fig. 79, Dorsal view of adult female; fig. 80 , Dorsal view of adult male; fig. 81, Dorsal view of young female, showing fifth legs at the posterior corners of the genital segment; fig. 82 , Second antenna of female; fig. 83 , Second maxilla; fig. 84 , Furca; figs. 85-88, First, second, third, and fourth swimming legs of female; fig. 89, Ventral surface of genital segment, showing the rement glands.

I'late VII. Cirligns mulubilis, new speries. Fig. 90, Dorsal view of female; fig. 91, Dorsal view of male; fig. 92, Second antenna; figs. 93 and 94, First and second maxillæ; fig. 95, Furca; figs. 96 and 97 , First and second

Proc. N. M, vol, xxviii-04_- 43 
maxillipeds; figs. 98, 100-102, First, second, third, and fourth swimming legs; fig. 99, One of the plumose setre from the posterior border of the terminal joint of the first legs. All the appendages are from the female.

Plate IX. Caligus aliuncus, new species. Fig. 103, Dorsal view of female; fig. 104, Second antenna; fig. 105, Second maxilla; fig. 106, Furca; fig. 107, Second maxilliped; fig. 108, First swimming leg; fig. 109, Terminal claw of same enlarged to show its serrated border; figs. 110, 111, Third and fourth swimming legs.

Plate X. Caligus curtus Müller. Fig. 112, Dorsal view of male; fig. 113, Dorsal view of female; fig. 114, Very young Chalimus, the third thorax segment not fully fused with the head; fig. 115, Fully developed male Chalimus; fig. 116, First maxilliped; fig. 117, Second maxilliped; fig. 118, Furca; fig. 119, Second swimming leg; fig. 120, First swimming leg; figs. 121, 122, Third and fourth swimming legs; fig. 123, Second antenna of male; fig. 124, Second maxilliped of male.

Plate XI. Caligus chelifer, new species. Fig. 125, Dorsal view of female without egg strings; fig. 126, Dorsal view of female with egg strings, showing difference in shape of genital segment; fig. 127, Second antenna and first maxilla; fig. 128, Second maxilla, showing rudimentary endopod; fig. 129, First maxilliped; fig. 130, Terminal claw, or chela, of second maxilliped; fig. 131, Furca; fig. 132, First swimming leg; fig. 133, Terminal joint of the same, enlarged; fig. 134, Fourth swimming leg.

Plate XII. Caligus belones Kröyer and Caligus latifrons, new species. Fig. 135, Caligus belones, dorsal view of female; fig. 136, Second antenna; fig. 137, First and second maxillæe, and furca; figs. 138 and 139, Third and fourth swimming legs; fig. 140, Caligus latifrons, dorsal view of female; fig. 141, Second antenna; fig. 142, Second maxilla; fig. 143, Second maxilliped; fig. 144, Furca; fig. 145, First swimming leg; fig. 146, Terminal joint of same enlarged; figs. 147-149, Second, third, and fourth swimming legs.

Plate XIII. Caligus bonito, new species, and Caligus pelamydis Kröyer. Fig. 150, Caligus bonito, dorsal view of female with egg strings; fig. 151, dorsal view of female without egg strings, drawn by Richard Rathbun; fig. 152, Dorsal view of male, drawn by Richard Rathbun; fig. 153, Posterior part of young female, showing the abdomen segments of about equal length; fig. 154, Caligus pelamydis, dorsal view of female; fig. 155, Second antenna; fig. 156, First and second maxillæ; fig. 157, Second maxilliped; fig. 158, Furca; figs. 159-161, Second, third, and fourth swimming legs.

Plate XIV. Caligus productus Dana and Caligus isonyx Steenstrup and Lütken. Fig. $161 \mathrm{a}$, First swimming leg of Caligus pelamydis; fig. 162, Caligus productus, dorsal view of female; fig. 163, Second antenna; fig. 164, Second maxilla; fig. 165, Furea; fig. 166, Second maxilliped; figs. 167-170, First, second, third, and fourth swimming legs; fig. 171, Caligus isonyx, dorsal view of female, after Steenstrup and Lütken.

Plate XV. North American species of Caligus not in the National Museum collection. Fig. 172, C. balistae, Steenstrup and Lütken, dorsal view of female; fig. 173, idem, Dorsal view of male; fig. 174, Furca; fig. 175, Second maxilliped; figs. 176, 177, Third and fourth swimming legs; fig. 178 , C. thymni Dana, ventral view of male; fig. 179, Dorsal view of genital segment and abdomen of female; fig. 180, C. hrmulonis Kröyer, dorsal view of female; fig. 181, idem, Dorsal view of male; 
fig. 182, Furca; fig. 183, First swimming leg, showing absence of plumose setæe on the terminal joint; fig. 184, C. isonyx, second maxilla; fig. 185, Furca; fig. 186, Fourth swimming leg. The figures on this plate are all taken from the respective authors named.

Plate XVI. Culigodes megrerphulus, new species. Fig. 187, Dorsal view of female; fig. 188, Second antenna; fig. 189, Second maxilla; fig. 190, Accessory spine on either side of the mouth tube; fig. 191, Furca; fig. 192, Second maxilliped; figs. 193-195, First, second, and fourth swimming legs.

I'late XVII. Ehetus typiris Kröyer. Fig. 196, Dorsal view of female; fig. 197, Side view of same female; fig. 198, Second antenna; fig. 199, Mouth tube and second maxilla; fig. 200, First maxilliped; fig. 201, Second maxilliped; figs. 202-205, First, secont, thirrl, and fourth swimming legs.

I'late XYIII. Lepeophtheirus. Fig. 206, Lepeophtheirus longipes, new species, dorsal view of female; fig. 207, Second antenna; fig. 208, Second maxilliped; fig. 209, Furca; figs. 210, 211, First and second swimming legs; fig. 212, L. thompsoni Baird, dorsal view of female; fig. 213, Second antenna; fig. 214, Furca; fig. 215, Second maxilla; fig. 216, Second maxilliped; figs. 217-219, First, second, and fourth swimming legs. Fig. 220, L. innominatus, new species, second maxilla; fig. 221, Furca. These two figures are under the same magnification as figs. 214 and 215. Fig. 222, L. longipes, second maxilla.

Plate XIX. Lepeophtheirus nordmannii Milne-Edwards. Fig. 223, Dorsal view of female, drawn by Emerton; fig. 224, Dorsal view of male; fig. 225, Second antenna; fig. 226, First maxilla; fig. 227, Second maxilla; fig. '2:s, Second maxilliped; fig. 229, Furca; figs. 230-233, First, second, third, and fourth swimming legs.

l'late IX. Lepeoplithrims hippoglossi Kröyer. Fig. 234, Dorsal view uf female; fig. 235, Dorsal view of male; fig. 236, Second antenna; fig. 237, Second maxilla; fig. 238, Second maxilliped; fig. 239, Furea; figs. 2t0-2 43 , First, second, third, and fourth swimming legs.

Plate IXI. Leprophlheirus erlurrdsi, new species. Fig. 244, Dorsal view of female; fig. 245 , Dorsal view of male; fig. 246 , Second antenna of female; fig. 247 , Terminal claw of second antenna of male; fig. 248 , Second maxilla of female; fig. 249, Second maxilla of male with accessory chitin ridge; fig. 250, Furca; fig. 251, Second maxilliped of female; figs. 252-255, First, second, third, and fourth swimming legs; fig. 256, Ventral view of genital segment of female, showing $c . g$. cement gland; o. oviduct; s. spermatophores; s. $r$. semen receptacles; $r a$. vagina; fig. 257 , Newly hatched nauplius, the pigment spots a deep yellowish purple.

Plate XXII. Lepmohthims. Fig. 258, L. erlumidsi, dorsal view of chalimus, half developed; fig. 259, $L$. dissimulatus, new species, dorsal view of male; fig. 260 , Dorsal view of female; fig. 261 , Second antenna of female; fig. 262 , Second antenna of male, showing branches; fig. 263, First maxilla; fig. 264, Second maxilla of Galapagos specimen; fig. 265, The same, Bermuda specimen; fig. 266, Furca of Galapagos specimen; fig. 267, The same, Bermuda specimen; fig. 268, Second maxilliped; figs. 269272, First, second, third, and fourth swimming legs; fig. 273, Ventral view of genital segment and aldomen of Bermuda specimen; fig. 274, The sawe, Galapagos specimen.

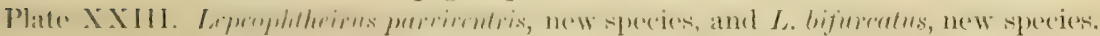
Fig. 275, L. parminentris, dorsal view of female; fig. 276 , Dorsal view of male; fig. 277 , second antenna, with accessory spine; fig. 278 , 
Second maxilla; fig. 279, Furca; fig. 280, Second maxilliped; figs. 281-284, First, second, third, and fourth swimming legs; fig. 285, L. bifurcatus, dorsal view of female; fig. 286 , Second antenna with accessory spine; fig. 287, First maxilla; fig. 288, Second maxilla; fig. 289, Second maxilliped; fig. 290, Furca; figs. 291-293, First, second, and fourth swimming legs, with one of the toothed and ribbed plates at the base of the spines on the fourth legs.

Plate XXIV. Lepeophtheirus salmonis Kröyer. Fig. 294, Dorsal view of female; fig. 295, Dorsal view of male; fig. 296, Second antenna; fig. 297, First maxilla; fig. 298, Furca; fig. 299, Second maxilliped; fig. 300, First maxilliped; figs. 301-303, First, second, and fourth swimming legs.

Plate XXV. Lepeoptheirus and Anuretes. Fig. 304, L. pacificus Gissler, dorsal view of female; fig. 305, Abdomen of the same after treatment with acetic acid; fig. 306, Second antenna; fig. 307, Second maxilla; fig. 308, Second maxilliped; fig. 309, Mandible; fig. 310, Fourth swimming leg. All the figures after Gissler. Fig. 311, L. cossyphi Kröyer, genital segment and abdomen of female; fig. 312, Fourth swimming leg; fig. 313, Third swimming leg. All the figures from Kröyer, and the only ones ever published. Fig. 314, L. robustus Kröyer, first swimming leg of male; fig. 315, Furca. Both figures from Kröyer, and the only ones ever published. Fig. 316, Anuretes heckelii Kröyer, ventral view of female; fig. 317, Second antenna; fig. 318, Second maxilla, fig. 319, Second maxilliped; fig. 320, Furca; fig. 321, Fourth swimming leg. All the figures from Kröyer.

Plate XXVI. Caligus teres, new species. Fig. 322, Dorsal view of female; fig. 323, Dorsal view of male; fig. 324, Second antenna and first maxilla; fig. 325 , Second maxilla; figs. 326, 327, First and second maxillipeds; fig. 328, Furca; figs. 329-332, First, second, third, and fourth swimming legs.

Plate XXVII. Caligus centrodonti Baird. Fig. 333, Dorsal view of female; fig. 334, Dorsal view of male; fig. 335, Second antenna; fig. 336, First maxilla; fig. 337, Second maxilla and mouth tube; fig. 338, Furca; fig. 339, Second maxilliped; figs. 340-343, First, second, third, and fourth swimming legs; fig. 344, Genital segment and abdomen of male, ventral view.

Plate XXVIII. Lepeophtheirus innominatus, new species, and L. chilensis, new species. Fig. 345, L. innominatus, dorsal view of female; fig. 346, Second maxilla; fig. 347, Second antenna; fig. 348, Second maxilliped; figs. 349-352, First, second, third, and fourth swimming legs; fig. 353, L. chilensis, dorsal view of female; fig. 354 , Dorsal view of male; fig. 355, Second antenna; fig. 356, First maxilla; fig. 357, Second maxilla; fig. 358, Furca; fig. 359, Second maxilliped; figs. 360-363, First, second, third, and fourth swimming legs; fig. 364, Dorsal view of genital segment and abdomen of a young female, showing fifth legs.

Plate XXIX. Homoiotes palliatu, new genus and new species. Fig. 365, Dorsal view of female; fig. 366, Dorsal view of male; fig. 367, Second antenna, fig. 369, Mandible; figs. 370, 371, First and second maxiliipeds; fig. 372, Furca; figs. 373-376, First, second, third, and fourth swimming legs; fig. 377, Dorsal view of genital segment and abdomen of male, showing dorsal plate grown down over the fifth and sixth legs; fig. 378 , Dorsal view of genital segment of young female, showing that the dorsal plate is really made up of two plates which start on either side at the base of the segment and afterwards fuse along the mid-line; fig. 379, Ventral view of genital segment of male, showing the fifth and sixth legs 

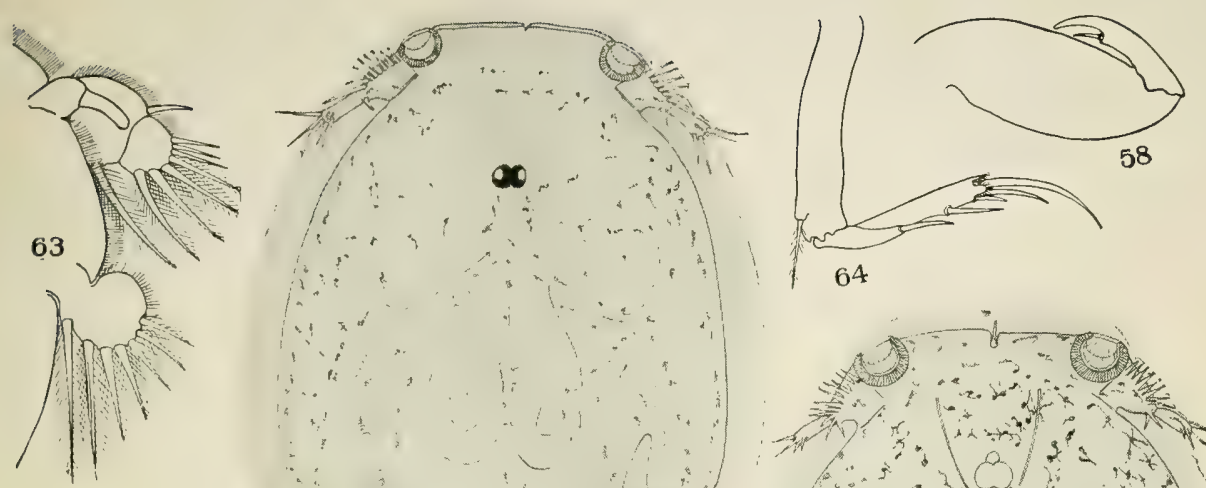

52
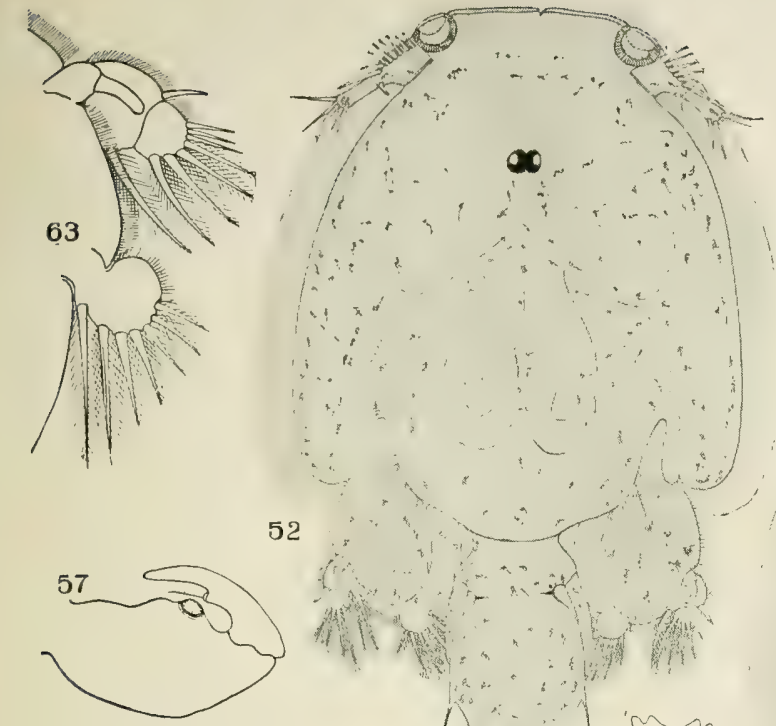

2
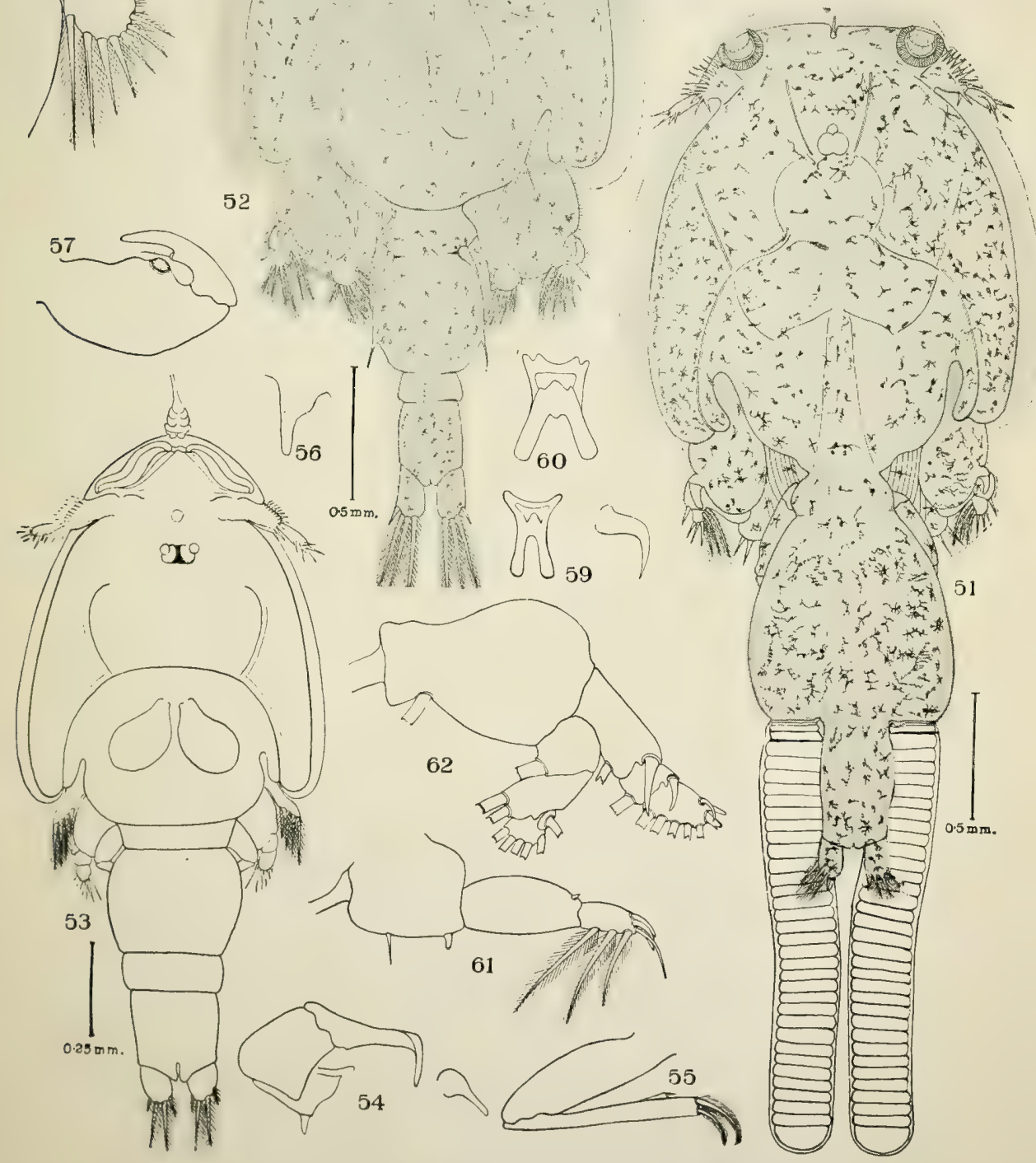

The male and female of Caligus rufimaculatus.

FOR EXPLANATION OF PLATE SEE PAGE 669. 




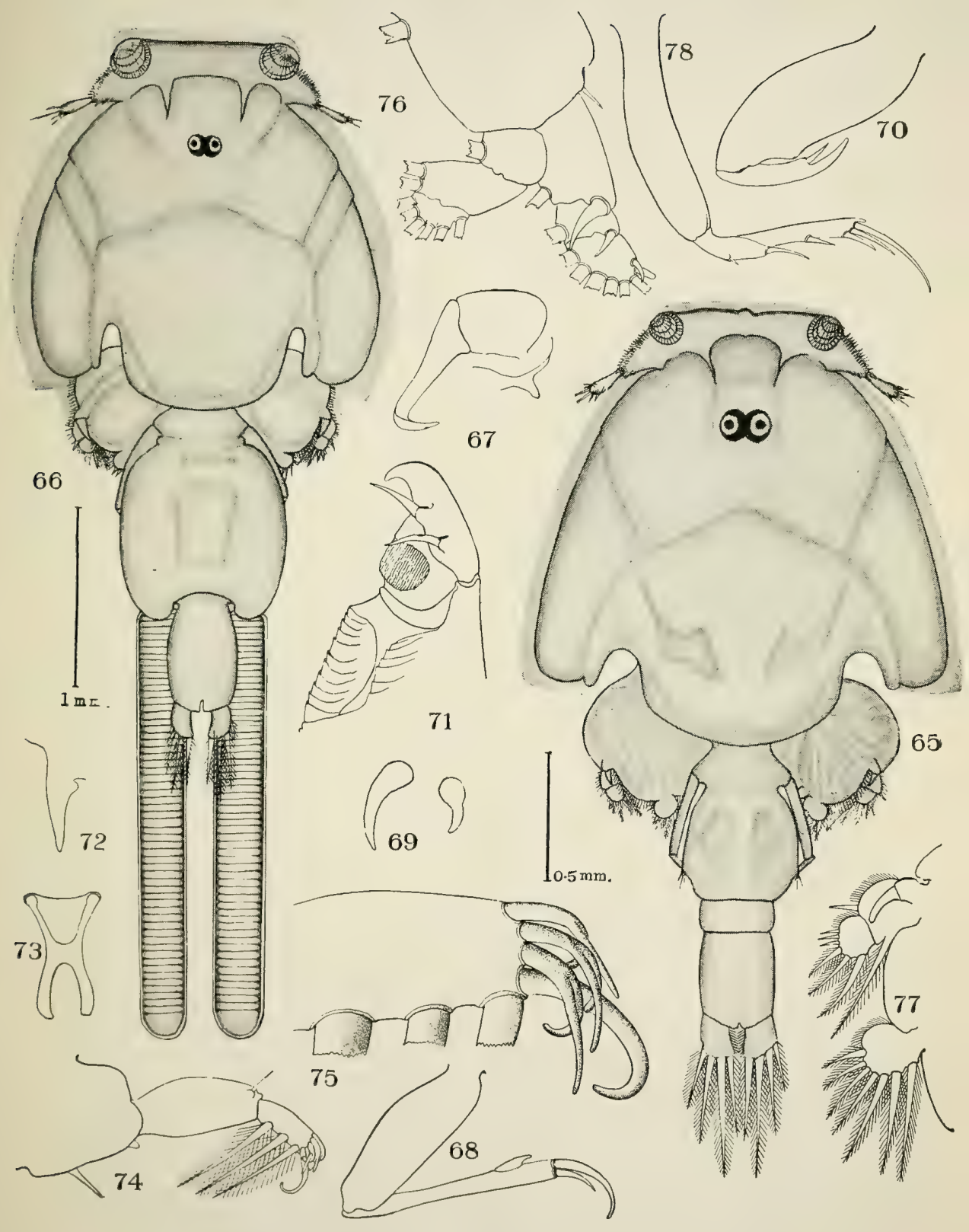

The Male and female of Caligus schistonyx.

For EXPLANATION OF PLATE SEE PAGE 669. 



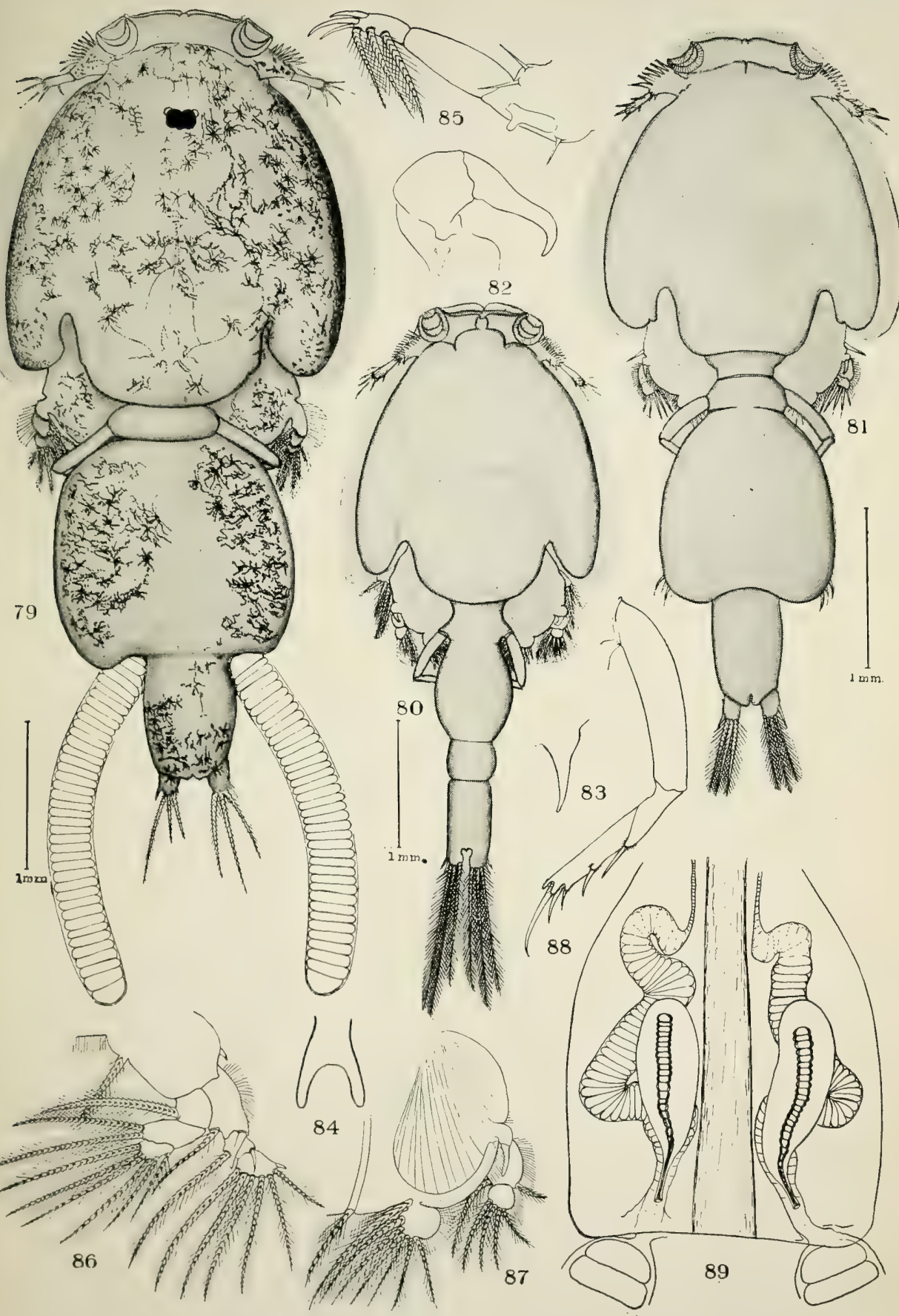

The Male and female of Caligus rapax. 




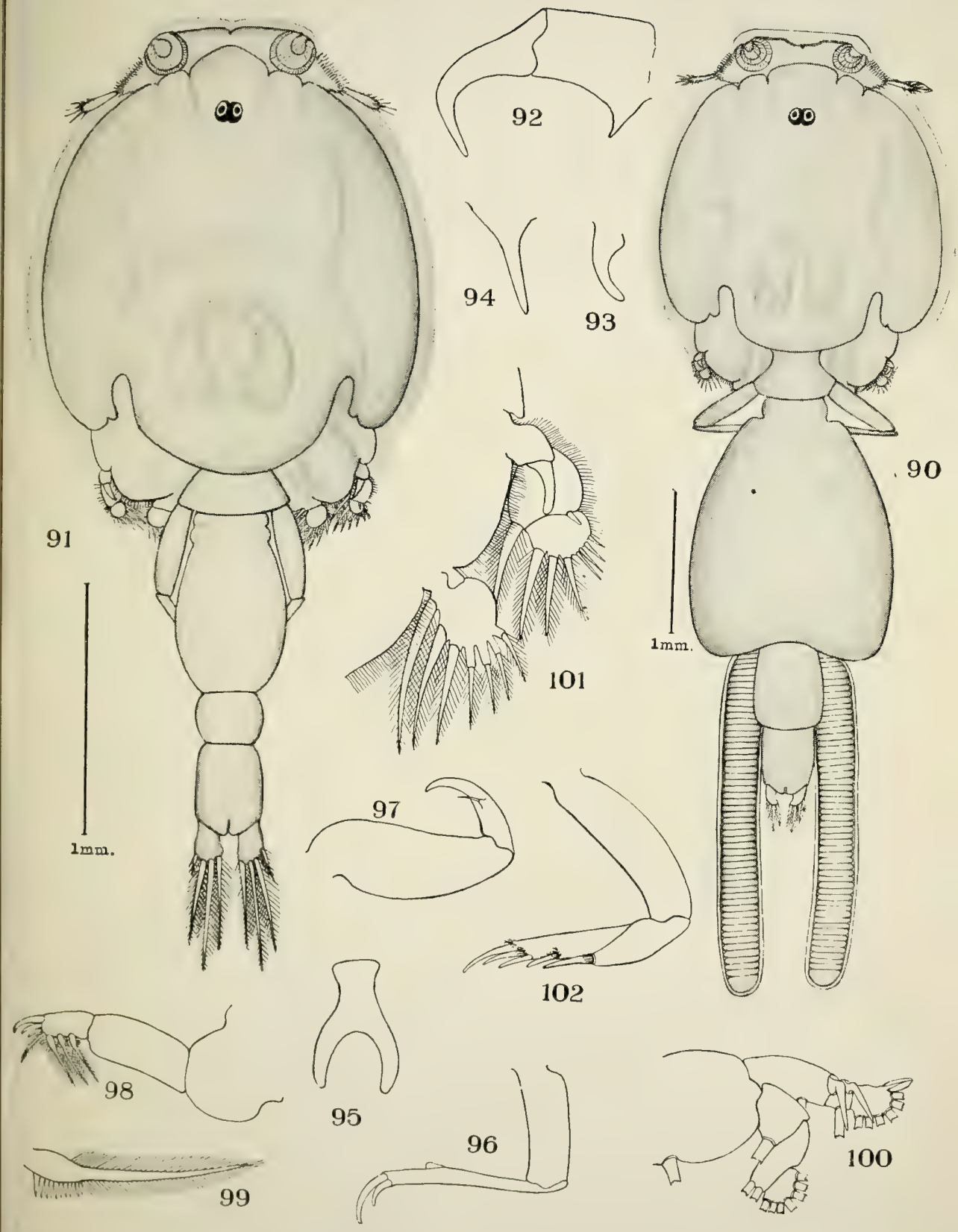

The Male and Female of Caligus mutabilis.

For explanation of PLATE see pages $669,670$. 



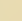







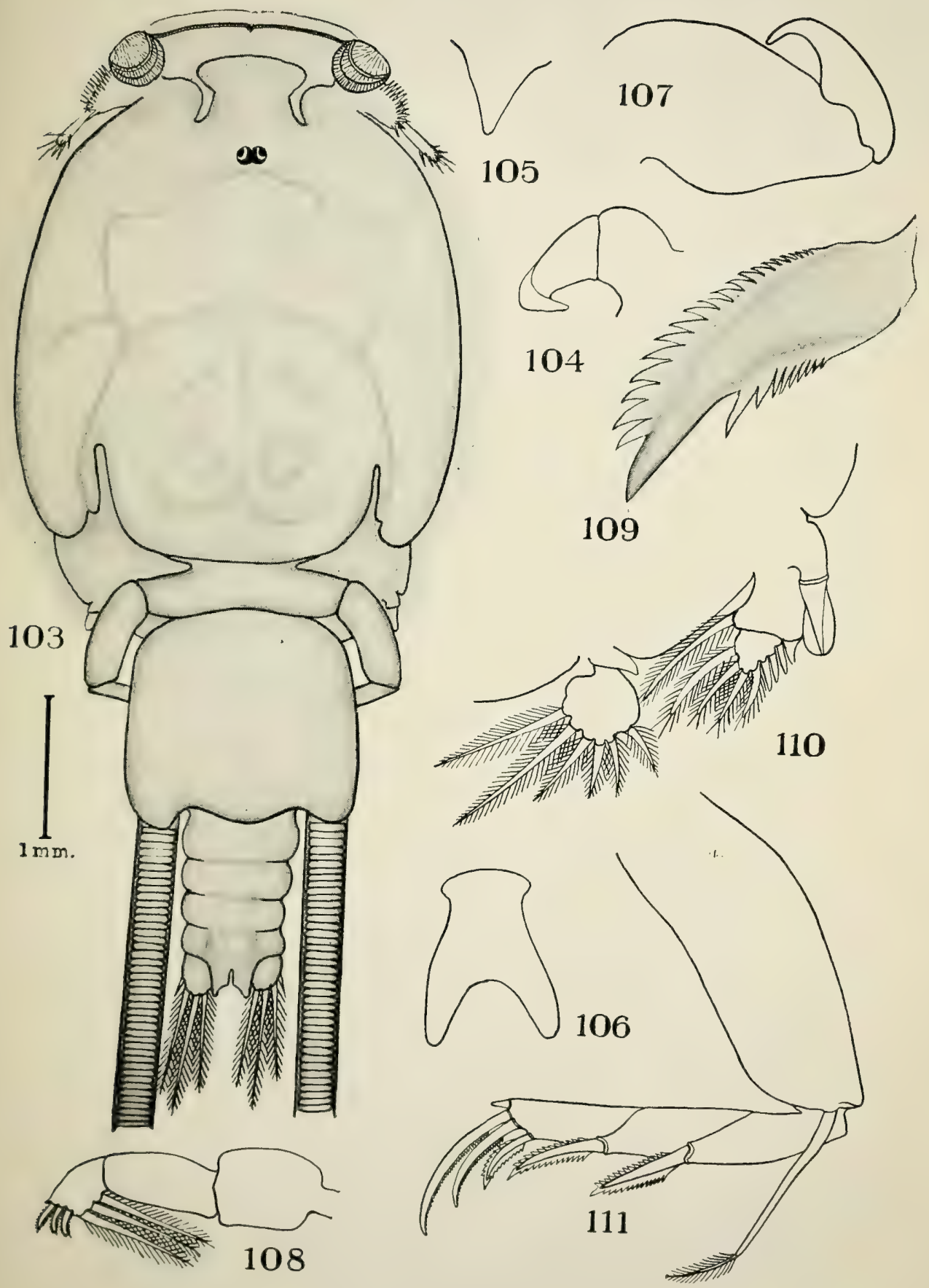

The female of Caligus aliuncus.

For EXPLANATION OF PLATE SEE PAGE 670. 





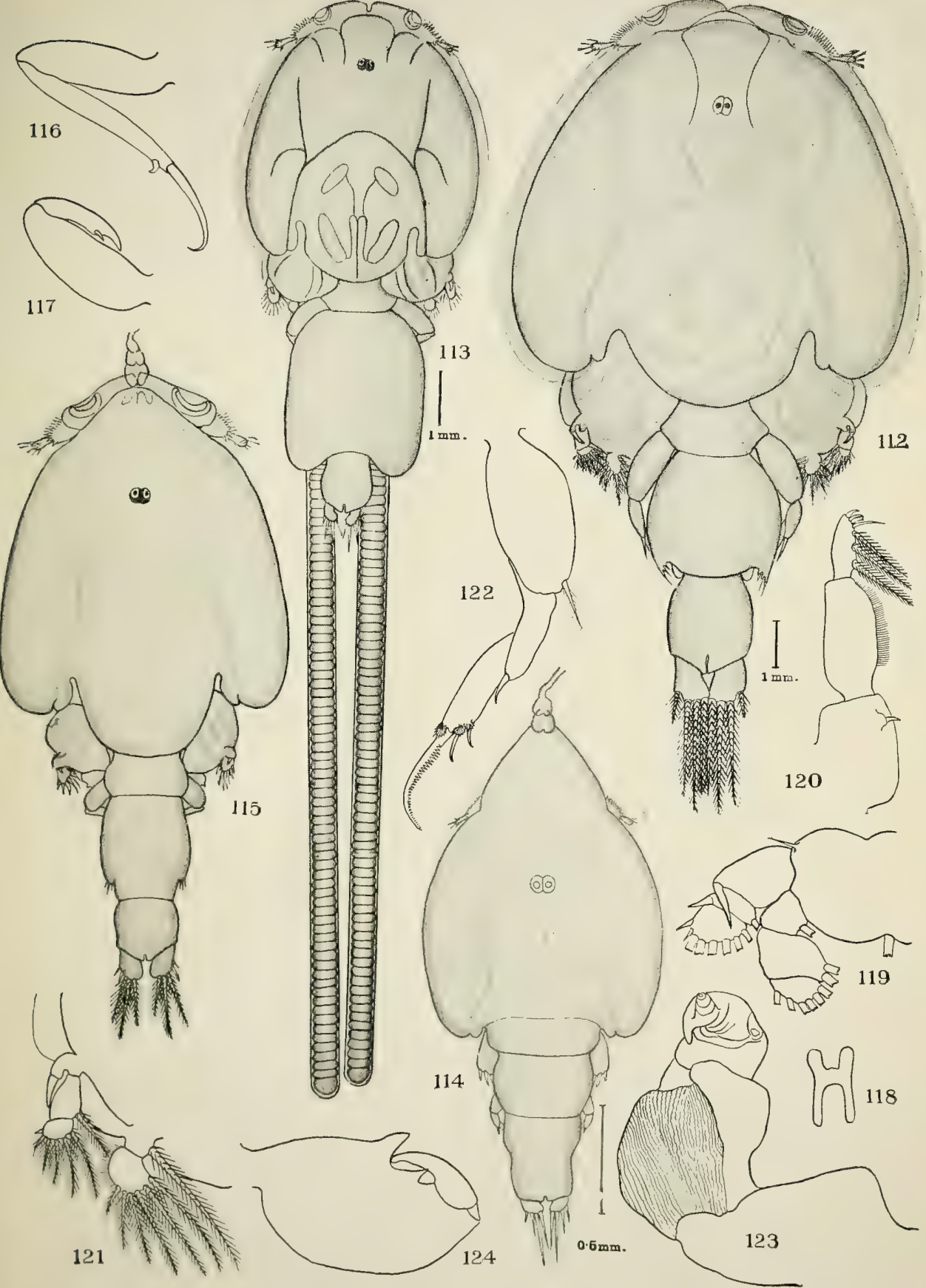

The male, female, and Chalimus of Caligus curtus.

For explanation of PLATE SEe PAGE 670. 



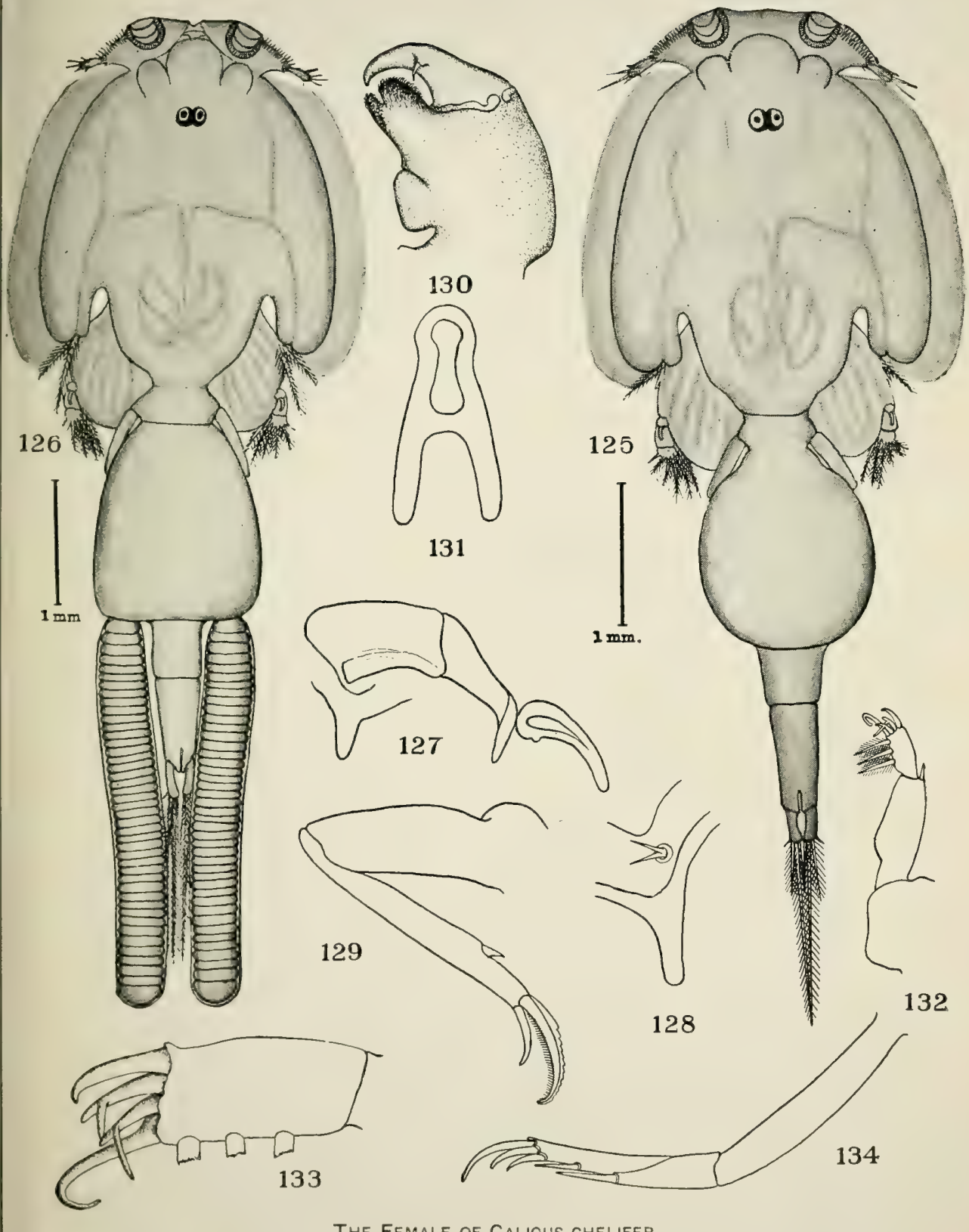

THE FEMALE OF CALIGUS CHELIFER.

FOR EXPLANATION OF PLATE SEE PAGE 670. 





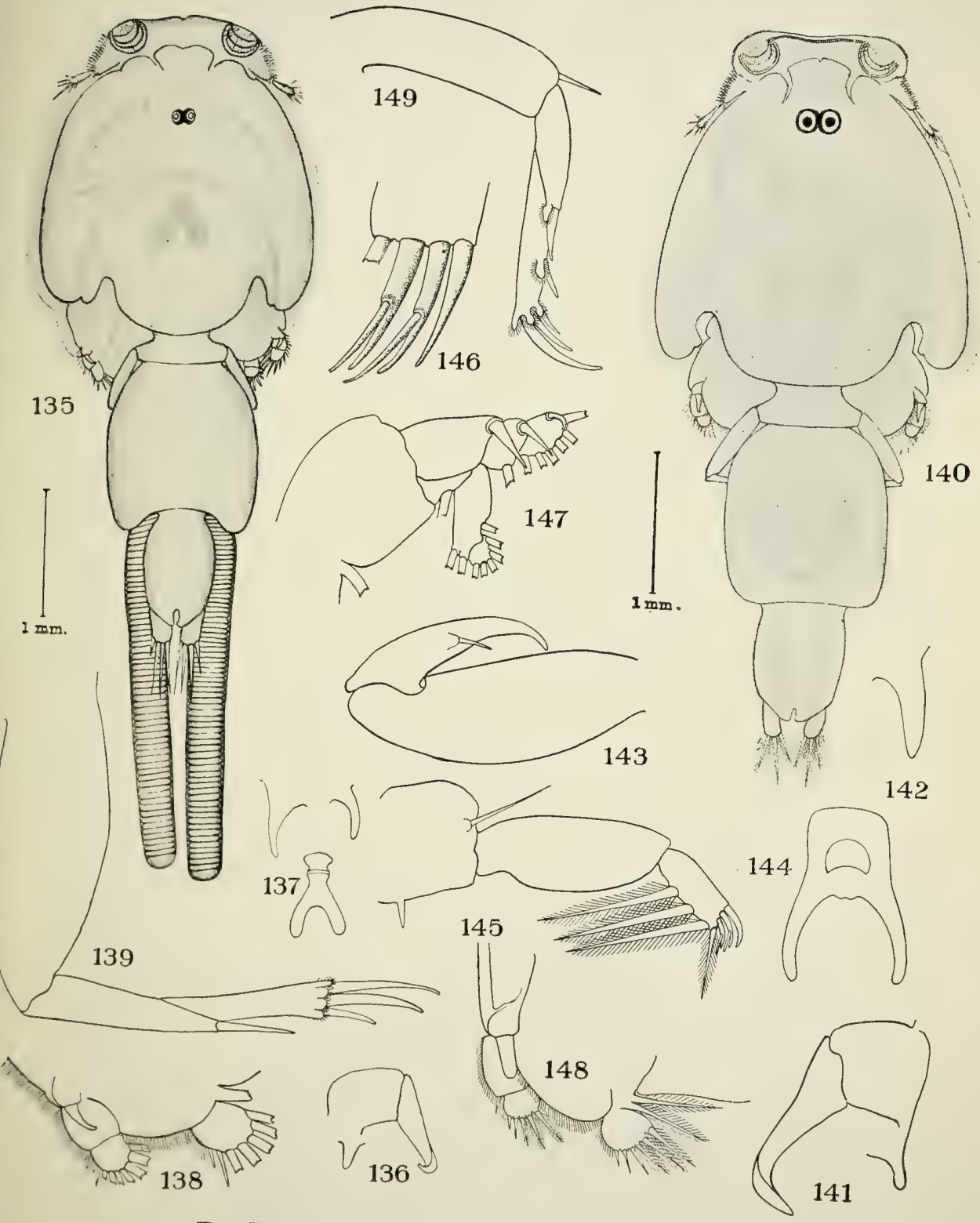

The females of Caligus belones and Caligus latifrons.

For EXPLANATION OF PLATE SEE PAGE 670. 





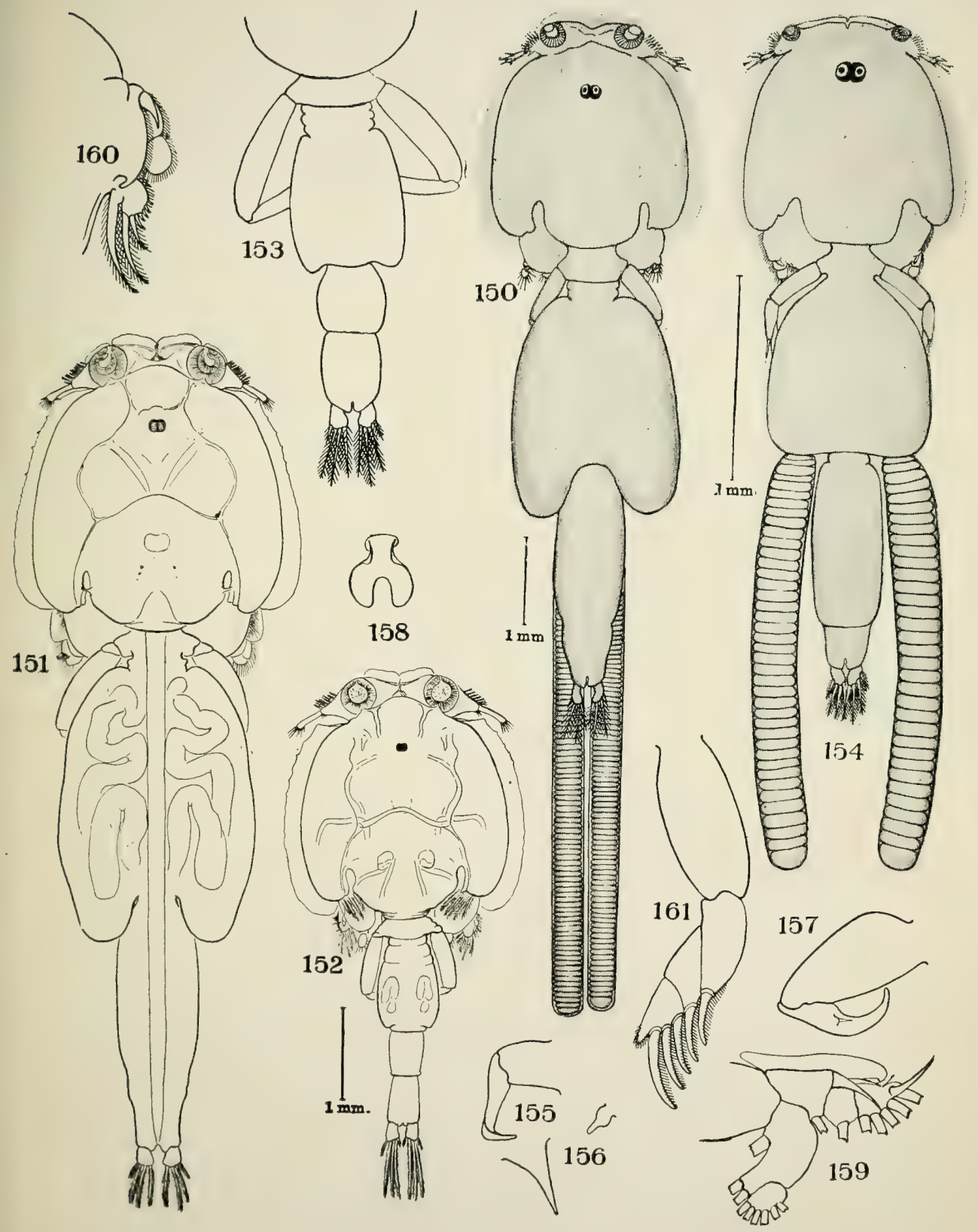

Cal'gus bonito and Caligus pelamydis.

For EXPLANATION OF PLATE SEE PAGE 670. 



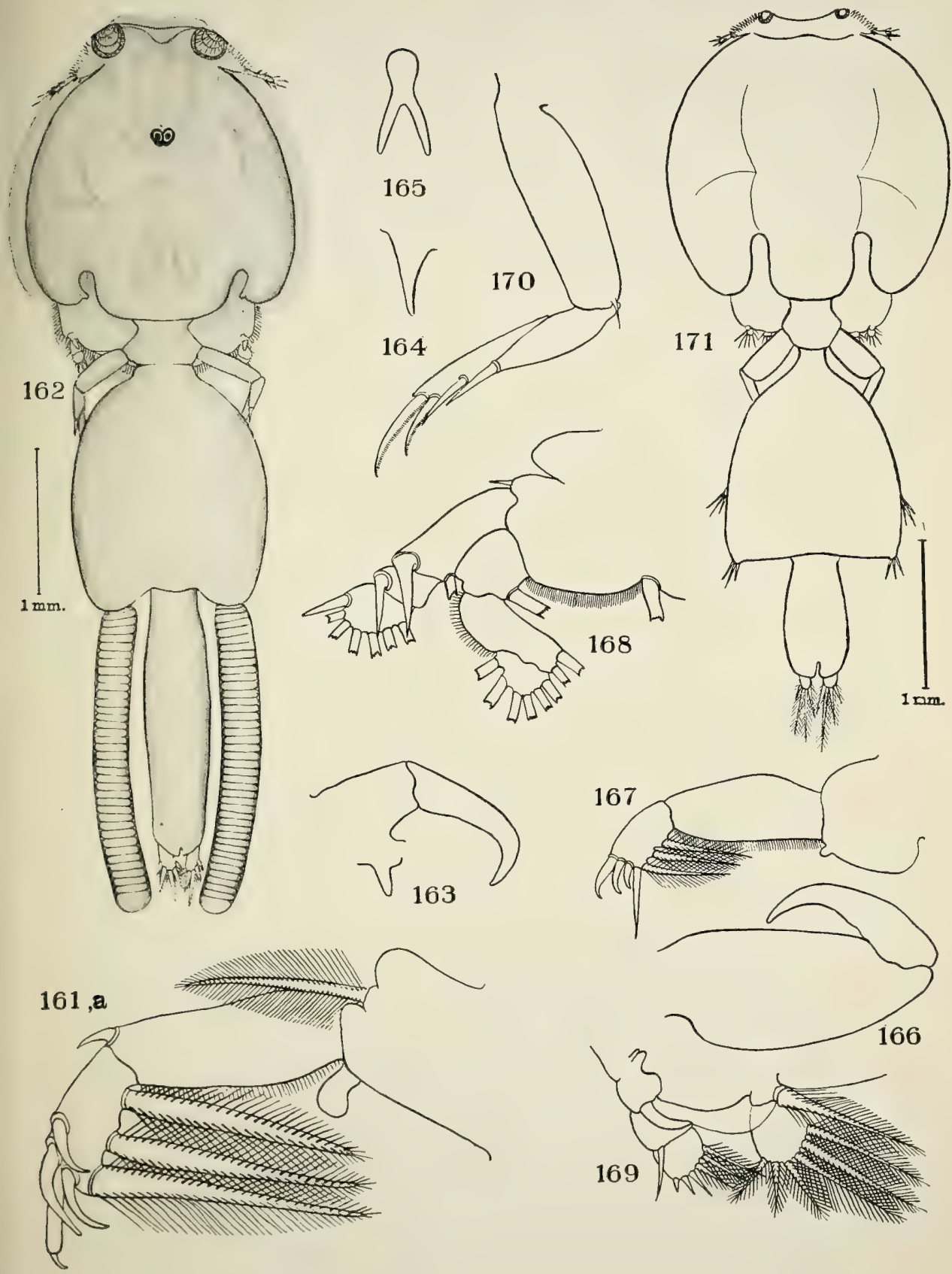

CALIGUS PRODUCTUS AND CALIGUS ISONYX.

For EXPLANATION OF PLATE SEE PAGE 670. 





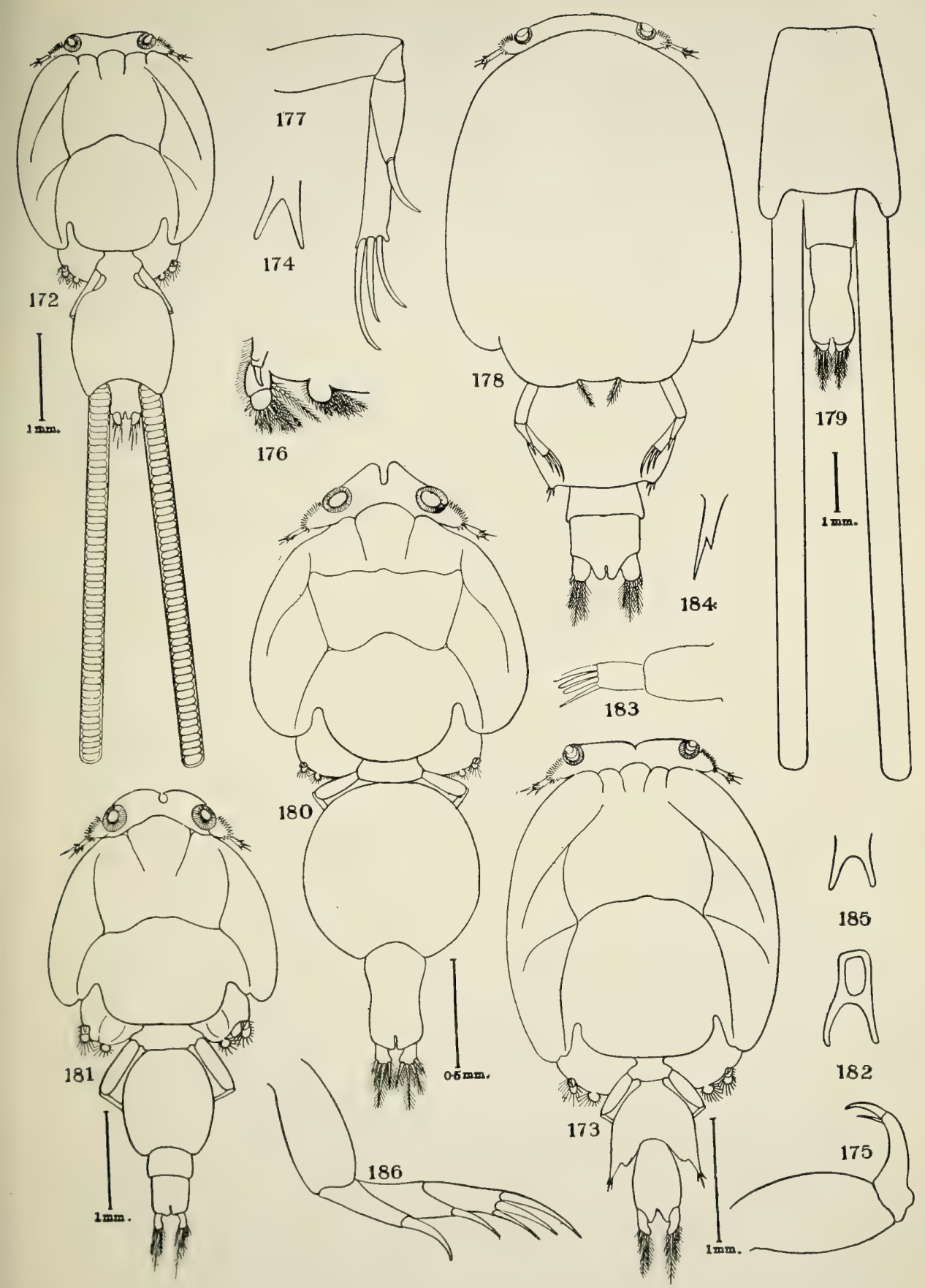

CALIgus SPECIES from the West INDIES.

FOR EXPLANATION OF PLATE SEE PAGES $670,671$. 



$$
\text { , }
$$








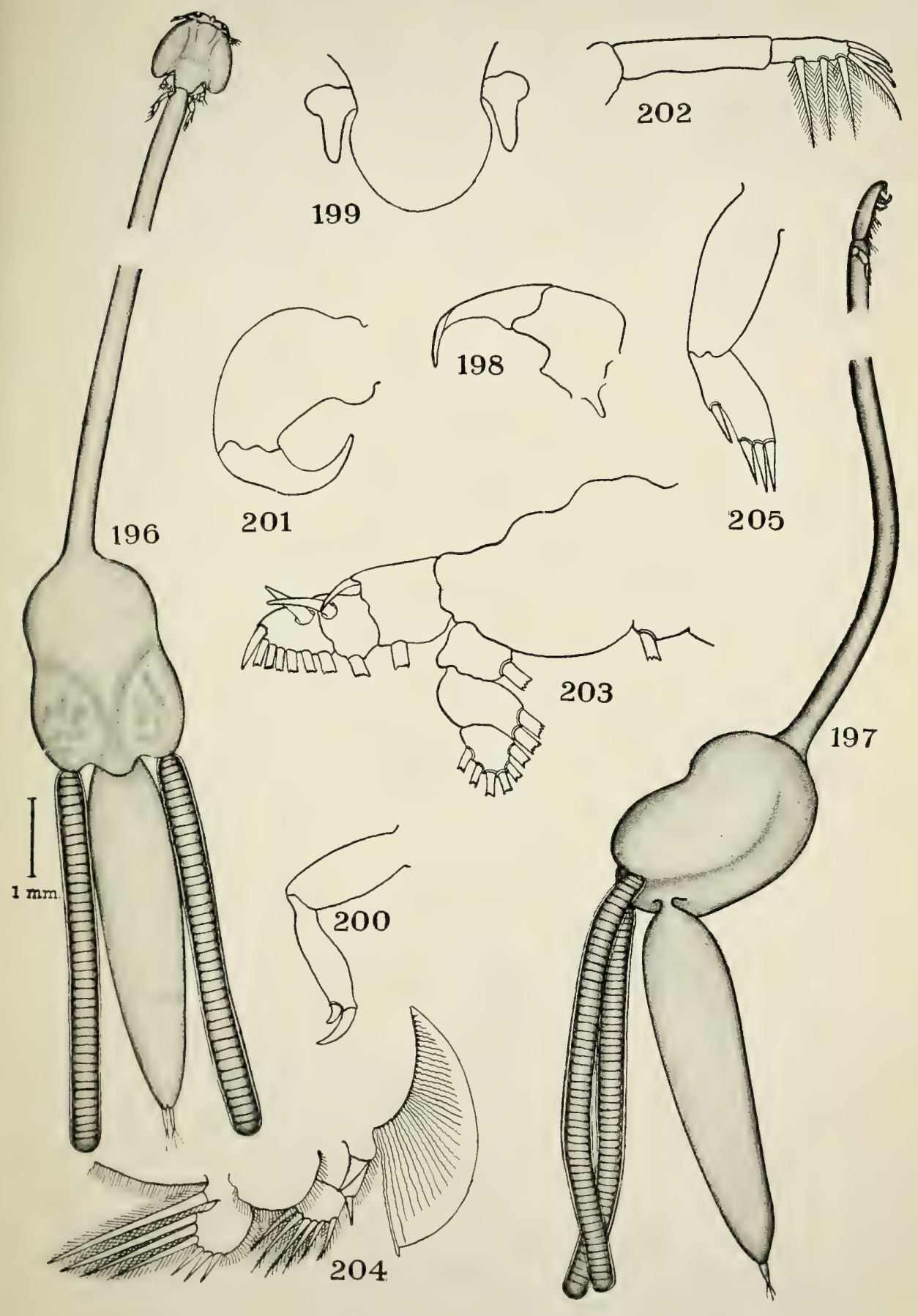

The female of Echetus typicus.

For explanation of PLATE see PAgE 671. 




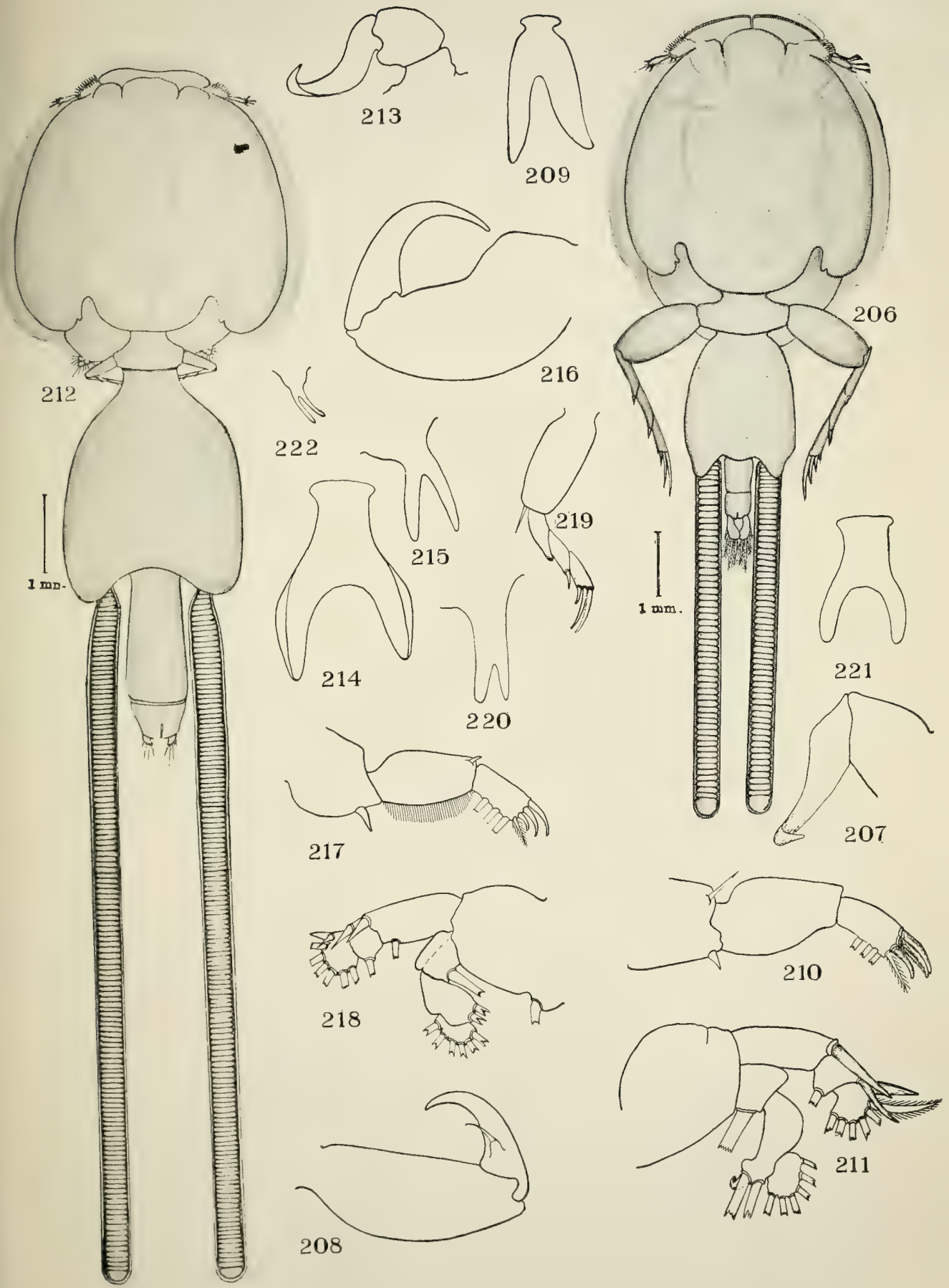

LEPEOPHTHEIRUS LONGIPES AND LEPEOPHTHEIRUS THOMPSONI.

For Explanation of PLATE see Page 671. 



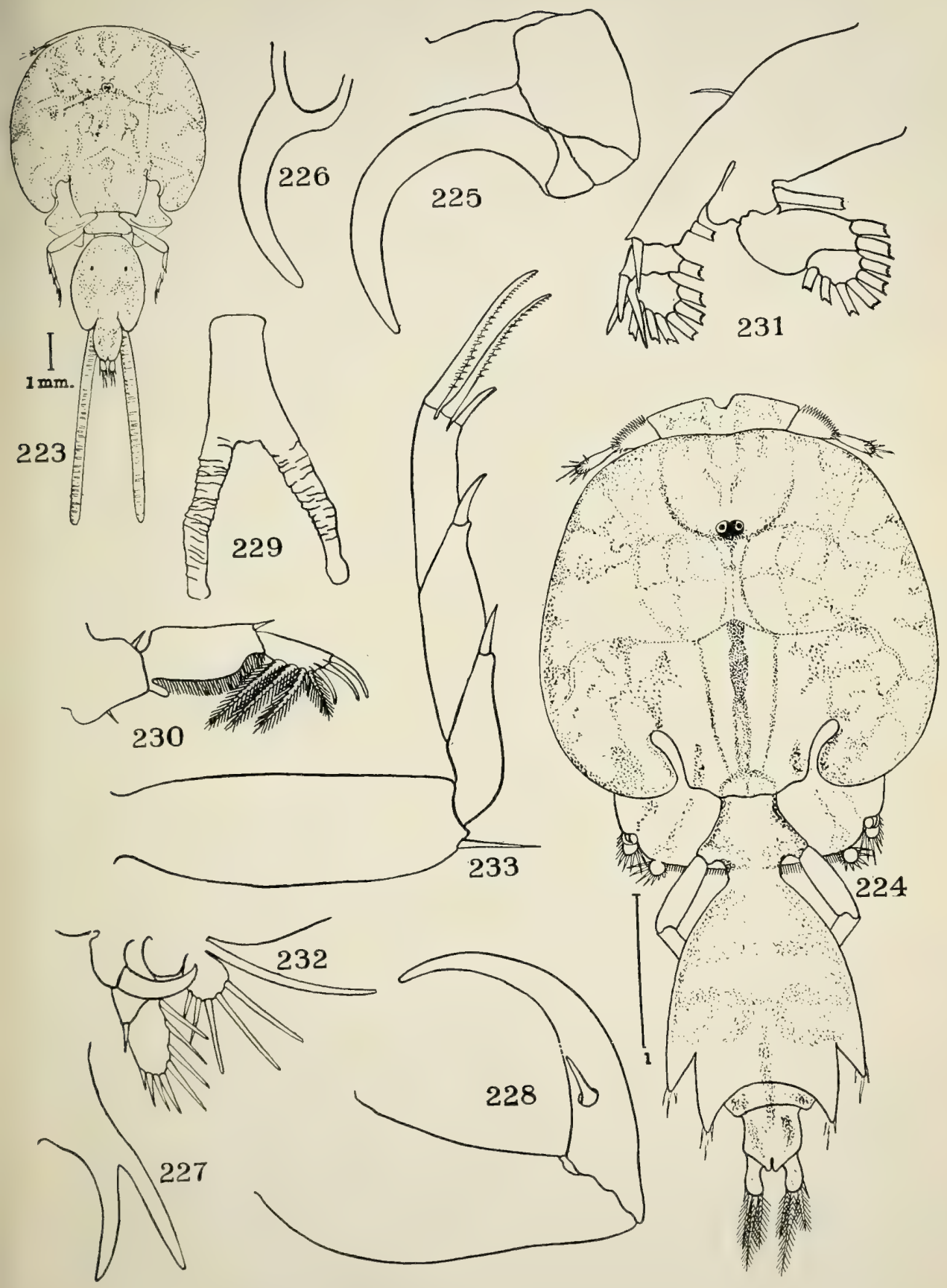

The Male and female of Lepeophtheirus nordmanNil. For EXPLANATION OF PLATE SEE PAGE 671. 




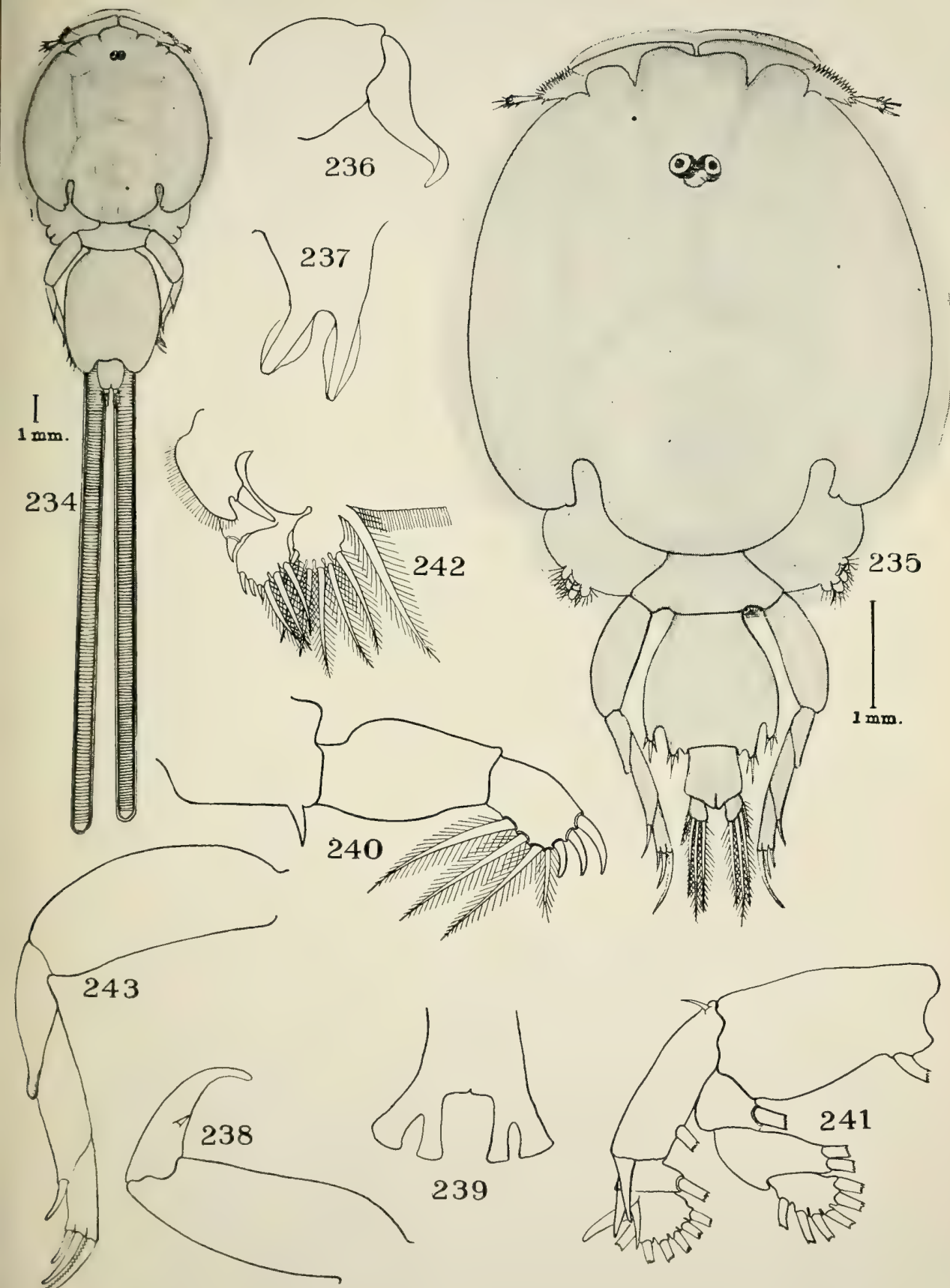

The Male and Female of Lepeophtheirus hippoglossi.

For EXPLANATION OF PLATE SEE PAGE 671. 





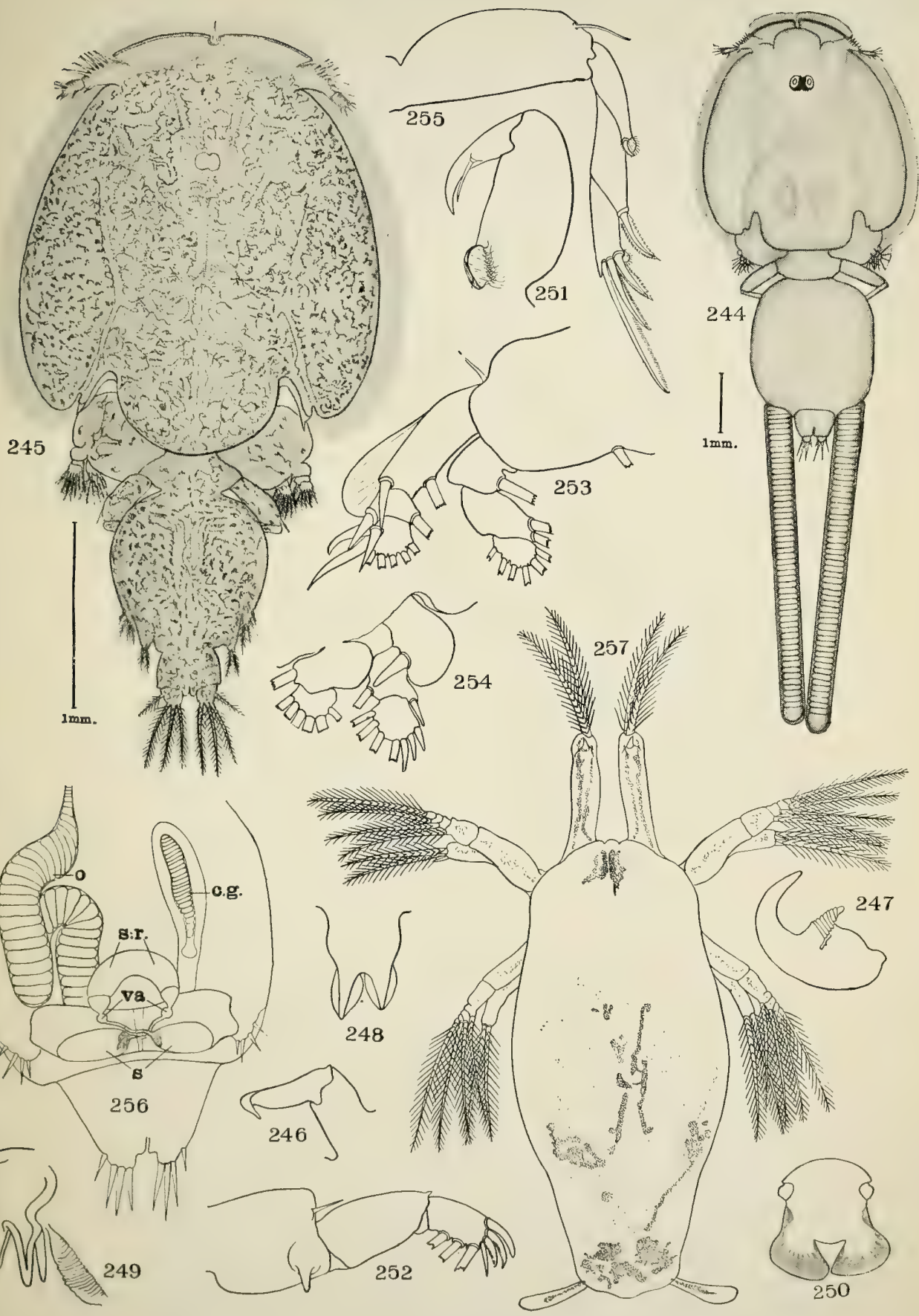

THE MALE, FEMALE, AND NAUPLIUS OF LEPEOPHTHEIRUS EDWARDSI.

FOR EXPLANATION OF PLATE SEE PAGE 671. 



$$
\text { . }
$$

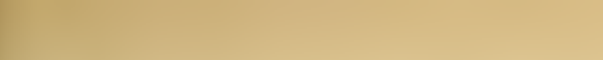





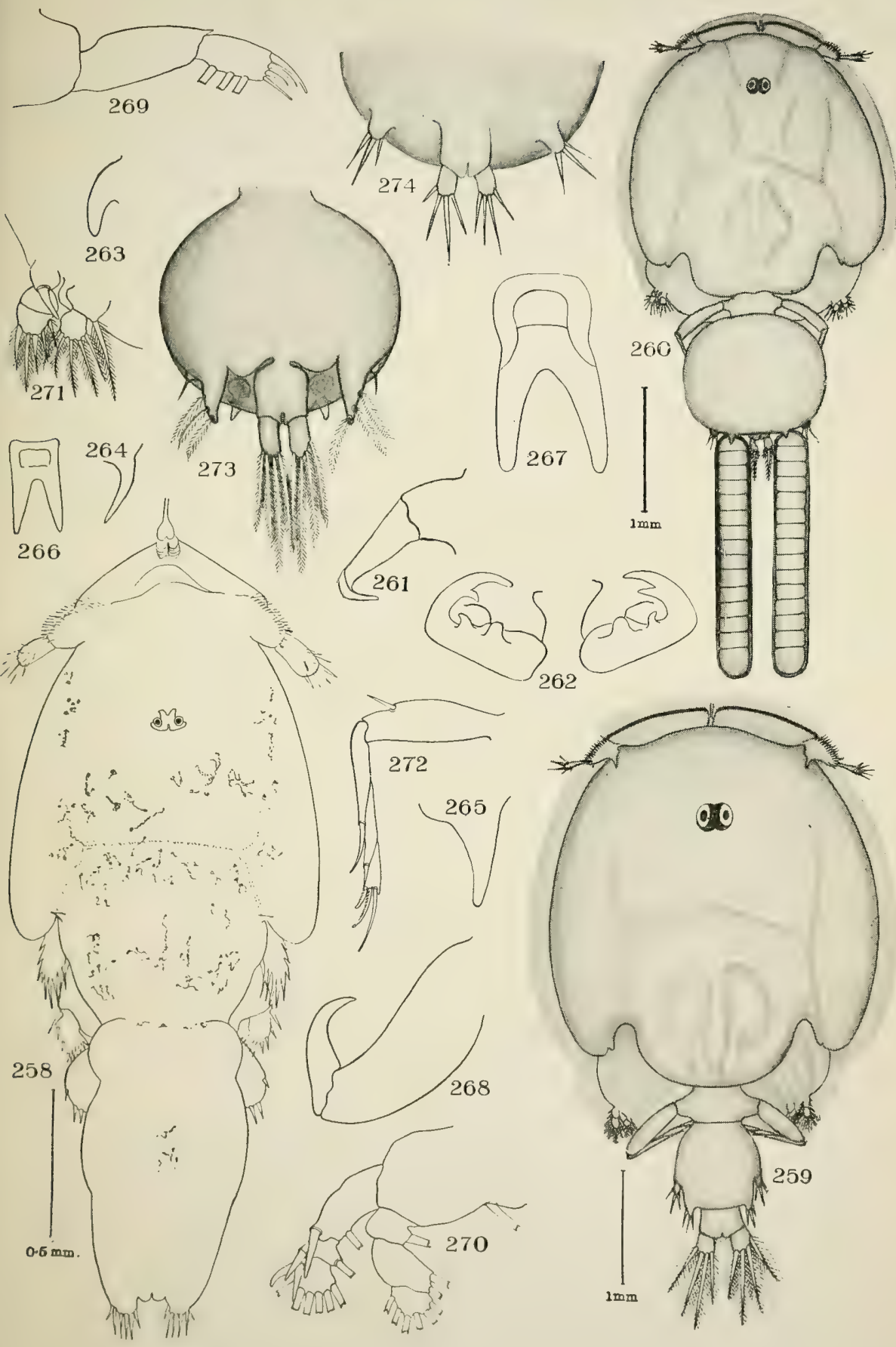

The Male and female of Lepeophtheirus dissimulatus. 



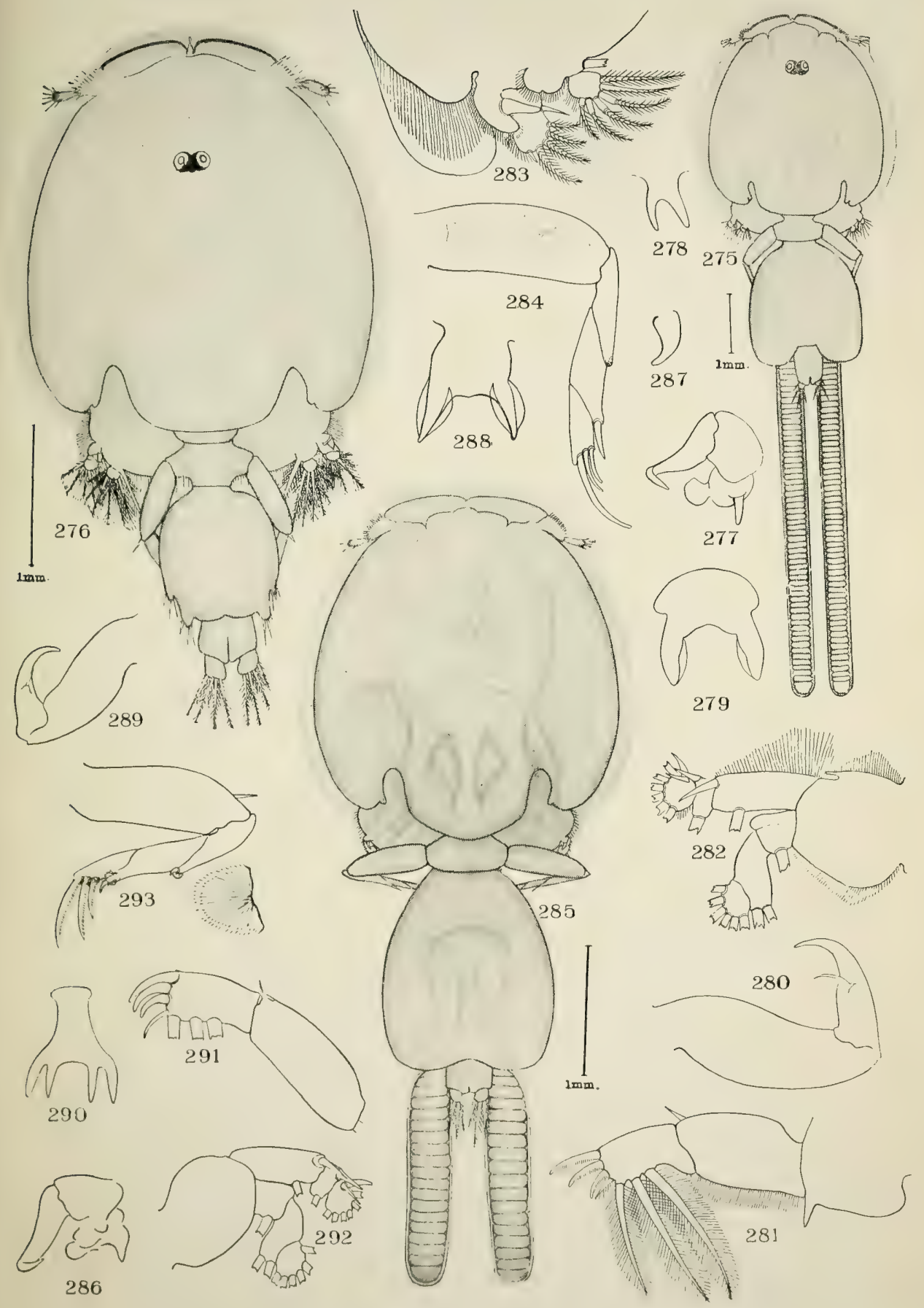

LEPEOPHTHEIRUS PARVIVENTRIS AND LEPEOPHTHEIRUS BIFURCATUS.

FOR EXPLANATION OF PLATE SEE PAGES 671,672 



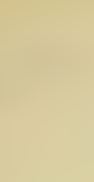
. .

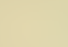





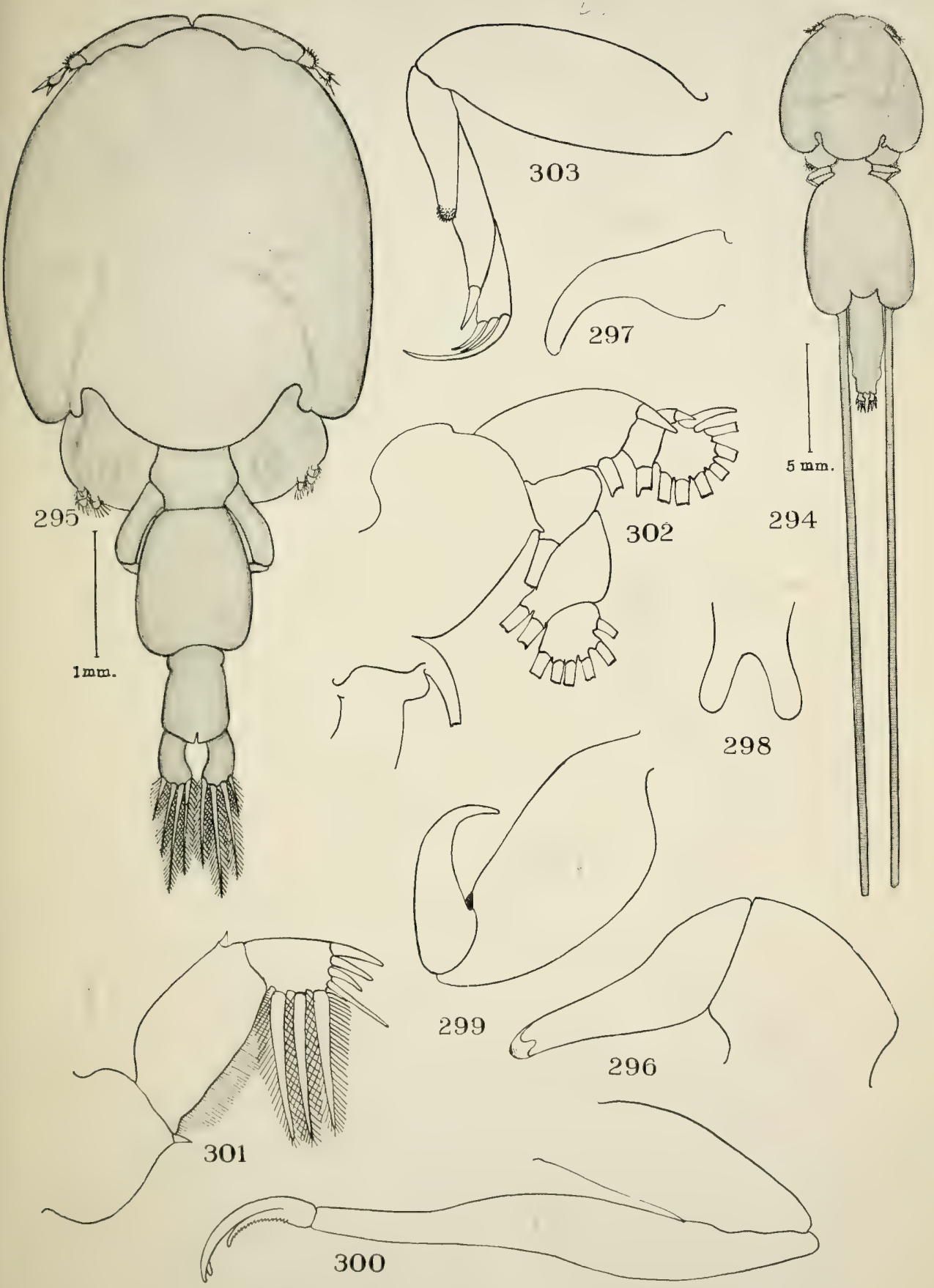

The MALE and Female of LePeophtheirus salmonis.

For EXPLANATION OF PLATE SEE PAgE 672. 





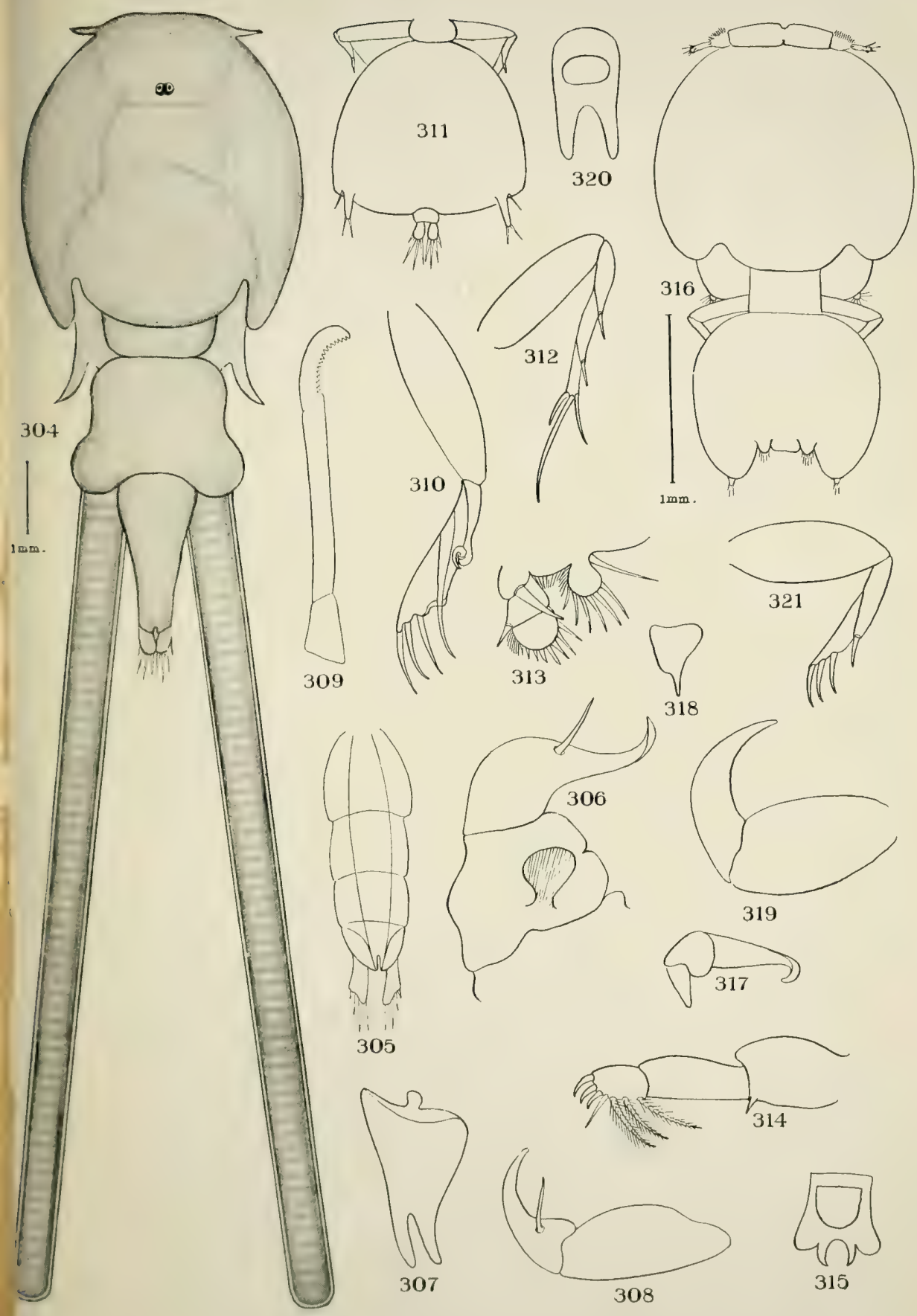

LEPEOPHTHEIRUS SPECIES AND ANURETES HECKELII.

Fon EXPLANATION OF PLATE SEE PAGE 672. 





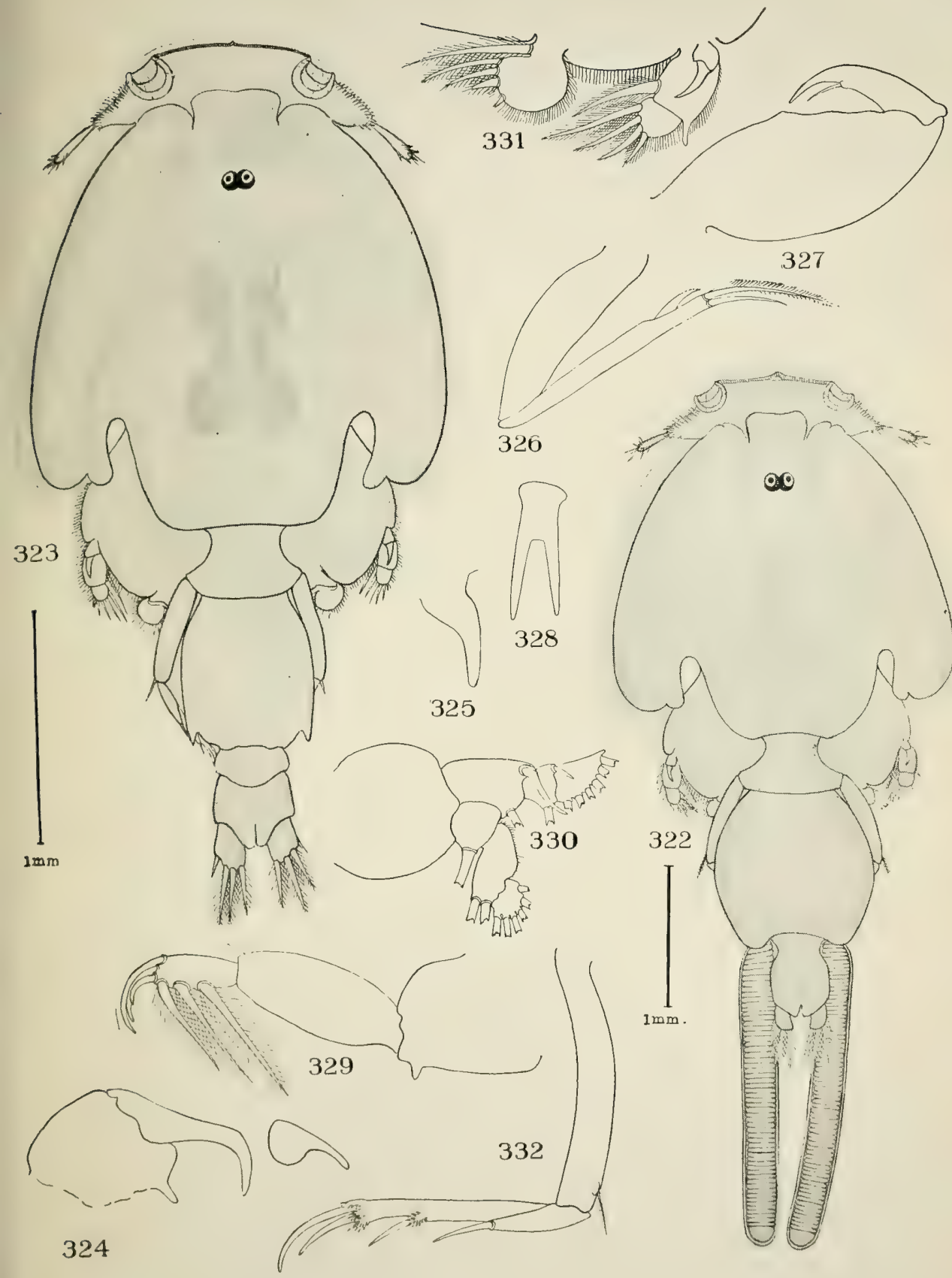

The Male and female of Caligus teres.

For EXPLANATION OF PLATE SEE PAGE 672. 



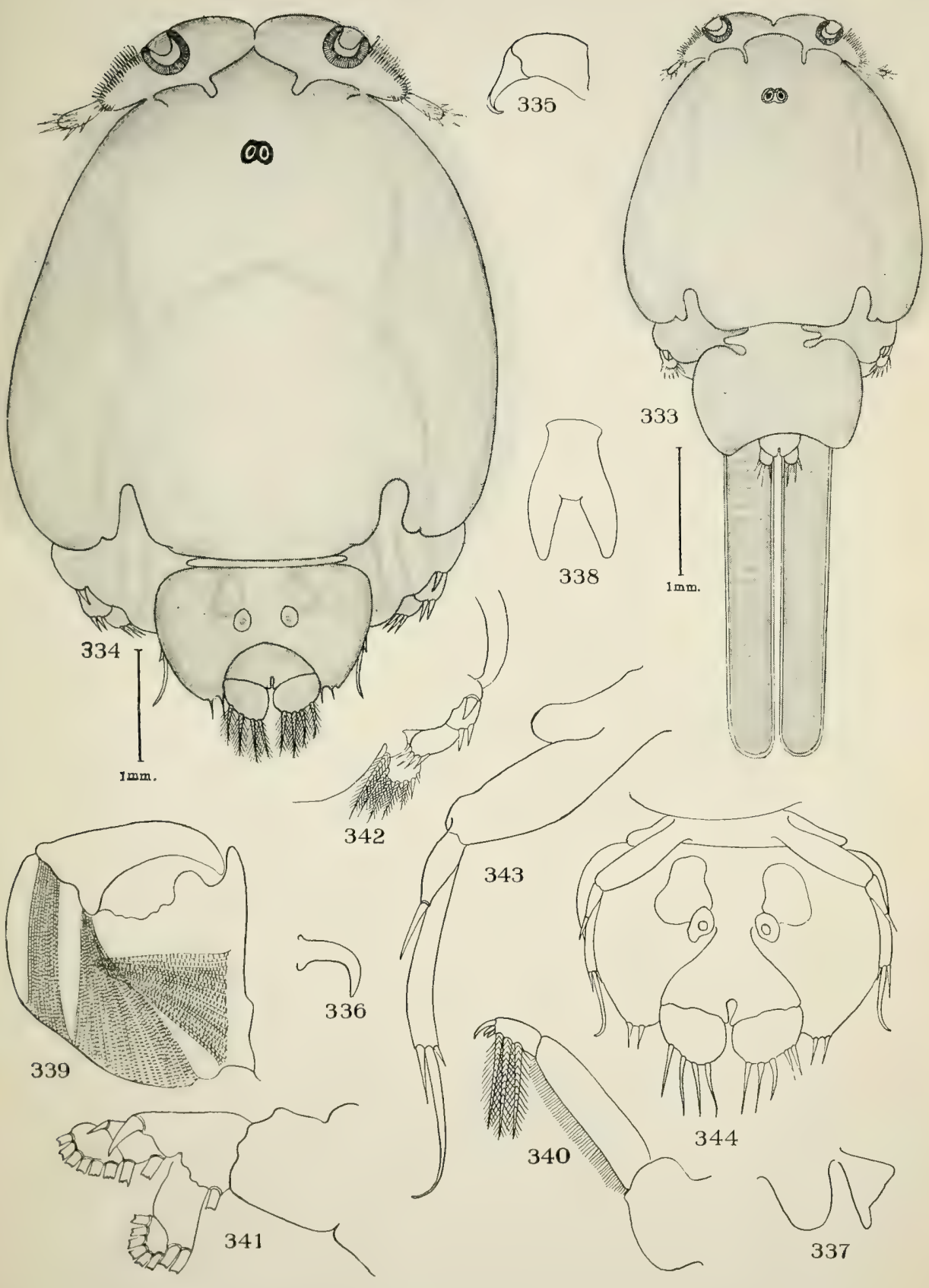

the male and female of Caligus centrodonti.

For EXPLANATION OF PLATE SEE PAGE 672. 




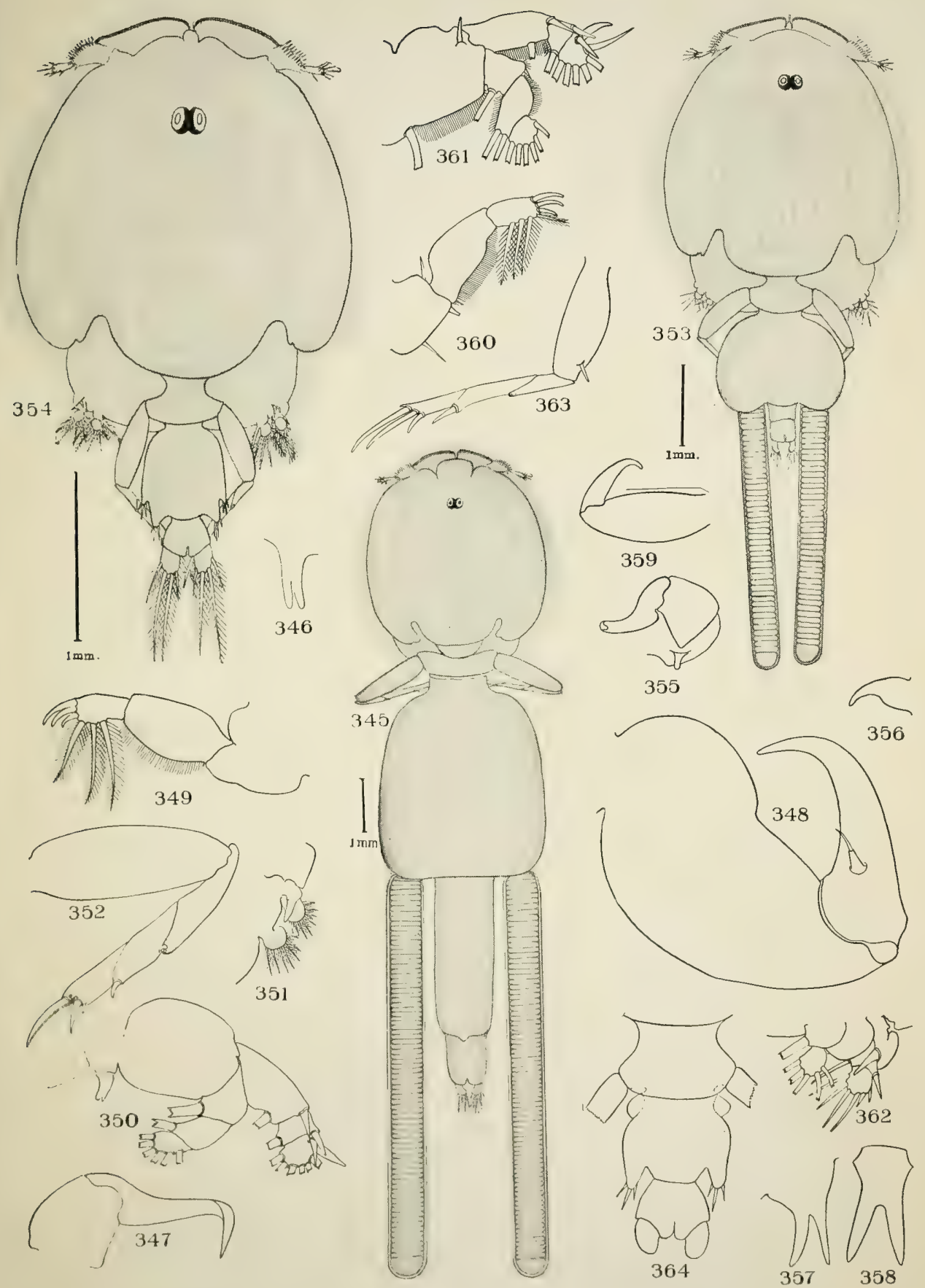

LEPEOPHTHEIRUS INNOMINATUS AND LEPEOPHTHEIRUS CHILENSIS.

FOR EXPLANATION OF PLATE SEE PAGE 672. 



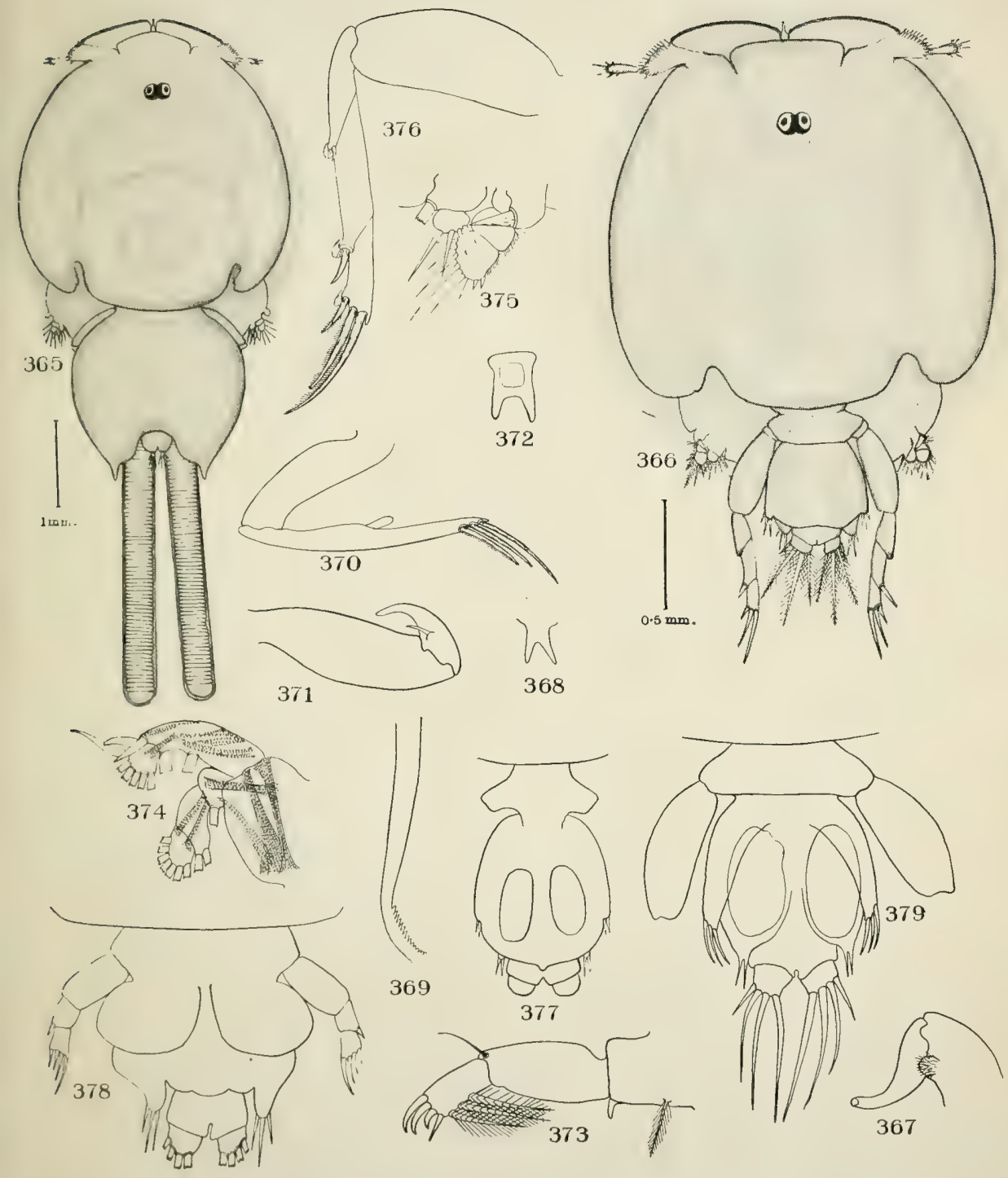

The Male and female of Homolotes palliata.

FOR EXPLANATION OF PLATE SEE PAGE 672. 





